\title{
DIE EISENERZFÜHRENDE FORMATION IN DER GEGEND VON GRÄNGESBERG
}

\section{INAUGURAL-DISSERTATION}

ZUP

ERLANGUNG DER DOKTORWÜRDE

DER

\section{MATEMATISCH-NATURWISSENSCHAFTLICHEN FAKULT̈̈T}

DER HOCHSCHULE ZU STOCKHOLM

MAJ 1910 VORGELEGT VON

HARALD JOHANSSON

uIC. PHIL.OS. 



\section{DIE EISENERZFÜHRENDE FORMATI0N IN DER GEGEND VON GRẢNGESBERG}

\section{INAUGURAL-DISSERTATION}

ZUR

ERLANGUNG DER DOKTORWÜRDE

DER

MATENATISCH-NATUR WISSENSCHAFTLICHEN FARULTäT

DER HOCHSCHULE ZU STOCKHOLM

MAJ 1910 VORGELEGT VON

HARALD JOHANSSON

LIC. PHILos. 
$\cdots$ 


\section{INHALT.}

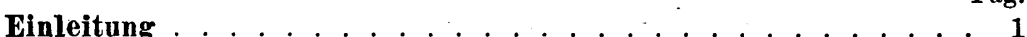

Übersicht über den geologischen Bau des Grängesberger Gebietes 3 Die Gneise

Rote Gneise . . . . . . . . . . . . . . . . . . 7

Granitgneise . . . . . . . . . . . . . . . . . 22

Plagioklasgneise . . . . . . . . . . . . . . . . 32

Zweiglimmergneis mit Cordierit . . . . . . . . . . . . . . . . . 38

Die Granulite

Porphyrische Granulite im $\mathrm{W}$ von Grängesberg. . . . . . . . . . . 39

Rote Granulite mit Granat und Epidot im W von Grängesberg. . . . 44

Rötliche Granulite im Lomberget . . . . . . . . . . . . . . . . . 47

Graue biotitreiche Plagioklasgranulite bei Grängesberg . . . . . . 51

Inhomogene amphibolitische Granulitgesteine in dem N. Hammargruben-

Gebiet. . ................. . 54

Skarnführende Grannlite . . . . . . . . . . . . . . 58

Die Grünsteine

Diorite und Gabbrodiorite. . . . . . . . . . . . . 68

Amphibolite . . . . . . . . . . . . . 70

Die Skarngesteine . . . . . . . . . . . . . . . . . . . . . . 82

Die Kalksteine. . . . . . . . . . . . . . . . . . . 85

Die Eisenerze . . . . . . . . . . . . . . . . . . . . . . . .86

Über die chemisch-mineralogische Systematik der mittelschwedischen

Eisenerze . . . . . . . . . . . . . . . 87

Das Grängesberger Exportfeld . . . . . . . . . . . . . . . . 101

Die A patiterze des südlichen Risbergfeldes . . . . . . . . . . . 111

Die N. Hammargrube . . . . . . . . . . . . . . . . . . . 113

Die Blötberg- and Fredmandbergfelder . . . . . . . . . . 115

Die Långblågruben. . . . . . . . . . . . . . . . . . . 115

Die schuppigen Quarzeisenerze des Grängesbergfeldes . . . . . . . 117

Die Skarn- and Kalkeisenerze des Björnbergfeldes. . . . . . . . 123

Die Sulflderze . . . . . . . . . . . . . . . . . . . . 127

Die Granite . . . . . . . . . . . . . . . . . . . . . . . . . 127

Die Diabase . . . . . . . . . . . . . . . . . . . . . . . . . . . 131

Die genetischen Verhältnisse der Gesteine der erzführenden Forma-

tion

Die chemischen Charaktere der Gestcine . . . . . . . . . . . 138

Die strakturelle Ausbildung der Gesteine. . . . . . . . . . . . . 154

Über die Verwendung des Namens, Granulit, als petrographische

Bezeichnung für die mittelschwedischen erzführenden Gesteine 162

Erklärungen der Tafeln . . . . . . . . . . . . . . . 170 


\section{Tafeln}

1-4. Mikrophotographische Abbildangen.

5. Graphische Zusammenstellnng der Analysen mittelschwedischer Eisenerze.

6. Grundriss und Profile des Grängesberger Exportfeldes. 1:2000.

7. Geologische Karte des Grängesberger Erzzuges. 1:10000.

8. Geologische Übersichtskarte der Grängesberger Gegend. 1:60000. 
Sonderabdruch aus d. Geol. Fören. i Stockholm Förhandl. Bd. 32. H. 2. Febr. 1910.

Die eisenerzführende Formation in der Gegend von Grängesberg.

\author{
Von \\ HaRaid Johansson. \\ (Hierzu Taf. 1-8.)
}

Der geologische Bau der Gegend von Grängesberg ist in seinen Hauptzügen auf Blatt I der TöRneBoHm'schen Übersichtskarte von "Mellersta Sveriges Bergslag» dargestellt. Der südlichste Teil des Grubenfeldes fällt auch in das Gebiet der von der Schwed. Geol. Landesanstalt herausgegebenen geologischen Karte der erzführenden Gegenden des Läns Örebro (S. G. U., Ser. Bb, No. 3, 1883). Über die geologischen Verhältnisse der Grängesberger Eisenerze finden sich in der geologischen Litteratur mehrere kürzere Angaben, z. B. von G. Lörstrand (G. F. F. 16 [1894]: 147-148); J. H. L. Vogt (G. F. F. 16 [1894]: 289); R. Beck (Z. f. prakt. Geol.r 1899. S. 7-9); L. De Launay (Ann. des Mines 1903); HJ. SJöGREN (G. F. F. 28 [1906]: 351-355); dem Verfasser (G. F. F. 26 [1904]: 361; 29 [1907]: 173-175). Kurze Beschreibungen des Grubenfeldes sind in den Lagerstättenkunden von BECK und Stelzner-Bergeat enthalten. Von praktischem Gesichtspunkt aus wurde das Grubenfeld von N. HedBerg beschrieben (The Grängesberg Iron Mines in 1898. Falun 1898). Neuerdings ist eine ausführliche Beschreibung der Grängesberger Erzvorkommen von demselben Verfasser publiziert worden (Jernk. Ann. 62 [1907]: 67-125). Der letztgenannten Arbeit. 
ist auch eine geologische Karte von dem Grubenfeld mit Umgegend beigefügt, nach geologischer Aufnahme von mir und mit Höhenkurven nach Abwägungen von HedberG. Von dem südlichisten Teil des Erzfeldes, dem s. g. Lombergfeld, findet sich auch eine Beschreibung von B. Santesson (S. G. U., Ser. Bb, Nr. 4, 145-147, 1889). Über die Eisenerzvorkommen im Kirchspiel Ludvika im NO und $\mathrm{O}$ von Grängesberg hat $\mathrm{H}$. Sundholm eine. Arbeit publiziert (Jernk. Ann. 53 [1898]: 85 -207).

Die der folgenden petrographisch-geologischen Beschreibung zu Grunde liegenden Felduntersuchungen sind grösstenteils in den Sommern 1903 und 1904 ausgeführt. Die geologischen Auf̣nahmen wurden später im letzten Sommer ergänzt und weiter ausgedehnt, wobei die vor kurzem erschienene Generalstabs-Konzept-Karte im Massstab 1:50,000 als topographische Unterlage benutzt werden konnte. Auf dieser Unterlage ist eine anf Tafel 8 wiedergegebene geologische Übersichtskarte im Massstab 1:60,000 zusammengestellt, welche Teile der Kirchspiele Grangärde und Ludvika im südlichen Dalekarlien wie auch den angrenzenden Teil des zum Län Örebro gehörenden Kirchspiels Nya Kopparberg umfasst. Von dem Grängesberger Erzzug ist eine auf Tafel 7 wiedergegebene geologische Spezialkarte im Massstab $1: 10,000$ zusammengestellt; als Unterlage dafür diente hauptsächlich eine der obenerwähnten Arbeit von HEDBERG beigefügte Utmåls-Karte im Massstab 1:8,000.

Bei den Felduntersuchungen ist mir in mehreren Hinsichten eine kräftige Unterstützung von Seiten der Grubenverwaltung zu teil geworden; von der Grubenverwaltung sind auch die Kosten für chemische Gesteinsanalysen bestritten worden, wodurch es ermöglicht wurde, die chemischen Charaktere der wichtigsten Gesteinstypen des Gebietes durch Analysen näher zu beleuchten. Vor allem bin ich dem Chef der Grängesberger Verwaltung, Herrn Direktor A. E. SaLwós, für die wohlwollende Unterstützung, die er meinen Un- 
tersuchungen entgegengebracht hat, zu grossem Dank verpflichtet. Dem Herrn Ingenieur N. HeDbeRG, der mir Karten und mancherlei Angaben mit freundlichem Entgegenkommen überlassen hat, spreche ich meinen besten Dank aus.

Die petrographische Untersuchung ist in dem mineralogischen Institut der Hochschule zu Stockholm ausgeführt worden, und bin ich dem Direktor des Institutes Herrn Professor H. Bäскsтröм für bei manchen Gelegenheiten geleistete Hülfe zu herzlichem Dank verpflichtet. Die Dünnschliffe sind mit gewohnter Geschicklichkeit von Herrn Präparator C. A. CarLSsoN verfertigt worden.

Von dem Dozenten an der Berghochschule zu Stockholm Herrn Bergingenieur A. GraBe sind zehn vollständige,Gesteinsanalysen und zwei Alkalibestimmungen ausgeführt worden. Für diese Freundlichkeit, wodurch er meine Arbeit sehr gefördert hat, spreche ich ihm meinen besten Dank aus.

Die beigefügten Mikrophotographien sind von Herrn A. LUNDQUIST, die Photographien nach Handstücken von dem Mechaniker bei der physiologischen Abteilung des Karolinischen Instituts zu Stockholm Herrn G. JARL ausgeführt worden.

\section{Übersicht über den geologischen Bau des Grängesberger} Gebietes.

Der geologische Bau des südlichen Dalekarlien, wie derselbe auf Bl. I-II der TöRneBonM'schen Übersichtskarte dargestellt ist, zeichnet sich durch eine ausserordentlich bunte $A b$ wechselung von Gneisen und Granulitgesteinen ${ }^{1}$ aus. Die zahlreichen, den Gneisen konform eingelagerten Granulitzüge erscheinen entweder als linsenartige Gebiete in den Gneisen und „Urgraniten» ganz eingeschlossen oder hängen mit dem grossen Granulitgebiete im nördlichen Teil von Örebro län direkt

1 Aus Gründen, die später (S. 162) angegeben werden, ist hier der Name Granulit in der von TörNeborm angewandten Bedeutang beibehalten worden. 
zusammen. Wie aus der Karte Tafel 8 hervorgeht, ist eine derartige Abwechselung von Gneis- und Granulitzügen auch für das Grängesberger Gebiet in hohem Mass bezeichnend. Nach meinen Beobachtungen erscheint dieselbe in den Details noch verwickelter, als es auf der TöRnEBoнm'schen Karte dargestellt werden konnte.

Nach geognostischen und petrographischen Merkmalen können die Gesteine unseres Gebietes zunächst in drei Hauptabteilungen gegliedert werden. $\mathbf{Z u}$ der ersten Abteilung, die auch als sdie eisenerzführende Formations bezeichnet werden könnte, gehören erstens die verschiedenen Arten von Gneisund Granulit-Gesteinen, die als vielfach abwechselnde linsenartige Zügge den weitaus grössten Teil des Kartengebietes einnehmen; dann weiter eine Reihe von Grünsteinen, meistens von amphibolitischem, z. T. auch von dioritischem oder gabbrodioritischem Charakter; Skarngesteinen; körnigen Kalksteinen und Eisenerzen, die sämtlich als kleinere, linsenartige Einlagerungen vor allem in die Granulitzüge in grosser Anzahl eingeschaltet sind; dieser Abteilung möchte ich auch die pegmatitischen und aplitischen Gesteine zurechnen, die in gewissen der vorigen Gesteine ziemlich häufig auftreten. - In die zweite Abteilung sind die sjüngeren Granite» gestellt, die in unserem Gebiet in zwei getrennten Massiven die Gesteine der vorigen Abteilnng mehr oder weniger deutlich durchbrechen. Die dritte Abteilung umfasst einige Gänge von Diabas von zweifellos postarchäischem, aber nicht näher zu bestimmendem Alter.

Unter den Quarz-Feldspatgesteinen der ersten Abteilung lassen sich die Vertreter der zwei petrographischen Hauptgruppen $\gg$ Gneise» und „Granulite» meistens ziemlich gut nach der Korngrösse auseinanderhalten. Es giebt aber auch in unserem Gebiete einige Gesteinszüge, wo die Korngrösse sich auf mittleren Werten hält (etwa 0.1 bis $0.3 \mathrm{~mm}$ an dem Quarz gemessen) oder auch besonders schnelle Schwankungen aufweist. Solche Gesteinszüge sind auf den Karten unter der 
Bezeichnung »granulitische Gneise» abgetrennt; bei der folgenden petrographischen Detailbeschreibung werden sie jedoch mit den typischen Gneisen zusammen besprochen werden.

Unter den Gneisen des Grängesberger Gebietes scheinen hauptsächlich drei chemisch-mineralogische Typen vertreten zu sein, die hier kurz als rote Gneise, Granitgneise und Plagioklasgneise bezeichnet werden mögen. Die Gneise des ersten Typus haben die grösste Verbreitung; sie sind durch ziemlich kräftig rote Farbe, sehr geringen Gehalt an femischen Mineralen und reichliche Beteiligung sowohl vọn Kalifeldspat als kalkarmem Plagioklas gekennzeichnet. Die Granitgneise stellen einen beträchtlich femischeren und kalkreicheren Typus dar; demnach enthalten sie reichlichen Glimmer und Hornblende und zeigen eine ausgesprochen flaserige, etwas augengneisartige Struktur. Die Gneise des dritten Typus zeigen meistens hellgraue Farbentöne und scharfkristallinisches Gefüge, das sich durch besonders rauhe Bruchflächen bekundet; der chemische Charakter hat sich als einen ausgesprochen natronreichen herausgestellt, was sich durch den Reichtum an kalkarmem Plagioklas bei vollständigem Fehlen oder starkem Zurücktreten des Kalifeldspats kundgiebt. Ein kleiner Zug aus tonerdereichem $Z_{w}$ eiglimmergneis mit Cordierit-Knollen kommt im östlichen Teil des Gebietes vor.

Die als Granulite bezeichneten Gesteinszüge zeigen eine grössere Mannigfaltigkeit in der chemisch-mineralogischen $\mathrm{Zu}$ sammensetzung. Es wäre gewiss zu wünschen gewesen, dass diese Variationen auf der Karte Tafel 8 zum näheren Vorschein hätten kommen können. Es ist aber bei den Granuliten weit schwieriger als bei den Gneisen, den chemischen Charakter allein nach dem makroskopischen Aussehen sicher zu beurteilen, und für die Ausnützung der mikroskopischen und chemischen Untersuchungsmethoden giebt es andererseits bei umfassenderen Kartenaufnahmen gewisse praktische Gren. zen. Dazu kommt, dass in vielen Granulitzügen eine rasche Abwechselung von verschiedenen chemischen Abarten zu kon- 
statieren ist. Es scheinen überhaupt die Granulitzüge eine ausgeprägte Linsen-Architektur aufzuweisen, indem sie aus kleineren, mehr oder weniger rasch auskeilenden Gesteinsbänken etwas verschiedener Zusammensetzung aufgebaut sind. Aus diesen Gründen hat es sich am ratsamsten erwiesen, bei der Zusammenstellung der Übersichtskarte auf eine detailliertere chemische Gliederung der Granulite zu verzichten und nur einige schon makroskopisch gut hervortretende Merkmale gewisser Granulitzüge, wie porphyrische Struktur oder schlierige Durchflechtung mit grünen Silikaten (Skarn), durch besondere Bezeichnungen zum Ausdruck zu bringen. Auf der Spezialkarte Tafel 7 ist indessen ein Versuch gemacht, die chemisch-mineralogischen Hauptvarietäten von Granuliten auseinandèr zu halten. - Als ein sehr bemerkenswertes Verhältnis mag hier auch hervorgehoben werden, dass die Granulite in unserem Gebiete fast überall in inniger Verwebung mit Amphiboliten erscheinen; machen doch in mehreren Granulitzägen die amphibolitische Komponente sicherlich ein Fünftel des ganzen Gesteinkomplexes aus. Um dieses Verhältnis zu veranschaulichen, habe ich auf der Karte Tafel 7 die Observationspunkte für Amphibolite und für Granulite durch verschiedene Zeichen anzudeuten versucht.

Bei der Anfertigung der Karten habe ich in der Darstellungsweise und Farbenwahl der Töвnевонм'schen Übersichtskarte möglichst nahe zu folgen gesucht. Nach dem Vorgang dieser Karte sind die Kontakte der zu der eisenerzführenden Formation gerechneten Gesteine immer konform verlaufend mit linsenartigem Auskeilen oder zahnigem und gefranstem Ineinandergreifen in der Streichrichtung gezeichnet. Dass diese Darstellungsweise den tatsächlichen Verhä]tnissen gut entspricht, bietet unser Gebiet öfters Gelegenheit zu konstatieren. Auch in der Richtung nach der Tiefe hin scheinen bei diesen Gesteinen durchaus ähnliche Verhältnisse zu bestehen, wie an den Grubenwänden des Exportfelder Tagebaues gut źu sehen ist. 
Bd 32. H. 2.] EISENERZFÜHR. FORMATION VON GRÄNGESBERG.

Das Hauptstreichen ist im zentralen Teil des Gebietes ziemlich regelmässig NNO-SSW; weiter gegen $\mathrm{N}$ and $\mathrm{W}$ nähert es sich mehr der Richtung $\mathrm{O}-\mathrm{W}$; ausnahmsweise, wie in der Umgegend des Sees Glaningen, kommen sogar Streichrichtungen von NW nach SO vor. Das Einfallen ist bei den NO nach SW streichenden Gesteinen sehr regelmässig steil, meistens etwa $70^{\circ}-75^{\circ}$, nach SO gerichtet, welche Richtung übrigens über ein grosses Gebiet hin im südlichen Dalekarlien bestehen bleibt. - Fast immer ist eine mehr oder weniger gestreckt lentikulare Orientierung zu sehen, die sowohl in den feineren Strukturen wie auch in der gröberen Architektur der Gesteine zum Vorschein kommt. Die Hauptorientierungsrichtung oder das "Einfallen im Felde» ist bei den NO nach SW streichenden Gesteinen meistens steil (etwa $70^{\circ}-80^{\circ}$ ) nach SW gerichtet; in dem nördlichen Teil des Gebietes geschieht dieses Einfallen jedoch nach NO.

\section{Die Gneise.}

\section{Rote Gneise.}

Bei der petrographischen Beschreibung der roten Gneise unseres Gebietes wollen wir mit dem roten Gneis im Lomberget anfangen, der als ein wenig breiter Zug das Liegende des Lomberger erzfübrenden Granulitzuges bildet. Das Gestein stellt eine relativ grobe und urgranitische, an femischen Mineralen sehr arme Varietät des roten, Gneistypus dar. Auf Querbruch lässt es kaum eine Andeutung von Parallelstruktur ersehen, sieht vielmehr einem aplitischen Granit ganz ähnlich aus. Auf steileren Bruchflächen wird jedoch einelineare Struktur deutlich merkbar, die besonders durch die stengelige Ausbildung der 2-3 $\mathrm{mm}$ breiten, trüb violett-bräunlichen Quarzfelder zum Vorschein kommt. - Der Gesteinszug ist sebr einförmig ausgebildet; auch die anderswo selten zu vermissenden amphibolitischen Einlagerungen fehlen hier ganz.

$\mathrm{Zu}$ näherer Ụntersuchung wurde eine Probe aus den Gneis- 
felsen westlich von der Grube Ivarrännan ausgewählt. Messungen in Dünnschliff nach der RosrwaL'schen Methode haben den folgenden Mineralbestand ergeben: Quarz 35.6\%; Miliroklinperthit 39.0\%; Albitoligoklas 25.4\%; dazu ein wenig Eisenglanz. ${ }^{1}$

-.Die Quarz-Stengelchen zeigen unregelmässige Mosaikstruktur mit zackiger Begrenzung der stark undulösen optischen Individuen. Feingranulierte Mörtelzonen kommen auch vor, was anderswo in den Gesteinen des Grängesberger Gebietes nur ausnahmsweise beobachtet ist. In Sprünge und Kornfugen hat sich öfters etwas Eisenoxyd herabgesetzt, was offenbar die oben erwähnte makroskopische Farbe des Quarzes bewirkt.

Der Mikroklinperthit erscheint in Körnern von sehr unregelmässiger Begrenzung. Die Mikroklinstruktur der Kalifeldspatkomponente ist ziemlich unvollkommen entwickelt; demnach zeigen die Schnitte öfters undulöse kryptomikroklinartige Auslöschung von variabler Schiefe. In Schnitten annähernd nach $\mathrm{M}$ wurden Auslöschungsschiefen von $6^{\circ}$ oder sogar darüber bestimmt, wonach auf eine noch vorhandene isomorphe Beteiligung von wenigstens 20 Mol. \% Natronfeldspat zu schliessen wäre. Dazu kommt noch der als perthitische Spindeln ausgeschiedene albitische Feldspat (Fig. 1, Tafel 1), der hier entschieden reichlicher als in den meistens 20 bis $25 \mathrm{Mol}$ \% Ab enthaltenden Mikroklinperthiten der allgemeineren Granit- und Pegmatit-Typen vorhanden ist, andererseits aber weit spärlicher als in den etwa $60 \mathrm{Mol} \%$ Ab enthaltenden perthitisierten Natronorthoklasen der meisten Alkaligranite und Alkalisyenite erscheint.

In einer früheren Mitteilung ${ }^{2}$ habe ich zufolge den Resultaten einer Zusammenstellung von Feldspatanalysen die Auffassung ausgesprochen, dass die Alkalifeldspatsilikate

1 Die hier gleichwie im Folgenden angeführten Resultate der Messungen nach Rosiwals Methode sind immer in Volumprozenten angegeben.

2 G. F. F. 27 (1905): 338-346. 
bei. Kristallisieren aus den meisten Eruptivmagmen befähigt sind, eine kontinuierliche Reihe von Mischkristallen $\mathrm{zu}$ bilden, und dass demnach die allgemein $\mathrm{zu}$ beobachtenden perthitischen Verwachsungen nicht bei dem primären Erstarren haben zustande kommen können, sondern durchweg einem sekundären Entmischungsprozesse zugeschrieben werden müssen, dem die anfänglich homogenen Mischkristalle bei tieferer Temperatur generell unterworfen sind. Eine derartige Anschauung wurde schon früher von BEcke ausgesprochen und ist später von mehreren Petrographen angenommen worden. Von diesem Standpunkte aus wäre es sehr zu wünschen, dass bei petrographischen Charakteristiken die Durchschnittszusammensetzung der perthitischen Kalifeldspatgemengteile näher angegeben werden könnte, wie auch überhaupt der Bestimmung des Mischungsverhältnisses des Kalifeldspats bei manchen Gesteinen offenbar mindestens gleich grosses Interesse beizumessen ist als derjenigen des Plagioklases. Bei den homogenen Orthoklasen und Sanidinen kommt zu diesem Zweck hauptsächlich die Auslöschungsschiefe in Schnitten nach M zur Anwendung, obwohl die Methode gewiss keine sehr genauen Bestimmungen erlaubt. ${ }^{1}$ Bei den perthitischen Feldspaten muss das anfängliche Mischungsverhältnis hauptsächlich nach dem jetzigen Gehalt an albitischen Spindeln beurteilt werden. Aus mehreren Ursachen, z. B. wegen der öfters geringen Breite und unregelmässigen Verteilung der Lamellen, sind genauere volumenometrische Messungen schwierig auszuführen; andererseits bleibt der im Wirt-Feldspat als isomorphe Beimengung noch immer vorhandene Natronfeldspat unter allen Umständen schwierig zu beurteilen, um so mehr als die Entmischung sogar bei einem und demselben Perthit-Individuum in verschiedenen Teilen offenbar verschieden weit fortgeschritten sein kann. Dennoch glaube ich, dass es auch bei den perthitischen Kalifeldspaten mancher Tiefengesteine und kristallinen

1 Bei Sanidinen scheint diese Auslöschnngsschiefe durchweg niedriger zu sein als bei den entsprechenden Orthoklasen. 
Schiefer bei einiger Übung sehr wohl möglich ist, allein nach dem Aussehen in Dünnschliff die Albitbeteiligung innerbalb nicht allzu weiter Fehlergrenzen zu beurteilen. Um die Mischungsverhältnisse der Kalifeldspate bei petrographischen Darstellungen zum Ausdruck zu bringen, scheint es mir erwünscht, für diese Feldspate eine den Plagioklasen entsprechende Gliederung einzuführen, und möchte ich die folgende Einteilung als eine aus mehreren Gesichtspunkten zweckmässige vorschlagen (vergl. Fig. 22, S. 155):

$$
\begin{aligned}
& A b t . \quad I \text {. . . OOr } r_{100} A b_{0}-O r_{83 \cdot 3} A b_{16 \cdot 7} \text { oder } O r-O r_{5} A b_{1} \\
& \text {, II . . } O r_{83 \cdot 3} A b_{16 \cdot 7}-O r_{66 \cdot 7} A b_{33 \cdot 3} \gg O r_{5} A b_{1}-O r_{2} A b_{1} \\
& \text {-III . . } O r_{66} A b_{33 \cdot 3}-O r_{50} A b_{50} \gg O r_{2} A b_{1}-O r_{1} A b_{1} \\
& \text {,IV. . . OOr } A r_{50} A b_{50}-O r_{33 \cdot 3} A b_{66 \cdot 7} \gg O r_{1} A b_{1}-O r_{1} A b_{2}
\end{aligned}
$$

Diese Gliederung könnte dann weiter nach dem albitischen Ende hin durchgeführt werden, wobei allerdings die reinsten $\mathrm{Al}$ bite (mit nur 4-5 Mol. \% Or) mit den kalkärmsten Plagioklasen zusammen als eine selbständige Abteilung am besten abzutrennen sind. Die verschiedenen Abteilungen könnten am einfachsten durch die entsprechenden Ordnungszablen bezeichnet werden. Ein Sanidin von einer Zusammensetzung zwischen $O r_{2} A b_{1}$ und $O r_{1} A b_{1}$ wäre demnach einfach als ein Sanidin $_{\text {III }}$ zu bezeichnen; ein homogener Orthoklas zwischen $O r_{1} A b_{1}$ und $O r_{1} A b_{2}$ könnte als ein Orthoklas ${ }_{I V}$ bezeichnet werden; Mikroklinperthite $z$ wischen $\mathrm{Or}_{5} \mathrm{~A} b_{1}$ und $\mathrm{Or}_{2} \mathrm{Ab}_{1}$ werden wir gleicherweise im Folgenden als Mikroklinperthite besprechen u. s. w.

Kehren wir nach dieser Abschweifung zu dem perthitischen Feldspat des Lomberger Gneises zurück, so ist derselbe seinem Aussehen nach unzweifelhaft in die Abteilung III der oben vorgeschlagenen Klassifikation und zwar etwa in die Mitte dieser Abteilung einzureihen. Unter Berücksichtigung, dass die Kalifeldspate der granitischen Gesteine meistens auch 2 bis $2^{1 / 2}$ Mol. \% An enthalten, dürfte die Molekularzusammensetzung unseres Perthits nicht weit von einem Verhältnis 
Bd 32. H: 2.] EISENERZFÜHR. FORMATION VON GRÄNGESBERG.

$O r_{60} A b_{38} A n_{2}$ liegen, was mit dem unten angegebenen Chemismus dieses Gneises auch gut übereinstimmt.

Der Plagiolilas bildet z. T. grössere, vielfach geknickte Körner, meistens aber Aggregate kleinerer Körner. Die optischen Eigenschaften (symmetrische Maximalauslöschung $11-12^{\circ}$; Auslöschung $\perp \mathrm{PM}-9^{\circ}-10^{\circ}$; Lichtbrechung der BEcke'schen Gruppe I) entsprechen nach den Diagrammen in Rosenbosch's Handbuch, 4 Auflage, etwa einem Mischungsverhältnis $A n_{11} A b_{89}$. Nàch den vorliegenden Analysen von Albitoligoklasen aus granitischen Gesteinen zu schliessen, ist sicherlich aber auch eine Beteiligung von zwischen 5 und 10 Mol. \% Or in dem Plagioklas unseres Gneises anzunehmen; eine geringe Menge von Mikroklin ist auch als antiperthitische Flecke ausgeschieden. Als der Durchschnitts-Plagioklas könnte demnach etwa ein Mischungsglied $A n_{10} A b_{82} O r_{8}$ angenommen werden. - Der Plagioklas enthält öfters rundliche Quarztröpfchen; myrmekitische Verwachsungen fehlen dagegen ganz, wie sie überhaupt meiner Erfahrung nach in sehr kalkarmen und demnach kalkarme Plagioklase und natronreiche Kalifeldspate enthaltenden Graniten und Gneisen zu fehlen scheinen.

Von femischen Silikaten sind Biotit und Orthit spurenweise zu sehen. Der fast einzige femische Gemengteil ist Eisenglanz, welches Mineral nicht nur als feines Pigment in den Feldspaten oder in den Sprüngen im Quarz vorhanden, sondern auch in kompakten Körnern dem Gestein eingesprengt ist.

Von dem beschriebenen Gestein hat Grabe die folgende Analyse (S. 12) ausgeführt.

Die erste Kolumne enthält die primären Analysenzahlen, die zweite Kolumne die entsprechenden Molekularzahlen; nach folgenden Molekulargewichten berechnet: $\mathrm{SiO}_{2}=60.4 ; \mathrm{Al}_{2} \mathrm{O}_{3}$ $=102.2 ; \mathrm{CaO}=56.0 ; \quad \mathrm{Na}_{2} \mathrm{O}=62.1 ; \mathrm{K}_{2} \mathrm{O}=94.2 ; \mathrm{TiO}_{2}=80 ;$ (Fe, $\mathrm{Mn}$ ) $\mathrm{O}=72 ; \mathrm{MgO}=40 ;$ bei $\mathrm{P}_{2} \mathrm{O}_{5}$ sind die als Apatit gebundenen $\mathrm{CaO}-\mathrm{Zahlen}$ in Parenthese angegeben. Die Zahlen 
in der dritten Kolumne geben die snormative Zusammensetzung des Gesteins nach der Berechnungsmethode der amerikanischen Petrographen an; der dieser Norm» entsprechende Platz ("Class", »Order», sRang" und „Subrang») und Name in dem amerikanischen Systeme sind unten in der vierten Kolumne angegeben. Ein der Ordnungszahl einer Abteilung beigefügtes + oder - Zeichen bedeutet, dass die Analyse nahe an die obere bezw. untere Grenze dieser Abteilung fällt.

\begin{tabular}{|c|c|c|c|}
\hline $\mathrm{SiO}_{2} \cdot . . .77 .28$ & 127.95 & Q.... 37.23 & $s \cdot . .$. \\
\hline $\mathrm{TiO}_{2} \ldots . . .0 .74$ & 0.05 & $\mathrm{Or} \cdot \cdot \cdot 24.86$ & \\
\hline $\mathrm{Al}_{2} \mathrm{O}_{3} \cdot \ldots .12 .36$ & 12.09 & $\mathrm{Ab} \cdot \cdot \cdot \cdot \cdot 32.81$ & Or $\cdot . \quad . \quad . \quad 39.9$ \\
\hline $\mathrm{FeO}^{1} \cdot . \cdot$ & 201 & $\mathrm{An} \cdot \cdot \cdot \cdot \cdot 2.59$ & $\mathrm{Ab} \cdot . \cdot 55.9$ \\
\hline $\mathrm{MnO} . .$. & 2.01 & $\mathrm{Al}_{2} \mathrm{O}_{3} \cdot \cdot \cdot \quad 0.50$ & $\mathrm{An} \cdot \ldots .4 .2$ \\
\hline $\mathrm{MgO} \cdot \cdot \cdot \cdot$ & 0.38 & $\Sigma$ sal. 97.99 & \\
\hline $\mathrm{CaO} \cdot$ & 1.00 & $\begin{array}{llll}\mathrm{MgSiO}_{3} & \ldots & 0.38\end{array}$ & $\Sigma \mathrm{F} \cdot . .22 .29$ \\
\hline $\mathrm{Na}_{2} \mathrm{O} \ldots$. & 6.23 & $\mathrm{FeTiO}_{3} \cdot . \quad 0.08$ & $\mathrm{Al}_{2} \mathrm{O}_{3} \ldots+0.49$ \\
\hline $\mathrm{K}_{2} \mathrm{O}$. . & 4.45 & $\mathrm{Fe}_{2} \mathrm{O}_{3} \cdot . \cdot 1.57$ & \\
\hline $\mathrm{P}_{2} \mathrm{O}_{5} \cdot \cdot \cdot \cdot \cdot$ & $\left(\begin{array}{lll}0 & 0 & 0\end{array}\right)$ & Apatit. . & \\
\hline Gl. V. . . · $\quad 0.60$ & & $\Sigma$ fem. 2.10 & Alaskos \\
\hline 100.53 & & 100.09 & \\
\hline
\end{tabular}

Oben in der vierten Kolumne sind einige Berechnungszahlen angegeben, die mir aus mebreren Gründen geeignet scheinen, eine schnelle Übersicht der chemischen Hauptcharaktere von Quarz-Feldspatgesteinen oder auch im allgemeinen von feldspatigen Gesteinen zu geben, und die darum von mir. in früheren Publikationen vielfach benutzt worden sind. Bei der Berechnung dieser Zahlen sind die Analysen hauptsächlich in derselben Weise wie nach der amerikanischen Berechnungsmethode zuerst in Molekularproportionen der snormativen» Mineralkomponenten gerechnet; aus diesen Molekular-

1 In den Analysen der sauren Gesteine warde auf eine Trennung von FeO und $\mathrm{Fe}_{2} \mathrm{O}_{3}$ verzichtet. Bei den Berechnungen ist das Eisen als $\mathrm{FeSiO}_{3}, \mathrm{Fe}_{2} \mathrm{O}_{3}$ oder $\mathrm{Fe}_{3} \mathrm{O}_{4}$ angeführt, je nachdem es hauptsächlich als $\mathrm{FeO}$-Silikate, Eisenglanz (bezw. Eisenoxyd-Silikate) oder Magnetit im Gestein vorhanden ist. 
zahlen werden dann die angeführten Berechnungszahlen direkt, ohne irgendwelche Umrechnungen auf Gewichtsprozente abgeleitet. Die Zahl $s$ bedeutet das Verhältnis der freien (nicht als Silikate gebundenen) $\mathrm{SiO}_{2}-$ Molekeln zu der Summe der feldspatbildenden Molekeln $(\mathrm{Or}+\mathrm{Ab}+\mathrm{An})$ und dient dazu, die Azidität des Gesteins zu charakterisieren. ${ }^{1}$ 'Die nächsten Zahlen geben die relativen Proportionen der drei feldspatbildenden Silikatkomponenten $O r, A b$ und $A n$ in Molekularprozenten an. Diese Zahlen bei Gesteinen zu kennen ist offenbar von grossem Interesse; merkwürdigerweise sind sie dennoch bei Darstellungen von Gesteinsanalysen bisher nur ausnahmsweise zur Anwendung gekommen. Sie bringen zwar bei Gesteinen dieselben chemischen Charaktere zum Ausdruck nach welchen in dem amerikanischen System der "Rang» und "Subrang» eines Gesteins abgeleitet wird, haben jedoch den grossen Vorteil, dass sie zu graphischer Darstellung durch Dreieckprojektionen direkt geeignet sind und dabei eine bequeme Vergleichung der Gesteinsanalyse mit den Resultaten der makroskopischen Feldspatbestimmungen ermöglichen. $\Sigma F$ bezeichnet die Summe der Molekularzahlen der Feldspatkomponenten $(\mathrm{Or}+\mathrm{Ab}+\mathrm{An})$; unter Berücksichtigung, dass diese Zahl für die einfachen Komponenten bezw. 36, 38 und 36 beträgt, kann sie über die Feldspatbeteiligung in dem Gestein zur Orientierung dienen. Unter der Bezeichnung $\mathrm{Al}_{2} \mathrm{O}_{3}+$ bezw. $\mathrm{Al}_{2} \mathrm{O}_{3}$ - wird schleisslich der bei der Analysenberechnung entstehende Tonerde-Überschuss, bezw. Tonerde-Mangel in Molekularzahlen angeführt; bei guten Analysen ist daraus sogleich zu sehen, ob das Gestein als femische Gemengteile kalkfreie oder kalkhaltige Silikate enthält.

Nach den oben angeführten Beobachtungen enthält der Lomberg-Gneis 39.0 Vol. \% Mikroklinperthit, etwa ron der Zusammensetzung $\mathrm{Or}_{60} \mathrm{Ab}_{38} \mathrm{An}_{2}$, und 25.4 Vol. \% Albitoligo-

1 Bei den an $(\mathrm{Mg}, \mathrm{Fe}) 0-$ Silikaten reicheren Gesteinen sind die Grenzwerte des Koeffizienten $s$ bei Abrechnung der zu $(\mathrm{Mg} ; \mathrm{Fe}) \mathrm{SiO}_{3}$-Bijdung erforderlichen $\mathrm{SiO}_{2}$-Menge, bezw. ohne eine solche Abrechnung angegeben. 
klas, etwa $=\mathrm{Or}_{8} \mathrm{Ab}_{82} \mathrm{An}_{10}$. Unter Vernachlässigung der Verschiedenheiten im spez. Gewicht berechnet sich daraus das Durchschnittsverhältnis $O r_{39 \cdot 5} A b_{55 \cdot 3} A n_{5 \cdot 2}$, während sich aus der Analyse das Verhältnis $O r_{39 \cdot 9} A b_{55 \cdot 9} A n_{4 \cdot 2}$ ergiebt. Der vorhandene Tonerdeüberschuss dürfte vielleicht z. T. daher kommen, dass die Kalkbestimmung ein wenig zu niedrig ausgefallen ist.

In der folgenden Tabelle sind die Berechnungszahlen einiger dem Lomberger Gneis chemisch verwandten Gesteine zum Vergleich zusammengestellt.

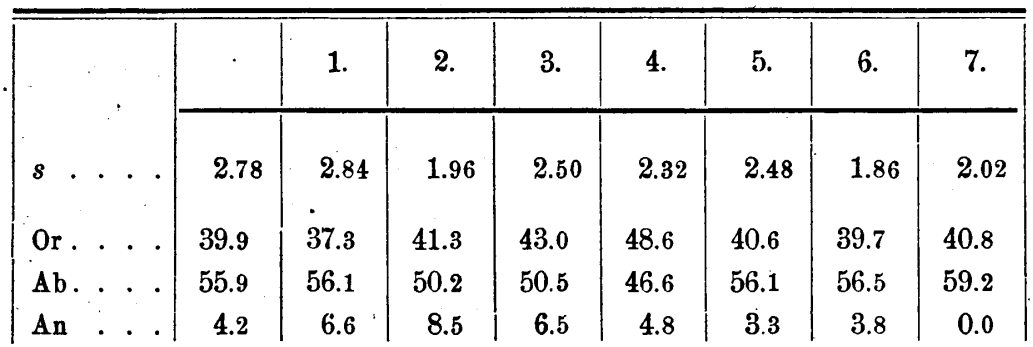

Unter den bisher chemisch untersuchten Gneisen aus Schweden stehen die roten Gneise aus dem Kirchspiel Nora in Örebro län dem Lomberger Gneis am nächsten. (Nr. 1-3: Gneise von Svartjärnstorp, Kristinelund und Jernboden. ${ }^{1}$ ) Es mag hier auch erwähnt werden, dass diese Gneise z. T. das Nebengestein des schuppige Eisenglanzerze enthaltenden Granulitzuges von Pershyttan darstellen, ganz wie der Lomberger Gneis das Nebengestein des Lomberger Granulitzuges bildet, der ebenso sich gerade durch den Reichtum an schuppigen Eisenglanzerzen auszeichnet. Auch die roten Perthitgneise aus Kullen in Schonęn ${ }^{2}$ (Nr. 4: Gneis von Arild) zeigen gewisse Übereinstimmungen, gehören jedoch einem weit kalireicheren und demnach plagioklasärmeren Typus an.

1 o. Gumasuius: Beskrifn. till kartbladet Nora. S. G. U., Ser. Aa, N:o. 56 (1875): $10-11$.

A. Hennig: Kullens kristalliniska bergarter. Lunds Univ. Årsskrift 24 (1898): 40. 
Unter den schwedischen Graniten sind am nächsten verwandt die von HoLmquist wegen ihres Gehaltes an natronreichem Perthit als Perthit-Quarz-Granite bezeichneten Varietäten, besonders gewisse rote Perthitgranite aus Småland, z. B. der Granit aus Jungfrun (Nr. 5) ${ }^{1}$; ebenso der mit Diabas eng verknüpfte Granophyr-Granit aus dem Brefven-Gange (Nr. 6). ${ }^{2}$ Durch die sehr geringe Beteiligung des An-Silikates nähert sich der Lomberg-Gneis chemisch auch den echten AlkaliGraniten (Nr. 7: Granit von Quincy ${ }^{3}$ ). Bei Klassifizieren nach dem amerikanischen Systeme würde in der Tat eine Verminderung des $\mathrm{SiO}_{2}$-Gehaltes um $1 \%$ ausreichend sein, um das Gestein aus dem sSubrang der Alakose in denjenigen der Liparose hinüberzubringen, wo die Mehrzahl der echten Alkaligranite ihren Platz haben. Nichtsdestoweniger besteht zwischen unserem Gneis gleichwie auch den mit ihm chemisch übereinstimmenden Graniten einerseits und den zu der foyaitischen Gesteinsassoziation gehörigen Alkaligraniten andererseits eine durchgreifende Verschiedenheit in dem Mineralbestand. Während bei den letzteren der ganze AbGehalt nebst dem bis auf Null sinkenden oder doch höchstens 1-2 $\mathrm{Mol}$. \% betragenden An-Gehalt in einem Orthoklas $_{I V}$ bezw. Perthit ${ }_{I V}$ stecken bleibt, genügt schon die geringe Vermehrung des An-Gehaltes bis auf 4 oder 5 Mol. \%, um in den ersteren Gesteinen ein reichliches Auskristallisieren eines sauren Plagioklases zu bewirken, der hier in selbständigen Kristallindividuen mit einem Orthoklas III bezw.

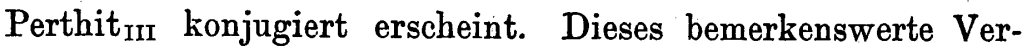
hältnis ist m. E. dadurch zu erklären, dass bei der schliesslichen Kristallisationstemperatur der diesen granitischen Gesteinen entsprechenden Magmen Alkalifeldspat-Mischkristalle der Abteilung IV zwar noch existenzfähig sind, aber von dem An-Silikat nur höchstens etwa 2 Mol. \% auf-

1 'P. J. Holmquist: Die Granite von Schweden, N:0 78.

2 K. I. Winae: G. F. F. 18 (1896): 195.

3 H. S. WAshington: Am. J. of Sc. 6 (1898): 121. 
zunehmen fähig sind; steigt der An-Gehalt auch nur wenig über diesen Wert hinaus, muss eine getrennte Kristallisation von Plagiolklas stattfinden.

Mit dem soeben beschriebenen Lomberg-Gneis stimmt nahe überein nicht nur in der petrographischen Beschaffenheit, sondern auch in dem geognostischen Verhalten der rote granitische Gneis im Gudmundberget, der inselartig mitten in den Granuliten westlich von Grängesberg auftritt. . Nur ist die stengelige Orientierung weniger kräftig ausgebildet. Das Gestein ist meistens mit Eisenerz, z. T. Magnetit, ziemlich reichlich eingesprengt; auch Flusspat tritt nicht selten makroskopisch hervor. - Der grossen Ähnlichkeit mit dem Lomberger Gneis nach zu schliessen, dürfte es nicht unwahrscheinlich sein, dass die isolierte Lage des Gudmundberger Gneises nur eine scheinbare ist, und dass die beiden Gesteine, z. B. in einem tieferen Abschnitt, sich als direkt zusammenhängend erweisen würden.

Das grosse Gneis-Terrain auf der östlichen Seite von dem See $N$. Hörken ist ebenso von einem Gestein eingenommen, der dem Lomberg-Gneis sehr nahe steht. Die hauptsächliche Verschiedenheit dürfte darin bestehen, dass der Hörken-Gneis anstatt des Eisenglanzes meistens ein wenig grüne Hornblende enthält. Die grosse petrographische Einförmigkeit dieses Gebietes wird nur durch einen Zug von kleineren Diorit- oder Gabbrodioritmassiven unterbrochen, der von Svanskogen aus bis nach dem südöstlichen Ufer des Sees $N$. Hörken verfolgt werden kann; auch in den übrigen Teilen des Gebietes sind kleinere amphibolitische Einlagerungen spärlich $\mathrm{zu}$ sehen.

Zwischen den Lomberg- und Hörken-Gneisen schiebt sich ein Zug aus rotem granulitischem Gneis ein. Ausser durch das feinere Korn und etwas reichlicheren Gehalt an dunklen Mineralen sticht dieser Granulitgneis durch eine fast überall $\mathrm{zu}$ beobachtende intime Verwebung mit Amphiboliten von den umgebenden gröberen Gneisen ab. In einer 
Bd 32. H. 2.] EISENERZFÜHR. FORMATION VON GRÄNGESBERG.

Probe aus den vorzüglich entblössten Felsen an der südöstlichen Seite von Orrleksdammen ergab sich folgender Mineralbestand: Quarz 26.0\%; Mikroklinperthit 38.5 \%; Albitoligoklas $33.0 \%$; Hornblende und Epidot $2.5 \%$. Der Quarz kommt z. T. als grössere, bis $1 \mathrm{~mm}$ breite, etwas stengelig ausgezogene Felder vor; z. T. bildet er in Körnern von etwa 0.1. -0.2 mm Breite mit Feldspaten vermischt ein kleinkörniges Grundgewebe. Dieses Grundgewebe ist etwas gröber als dasjenige der typischen Granulite der Grängesberger Gegend und erinnert in der Ausbildung des Quarzes an die Struktur der Aplite. - Der Mikroklinperthit zeigt unvollkommene Mikroklinstruktur und ungleichförmig verteilte perthitische Spindeln, die entschieden spärlicher als in dem Feldspat des Lomberg-Gneises vorhanden sind; wahrscheinlich entspricht die Zusammensetzung einem Grenzgliede zwischen den Abteilungen II und III. Der Plagioklas kommt z. T. in dem Grundgewebe, z. T. als grobkörnigere »Anhäufungen» vor; er entspricht optisch einem Mischungsverhältnis etwa $A_{14} A_{86}$. Typischer Myrmekit fehlt. Die dunklen Minerale sind in einzelnen striemenähnlich ausgezogenen Flasern angehäuft, die hauptsächlich aus einer kräftig gefärbten Hornblende bestehen, wozu sich etwas Epidot, Titanit, Magnetit, Apatit und Zirkon nebst einzelnen grossen Körnern eines etwas orthitähnlichen Minerals gesellen. Biotit fehlt. - Der Granulitgneis ist nicht analysiert worden; dem Mineralbestande nach zu schliessen, dürfte er dem Lomberg-Gneis gegenüber einige Prozente weniger $\mathrm{SiO}_{2}$, dafür etwas mehr $\mathrm{CaO}$ und $\mathrm{MgO}$ enthalten. Wenn wir in dem Gestein einen Mikroperthit $\mathrm{Or}_{65}$ $\mathrm{Ab}_{33} \mathrm{An}_{2}$ neben einem Plagioklas $\mathrm{Or}_{8} \mathrm{Ab}_{79} \mathrm{An}_{13}$ annehmen, berechnet sich das durchschnittliche Verhältnis $O r_{3 \times \cdot 7} A b_{54 \cdot 2} A n_{7 \cdot 1}$.

Auf der südwestlichen Seite von $N$. Hörken sind rote Gneise zwischen diesem See und Pingstaberg spärlich entblösst. Es sind hier z. T. gröbere granitische Varietäten, z. T. feinkörnige, stark gestreckte, öfters drusige und flussspatreiche Gesteine beobachtet. Wie auf dem Blatt IV der 
TöRNевонм'schen Übersichtskarte dargestellt ist, streckt sich von Pingstatorp noch weiter südlich bis in die Nähe ron Bredsjö ein Zug aus surgranitischen» Gesteinen; diese »Urgranite» stimmen in chemisch-mineralogischer Hinsicht mit den roten Gneisen des Grängesberger Gebietes nahe überein, obwohl sie meistens etwas gröber und massiger ausgebildet sind.

Nördlich von Grängesberg sind rote Gneise an mehreren Lokalen in der Gegend südlich von Björnhyttan und Glaningen beobachtet worden. Neben typischen roten Gneisen kommen hier aber auch blassrötliche oder hellgraue Varietäten vor, die sich wenigstens z. T. als Plagioklasgneise herausgestellt haben. Der starken Erdbedeckung dieser Gegend zufolge habe ich auf eine detailliertere Abtrennung der verschiedenen Gneisarten verzichten müssen.

Die roten Gneise im nordwestlichen Teil des Kartengebietes gehören zu einem Gneiszug, der mit der grossen Gneisformation weiter nördlich in Dalekarlien direkt zusammenhängt. Diese Gneise weichen durch ein feineres und gleichmässigeres Korn von den vorher baschriebenen granitischen Varietäten etwas ab. Es sind z. T. kleinkörnige aplitenähnliche, an femischen Silikaten sehr arme Gesteine, die dafür öfters Magnetit in nicht geringer Menge enthalten. Im westlichen Teil des Gebietes walten etwas femischere, scharfkristallinische Varietäten vor, die durch feine, striemenartig ausgezogene Biotitflasern eine charakteristische Parallelstruktur erhalten. - Grünsteine von amphibolitischem oder dioritischem Charakter sind in die Gneise vielfach eingeschaltet. - Eine Probe des biotitflaserigen Gneises nördlich von Mărtenstorp zeigte im Dünnschliff einen Mineralbestand von $35 \%$ Quarz; $21.6 \%$ Mikroklinperthit (II oder III); $38.6 \%$ Albitoligoklas, optisch etwa $A n_{14} A b_{88} ; 3.4 \%$ Biotit; $0.7 \%$ Magnetit; $0.7 \%$ Titanit und Apatit, nebst etwas Orthit und Zirkon. Der Quarz ist grösstenteils als stark ausgezogene stengelige Felder vorhanden; der Mikroperthit ist hauptsächlich als eine untergeord- 
nete Füllmasse zwischen den reichlichen Plagioklaskörnern eingeklemmt; myrmekitische Zapfen sind häufig. Nehmen wir in diesem Gestein einen Plagioklas $\mathrm{Or}_{8} \mathrm{Ab}_{79} \mathrm{An}_{13}$ neben einem Mikroperthit $\mathrm{Or}_{65} \mathrm{Ab}_{33} \mathrm{An}_{2}$ an, was jedoch vielleicht für den Mikroperthit einen etwas zu grossen Natrongehalt ergeben dürfte, berechnet sich ein Durchschnittsverhältnis $O r_{28 \cdot 4} A b_{62 \cdot 5} A n_{9 \cdot 1}$. Diese dünnflaserigen roten Gneise scheinen demnach (Fig. 20, S. 141) in chemischer Hinsicht Übergangsglieder zwischen den typischen roten Gneisen und den Plagioklasgneisen $\mathrm{zu}$ bilden; durch das scharfkristallinische Gefüge und gleichmässige Korn stimmen sie mit den letzteren Gneisen in struktureller Hinsicht am meisten überein. - Ganz ähnliche Gneise sind auch in einigen Felsen zwischen Gonäs och Skeppmora beobachtet worden.

Die roten Gneise östlich voin dem Björnberger Erzfelde wurden zuerst auf der TöRNEBOHM'schen Übersichtskarte mit dem jüngeren Enkullen-Granit zusammengestellt; auf der später erschienenen Übersichtskarte von Schweden sind sie jedoch davon abgetrennt worden und mit der Farbe der sersten Granit-Gruppe» bezeichnet. Die Gesteine sind meistenteils den vorher erwähnten Hörken-Gneisen äbnlich; im nordwestlichen Teil des Gebietes treten jedoch viel gröbere, urgranitische, etwas hornblendeflaserige Varietäten auf. Im Dunsberget kommt ein eigentümlicher, massiger, poröser, sehr rauh anzufühlender Urgranit von hell rötlich-gelber Farbe vor. Der hellgraue Quarz ist in grossen bis cm-breiten Feldern ausgeschieden; die Feldspate bilden lockere, kleinkörnige Aggregate; von dunklen Gemengteilen sind vereinzelte Anhäufungen von Magnetit nebst etwas Orthit und Titanit neben staubigen bräunlichen Zersetzungsprodukten eines wahrscheinlich eisenreichen Silikates zu sehen. Nach einer volumenometrischen Messung, die besonders in Bezug auf den Quarzgehalt keine Genauigkeit beanspruchen kann, enthält das Gestein 33.6 \% Quarz, $25.2 \%$ Kalifeldspat I $_{\text {I }}$ und $40 \cdot 7$ \% Albitoligoklas. Der Plagioklas zeigt : sehr schöne und regelmässige Zwillings3-100170. 
lamellierung mit Auslöschungsschiefen, einem Verbältnis etwa $\mathrm{An}_{8} \mathrm{Ab}_{92}$ entsprechend. Der Kalifeldspat ist ein vorzüglich gegitterter Mikroklin fast ohne jede Andeutung von typischer Perthitstruktur; grössere Körner enthalten dafür bisweilen unregelmässige Plagioklasflecke. Wenn man einen Kalifeldspat $\mathrm{Or}_{83} \mathrm{Ab}_{15} \mathrm{An}_{2}$ neben einem Plagioklas $\mathrm{Or}_{6} \mathrm{Ab}_{86} \mathrm{An}_{7}$ annimmt, würde sich ein Feldspatverhältnis $O r_{36} A b_{59} A n_{5}$ berechnen. Das Gestein wäre demnach dem Lomberg-Gneis chemisch nahe verwandt, obwohl der Kalifeldspat hier in weit reinerem Zustand ausgeschieden ist. Diese Anomalie dürfte vielleicht in Zusammenhang mit dem drusigen Gefüge des Gesteins stehen; auch in den drusigen ultrasauren Gneisen auf der westlichen Seite von N. Hörken ist statt Perthits reiner Mikroklin ausgeschieden.

Die Kontaktverhältnisse der roten Gneise gegen die Granulite scheinen auf verschiedenen Lokalen etwas verschiedenartig ausgebildet. Es sind hauptsächlich drei Arten von Kontakten beobachtet:

1) Unscharfe Kontakte mit Übergangsgesteinen.

2) Scharfe Kontakte ohne merkbare Überquerungen oder Durchdringungen.

3) Scharfe Kontakte mit Andeutungen zum intrusiven Verhalten des Gneises.

Als Beispiel von Kontakten ersterer Art können die Kontakte des Lomberger Gneises gegen die schuppige Eisenglanzerze enthaltenden, rötlichen, ziemlich kalireichen Granulite im Lomberget angeführt werden. An der Grenze gegen den Granulit hin nimmt die Korngrösse des Gneises rasch ab, es stellt sich ein rotes granulitisches Gestein ein, das weiter gegen 0 . etwas glimmerreicher wird und in den typischen Lomberg-Granulit äbergeht. Die Breite der Übergangszone beträgt jedoch nur einige Meter. - Ganz ähnliche Verhältnisse wiederholen sich auf der östlichen Seite des Gudmundberger Gneises. Dieses Gneisgebiet ist auch auf der westlichen Seite von roten granulitischen Gesteinen umge- 
Bd 32. H. 2.] EISENERZFÜHR. FORMATION VON GRÄNGESBERG.

ben, denen die schuppigen oder z. T. quarzgebänderten Eisenglanzerze des Gudmundbergfeldes eingelagert sind. Diese Gesteine sind von dem Gneise durchaus unscharf abgegrenzt, zeigen vielmehr selbst einen zwischen Gneis und Granulit vielfach schwankenden Charakter. Ähnliche Übergangsgesteine treten auch an dem nördlichen Abhang von Gudmundberget in der Streichrichtung des Gneises auf. - Die beiden Gneisgebiete im Lomberget und Gudmundberget sind in der Streichrichtung durch einen $\mathrm{Zug}$ aus roten kalireichen Granuliten mit Klümpchen und Adern von Granat und Epidot von einander abgetrennt. Die Gneise und der Granulit scheinen dabei mit mehreren keilförmigen Abzweigungen ineinanderzugreifen, wie am besten im Lomberget zu sehen ist. Die Gneiszweige nehmen gegen den Granulit hin eine feinkörnigere Struktur an und scheinen ziemlich unmerklich auszukeilen. In den Granulitkeilen finden sich so wohl im Gudmundsberget als im Lomberget mehrere kleinere Vorkommisse von quarzigen Eisenerzen mit etwas Epidot, Granat, Hornblende u. s. w.

Beispiele von Kontakten der zweiten Art liefern die Kontakte zwischen dem Granulitgneis bei Orrleksdammen und den weiter nördlich auftretenden Porphyrgranuliten. Diese Gesteine greifen in der Streichrichtung vielfach ineinander ein, ohne dass Übergangsgesteine zu sehen sind. Auch der rote Urgranit nördlich vom Björnberget wurde in ganz scharfem Kontakt mit den in seinem Liegenden anstehenden skarneisenerzführenden Plagioklasgranuliten gesehen; nur zeigte sjch das Gestein am Kontakt ein wenig feinkörniger.

Ein Kontakt der dritten Art wurde an dem nördlichen Abhang des Gudmundberges etwa WSW von Lundbergstorp gesehen, wo eine massige Varietät des roten Gneises an einen biotitreichen, etwas porphyrischen grauen Granulit des iExportfeld-Typus» in der Streichrichtung grenzt. Der Granulit ist am Kontakt von roten granitischen Gängen und Adern netzförmig durchschwärmt, deren Gesteinsmaterial von dem massigen Gneis selbst nicht zu trennen ist. - Ein wenig 
nördlich von den Quarz-Granat-Magneteisenerzgruben, etwa $1.8 \mathrm{~km}$ südlich von Björnhyttan finden sich einige Ausbisse von rotem granitischem Gneis, der mit dioritischen Gesteinen breccienartig verwoben erscheint. Auf der Südseite dieser Gneis-Diorit-Felsen sind einige Blössungen eines ebenschieferigen, den Porphyrgıanuliten etwas ähnlichen Granulits, der auch breccienartig von dem roten granitischen Gestein durchadert ist und anscheinend schollenartig in ihm eingeschlossen vorkommt. - In diesem Zusammenhang könnte auch erwähnt werden ein derartiger sintrusiver» Kontakt zwischen einem roten ultrasalischen Gneis und einem biotitreichen Granulit, der in einem Eisenbahneinschnitt im W von dem Iviks-Felde auf der nördlichen Seite des Wessman Sees, etwas ausserhalb der nördlichen Kartengrenze, vorzüglich aufgeschlossen ist.

Den angeführten Observationen nach zu schliessen, scheint es nicht unwahrscheinlich, dass die Ausbildung der Kontakte der roten Gneise von dem chemischen Charakter der angrenzenden Granulite etwas abhängig ist. Während diese Gneise gegen die femischen oder kalkreicheren Granulite des "Exportfeld»- bezw. "Porphyrgranulit»-Typus scharf absetzen oder sich sogar intrusiv verhalten, scheinen sie gegen die salischeren und kalkärmeren Granulite des "Lomberg,Typus weniger scharf abgegrenzt zu sein. Gute Aufschlüsse sind jedoch allzu selten, um allgemeinere Schlüsse in dieser Richtung zu erlauben.

\section{Granitgneise.}

Östlich von dem Grängesberger Erzfeld nahe im Hangenden des Apatiteisenerzzuges des Exportfeldes tritt ein grobflaseriger, etwas rötlicher granitischer Gneis auf, der als eine langgestreckte, 1,100 bis $1,200 m$ breite Linse von der Eisenbahnstation Silfverhöjden im $\mathbf{S}$ bis nach Långblå im $\mathrm{N}$ zu verfolgen ist. Durch den grösseren Gehalt an Biotit und 
Hornblende weicht dieser Gneis von den vorher beschriebenen Gneisen scharf ab. Die dunklen Minerale sind zu groben Flasern angehäuft, deren Längenachsen in der gewöhnlichen Streckungsrichtung (steil nach SSW) orientiert sind; diese Flasern schliessen dann linsenförmige Zentren aus hellen Mineralen ein, wodurch eine etwas augengneisartige Struktur zustande kommt (Fig. 1). In diesen Zentren treten hie und da bis über $1 \mathrm{~cm}$ grosse Feldspatkristalle hervor.

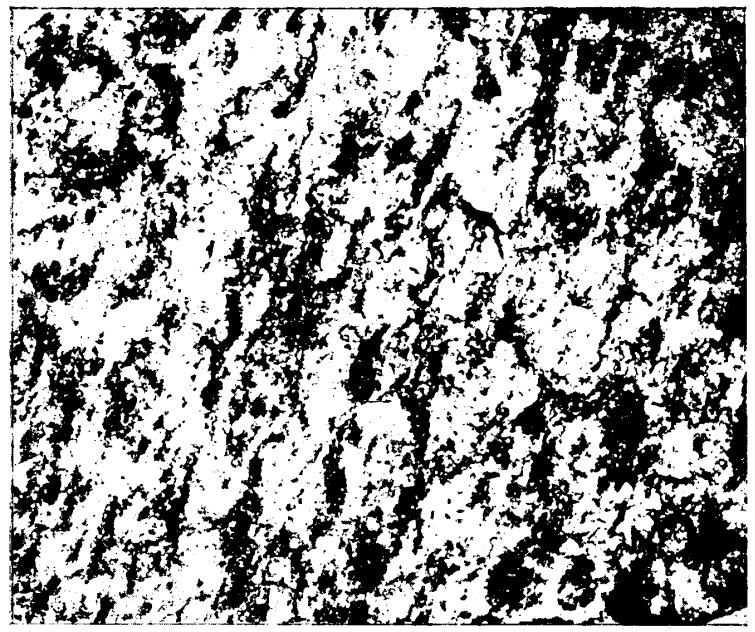

Fig. 1. Granitgneis aus dem Karl-Johan-Schacht. 3/4.

In einer typischen Probe aus dem Karl-Johan-Schacht wurde der folgende Mineralbestand gemessen: Quarz 21.4.\%; ,Mikroklinperthit $\mathrm{II}_{\mathrm{II}}$ 26.2\%; Oligoklas 43.0.\%;1 Biotit $5.6 \%$; Hornblende $3.0 \%$; Titanit $0.8 \%$. Der Quarz bildet stengelige Felder, etwa von den Dimensionen $2 \times 5 \times 15 \mathrm{~mm}$ mit grober Mosaikstruktur; Mörtelstruktur fehlt ganz, und die undulöse Auslöschung ist nicht sehr ausgesprägt. Der Mikroklinper-

${ }^{1}$ Einschliesslich der poikilitisch eingeschlossenen Quarztröpfchen. 
thit erscheint z. T. als grosse unregelmässige Kristallindividuen, z. T. als kleinkörnigere Aggregate; die Mikroklinstruktur ist vorzüglich entwickelt; die Zusammensetzung dürfte, der Beteiligung von perthitischem Albit nach zu schliessen, einem ziemlich natronreichen Glied der Abteilung II, etwa $\mathrm{Or}_{3} \mathrm{Ab}_{1}$, entsprechen. Der Oligoklas ist spärlich als grössere Körner, sehr reichlich als kleinkörnige Aggregate vorhanden. Die symmetr. Max.-Ausl. beträgt $+5^{\circ}$ bis $+6^{\circ}$ in den kleineren Körnern, steigt aber bis auf $+9^{\circ}$ oder $+10^{\circ}$ in den Kernen der grösseren Individuen; der Durchschnittsplagioklas dürfte demnach dem Verhältnis $\mathrm{An}_{25} \mathrm{Ab}_{75}$ nahe entsprechen. Die grösseren Körner sind öfters durch glimmerige Substanzen nebst Epidot und Kalzit etwas getrübt. Der Plagioklas ist sehr häúfig mit Quarztröpfchen poikilitisch gespickt (Fig. 3, Taf. 1); derartiger quarzgespickter Oligoklas bildet mit etwas Mikroklin und Quarz ein kleinkörniges Grundgewebe zwischen den gröberen Gemengteilen. Typischer Myrmekit ist auch reichlich in die Ränder der grösseren Mikroklinkörner eingewachsen. - Die femischen Flasern bestehen aus olivbraunem Biotit und grüner Hornblende, beide wie gewöhnlich in derartigen Gesteinen durchaus unregelmässig und lappig ausgebildet; dazu reichlicher Titanit, Apatit und Zirkon; spärlicher Orthit, Magnetit und Schwefelkies. Kalzit und Epidot kommen nicht nur als Absätze in getrübtem Plagioklas, sondern auch als kompaktere selbständige Körner nicht selten vor.

Der chemische Charakter des beschriebenen Gneises geht aus der folgenden von GRABE ausgeführten Analyse hervor (S. 25).

Der vorhandene Tonerdemangel stimmt mit dem tatsächlichen Gehalt an Hornblende überein. Nehmen wir an, dass das Gestein $26.2 \%$ Mikroklinperthit $\mathrm{Or}_{73} \mathrm{Ab}_{25} \mathrm{An}_{2}$ und $43.0 \%$ Oligoklas $\mathrm{Or}_{7} \mathrm{Ab}_{70} \mathrm{An}_{23}$ enthält, so ergiebt sich ein Durchschnittsverhältnis $\mathrm{Or}_{32 \cdot 0} \mathrm{Ab}_{53 \cdot 0} \mathrm{An}_{15 \cdot 0}$, während sich aus der Analyse das Verhältnis $O r_{32 \cdot 4} A b_{52 \cdot 0} A n_{15 \cdot 6}$ berechnet. Dem 


\begin{tabular}{|c|c|c|c|}
\hline $\mathrm{SiO}_{2} \ldots . .68 .96$ & 114.17 & Q.....24.38 & $s . . .1 .80-2.20$ \\
\hline $\mathrm{TiO}_{2} \ldots . .0 .72$ & 0.90 & Or ....20.34 & . \\
\hline $\mathrm{Al}_{2} \mathrm{O}_{3} \ldots . .13 .28$ & 12.99 & $\mathrm{Ab} . . . .30 .78$ & Or. . . . 32.4 \\
\hline $\mathrm{FeO} . . .$. & \multirow{2}{*}{7.67} & An . . . 9.79 & $\mathrm{Ab} . . .52 .0$ \\
\hline $\mathrm{MnO} \cdot . . .0 .12$ & & $\Sigma$ sal. 85.29 & An . . . 15.6 \\
\hline . . & 2.43 & $\mathrm{CaSiO}_{3} \quad . \quad 0.80$ & ' \\
\hline $\mathrm{CaO} . .$. & 4.57 & $\mathrm{MgSiO}_{3} . .2 .50$ & $\Sigma \mathrm{F} \cdot \ldots .22 .48$ \\
\hline $\mathrm{Na}_{2} \mathrm{O} \cdot \ldots \cdot$ & 5.85 & $\mathrm{FeSiO}_{3}$. . 8.96 & $\mathrm{Al}_{2} \mathrm{O}_{3} \ldots .-0.69$ \\
\hline $\mathrm{K}_{2} \mathrm{O} \cdots \cdots$ & 3.64 & $\mathrm{FeTiO}_{3}$ & \\
\hline $\mathrm{P}_{2} \mathrm{O}_{5} \ldots \ldots$ & $(0.38)$ & Apatit. . . 0.38 & II $: 4:$ II $: 3$ \\
\hline Gl. V. . . · & & $\Sigma$ fem. 14.01 & \\
\hline 100.19 & & 99.3 & \\
\hline
\end{tabular}

femischeren Charakter dieses Gneises entsprechend fällt er in die Klasse der »Dosalane» des amerikanischen Systems; dabei ist allerdings $\mathrm{zu}$ bemerken, dass der femische Anteil wahrscheinlich einige Prozente $\mathrm{zu}$ hoch ausgefallen ist, indem alles Eisen als $\mathrm{FeSiO}_{3}$ berechnet ist, während gewiss mehreres Eisenoxyd im Biotit und Magnetit oder als ferritisches Pigment vorhanden ist. - Unter den analysierten schwedischen Gneisen findet sich kein chemisch näher verwandtes Gestein repräsentiert. Unter den Graniten stehen die EringsbodaGranite aus der Provinz Bleking offenbar dem Grängesberger Granitgneise sehr nahe (Nr. 1 der Tabelle unten: Granit von Stångsmåla) ${ }^{1}$; sogar der Gehalt an Kalzit ist den beiden Gesteinen gemeinsam. Auch unter den Augengraniten aus der Provinz Småland kommen chemisch verwandte Typen vor (Nr. 2=3 unten: Granite von Finsjö und Högsbo) ${ }^{2}$; die Augengranite vom Filipstad-Typus stellen dagegen einen weit kalireicheren Typus dar (Nr. 4-5 unten: Granite von Gammalkroppa und Kortfors). ${ }^{3}$

1 H. Hedström: S. G. U., Ser. A, a. N:o 5 (1906): 60; P. J. HolmqUist : 1. c. $\mathrm{N}: 024$.

${ }^{2}$ H. Hedström: S. G. U., Ser. Ac, N:o 8 (1904): 18; P. J. Holmqdist : 1. c. $\mathrm{N}: 085$ und 84 .

${ }^{8}$ S. G. U., Ser. Ba, N:0 6 (1901): 23; P. J. HoLMQUIST: 1. c., N:o 97 and 95 . 


\begin{tabular}{|c|c|c|c|c|c|c|}
\hline & - & 1. & 2. & 3. & 4. & 5. \\
\hline$s \cdot . \cdot$ & $1.80-2.20$ & $1.55-1.89$ & $1.69-2.06$ & $2.00-2.40$ & $2.29-2.67$ & $1.95-2.40$ \\
\hline Or .... & 32.4 & 33.9 & 35.5 & 36.2 & 45.5 & 49.0 \\
\hline $\mathbf{A b}$. & 52.0 & 49.8 & 46.6 & 46.7 & 39.0 & 34.4 \\
\hline An . & 15.6 & 16.3 & 17.9 & 17.1 & 15.5 & 16.6 \\
\hline
\end{tabular}

Der Grängesberger Granitgneis zeigt im ganzen eine sehr gleichförmige Ausbildung; nennenswerte Änderungen in der Zusammensetzung sind hauptsächlich nur an den Enden des Gebietes zu sehen. Im südlichsten Teil des Gebietes nimmt das Gestein einen salischeren Charakter an und nähert sich im Aussehen etwas den roten Gneisen; übrigens ist es hier auch öfters gequetscht und von Trümmerzonen vielfach durchzogen, was vielleicht mit gewissen Dislokationen zusammenhängt, die zur Entstehung des Hörkenseebeckens beigetragen haben dürften. Auch in dem nördlichsten Teil des Gesteinszuges scheint der Gneis etwas salischer zu werden; gleichzeitig stellen sich Gesteinsbänke eines roten sauren Gneistypus oder auch eines grauen, den Plagioklasgneisen ähnlichen Gesteines in Abwechselung mit dem Granitgneis ein. Kleine, schlierenartige Gesteinsbänke von graulich gefärbten Plagioklasgneisen sind auch bei Grängesberg, z. B. in dem Eisenbahneinschnitt gleich östlich von dem Exportfelde, in dem normalen Granitgneis zu sehen.

Einlagerungen von Grünsteinen sind in dem Granitgneis ziemlich selten. Im nördlichsten Teil des Gebietes ist ein Zug von meistens glimmerreichen dioritischen Gesteinen in den Gneis eingeschaltet; ähnliche Gesteine sind auch südlich von Lomtjärn an einigen Lokalen beobachtet; übrigens wurden nur einige Glimmeramphibolite vereinzelt gesehen. Dafür ist das Gestein mit kleineren sbasischen Konkretionen» fast überall reichlich gespickt. Von solchen Konkretionen giebt es zwei Arten, eine hornblendenreiche mit untergeordnetem Plagio- 
klas und Biotit, die andere hauptsăchlich aus Biotit und Plagioklas zusammengesetzt. Kleine rundliche oder etwas linsenförmige Konkretionen ersterer Art sind sehr allgemein; auch grössere bis $1 \mathrm{~m}$ lange Linsen von glimmeramphibolitischem Charakter kommen bisweilen vor. Die Plagioklas-Biotit-Konkretionen sind seltener und meistens weniger scharf gegen das Muttergestein abgegrenzt. Mit den Konkretionen letzterer Art möchte ich auch ein eigentümliches Gestein zusammenstellen, das ein wenig südlich von Lomtjärn an der Chaussee nach Silfverhöjden als ein $1 / 2 m$ breites und mindestens 25 $m$ langes Lager in dem Granitgneise zu sehen ist. Das Gestein besteht aus einer verfilzten Masse von Biotit, die mit Körnern von Oligoklas, etwa $\mathbf{A n}_{27} \mathbf{A b}_{73}$, nebst etwas Apatit gesprenkelt ist. In diesem Gestein liegt offenbar ein Übergangsgeștein nach jenen eigentümlichen Biotit-Slkarn- oder Biotit-sSlöls-Gesteinen hin vor, die so allgemein mit den mittelschwedischen Eisenerzen assoziiert sind; und die öfters auch etwas Plagioklas enthalten; es dürfte übrigens mit den von Grubenmanv $^{1}$ erwähnten Biotit-Plagioklas-Schiefern aus den St.' Gotthard-Gneisen verwandt sein, die gewissermassen als kristallinschieferige Entwickelungsformen von lamprophyrischen Gesteinen aufgefasst werden.

Der Reichtum an femischen Konkretionen hat sein komplementäres Gegenbild in dem Reichtum an aplitischen Gängen. Diese Gänge verlaufen am häufigsten in der Ebene $\perp$ zur Stengeligkeitsrichtung des Granitgneises. Die Mächtigkeit beträgt meistens nur 1 bis $2 d m$; breitere Gänge zeigen vielfach pegmatitische Sahlbänder. Ein Gang in dem oben beschriebenen Granitgneis aus dem Karl-Johan-Schacht ergab im Dünnschliff einen Mineralbestand aus $31.5 \%$ Quarz; $30.2 \%$ Mikroklinperthit (etwa $\mathrm{Or}_{74} \mathrm{Ab}_{24} \mathrm{An}_{2}$ ); $36.9 \%$ Oligoklas (optisch $=A_{23} A_{b 7}$, bisweilen mit scharf begrenzten trüben Kernen von $A_{27} A_{b 3} ;$ im Durchschnitt etwa $\left.=0 \mathrm{r}_{7} \mathrm{Ab}_{71} \mathrm{An}_{22}\right) ; 1.2 \%$

1 U. Grubenmana: Die kristallinen Schiefer II: 128. 
Biotit und $0.2 \%$ Kalzit. Aus diesen Angaben berechnet sich ein Feldspatverhältnis in dem Gestein $=\mathrm{Or}_{37 \cdot 2} \mathrm{Ab}_{49 \cdot 8} \mathrm{An}_{13 \cdot 0}$. Die Feldspate des Ganggesteins sind offenbar in qualitativer Hinsicht denen des Muttergesteins sehr ähnlich geblieben; nur hat sich das quantitative Verbältnis etwas zu Gunsten des Mikroperthits verschoben. Die Differentiation ist hauptsächlich in der Weise vor sich gegangen, dass die femischen Bestandteile fast völlig ausgetreten sind und dafür der Quarz angereichert worden ist; auch der Kalzit scheint sich in den Apliten etwas angereichert zu haben. - Unter den Blöcken, die bei der Absenkung des Karl-Johan-Schachtes hinaufgefördert worden waren, fanden sich auch Blöcke von sgemischten Gängen». Ein

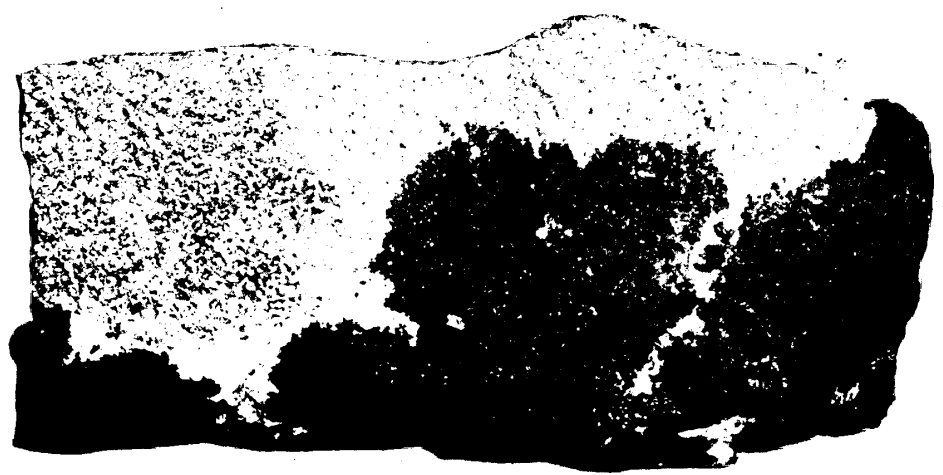

Fig. 2. Gemischter Gang aus dem Karl-Johan-Schacht. 1/2.

Handstück von dem Mischgestein ist in Fig. 2 wiedergegeben. Der belle Anteil ist ein blassrötlicher Aplit vom gewöhnlichen Typus; der dunkle Teil entspricht einem hornblendereichen Gestein, das mit rundlich gebuchtetem Kontakt scharf gegen den Aplit abgegrenzt ist; die Grenzzone besteht hauptsächlich aus weissem Oligoklas $\mathrm{An}_{23} \mathrm{Ab}_{\gamma \gamma}$ nebst etwas Titanit und Quarz. Andere Handstücke zeigen den Granitgneis senkrecht zu seiner Stengeligkeit durch das dunkle Gestein scharf abgeschnitten. Wahrscheinlich stammen die Blöcke aus einem 
flachen Gang, der auf der einen (unteren?) Seite von dem dunklen Gestein, auf der anderen von dem Aplit ausgefüllt war. Das dunkle Gestein besteht unter dem Mikroskope aus rundlichen Zentren einer verfilzten grünen Hornblende, die in ein kleinkörniges, polygonales, von gut begrenzten Biotittafeln durchspicktes Grundgewebe aus selten lamelliertem Andesin (?) nebst etwas Hornblende und Titanit eingebettet sind (Fig. 20, Taf. 4). In der von Rosenbusch gegebenen Systematik dürfte ein derartiges mikrodioritisches Gestein am besten unter die »Ganggesteine von malchitischem Habitus» einzureihen sein.

Schliesslich sind noch unter den mit dem Granitgneise assoziirten Gesteinen auch einige Eisenerze zu erwähnen. Die wichtigsten Vorkommnisse sind die Apatiteisenerze der Långblå-Gruben, die als zwei in einer Entfernung von etwa $200 \mathrm{~m}$ von einander gelegene Komplexe in den Granitgneis gerade bei der nordöstlichen Ausspitzung des Gneisgebietes eingeschaltet sind; ein kleineres Vorkommnis wurde auch von einer Strecke zwischen dem Karl-Johan-Schacht und der Grube Skärningen geschnitten.

Der Granitgneis scheint auf allen Seiten von natronreichen Gesteinen umgeben zu sein. Die östliche Seite entlang wird er von einem Zug aus Plagioklasgneisen begleitet; auf der westlichen Seite grenzt er grösstenteils gegen die chemisch ganz analogen biotitreichen Plagioklasgranulite des ,Exportfeld-Typus» an; auch gegen $\mathrm{N}$ und NW scheint er nach den spärlichen Ausbissen zu schliessen an natronreiche Gneise zu grenzen, die z. T. zu den Plagioklasgneisen gehören, z. T. Zwischengesteinen zwischen solchen Gneisen und Gesteinen des roten Gneis-Typus entsprechen dürften. Die genannten Gneise zeigen meistens in der Nähe der Kontakte eine ziemlich grobe granitische Struktur; bei den Kontakten scheinen in der Tat keine anderen Strukturveränderungen sich abzuspielen als solche, die mit den Änderungen der chemisch-mineralogischen Zusammensetzung notwendigerweise verknüpft sein müssen. In Bezug auf die Änderungen in che- 
misch-mineralogischer Hinsicht ist hervorzuheben, dass homogene Übergangsgesteine zwischen Gesteinen des Granitgneis. Typus und solchen vom Typus der Plagioklasgneise niemals in unserem Gebiete beobachtet worden sind und, wie später etwas näher erörtert werden soll, überhaupt in der Natur unter granitischen Gesteinen ganz zu fehlen scheinen. Demnach sind auch niemals kontinuierliche Übergänge zwischen diesen Gneisen $\mathfrak{z u}$ sehen, sondern die Gesteine grenzen entweder scharf an einander an, wie es meistens bei dem östlichen Kontakt des Granitgneises der Fall ist; oder es stellt sich eine mehr oder weniger ausgedehnte inhomogene Zwischenzone ein, wo die Gesteine in wiederholter Abwechselung erscheinen oder auch schlierig mit einander vielfach verwoben auftreten; als Beispiel dafür könnte das Verhalten des Granitgneises- bei seiner Ausspitzung gegen NO in der Nähe von Långblå angeführt werden.

An der Grenze gegen den Exportfeld-Granulit hin ist die Änderung in chemisch-mineralogischer Hinsicht auch von . einer deutlichen Änderung in der Struktur, vor allem in der Korngrösse, begleitet. Der Struktur-Kontakt scheint hier im ganzen ein ziemlich scharfer zu sein, obwohl der Granitgneis in der unmittelbaren Nähe des Kontaktes meistens eine etwas dünner flaserige Struktur annimmt; bei einem Kontakt etwas südlich von Lomtjärn auf der westlichen Seite der FröviLudvika-Eisenbahn scheint der Granitgneis indessen durch eine gneisgranulitische $Z_{\text {wischenzone ohne schärfere Struktur- }}$ grenze an dem Granulit verlötet zu sein. In chemisch-mineralogischer Hinsicht liefern die Kontakte einige gute Beispiele von dem oben erörterten Kontakt-Typus mit inhomogener

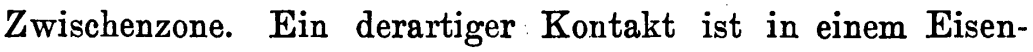
bahneinschnitt zwischen N. Hörken und Lomberget aufgeschlossen. Der südliche Teil des Profils geht durch einen ziemlich typischen, ebenschieferigen Exportfeld-Granulit; darauf folgt mit anscheinend scharfer Strukturgrenze der Granitgneis, der jedoch anfänglich eine sehr inhomogene Ausbil- 
dung mit vielfach eingeschalteten Gésteinsbänken aus roten, saureren Gneisvarietäten ebenso wie aus grauen, plagioklasgneisähnlichen zeigt. - Bei Laritstorp, etwas nördlich von Grängesberg, ist ein eigentümliches, sehr inhomogenes Kontaktgestein zu sehen. Typischer Exportfeld.Granulit ist hier nicht entblösst; die ersten Gesteinsbänke von W aus gerechnet bestehen aus einem graulichen, inhomogenen, granulitischen Gestein mit dunkleren hornblendereichen Schlieren und einigen schärfer abgegrenzten Amphibolitbänken; dann folgt eine breccienartige Zone, die aus verschiedengestaltigen, dunklen, hornblendereichen Gesteinsbrocken, in einer hellrötlichen, z. T. etwas gröberen und gneisähnlichen $Z_{w}$ wischenmasse eingebettet, besteht; schiesslich folgt mit anscheinend ziemlich scharfer Grenze ein deutliches, obwohl etwas helleres und weniger grobflaseriges Granitgneis-Gestein, das rasch von typischem Granitgneis abgelöst wird. Die ganze Gesteinsreihe ist von einem Netz aus aplitenartigen oder pegmatitischen Gängen durchzogen. - An den Kontakten, die bei Grängesberg in den Ausfuhrstrecken nach den Müller- und KarlJohan-Schächten aufgeschlossen sind, gleichwie auch an einem Kontakte südlich von Ormbergstjärn scheint der Granitgneis von dem Granulit scharf abgegrenzt zu sein; der Granulit selbst zeigt jedoch an diesen Lokalen eine sehr inhomogene Ausbildung.

Ausserhalb des oben beschriebenen Gebiets kommt ein mit dem Grängesberger Granitgneis fast vollständig übereinstimmendes Gestein als lokale Moräne innerhalb einer Area südlich vom Blötberget vor. Mit der Bezeichnung des Granitgneises ist auch der granitische hornblendeführende Gneis bei Klenshyttan kartiert, der auf der TöRnевонм'schen Karte als eine direkte Fortsetzung des Grängesberger Granitgneises gezeichnet ist, was allerdings nicht zutrifft. Das Gestein zeigt eine diesem Granitgneise etwas ähnliche grobe Struktur, weicht aber durch weit geringeren Gehalt an Biotit und demnach weniger deutliche Flaserigkeit ab. Eingehendere pe- 
trographische Untersuchungen von diesem Gneis sind nicht unternommen; nach einem Dünnschliff einer Gesteinsprobe nördlich von der Eisenbahnstation Klenshyttan zu schliessen, dürfte er von dem Granitgneis-Typus chemisch verschieden sein und wäre vielmehr unter die vorher (S. 18) erwähnten Zwischengesteine zwischen den Plagiosklasgneisen und den roten Gneisen einzureihen. Das Gestein ist auf der westlichen Seite anscheinend ohne: scharfe Grenze von einem wenig breiten Zug aus massigem rotem Gneis begleitet; eine Gesteinsprobe von Grindfallet ist durch das Vorhandensein von grob-granophyrischen Mikroklinperthit-Quarz-Verwachsungen, ebenso von grossen Orthitkörnern bemerkenswert, im übrigen stimmt mineralogisch mit den roten Gneisen unseres Gebietes überein.

\section{Plagioklasgneise.}

Der Grängesberger Granitgneis wird auf der östlichen Seite regelmässig von einem 300 bis $350 m$ breiten Plagioklasgneis-Zug begleitet. Das Aussehen dieser Gneise ist etwas wechselnd. Näher an dem Kontakt gegen den Granitgneis kommen etwas gröbere, granitische, an dunklen Gemengteilen reichere Varietäten vor, die eine flaserig ausgezogene zentrische Struktur erkennen lassen, obwohl sie niemals die Grobflaserigkeit des benachbarten Granitgneises erreichen. Weiter von dem Kontakt werden die Gesteine heller und salischer; die zentrische Anordnung wird undeutlicher und macht einer mehr gleichmässig körnigen, scharfkristallinischen Struktur Platz, die für die meisten Plagioklasgneise unseres Gebietes bezeichnend ist. Es kommen auch, z. B. auf der Südseite der nördlichen Bucht von S Hörken, sehr salische, blassrötliche und feinkörnige Varietäten vor, die zu den später zu beschreibenden Plagioklasgranuliten hinüberführen.

Zu näherer Untersuchung wurde ein scharfkristallinisches hellgraues Gestein ausgewählt, das in einem Eisenbahneinschnitt bei Skakelbacken etwas östlich von Blåns vorzüglich 
aufgeschlossen ist. Im Dünnschliff zeigte das Gestein einen einfachen Mineralbestand aus $26.8 \%$ Quarz; $67.3 \%$ Albitoligollas; $5.0 \%$ Amphibol und $0.9 \%$ Titanit; dazu ein wenig Biotit und Apatit nebst Spuren von Orthit und Magnetit. Kalifeldspat fehlt ganz. Der Quarz ist in stengelig ausgezogene Felder gesammelt, wie gewöhnlich in den Gneisen unseres Gebietes. Die einzelnen Individuen sind innen sehr reich an Flüssigkeitsinterpositionen, während ein etwa $0.1 \mathrm{~mm}$ breiter Saum neben den Kornfugen ganz frei davon ist, eine Erscheinung, die in den meisten untersuchten Plagioklasgneisen sehr ausgeprägt ist. Der sehr frische Plagioklas bildet Aggregate von polygonalen, ziemlich isometrischen Körnern mit ausgezeichneter Zwillingslamellierung und Spaltbarkeit (Fig. 5, Taf. 1). Die optischen Eigenschaften entsprechen einem Mischungsglied nahe $\mathrm{An}_{7} \mathrm{Ab}_{93}$ mit symmetr. max. Ausl. von $-15^{\circ}$. Poikilitische Einschlüsse von rundlichen Quarztröpfchen sind eine sehr allgemeine Erscheinung. Das Amphibolmineral zeigt makroskopisch graulich grüne Farbe; im Dünnschliff wird es fast farblos mit $\mathrm{c}: \mathrm{c}=18^{\circ}-19^{\circ}$ und negativer Doppelbrechung $\gamma-\alpha$ etwa 0.022. Der Titanit zeigt sehr deutlichen Pleochroismus mit c ziemlich kräftig gelbrot. Eine chemische Analyse von GraBE hat die folgenden Zahlen ergeben:

\begin{tabular}{|c|c|c|c|}
\hline $\mathrm{SiO}_{2} \cdot . . .74 .00$ & 122.52 & Q..... 29.48 & $s . . .2 .15-2.46$ \\
\hline $\mathrm{TiO}_{2}$... 0.28 & 0.35 & Or .... 3.68 & \\
\hline $\mathrm{Al}_{2} \mathrm{O}_{3} \cdot \ldots \cdot 13.48$ & 13.20 & $\mathrm{Ab} \cdot \ldots .51 .56$ & Or $\ldots . .5 .8$ \\
\hline $\mathrm{FeO} \ldots . \cdot 1,80$ & 264 & An : . . . 5.21 & $\mathrm{Ab} \cdot . .86 .0$ \\
\hline $\mathrm{MnO} . . . . \quad 0.10$ & & $\mathrm{Al}_{2} \mathrm{O}_{3} \cdot \cdot \quad . \quad 0.89$ & An ... 8.2 \\
\hline $\mathrm{MgO} \cdot . . . \quad 1.99$ & 4.98 & $\Sigma$ sal 90.82 & \\
\hline $\mathrm{CaO} \cdot . \cdot$ & 2.04 & $\mathrm{MgSiO}_{3}: . \quad . \quad 4.99$ & $\Sigma \mathrm{F} . . .22 .77$ \\
\hline $\mathrm{Na}_{2} \mathrm{O} . \cdot \cdot 6.08$ & 9.79 & $\mathrm{FeSiO}_{3} \cdot . \quad 3.03$ & $\mathrm{Al}_{2} \mathrm{O}_{3} \therefore+0.87$ \\
\hline $\mathrm{K}_{2} \mathrm{O} \ldots \ldots . \quad .62$ & 0.66 & $\mathrm{FeTiO}_{3} \cdot \cdot \cdot 0.53$ & 4 \\
\hline $\mathrm{P}_{2} \mathrm{O}_{6} \ldots \cdot \cdot 0.07$ & $(0.16)$ & Apatit . . $\quad 0.17$ & \\
\hline Gl. V. $\cdot \cdot .0 .80$ & & $\Sigma \overline{\text { fem. } 8.72}$ & Maripos \\
\hline 100.36 & & 99.54 & \\
\hline
\end{tabular}


Die sich aus der Analyse ergebende Feldspatmischung stimmt mit dem optisch ermittelten Plagioklas gut überein, besonders wenn man auch die als Titanit gebundene $\mathrm{CaO}$ Menge berücksichtigt. Der nur $5.8 \mathrm{Mol}$ \% betragende Gehalt an Or-Silikat steckt offenbar ganz in dem Plagioklase. Aus der Analyse ist auch zu schliessen, dass das Amphibolmineral des Gesteines nicht zu der Strahlsteinreihe gehört, sondern einem CaO-freien, ziemlich $\mathrm{Al}_{2} \mathrm{O}_{3}$-reichen, monoklinen ( $\mathrm{MgFe}$ )-Amphibol entsprechen muss. Derartige Amphibolanthophyllite, die vielleicht einfacher als Klinoanthophyllite bezeichnet werden könnten, sind, ebenso wie gewisse chemisch analoge rhombische Amphibole der Anthophyllit-Gedrit-Reihe, recht häufig in den Plagioklasgneisen und Plagioklasgranuliten unseres Gebietes beobachtet worden. Es ist auch leicht zu verstehen, dass die chemischen Charaktere dieser Gesteine zur Bildung derartiger seltenen Amphibole prädisponieren müssen, indem einerseits die Kaliarmut der Bildung von Biotit entgegensteht, andererseits die Azidität und die AnArmut den rhombischen Pyroxenen wenig günstige Bildungsbedingungen darbieten.

Obwohl makroskopisch etwas verschieden, stimmt mit dem oben beschriebenen Gestein mikroskopisch nahe überein eine Probe von granitischem Plagioklasgneis aus dem westlichen, dem Granitgneiskontakt benachbarten Teil desselben Eisenbahneinschnittes. Anstatt des blassen Klinoanthophyllits ist eine grüne Hornblende neben reichlichem Biotit und grossen Orthiten vorhanden; winzige Partien von Mikroklin sind zwischen den Plagioklaskörnern eingeklemmt oder als antiperthitische Flecke in den grösseren Plagioklașindividuen aúsgeschieden.

Der vorher erwähnte grünlichgraue Plagioklasgneis, der schlierenartig in dem Granitgneis etwas östlich von dem Exportfelde auftritt, ist dem Gneis bei Skakelbacken sehr ahnlich; das femische Hauptmineral ist jedoch hier ein deutlich pleochroitischer hellgrüner Pyroxen, wahrscheinlich ein mala- 
kolithischer Augit, wozu sich noch etwas Hornblende, reichlicher Titanit von der oben erwähnten pleochroitischen Art, häufiger Apatit und Orthit und sogar auch Kalzit in nicht ganz unerheblicher Menge gesellen. Eine feinkörnige, etwas gebänderte Schliere aus demselben Lokale enthält statt des Pyroxens Magneteisenerz dermassen angereichert, dass die ganze Plagioklasgneisschliere als ein kleines Erzembryo bezeichnet werden könnte.

In dem Gneisterrain zwischen Grängesberg und dem See Glaningen scheinen Plagioklasgneise eine grosse Verbreitung zu haben und stellen wahrscheinlich das Hauptgestein des dortigen Gneiskomplexes dar, obwohl eine genauere Unterscheidung von den assoziierten, dem roten Gneistypus näher stehenden Gesteinen auf der Karte nicht durchgeführt werden konnte. Es sind hellgraue bis schwach rötliche, scharfkristallinische Gneise, die als femischen Hauptgemengteil meistens einen grünlichen Biotit enthalten; neben dem charakteristischen sauren Albitoligoklas (mit 7 bis $12 \mathrm{Mol} \%$ An) scheint immer ein wenig Mikroklin vorzukommen. Neben den gröberen, g̀leichmässig körnigen Varietäten sind mehrere Züge aus feinkörnigeren granulitgneisigen Gesteinen beobachtet; diese Gesteine enthalten öfters grössere Körner oder gröbere »Anhäufungen» von Plagioklas und Quarz einsprenglingsartig in einer grobgranulitischen Grundmasse eingebettet. Auch wurden in derartigen feinkörnigen Plagioklasgneis-Zügen kleine schlierige Erz-Apatit-Anhäufungen mehrmals beobachtet, z. B. in dem Eisenbahneinschnitt östlich von Långsyna. - In diesem Zusammenhang könnte auch eine etwas weiter östlich von dem genannten Lokal anstehende, dunkelgraue, biotitreiche Granulitgneisvarietät erwähnt werden, die durch ihre ausgezeichnete porphyrische Struktur bemerkenswert ist. Das Gestein enthält reichliche Plagioklaseinsprenglinge von einer Grösse bis zu $6 \mathrm{~mm}$, die unter dem Mikroskop einen vorzüglich zonaren Bau erkennen lassen, mit Kernen von Andesin, bis zu $\mathrm{An}_{37} \mathrm{Ab}_{63}$, die, von einem Saum aus Oligoklas, etwa $A n_{24} A b_{i 6}$, 4-100170. 
umgeben sind (Fig. 7, Taf. 2). Die Korngrösse des Grundgewebes, an dem Quarz gemessen, beträgt etwa $0.15 \mathrm{~mm}$; neben dem vorwaltenden Oligoklas kommt auch ein Mikroklinperthit $_{\text {II }}$ vor. Eine schlierige Anreicherung von Magnetit und Apatit hat auch in diesem Granulitgneis stattgefunden. In chemischer Hinsicht weicht das Gestein durch den weit basischeren Plagioklas und grösseren Gehalt an Kalifeldspat offenbar von den vorher beschriebenen Plagioklasgneisen ab. Nehmen wir nach einer ziemlich groben Schätzung einen Feldspatbestand von 1 Teil Kalifeldspat $\mathrm{Or}_{73} \mathrm{Ab}_{25} \mathrm{An}_{2}$ auf 4 Teile Plagioklas von der Durchschnittsmischung $\mathrm{Or}_{6} \mathrm{Ab}_{67} \mathrm{An}_{27}$ an, so berechnet sich ein Verhältnis $O r_{20} A b_{58} A n_{22}$; es ist dies ein Verhältnis, das der Zusammensetzung der meisten in der Litteratur bisher beschriebenen s. g. Natrongranite und Natrongneise nahe kommt.

Bei den Plagioklasgneisen dürfte schliesslich auch der erzführende Gesteinszug im Blötberget und Fredmundberget am besten erwähnt werden, obwohl die dortigen Gesteine eine sehr schwankende Zusammensetzung und Struktur zu besitzen scheinen. Nach den spärlich vorhandenen Ausbissen zu schliessen, dürften graue, feinkörnige Plagioklasgneise das Hauptgestein bilden, die jedoch mit rötlichen, kalireichen Gesteinsbänken und Massen von Kali-Pegmatiten unablässig assoziiert sind. Amphibolite oder auch massigere dioritische Grünsteine sind sehr häufig. Fast alle Gesteine erweisen sich als mit Eisenerzen imprägniert; den rötlichen, kalireicheren und salischeren Gesteinen sind phosphorärmere grobkörnige Magneteisenerze oder schuppige Eisenglanzerze in grosser Zahl eingelagert, während die grauen Plagioklasgneise eine Reihe von Apatiteisenerzen enthalten. - Unter den hier beobachteten Plagioklasgneisvarietäten verdienen die Gesteine aus dem Liegenden der wichtigsten Apatiteisenerzgrube, der s. g. Kalbengrube, im Blötberg-Felde eine etwas nähere Beschreibung. Es sind Gneisgranulite von hellgrauer Farbe mit jenem Stich ins Bräunlichgrüne, der die Abwesenheit von ( $\mathrm{Mg}, \mathrm{Fe})$-Amphibolen 
(oder auch von Pyroxenen) anzudeuten pflegt, und gleichzeitig mit jenem fettigen Glanz, der für cordieritführende Gneisvarietäten öfters charakteristisch.ist. Unter dem Mikroskop treten striemenartig ausgezogene, etwas gröbere Quarzfelder neben linsenförmigen grobkörnigeren „Anhäufungen» von Albitoligoklas $\mathrm{An}_{9} \mathrm{Ab}_{91}$ aus einem granulitischen, magnetitimprägnierten Quarz-Plagioklas-Grundgewebe hervor, dessen Struktur jedoch im Vergleich mit derjenigen der typischen Plagioklasgranulite unseres Gebietes etwas gröber und ungleichmässiger ist. In dem Grundgewebe liegen zahlreiche Nadeln von einem rhombischen Amphibol nach der Stengeligkeit angeordnet. Das Mineral ist optisch positiv mit $\gamma-\alpha$ etwa $=0.020 ;$ Pleochroismus wenig merkbar mit $c$ schwach violettgrau, $a$ und $b$ bräunlich gelb; wahrscheinlich liegt ein recht eisenreicher Gedrit vor. Auch Körner von Cordierit kommen, obwohl nicht sehr reichlich, vor. - Dieses Gestein erscheint von Interesse, weil in ihm der extrem natronreiche chemische Charakter der Plagioklasgneise sich mit einem tonerdereichen und $\mathrm{Ca} \mathrm{Si}_{3}$-armen „Para-Charakter» kombiniert hat, was zur Entstehung der charakteristischen Mineralassoziation Cordierit + Gedrit (bezw. Klinoanthophyllit) Veranlassung giebt. ${ }^{1}$ Derselbe chemische Gesteinscharakter ist nun in manchen anderen Teilen der mittelschwedischen Eisenerzformation von mir beobachtet worden, z. B. auf Getön bei Persberg, in gewissen Gesteinszügen bei Striberg und Bispberg und in vielen Sulphiderzbezirken; in seinen extremsten Formen wird er in der Gegend von Westanfors angetroffen. Diese tonerdereichen Plagioklasgesteine vermitteln auch die Ver. knüpfung derjenigen in der nächsten Abteilung zu beschreibenden tonerdereichen »Para-Gneises mit der übrigen Gesteins-

1 Das Mineral Gedrit warde aus Schweden zum ersten Mal in einem Gestein von W. Silfberget, etwas nördlich von dem Grängesberg-Gebiet, von WEIBULL (G. F. F. 18 [1896] : 377-385) beschrieben; eine ebenda publizierte Analyse von Petrén zeigt die folgende $\mathrm{Zusammensetzung:} \mathrm{SiO}_{2} 47.40 ; \mathrm{Al}_{2} \mathrm{O}_{3} 13.68$ $\mathrm{FeO} 23.38 ; \mathrm{MnO} 2.36 ; \mathrm{MgO} 7.32 ; \mathrm{Na}_{2} \mathrm{O} 3.21 ; \mathrm{K}_{2} \mathrm{O}$ sp; $\mathrm{H}_{2} \mathrm{O}$ 1.97. 
reihe unseres Gebietes, deren Auftreten hier sonst vielleicht etwas Befremdendes an sich haben könnte.

Wie ich schon früher betont habe, ${ }^{1}$ dürfte das Auftreten von extrem natronreichen sauren Plagioklasgesteinen in derartiger Menge und Gesteinsassoziation, wie es in unserem Gebiete gleichwie auch in vielen anderen Teilen der mittelschwedischen Eisenerzformation der Fall ist, bisher vorliegenden Daten nach zu schliessen, ziemlich allein stehen. Die von Grubenmann ${ }^{2}$ unter dem Namen "Plagioklasgneise» angeführten alpinen Gneise scheinen meistens eine kalkreichere, z. T. quarzdioritische Zusammensetzung zu haben. Unter den granitischen Tiefengesteinen fehlt noch die Gruppe der extrem natronreichen Plagioklasgranite; die entsprechenden Gesteine scheinen bisher nur in der Form von kleineren aplitischen, meistens aus Grünsteinsmagmen stammenden Spaltungsprodukten ohne geologische Selbständigkeit bekannt zu sein.

\section{Zweiglimmergneis mit Cordierit.}

Etwas westlich von dem Björnberger Grubenfeld tritt mitten in den dortigen feinkörnigen Plagioklasgranuliten ein höchstens $100-150^{\circ} \mathrm{m}$ breiter $\mathrm{Zug}$ aus einem ziemlich groben Zweiglimmergneis von graulicher Farbe und fettigem Glanz auf. Eine Probe des etwas nördlich von der Chaussee nach Björnberget anstehenden Gesteins zeigt im Dünnschliff einen Mineralbestand aus $48 \%$ Quarz; $18 \%$ Mikroklinperthit $t_{\mathrm{III}}$ mit reichlichen, einem Gehalt von etwa $35-40 \% A b$ entsprechenden Perthitspindeln; $5 \%$ Albitoligoklas etwa $A n_{12} A b_{88} ; 11 \%$ Cordierit und Cordieritpseudomorphosen; $13 \%$ Biotit und $5 \%$ Muskovit; dazu einzelne Prismen von Rutil und Turmalin nebst reichlichem Zirkon. Der Biotit zeigt jene kastanienbraune Farbe, die für tonerdereiche Glimmergneise meistens bezeichnend ist; z. T. ist er unter reichlicher Sagenitausscheidung in eine sehr blassgrünliche Modifikation umgewan-

1 G. F. F. 29 (1907) : $15 \check{0}-158$.

2 Die kristallinen Schiefer II : 30 . 
delt. Der Muskovit ist meistens mit Quarz skelettartig verwachsen. Die Struktur stimmt mit derjenigen mancher s. g. "Sörmlandsgneise überein. - Eine andere Varietät, die nur in losen Blöcken zu sehen war, ist reicher an Plagioklas und Muskovit und enthält den Cordierit grösstenteils in linsenförmigen, fettglänzenden, von Quarzkörnern durchspickten Knollen ausgeschieden. Auch in dieser Varietät sind kleine Turmaline vorhanden.

Der Zweiglimmergneis scheint an beiden Seiten von weisslichen Plagioklasgranuliten umgeben zu sein, die durch eingestreute Nadeln von Klinoanthophyllit gekennzeichnet sind; auf der östlichen Seite sind sogar skarnartige Klinoanthophyllitgesteine und Klinoanthophyllit-führende Magneteisenerze in einigen Schürfen aufgeschlossen. In einem Bacheinschnitt auf der westlichen Seite des Gneises ist ein eigentümliches, etwas konglomeratähnliches Übergangsgestein entblösst, das $d m$-grosse Ovoide von weissem Plagioklasgranulit in einer gneisigen, cordierit- und biotitreichen $Z_{w}$ ischenmasse enthält; durch Zurücktreten der Zwischenmasse geht das Gestein in den normalen Plagioklasgranulit über. Eine derartige Tendenz, gewisse Mineralgemengteile in linsenförmigen oder sogar kugeligen Knollen auszuscheiden, scheint sehr ausgeprägt in den tonerdereicheren Gesteinen der mittelschwedischen Eisenerzformation zu sein. Ähnliche Gesteine kommen nach Törneвонм auch bei Hellsjön etwas östlich von unserem Kartengebiet gleichwie auch östlich von Ställdalen etwas ausserhalb der südlichen Kartengrenze vor.

\section{Die Granulite.}

\section{Porphyrische Granulite im W von Grängesberg.}

Unter den Granuliten im Liegenden der erzführenden Hauptzone bei Grängesberg haben Gesteine mit ausgezeichneter porphyrischer Struktur eine grosse Verbreitung. Wie später gezeigt werden soll, ist porphyrische Strulstur zwar eine recht allgemeine Erscheinung in den granulitischen Ge- 
steinen unseres Gebietes, sie ist aber selten so vorzüglich entwickelt und schon makroskopisch so deutlich hervortretend wie in den hier $\mathrm{zu}$ besprechenden Granulitarten. Auch in chemischer Hinsicht scheinen diese Granulite einen gut zu charakterisierenden Typus zu konstituieren.

Das makroskopische Aussehen eines typischen, bei Täppan anstehenden Porphyrgranulites ist in Fig. 3 wiedergegeben (die Photographie ist leider nicht sehr gut gelungen). Reichliche bis $6 \mathrm{~mm}$ lange Durschschnitte von mattgefärbten Feldspat-Einsprenglingen treten aus einem feinkörnigen röt-

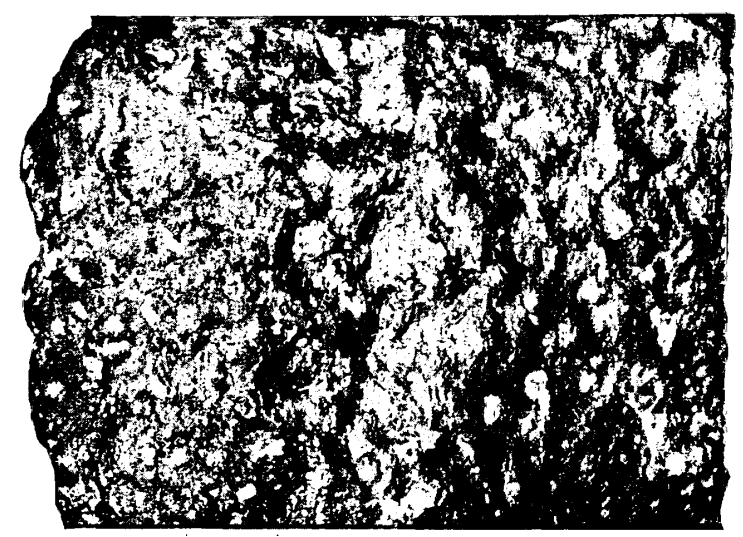

Fig. 3. Porphyrischer Granulit bei Täppan, Grängesberg. ${ }^{3 / 4}$.

lichgrauen Grundgewebe hervor. Eine deutliche Parallelstruktur wird durch streifenähnlich ausgezogene dunkle Flasern hervorgerufen. Unter dem Mikroskop können vier verschiedene Strukturelemente unterschieden werden (Fig. 8, Taf. 2): 1) Plagioklas-Einsprenglinge; 2) Salische »Anhäufungen»; 3) $\mathrm{Fe}$ mische Flasern; 4) Ein granulitisches Grundgevebe.

Die Plagioklas-Einsprenglinge machen volumenometrisch etwa $12 \%$ von dem Gestein aus. Sie sind meistens stark zersetzt und mit glimmerigen Substanzen nebst Epidot und Kalzit erfüllt; die opaken Körner haben jedoch immer einen schmalen Saum aus frischerem, kalkärmeren Feldspat. Ein symmetrischer Schnitt mit ziemlich gut erhaltener Lamellie- 
rung zeigte eine Auslöschungsschiefe von $18^{\circ}-19^{\circ}$, einem $A n$ desin $A n_{36} A b_{64}$ etwa entsprechend; dies könnte wenigstens als ein Minimum für die Basizität angeführt werden. Die hellere Randzone entspricht optisch einem Oligoklas $A n_{24} A b_{76}$. Dieser Saum ist immer durchaus unregelmässig begrenzt, schliesst Quarzkörner des Grundgewebes ein und hăngt mit dem Grundgewebe-Feldspat eng zusammen. In der Richtung der Stengeligkeit werden die Einsprenglinge häufig von grobkörnigen Feldspatanhäufungen fortgesetzt.

In seiner Arbeit »Vestanåfältet» ${ }^{1}$ hat Bäcksrröm aus den granulitischen Gesteinen dieser Gegend linsenförmige grobkörnigere Mineralaggregate beschrieben, die er als sAnhäufungens bezeichnete und als umgewandelte, aus Lavagesteinen stammende Einsprenglings-Kristalle deutete. Derartige Gebilde sind für die meisten Granulite unseres Gebietes sehr charakteristisch. In dem vorliegenden Porphyrgranulit kommen Anhäufungen von Plagioklas sowie auch solche von Mikroklinperthit und Quarz, obwohl nicht in grösserer Menge vor. Sie haben rundliche oder linsenartige Form mit einer Breite von etwa 0.5 - 1 mm; zwischen den kleineren Anhäufungen und den gröberen Körneraggregaten des' Grundgewebes besteht übrigens kein scharfer Unterschied. Der Plagioklas der Anbäufungen ist weniger getrübt als derjenige der Einsprenglinge und stimmt in der Zusammensetzung mit dem sauren Saum der letzteren näher überein; die Korngrösse beträgt meistens 0.1 bis $0.3 \mathrm{~mm}$. Der Mikroklin der Anhäufungen zeigt nur spärliche perthitische Spindeln und dürfte einem Ab-ärmeren Glied der Abteilung II entsprechen. Die spärlichen Quarzanhäufungen bestehen aus unregelmässigen undulösen Individuen und haben eine rundliche Form, dem Quarz gewisser porphyrartigen »Hälleflinten» ähnlich.

Unter den femischen Gemengteilen ist eine bläulich grüne Hornblende das Hauptmineral; Biotit ist sehr untergeordnet, Titanit reichlich, Epidot und Orthit häufig, Magnetit spärlicher, Apatit und Schwefelkies unregelmässig vorhanden. Diese

1 Sv. Vet. Ak. Handl. 29 (1897): 59-63. 
Minerale baben die Tendenz, sich zu gröberen Flasern anzuhäufen, die jedoch mit den salischen Gemengteilen immer schwammig verwachsen sind; von diesen Flasern aus mischen sie sich als kleinere Körner dem Grundgewebe bei.

Das Grundgewebe beträgt etwa $70 \%$ der Gesteinsmasse und besteht aus 40 bis $45 \%$ Quarz; 35 bis $40 \%$ Mikroklinperthit $_{\text {II }}$ und nur etwa $20 \%$ Oligoklas. Die durchschnittliche Korngrösse des Quarzes beträgt etwa 0,07 $\mathrm{mm}$, was überhaupt als Durchschnittswert für die meisten Granulite der Grängesberger Gegend gelten könnte. Bei entsprechender Korngrösse bleibt auch die Grundgewebestruktur aller dieser Gesteine im Ganzen sehr gleichartig, wie aus den Photographien auf Taf. 2-3 hervorgeht. Diese Struktur stellt eine Art der gewöhnlich als Hornfelsstruktur oder auch als Bienenwabenstruktur bezeichneten Strukturen dar, die ja im allgemeinen für feinkörnige kristalline Schiefer von Quarz-Feldspat-Zusammensetzung charakteristisch sind. Dass sie auch mit den Strukturen gewisser massigen Quarz-Feldspat-Gesteine von entsprechender Korngrösse, z. B. mit denjenigen der Mikrogranite und feinkörnigen Aplite, Ähnlichkeiten aufweist, ist nicht zu leugnen.

Eine chemische Analyse von dem soeben beschriebenen Gestein wurde von Grabe ausgeführt.

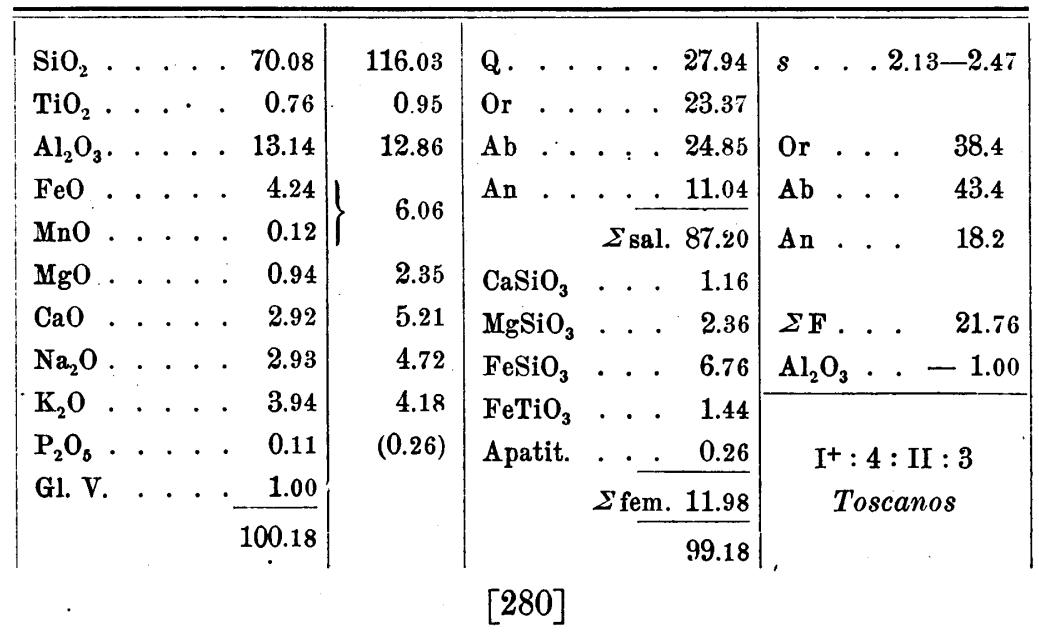


Das als $\mathrm{CaSiO}_{3} \mathrm{zu}$ berechnende relativ bedeutende $\mathrm{Al}_{2} \mathrm{O}_{3}$ Defizit stimmt mit dem tatsächlich vorbandenen Hornblendereichtum überein. Der totale Plagioklasgehalt beträgt etwa $28 \%$ (12\% Einsprenglinge + etwa $2 \%$ Anhäufungen $+14 \%$ in dem Grundgewebe); der Mikroperthit scheint etwa in gleicher Menge vorhanden zu sein (etwa $2 \%$ Anhäufungen +24 bis $28 \%$ in dem Grundgewebe). Schätzen wir nach den mikroskopischen Beobachtungen die Zusammensetzung des Durchschnitts-Plagioklases zu $\mathrm{Or}_{6} \mathrm{Ab}_{65} \mathrm{An}_{29}$ und die des Mikroperthites zu $\mathrm{Or}_{78} \mathrm{Ab}_{20} \mathrm{An}_{2}$, so berechnet sich ein Verhältnis $O r_{42 \cdot 0} A b_{42 \cdot 5} A n_{15 \cdot 5}$, während sich aus der Analyse das Verhältnis $O r_{38 \cdot 4} A b_{43 \cdot 4} A n_{18 \cdot 2}$ ergiebt. Der Chemismus dürfte mit demjenigen' mancher kalkreicheren, hornblendeführenden Augengranite übereinstimmen und schliesst sich auch demjenigen des vorher beschriebenen Granitgneises recht eng an. Überhaupt sind die Porphyrgranulite basischer und zwar Anreicher als die meisten anderen Granulittypen unseres Gebietes.

In den Porphyrgranulitzügen sind die vorzüglich porphyrstruierten Gesteine von dem oben beschriebenen Typus jedoch im Ganzen anderen Varietäten quantitativ untergeordnet, bei welchen die porphyrische Struktur weniger deutlich hervortritt. Es sind meistens dunklere hornblendereiche Gesteine von flammigem, seltener etwas gebändertem Aussehen infolge der inhomogenen Verteilung der dunklen Gemengteile. Deutlich begrenzte Einsprenglinge fehlen mehr oder weniger vollständig; anstatt derselben kommen unscharf begrenzte helle Flecke vor, die meistens in der Richtung der Stengeligkeit ausgezogen sind und in den am. kräftigsten ausgewalzten Varietäten schliesslich nur als etwas gröberkörnige hellere Streifen aus der dunklen Gesteinsmasse hervortreten. Als Beispiel dieser Varietäten könnte ein Gestein aus dem Wasserleitungsgraben nördlich von Sköttorp erwähnt werden. Das Gestein zeigt im Dünnschliff noch einige grössere Plagioklaskörner, die als Einsprenglinge bezeichnet werden können, dei aber eine 
beginnende Granulierung und Umwandlung in Anhäufungen erkennen lassen. Ein grosser Teil der Gesteinsmasse wird von Oligoklas- und Mikrolinperthit ${ }_{I I}$-Anhäufungen gebildet. Typische Quarzanhäufungen fehlen: das Gestein enthält dafür einzelne grössere aderartige Quarzstreifen, die von der übrigen Gesteinsmasse nicht $\mathrm{zu}$ trennen sind. Hornblende und Titanit sind reichlich; Biotit fehlt. Das Grundgewebe ist an Menge sehr zurückgetreten; in dieser Hinsicht ähnelt diese Varietät den in nächster Abteilung zu beschreibenden GranatEpidot-Granuliten, nach welchen Übergangsgesteine auch vorhanden $z \mathfrak{u}$ sein scheinen.

Die Porphyrgranulite sind an manchen Lokalen ziemlich gut entblösst. Dabei ist eine unablässige bankartige Abwechselung zwischen etwas verschiedenen Gesteinsvarietäten zu sehen; überdies mischen sich Amphibolite in diesen Granulitzügen ungemein häufig bei. - Wenn man von einigen kleineren Kiesanhäufungen absieht, sind Erzvorkommnisse niemals in unmittelbarem Zusammenhang mit typischen Porphyrgranuliten gesehen worden; dagegen finden sich mehrere kleine Vorkommnisse von Magneteisenerz mit Quarz, Granat und Amphibol in gewissen schmäleren granatführenden Gesteinszügen eingelagert, die vielfach mit den Porphyrgranuliten abwechseln.

An die Porphyrgranulite schliessen sich auch gewisse hornblendereiche rötliche Granulitvarietäten in der südlichen Fortsetzung der Lomberg-Granulite ebenso wie einige Gesteine in dem Finnäs-Gebiet an. Dieser Typus scheint dagegen in den grossen skarnerzführenden Gebieten im östlichen gleichwie im westlichsten Teil des Kartengebietes ganz zu fehlen.

\section{Rote Granulite mit Granat und Epidot im W. von Grän- gesberg.}

Die hier zu besprechenden Granulite sind am besten in der Umgegend von Sköttorp zu studieren; nach einigen Ausbissen bei Myrbo, Smedenstorp und Laxtorp zu schliessen, nehmen sie wahrscheinlich das ganze Terrain zwischen den 
Bd 32. H. 2.] EISENERZFÜHR. FORMATION VON GRÄNGESBERG.

Porphyrgranuliten im $\mathrm{W}$ und den ,eisenerzführenden $\mathrm{Ge}$ steinen des Ormberg-Risberg-Zuges im 0 ein. Von diesem Gebiet aus scheinen mehrere keilförmige Abzweigungen in die Porphyrgranulite hineinzuragen.

Die Granulite dieses Typus zeigen meistens eine glimmerfreie, rote Gesteinsmasse, die mit etwa erbsengrossen Klümpchen von rotbräunlichem Granat und hellgrünem Epidot gesprenkelt ist. Auch mehrere andere Minerale, wie Quarz, Hornblende, Pyroxen, Kalzit, Magnetit und Schwefelkies, mischen sich öfters diesen Skarnklümpchen bei. Die Form und Grösse der Granat-Epidot-Anhäufungen ist übrigens eine ziemlich wechselnde; in einigen Varietäten sind sie zu dünnen Streifen ausgewalzt; in anderen bilden sie $d m$-breite linsenförmige Schlieren; zuweilen werden sie durch unregelmässige, überquerende Granat-Epidot-Adern ersetzt.

$\mathrm{Zu}$ näherer Untersuchung wurde eine Probe eines typischen, etwas nordöstlich von Sköttorp anstehenden Granatgranulits ausgewählt. Das Gestein besteht zum grössten Teil aus verschiedenartigen grobkörnigeren Anhäufungen, um welche sich ein granulitisches Grundgewebe von ziemlich wechselnder Korngrösse und Zusammensetzung herumwindet. Der Quarz ist grösstenteils als etwas gröbere Streifen dem Grundgewebe eingelagert. Der wenig perthitische Mikrolin kommt reichlich als ausgewalzte Anhäufungen vor, bildet auch den Hauptbestandteil des Grundgewebes. Der Plagioklas ist stark getrübt und bis zu fast vollständiger Verdrängung mit Epidot und Granat schwammig durchwoben; besser erhaltene Körner entsprechen optisch einem Oligoklas etwa $A_{25} A b_{75}$. Die Granat-Epidot-Anhäufungen sind meistens schwammig mit Quarz, Plagioklasüberresten und Hornblendefetzen verwoben. Eine grössere Anhäufung zeigte im Inneren einen negativen Kristallkern aus Quarz, dann eine kompakte, zonar gebaute Granatschale und schliesslich eine Aussenzone aus schwammigem Epidot. Körnchen von einem kräftig grünen Pyroxen nebst etwas Hornblende bilden die spärlichen femi- 
schen Flasern. Der Titanit und sogar der Apatit erscheint in grossen Anhäufungen ganz wie die anderen Minerale; Zirkon ist sehr reichlich durch das ganze Grundgewebe zerstreut. - Von diesem Gestein hat GraBe die folgende Analyse ausgeführt:

\begin{tabular}{|c|c|c|c|}
\hline $\mathrm{SiO}_{2} \cdot . \cdot .64 .11$ & 106.14 & Q..... 19.91 & $s . . .1 .37-1.44$ \\
\hline $\mathrm{TiO}_{2} . . . . \quad 0.76$ & 0.95 & Or . . . 35.18 & \\
\hline $\mathrm{Al}_{2} \mathrm{O}_{3}$. . . 15.04 & 14.72 & $\mathrm{Ab} \cdot . \cdot .15 .77$ & 52.5 \\
\hline $\mathrm{FeO} \ldots \ldots$ & $E, 0$ & An . . . . 15.14 & $\mathrm{Ab} .$. \\
\hline $\mathrm{MnO} . . .$. & & 2 sal 86.00 & An $\cdot \cdot$ \\
\hline $\mathrm{MIgO}$ & 1.70 & $\mathrm{CaSiO}_{3} . \ldots . \quad \overline{5} .69$ & \\
\hline$\cdot \cdots$ & 10.73 & $\mathrm{MgSiO}_{3} \cdot . . \quad 1.71$ & $\Sigma \mathrm{F} .$. \\
\hline $\mathrm{Na}_{2} \mathrm{O} . . \cdot$ & 3.00 & $\mathrm{FeTiO}_{3} \cdot . \quad 1.44$ & $\mathrm{Al}_{2} \mathrm{O}_{3} \cdot-4.88$ \\
\hline $\mathrm{K}_{2} \mathrm{O} \cdot \cdot \cdot$ & 6.30 & $\mathrm{Fe}_{2} \mathrm{O}_{3} \cdot . \cdot 4.01$ & \\
\hline $\mathrm{P}_{2} \mathrm{O}_{5} \ldots \ldots$ & $(0.42)$ & Apatit . . . 0.43 & $\mathrm{II}^{-}: 4: \mathrm{II}^{+}: 2$ \\
\hline Gl. V.. • · • & & $\Sigma$ fem. 13.28 & \\
\hline 99.59 & & 99.28 & Name fehlt \\
\hline
\end{tabular}

Es ist dies eine ganz ungewöhnliche chemische Zusammensetzung. Wenn man wie gewöhnlich alles $\mathrm{Al}_{2} \mathrm{O}_{3}$ als Feldspate berechnet, was durchaus nicht dem »Modus» dieses epidotreichen Gesteins entspricht, bleibt eine grosse als $\mathrm{Ca} \mathrm{Si} \mathrm{O}_{3}$ zu berechnende Menge von Kalziumoxyd übrig, die bei dem geringen Gehalt an Pyroxen und Hornblende offenbar zum grössten Teil in einem Ca Fe-Granat stecken muss. Sogar wenn diese $\mathrm{CaSiO}_{3}$-Menge nicht vorhanden wäre, muss ein Quarz-Feldspat-Gestein von dem oben berechneten Feldspatverhältnis als eine Seltenheit bezeichnet werden. In der Tat finden sich in der von WASHINGTON herausgegebenen Zusammenstellung von Gesteinsanalysen nur sehr spärliche Representanten für denselben gleichzeitig kalk- und kalireichen »Subrang», wozu unser Granat-Epidot-Granulit gehört. - Nach dem Chemismus des Gesteins sollte man das Auftreten eines ziemlich basischen Plagioklases exwarten. Es deutet in der Tat die Struktur des Gesteins darauf, dass Einsprenglinge von basischem Plagioklas anfänglich vorhanden waren, die 
aber in einer späteren Phase der Gesteinsentwickelung instabil wurden und einer Umwandlung in Granat und Epidot anheimfielen.

Innerhalb der Granat-Epidot-Granulite scheinen kleinere Eisenerzanhäufungen nicht selten $z u$ sein und sind an mehreren Lokalen, z. B. bei Laxtorp, südlich von Sköttorp und bei Sporrtorp, durch Schürfe aufgeschlossen. Diese Eisenerze gehören zu einem in Dalekarlien häufig repräsentierten, aber wenig charakteristischen Typus, der hier als der sTunaHästberg-Typus» bezeichnet werden soll. Es sind vorwiegend Magneteisenerze, die als Lagerarten dieselben Minerale - Granat, Epidot, Amphibol und Quarz - enthalten, die ja auch in den umgebenden Granuliten selbst in der Form der kleinen Granatanhäufungen enthalten sind. Dieselbe Mineralassoziation wird übrigens auch in mehr gesammelter und reiner Form in einigen Quarz-Granat-Skarneinlagerungen angetroffen, die nördlich von Laxtorp den Granuliten eingeschaltet sind.

\section{Rötliche Granulite im Lomberget.}

Die hier zu besprechenden Granulite, die im folgenden kurz als Granulite von Lomberg-Typus bezeichnet werden mögen, können als die spezifischen Träger der innerhalb des Grängesberggebiets auftretenden, phosphorärmeren, schuppigen Quarzeisenerze des sLomberg-Pershytte-Typus» angesehen werden. Es sind ziemlich kalireiche, biotitführende Mikroklinperthit $\mathrm{II}_{\mathrm{I}}$-Oligoklas-Granulite von rötlicher oder rötlich-grauer Farbe. Hornblende scheint immer in diesen Granuliten zu fehlen; vielmehr enthalten sie dafür meistens Muskovit, wenn auch niemals in beträchtlicher Menge. Eine Imprägnation mit Eisenerzen, sowohl Eisenglanz als Magnetit, tritt fast überall schon makroskopisch hervor; in den erzführenden Zonen reichern sich diese Minerale zu Schlieren und Bändern an, die sich dann allmählich zu kompakteren Erzlagern konzentrieren. - Das Aussehen dieser Granulite ist übrigens ein recht wechselndes; es treten verschiedene Varietäten in unab- 
lässiger Abwechselung mit einander und mit grauen BiotitPlagioklas-Granuliten von dem später zu beschreibenden "Exportfeld-Typuss auf. Auch im kleinen neigen sie fast immer zu einer inhomogenen, gebänderten oder geflammten Ausbildung, wobei sich der Plagioklas und Biotit zu dunkleren grauen Schlieren oder Bändern sammeln, während sich der Kalifeldspat zu helleren roten Partien anbäuft, die öfters eine gröbere, aplitenähnliche Ausbildung annehmen. Es kommen sogar kleinere Gesteinsbänke vor, die aus fast reinem Mikroklinfels mit Eisenerz nebst etwas Epidot und Chlorit bestehen. Auch sind Gesteine von verschwommen porphyrischer Struktur beobachtet, die reichlich grössere Anhäufungen van Oligoklas und Mikrolinperthit in einem Quarz-Feldspat-Grundgewebe enthalten. Amphibolite sind vielfach mit den Lomberg-Granuliten vergesellschaftet, kommen aber hier entschieden spärlicher als in den umgebenden Granulitzügen vor; sie sind meistens etwas quarzführend, neigen zu Epidotbildung und enthalten, gleichwie die Granulite, Magnetitkörner in der Gesteinsmasse mehr oder weniger reichlich eingestreut.

$\mathrm{Zu}$ näherer Untersuchung wurde ein feingebändertes Gestein an dem Kanale etwa mitten zwischen der Ängesgrube und der Grube Ivarrännan ausgewählt. Das Gestein zeigt im Dünnschliff eine bänderförmige Abwechselung zwischen einerseits grobkörnigeren Partien, in denen Feldspate, vor allem der Plagioklas, und Biotit angereichert sind, und andererseits feinkörnigen, fast plagioklas- und biotitfreien Streifen, die von feinen Erzkörnchen dicht gesprenkelt sind (Fig. 12, Taf. 2). Der Quarz ist in der grobkörnigeren Hauptmasse ziemlich untergeordnet, reichert sich aber in den helleren Streifen stark an. Der immer brăunlich bestäubte Plagioklas ist meistens in kleinere linsenförmige Streifen gesammelt, bildet auch einselne typische Anhäufungen; besser erhaltene Körner haben sich optisch als basische Oligoklase, etwa $\mathrm{An}_{31} \mathrm{Ab}_{69}$, erwiesen. Der hellere Mikroklin bildet den Hauptgemengteil des Grund- 
gewebes, kommt auch als gröbere Anhäufungen vor, die nur wenige perthitische Spindeln erkennen lassen. Der Biotit bildet regelmässig parallelgeordnete, olivbraune oder grünlich gebleichte Täfelchen; Muskovit ist auch in geringer Menge vorhanden. Orthit und Apatit sind ziemlich häufig, Titanit fehlt dagegen fast ganz, wie es meistens in muskovitführenden Gesteinen der Fall ist. Epidot ist fleckenweise angehäuft. - Eine Analyse von Grabe hat die folgenden Zahlen ergeben:

\begin{tabular}{|c|c|c|c|}
\hline $\mathrm{SiO}_{2} \cdot . \cdot \cdot 68.45$ & 113.33 & Q.... . 27.32 & $s . . .2 .00-2.10$ \\
\hline $\mathrm{TiO}_{2} \cdot . . .0 .41$ & 0.51 & Or . . . 37.19 & \\
\hline $\mathrm{Al}_{2} \mathrm{O}_{3}, \ldots . .12 .94$ & 12.66 & $\mathrm{Ab} . . . .18 .74$ & . . . . 58.5 \\
\hline . . 6.01 & 85 & An . . . . & $\mathrm{Ab} \cdot . . .31 .4$ \\
\hline $\mathrm{MnO} . . . . .0 .15$ & 0.06 & $\mathrm{Al}_{2} \mathrm{O}_{3} \cdot \ldots \cdot 0.23$ & An .... 9.8 \\
\hline $\mathrm{MgO} \cdot . . . \quad 0.95$ & 2.38 & $\quad \Sigma$ sal 89.67 & . \\
\hline $\mathrm{CaO} \cdot . \cdot \cdot$ & 2.50 & $\mathrm{MgSiO}_{3} \ldots 2.38$ & $\Sigma F \cdot . .22 .65$ \\
\hline $\mathrm{Na}_{2} \mathrm{O} \cdot \cdot \cdot \cdot$ & 3.56 & $\mathrm{FeTiO}_{3} \cdot . \quad 0.78$ & $\mathrm{Al}_{2} \mathrm{O}_{3} . .+0.23$ \\
\hline $\mathrm{K}_{2} \mathrm{O} \ldots \ldots$ & 6.66 & $\mathrm{Fe}_{3} \mathrm{O}_{4} \ldots .6 .22$ & \\
\hline $\mathrm{P}_{2} \mathrm{O}_{6} \ldots . . .0 .12$ & $(0.28)$ & Apatit. . . 0.29 & $\mathrm{I}: 4: \mathrm{II}: 2$ \\
\hline Gl. V. . . $\doteq 0.96$ & & $\Sigma$ fem. 9.67 & Dellenos \\
\hline 99.87 & & 99.34 & \\
\hline
\end{tabular}

Die Analyse ergiebt einen geringen $\mathrm{Al}_{2} \mathrm{O}_{3}$-Überschuss, wie man es in einem etwas glimmerführenden hornblendefreien Gestein zu erwarten hat. Die Feldspatsilikate könnten auf $30 \%$ Oligoklas $\mathrm{Or}_{7} \mathrm{Ab}_{65} \mathrm{An}_{28}$ und $70 \%$ Mikroklinperthit $\mathrm{II}_{\mathrm{II}} \mathrm{Or}_{80} \mathrm{Ab}_{18} \mathrm{An}_{2}$ verteilt werden; genauere volumenometrische Bestimmungen sind in diesen feinkörnigen Gesteinen schwierig auszuführen.

Von der reichlichen Erzimprägnation abgesehen, giebt die obige Analyse ganz die Zusammensetzung eines „BohuslänGranites» an (Nr. I-II unten: Granite von Solhem und Gånehed $\left.{ }^{1}\right)$.

1 P. J. Holmquist: Die Granite von Schweden, Nr. 48 and 46. 


\begin{tabular}{|c|c|c|c|c|c|c|c|}
\hline \hline & - & 1. & 2. & 3. & 4. & 5. & 6. \\
\hline$s$. & $2.00-2.10$ & $2.59-2.81$ & $2.01-2.21$ & $1.72-1.96$ & $1.85-2.15$ & $4.48-4.64$ & $4.56-4.74$ \\
& & & & & & & \\
Or. & 58.5 & 58.0 & 57.3 & 50.1 & 47.0 & 80.1 & 83.8 \\
Ab. & 31.4 & 30.5 & 34.9 & 39.4 & 40.9 & 16.0 & 9.7 \\
An. & 9.8 & 11.4 & 7.8 & 10.5 & 12.1 & 3.9 & 6.5 \\
\hline
\end{tabular}

Von den „Järngneisen» (Nr. III: Järngneis von Töllesjö, Älfsborgs Jän ${ }^{1}$; Nr. IV: Järngneis von Stenshufvud in Schonen ${ }^{2}$ ) weicht der analysierte Lomberg-Granulit durch den kalireicheren Charakter ab; gewisse inhomogenere, plagioklasreiche Bänder enthaltende Varietäten dürften jedoch eine diesen Gneisen ähnliche Durchschnittszusammensetzung haben. Von anderen, Quarzeisenerze enthaltenden Granuliten aus Mittelschweden liegen bisher Analysen von den Nebengesteinen der quarzgebänderten Striberg-Erze vor (Nr. V-VI: Granulite von Prestaberg und Ringshyttan ${ }^{3}$ ). Letztere Gesteine scheinen nach diesen Analysen noch kalireicher, überdies auch weit quarziger zu sein; die Alkalibestimmungen sind indessen wahrscheinlich ețwas zu niedrig ausgefallen.

Die Lomberg-Granulite gehen im südlichsten Teil des Grubenfeldes in hellrote, nicht glimmerführende Gesteinsvarietäten über, die sich chemisch den Granat-Epidot-Granuliten nähern dürften und gleichwie diese Granulite von granatreichen, mehr oder weniger quarzigen Erzen begleitet sind. - In der nördlichen Fortsetzung der Lomberger Erzzüge innerhalb der Ormberger und Risberger Grubenfelder sind rötliche kalifeldspatreiche und erzimprägnierte Granulite von Lomberg-

1 A. E. Törneboнm: Upplysn. till Geol. Öfrersiktskarta öfver Sveriges Berggrund, S. 10.

2 A. E. Törnebohm and A. Hennig: S. G. U. Ser. A1, a N:r 1-2 (1904): 29.

3. SANTesson: Kemiska bergartsanalyser. S. G. U. Ser. C, N:r 17 (1877): $53-54$. 
Typus fast bei allen dortigen Gruben zu sehen; sie sind jedoch hier überall mit grauen Granuliten von Exportfeld-Typus assoziiert, welch letztere dem Hauptgesteinstypus zu entsprechen scheinen. Der intimen Verwebung der beiden Gesteinstypen und des mächtigen Erdlagers dieser Gegend zufolge habe ich bei der Herstellung der Karte auf eine Trennung der beiden Granulitarten verzichten müssen. - Kalifeldspatreiche, den Lomberg-Granuliten in der Zusammensetzung mehr oder weniger ähnliche, obwohl meistens viel gröbere Gesteine begleiten auch die schuppigen Quarzeisenerze im Gudmundberget, Blötberget und Fredmundberget.

\section{Graue biotitreiche Plagioklasgranulite bei Grängesberg.}

Während die schuppigen Quarzeisenerze die rötlichen kalireichen Granulite von Lomberg-Typus bevorzugen, treten die Apatiteisenerze meistens in grauen natron-reichen Granuliten auf, die hier als Granulite von Exportfeld-Typus bezeichnet werden mögen. Es sind dunkelgrau gefärbte Gesteine von ausgeprägter grober Schieferigkeit, die durch reichliche, in der gewöhnlichen steilen Stengeligkeitsrichtung kräftig ausgezogene Biotitflasern hervorgerufen wird. Einzelne einsprenglingsartige Feldspatkristalle treten öfters aus der Gesteinsmasse hervor; einige Varietäten zeigen sogar eine ausgesprochen porphyrische Struktur. Von den vorher beschriebenen, sämtlich mehr oder weniger kalifeldspatreichen Granulittypen weichen sie durch den Reichtum an saurem Plagioklas bei völligem oder fast völligem Fehlen von Kalifeldspat ab; von den'später zu beschreibenden, ebenfalls natronreichen, skarnführenden Granuliten weichen sie durch geringeren Quarzgehalt und den Reichtum an Biotit ab. Der Grundgewebe-Feldspat der Exportfeld-Granulite ist übrigens im allgemeinen von ziemlich grobem Korn, was im Verein mit der grobflaserigen Ausbildung des Biotits diesen Granuliten im Vergleich mit den meisten anderen Granuliten unse$5-100170$. 
res Gebietes ein gröberes, mehr gneisiges Aussehen verleiht.

Als Repräsentant für die am meisten verbreitete Varietät unter den hierher gehörigen Granuliten könnte ein Gestein aus dem Hangenden des Apatiterzes im südlichen Teil des Tagebaues Skärningen beschrieben werden. Deutliche Plagioklaseinsprenglinge fehlen diesem Gestein, dafür treten indessen im Dünnschliff reichliche rundliche Anhäufungen aus polygonalen, $0.1-0.3 \mathrm{~mm}$ messenden, sehr frischen und gut lamellierten Plagioklaskörnern hervor, die nach der symmetr. Auslöschungsschiefe von $-10^{\circ}$ als ein Albitoligoklas etwa $\mathrm{An}_{13} \mathrm{Ab}_{87} \mathrm{zu}$ bestimmen sind (Fig. 9, Taf. 2). Diese Anhäufungen sind den Plagioklasaggregaten der vorher beschriebenen Plagioklasgneise sehr ähnlich; gleichwie die Feldspate dieser Gneise sind auch die Anhäufungsplagioklase der Plagioklasgranulite, vor allem der nicht zu kalkarmen Varietäten, mit zahlreichen Quarztröpfchen öfters poikilitisch gespickt. Einsprenglinge oder Anhäufungen von Quarz fehlen diesem Gestein, wie den Exportfeld-Granuliten überhaupt, völlig; sie sind dazu offenbar zu basisch. Der Quarz steckt ganz in dem Grundgewebe, mit einem unverzwillingten oder nur vereinzelte Zwillinglamellen zeigenden Feldspat vermengt, der jedoch in anderen Eigenschaften nicht von dem Anhäufungsplagioklas merklich verschieden ist. Sicherer Mikroklin konnte nur als antiperthitische Flecke in einigen grösseren Plagioklaskörnern beobachtet werden. Der kräftig olivbraune Biotit bildet z. T. gröbere Flasern, die sich um die Plagioklasanhäufungen herumwinden, ist übrigens in kleineren Tafeln und Scheibchen durch das ganze Gewebe zerstreut. Apatit und Magnetit sind in diesem Gestein wie in allen untersuchten Granuliten dieses Typus reichlich vorhanden und haben die Tendenz, sich schlierenweise anzuhäufen. Titanit fehlt dagegen fast völlig; der nicht geringe $\mathrm{TiO}_{2}$-Gehalt steckt offenbar in dem Biotit. - Das beschriebene Gestein ist von GraBE mit folgenden Resultaten analysiert worden: 


\begin{tabular}{|c|c|c|c|}
\hline $\mathrm{SiO}_{2} \cdot . \cdot .68 .96$ & 114.17 & Q.... . 2460 & $s . . .1 .89-2.41$ \\
\hline . . 0.80 & 1.00 & Or.... . 10.98 & \\
\hline . . 13.30 & 13.01 & . . . 40.53 & Or . . . . 18.3 \\
\hline $\mathrm{FeO}$. & 788 & An . . . . 6.06 & $\mathrm{Ab} \cdot .71 .6$ \\
\hline $\mathrm{MnO} .$. & 1.86 & $\mathrm{Al}_{2} \mathrm{O}_{3} \ldots \cdot . \quad 1.21$ & An . . . 10.1 \\
\hline $\mathrm{MgO}$ & 4.28 & $\Sigma_{\text {sal }} 83.38$ & \\
\hline $\mathrm{CaO}$. & 2.57 & $\mathrm{MgSiO}_{3} \cdot . \quad .4 .29$ & $\Sigma$ F. . . 21.49 \\
\hline . . . 4.78 & 7.70 & $\mathrm{FeSiO}_{3}$. . . 9.08 & $\mathrm{Al}_{2} \mathrm{O}_{3} . .+1.18$ \\
\hline . . . 1.85 & 1.96 & $\mathrm{FeTiO}_{3} \cdot . \quad . \quad 1.52$ & \\
\hline $\mathrm{P}_{2} \mathrm{O}_{5} \cdot \ldots . \quad 0.17$ & $(0.40)$ & Apatit. . . . 0.40 & II $: 4:$ II $: 4$ \\
\hline Gl. V. . . . . 1.12 & & $\Sigma$ fem. $\quad 15.29$ & \\
\hline 99.79 & & 98.67 & \\
\hline
\end{tabular}

Der recht bedeutende Tonerdeüberschuss steckt in dem reichlichen Biotit, der volumenometrisch etwa $12.5 \%$ beträgt, was in Gewichtsprozenten etwa $14 \%$ entsprechen dürfte. Wenn man in dem Biotit einen Gehalt von $9 \% \mathrm{~K}_{2} \mathrm{O}$ annimmt, bleibt eine Kalimenge von $0.60 \%$ übrig, die in dem Plagioklas stecken muss; die Zusammensetzung dieses Plagioklases berechnet sich demnach zu $\mathrm{Or}_{6 \cdot 8} \mathrm{Ab}_{81 \cdot 7} \mathrm{An}_{11 \cdot 5}$, was seinen optischen Charakteren gut entspricht. - Die Granulite von Exportfeld-Typus stehen offenbar den Plagioklasgneisen unseres Gebietes chemisch sehr nahe und weichen hauptsächlich durch den grösseren Gehalt an Biotit von denselben ab.

Neben der oben beschriebenen Varietät, die wenigstens auf der östlichen Seite des Exportfeldgranulitzuges das Hauptgestein bildet, treten, z. B. im Liegenden des Exportfeldes, Varietäten mit etwas saureren Plagioklasen (bis zu $\mathrm{An}_{7}\left(\mathrm{Ab}_{93}\right)$ auf, die meistens mehr oder weniger deutlich porphyrisch ausgebildet sind. Die Einsprenglingsplagioklase zeigen eine charakteristische bräunliche Bestäubung und sind meistens mit Biotittäfelchen ganz durchspickt; sie zeigen übrigens öfters einen sehr unregelmässigen Zwillingsbau und jene undulöse Auslöschung, die für Albitanorthoklase oder kalireichere Albitoligoklase charakteristisch zu sein scheint; antiperthitische Mikroklinflecke sind übrigens in diesen Feld- 
spaten nicht selten. Andererseits sind im Risbergfelde kalkreichere Gesteine vorhanden, deren Einsprenglingsfeldspate bis zu $\mathrm{An}_{\mathbf{2 0}} \mathrm{Ab}_{\mathbf{8 0}}$ oder vielleicht darüber erreichen, während die Anhäufungs- und Grundgewebefeldspate nicht unter $\mathrm{An}_{1 \mathbf{5}} \mathrm{Ab}_{8 \mathbf{5}}$ gehen. Proben von Exportfeld-Granulit aus dem Ormberger Gebiete zeigen sehr hübsche langlinsenförmige Anhäufungen und weichen übrigens durch eine mehr oder weniger hervortretende Einmengung von Mikroklin in dem Grundgewebe von den vorher erwähnten Varietäten ab.

Wie früher bemerkt wurde, sind die Granulite von Exportfeld-Typus z. T., besonders innerhalb des Ormberg-RisbergZuges aber auch an mehreren anderen Lokalen, z. B. in dem Liegenden des Exportfelder Erzzuges, mit rötlichen Granuliten von Lomberg-Typus intim verwoben. Im Hangenden des Exportfeldes und weiter nördlich in dem Strandberg-Felde und bei Salomonstorp treten sehr inhomogene hornblendeschlierige Gesteine, die sich den in der nächsten Abteilung zu beschreibenden Gesteinen des N. Hammargrube-Gebietes anschliessen, in vielfacher Abwechselung mit den typischen ExportfeldGranuliten auf. Auch aplitische und pegmatitische Gänge kommen häufig vor. In Bezug auf die Intensität der Amphibolitenverwebung können nur die Porphyrgranulit-Gebiete mit dem Exportfeldgranulit-Zuge verglichen werden. - Nach eimigen spärlichen Ausbissen zu schliessen, dürften Granulite von Exportfeld-Typus auch auf der nördlichen Seite des Gudmundberget vorkommen. Gegen Süden hin lässt sich dieser Gesteinszug bis zu dem die beiden Hörken-Seen verbindenden Kanale verfolgen.

Inhomogene amphibolitische Granulitgesteine in dem $\mathbf{N}$. Hammargruben-Gebiet.

In der Umgebung der N. Hammargrube im nördlichsten Teil des Grängesberger Erzfeldes zeigen die erzführenden Gesteine eine sehr eigentümliche und interessante Ausbildung. 
Der Gesteinscharakter entspricht hier im Durchschnitt demjenigen eines an Magnetit, Apatit und Titanit überreichen biotit- oder pyroxenführenden Quarz-Oligoklas-Amphibolites; durch die ganze Gesteinsarea herrscht aber eine ausserordentliche, bis in die feinsten Details eingreifende Inhomogenität. Das Aussehen eines in diesem Gebiet gewöhnlichen Gesteinstypus ist in Fig. 4 wiedergegeben. Das Gestein ist in zwei Komponenten gespalten, eine helle, die bald einem Plagioklasgranulit, bald einem Oligoklasit entspricht; und eine dunkle, die als Hornblendeskarn bezeichnet werden könnte.

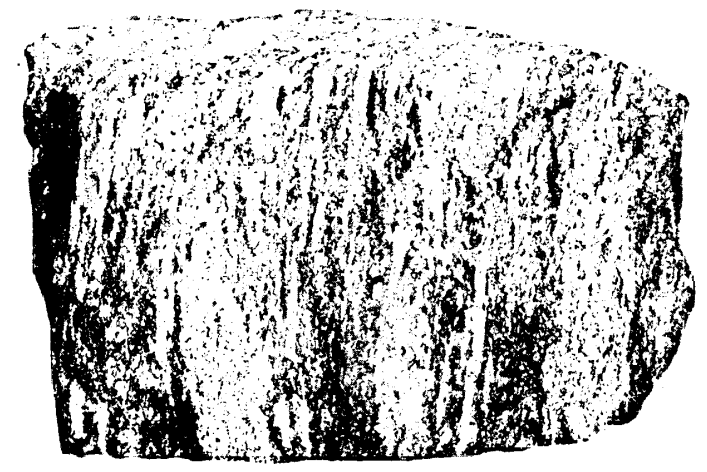

Fig. 4. Inhomogener amphibolitischer Granulit aus dem N. HammargrabenGebiet. $1 / 1$.

Die Verwebungsart dieser Komponenten könnte vielleicht eine eutaxitische benannt werden, eine Bezeichnung, die ja nicht nur für Laviagesteine, sondern auch für mehr abyssische Gesteine von ähnlicher Schlierenbreccienstruktur in Brauch gekommen ist.

Bei genauerer Betrachtung dieser eutaxitischen Verwebung treten einige Verschiedenheiten in dem gegenseitigen Verhàlten der Komponenten zu Tage, die mir von Interesse erscheinen, weil dadurch meiner Meinung nach die Deutung gewisser anderer, später zu beschreibender eigentümlicher Verhältnisse innerhalb der erzführenden Formation unseres 
Gebietes sehr erleichtert wird. Die Verhältnisse könnten vielleicht durch das Bild eines allerdings sehr unregelmässigen und lückenhaften Netzes veranzchaulicht werden, dessen Maschen von der femischen Komponente gebildet sind, während der salische Anteil die $\mathrm{Z}_{w}$ ischenräume ausfüllt. Bei kräftigerer Orientierung und schärferer Differentiierung nehmen die Gesteine ein Aussehen an, das in Fig. 5 veranschaulicht wird. Die dunkle Komponente erscheint z. T. als unregelmässige vielfach gegabelte Bänder, z. T. ist sie in unregelmässigen kürzeren Partien angehăuft, die zwischen die hellen Bänder in der Richtung des Streichens eingeschoben sind und in diese mit vielen

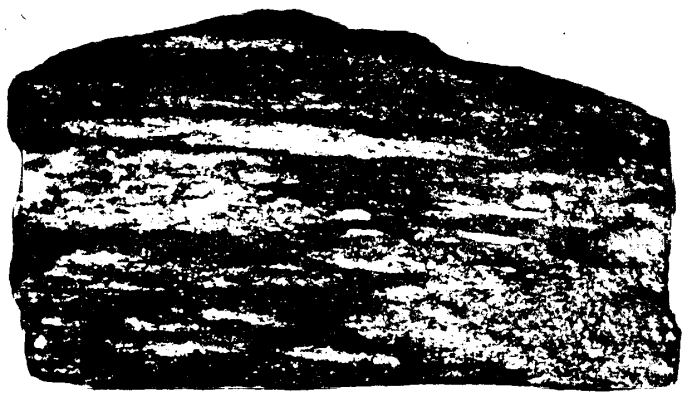

Fig. 5 . Inhomogenes amphibolitisches Gestein aus dem N. HammargrabenGebiet. ${ }^{1 / 1}$.

Fränzchen und Zäckchen hereingreifen. Die grösseren dunklen Partien sind durch schmälere Zwischenbälkchen mit einander verbunden, die den Eindruck von schief überquerenden Gängchen machen könnten.

Der Mineralbestand dieser inhomogenen Gesteine ist selbstverständlich ein sehr schwankender. Der Plagioklas scheint in den quarzärmeren plagioklasitischen Schlieren einem Oligoklas mit 25-28\% An zu entsprechen, ist aber in den saureren plagioklasgranulitischen Partien ein Albitoligoklas mit 10-15\% An. Die Hornblende gehört z. T. zu einer kräftig tintenblauen, wahrscheinlich eisenreichen Varietät. In man- 
chen Varietäten tritt ein ziemlich kräftig gefärbter und deutlich pleochroitischer grüner Augit hinzu; in gewissen Zügen ist endlich Biotit das vorherrschende femische Mineral und häuft sich öfters zu kompakteren verfilzten Biotitskarnmassen an. Titanit ist immer reichlich vorhanden und zeigt hier dieselbe lebhaftere Färbung wie die vorher erwähnten Titanite aus den Plagioklasgneisen; auch Orthit ist in diesen Gesteinen ein konstanter Gemengteil. Apatit und Magnetit sind durch die ganze Gesteinsmasse sehr reichlich eingestreut und häufen sich in gewissen Zügen zu kleineren oder grösseren Klumpen und Schlieren an.

Die geologische Erscheinungsform und die Kontaktverhältnisse der N. Hammargruben-Gesteine scheinen in grösserem Massstabe ganz ähnliche Verhältnisse wiederzuerzeugen, wie man sie im kleinen in manchen Handstücken dieser Gesteine beobachten kann. Die Gesteine nehmen offenbar eine vielfach gegabelte Area von geringer Länge im Verhältnis zu der maximalen Breite ein, die in den Exportfeld-Granulitzug quer zu dem Streichen eingeschaltet ist. Die beiden Gesteine sind auf der westlichen Seite meistens recht scharf von einander abgegrenzt; bemerkenswert ist dabei, dass die den Exportfeld-Granuliten eingelagerten Erzzüge dennoch, obwohl mit verändertem Erzcharakter, sich in dem Verbreitungsgebiet der N. Hammargruben-Gesteine unbehindert fortsetzen. Auf der östlichen Seite, wo Ausbisse allerdings nur spärlich vorkommen, scheinen die N. Hammargruben-Gesteine dagegen einen weit weniger femischen Charakter anzunehmen und ziemlich unscharf in die Exportfeld-Granulite überzugehen. Diese Granulite sind hier, wie vorher bemerkt wurde, an mehreren Lokalen, z. B. in dem Hangenden der ExportfeldErze und ihrer Fortsetzung in dem Strandberg-Felde, mit hornblendeschlierigen Gesteinsbänken vermengt, die als schlierige, sich allmählich verlierende Ausläufer der N. Hammargruben-Gesteine aufgefasst werden könnten. 


\section{Skarnführende Granulite.}

Die grossen Granulitgebiete in den periphereren Teilen des Kartengebietes zeigen eine Ausbildung, die in mehreren Hinsichten von den vorher beschriebenen Granuliten abweicht; dagegen zeigen ihre Gesteine untereinander so bedeutende Übereinstimmungen, dass sie hier unter der Bezeichnung sSkarnfuihrende Granulite» zusammengefasst werden mögen. Makroskopisch zeichnen sich die meisten hierhergehörigen Gesteine durch sehr helle, weissliche oder schwach rötliche Farben und ein sehr gleichmässiges, zuckerkörniges Gefüge mit rauh anzufühlenden Bruchflächen aus; die Kornfestigkeit mancher Varietäten ist derart gering, dass sie schon bei gelindem Druck zu Pulver werden. Porphyrische Ausbildung ist seltener makroskopisch deutlicher hervortretend, fehlt gewissen Varietäten auch mikroskopisch fast ganz. Als femisches Mineral kommt Biotit am häufigsten vor, obwohl selten reichlich genug, um eine deutlichere Schieferigkeit zu erzeugen; übrigens neigt das Mineral zu inhomogener Verteilung, wodurch die Gesteine öfters ein etwas geflammtes Aussehen bekommen. Hornblendeführende Varietäten sind indessen fast in allen diesen Gesteinszügen $a b$ und $z u$ eingestreut und walten in gewissen Gebieten vor. Letzteres Mineral zeigt niemals eine gleichmässige Verteilung in der Gesteinsmasse, sondern neigt immer zu schlieriger oder breccienartiger Verwebung mit der hellen Granulitmasse. Diese Erscheinung ist für die skarnführenden Granulite eine sehr charakteristische; sie stimmen in dieser Hinsicht mit den N. Hammargruben-Gesteinen überein, erreichen jedoch nur ganz lokal den gleichen femischen, quarzamphibolitischen Durchschnittscharakter, der im letzteren Gesteinsgebiet durchgängig angetroffen wird. Innerhalb derartiger schlieriger und breccienartiger Granulitzüge häufen sich die femischen Gemengteile ab und zu als kleinere oder grössere kompaktere Massen an (Fig. 6); es sind diese dunklen Gesteinsmassen die Skarngesteine. Auch amphibolitische oder 
Bd 32. H. 2.] EISENERZFÜHR. FORMATION VON GRÄNGESBERG. 59 sogar dioritische Grünsteine treten in gewissen Skarngranulitzügen reichlich hinzu; diese Gesteine neigen dabei ebenfalls $\mathbf{z u}$ einer inhomogenen Ausbildung und sind durch breccienartige Skarn-Granulit-Mischgesteine mit den Granuliten verbunden. Eisenerzkonzentrationen sind sehr häufig mit den. Skarnen und Grünsteinen vergesellschaftet; mit Ausnahme einiger Kalkeisenerz-Vorkommen gehören sie alle zu der Gruppe der Skarneisenerze; am häufigsten vertreten sind Hornblende- oder Pyroxen-Hornblende-führende Erze von einem Typus, der hier als der Björnberg-Typus bezeichnet werden soll.

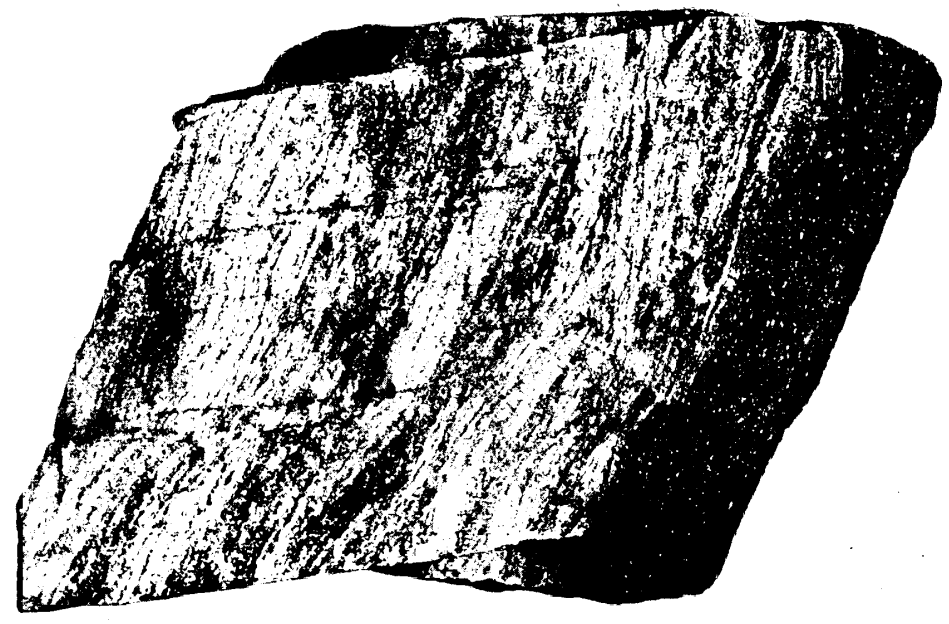

Fig. 6. Hornblendeschlieriger Granulit und Hornblendeskarn. Öraberget, Grängesberg. $2 / 3$.

Auch sämtliche Vorkommen von körnigen Kalksteinen innerhalb unseres Gebietes haben ihre Heimat bei den skarnführenden Granuliten.

In chemischer Hinsicht schliessen die sskarnführenden Granulite» offenbar mehrere etwas verschiedene Gesteinstypen ein, die indessen manchmal nicht sicher voneinander makroskopisch zu trennen sind. Nach den bisher ausgeführten Untersuchungen, die allerdings in diesen weit ausgedehnten Gesteinsgebieten nicht sehr ins Detail haben geführt werden können, ist jedoch kaum zu bezweifeln, dass die skarnführen- 
den Granulitzüge ihrer Hauptmasse nach aus sehr natronreichen, den Plagioklasgneisen unseres Gebietes chemisch nahe entsprechenden Gesteinen aufgebaut sind. Als untergeordnete Bänke oder Bänder sind Gesteine von oligoklasitischer Zusammensetzung vielfach beobachtet worden, die fast ganz aus einem Oligoklas mit 20-25\% An bestehen. Diesen Gesteinen mischen sich in gewissen Gebieten mikroklinführende Varietäten bei, die unter den Gneisen unseres Gebietes mit den vorher erwähnten Zwischengesteinen zwischen den roten Gneisen und den Plagioklasgneisen am nächsten verwandt sein dürfen. Auch das Vorhandensein von etwas kalk- und kalireicheren Gesteinen unter den skarnführenden Granuliten ist konstatiert worden.

Die angeführten allgemeinen Charaktere dieser Granulite sollen im Folgenden durch einige Beispiele erläutert werden, und wollen wir dabei mit den Granuliten in der Umgegend von Örabergsdammen, im $\mathrm{O}$ von Grängesberg, anfangen. Diese Granulite treten im Hangenden der S. 32-34 beschriebenen Plagioklasgneise auf; der Kontakt ist nicht schwierig $\mathrm{zu}$ bestimmen, obwohl der Gneis in der Näbe des Granulits eine entschieden feinkörnigere Struktur annimmt. Die Granulite zeigen sehr helle Farbe und sehr gleichmässige, nicht porphyrische Struktur. Öfters gehen sie eine breccienartige Verwebung mit Hornblendeskarn ein, wie auf der nördlichen Seite von Örabergsdammen schön zu sehen ist; gewisse Varietäten enthalten auch Schlieren mit Granat und Epidot. Mehrere Linsenkomplexe aus Kalkstein mit Amphiboliten und Granat-Hornblende-Skarnen kommen vor. Eisenerze fehlen hier, obgleich sowohl die Skarne als die Kalksteine bisweilen erzimprägniert sind. - Von einem weisslichen Granulit mit feinen Biotitflasern, der an dem Kanale etwas nördlich von Örabergsdammen ansteht, wurde eine partielle Analyse von mir ausgeführt, die durch Alkalibestimmungen von GraBE komplettiert worden ist: 


\begin{tabular}{|c|c|c|c|}
\hline $\mathrm{SiO}_{2} \cdot . . .76 .65$ & 126.90 & Q..... 43.19 & $s . . .3 .85-4.04$ \\
\hline $\mathrm{Al}_{2} \mathrm{O}_{3}$. . . . 12.55 & 12.28 & $\mathrm{Or} \cdot . \cdot 13.65$ & Or . . . 26.2 \\
\hline $\mathrm{FeO} . . . . \quad 1.21$ & \multirow{2}{*}{1.79} & $\mathrm{Ab} \cdot . \cdot .26 .29$ & $\mathrm{Ab} . . .53 .9$ \\
\hline $\mathrm{MnO} . . .$. & & An . . . . 10.26 & An $\ldots . .19 .9$ \\
\hline $\mathrm{MgO}$ & 1.65 & $\mathrm{Al}_{2} \mathrm{O}_{3} \ldots . . \quad 1.19$ & \multirow{3}{*}{$\begin{array}{l}\Sigma \mathrm{F} . .+18.55 \\
\mathrm{Al}_{2} \mathrm{O}_{3} \cdot+1.17 \\
\end{array}$} \\
\hline $\mathrm{CaO}$ & 3.68 & $\Sigma$ sal 94.58 & \\
\hline $\mathrm{Na}_{2} \mathrm{O} . .$. & 4.99 & $\mathrm{MgSiO}_{3} \cdot \cdot \cdot \cdot 1.66$ & \\
\hline $\mathrm{K}_{2} \mathrm{O}$ & 2.44 & $\mathrm{FeSiO}_{3} \cdot \cdot \quad 2.37$ & \multirow{3}{*}{$\begin{array}{l}\mathrm{I}: 3: \mathrm{II}: 4 \\
\text { Alsbachos }\end{array}$} \\
\hline Gl. V. . . & & $\Sigma$ fem. 4.03 & \\
\hline 99.71 & & 98.61 & \\
\hline
\end{tabular}

In dem Feldspatverhältnis nähert sich dieses Gestein einerseits dem Grängesberger Granitgneis, andererseits gewissen s. g. Natrongraniten, weicht aber von den meisten derartigen Gesteinen durch seinen Quarzreichtum und die Armut an femischen Gemengteilen ab. Die Struktur dieses Granulites ist in Fig. 17-18, Taf. 3 dargestellt. Das ganze Gestein ist als ein sehr gleichmässiges granulitisches Gewebe ausgebildet, das beinahe zur Hälfte aus Quarz besteht; der Feldspat ist ein bestäubter und zersetzter, selten lamellierter Plagioklas, wahrscheinlich ein basischer Oligoklas, dem ein hellerer Mikroklin in nicht unbedeutender Menge beigemengt ist. - Eine rötliche skarnschlierige Varietät aus demselben Lokale zeigt den Mikroklin mit einem saureren Plagioklas, etwa $\mathrm{An}_{12} \mathrm{Ab}_{88}$, vergesellschaftet; der Plagioklas zeigt dabei die Tendenz, sich als grössere Individuen auszuscheiden, die mit rundlichen Quarzkörnern, etwa von der Grösse des Grundgewebequarzes, poikilitisch dicht gespickt sind, wie es Fig. 7 (nach einer Photographie von HormqUIsT) angiebt. Ähnliche Gesteine, die fast ganz aus quarzpoikilitischem Albitoligoklas bestehen, sind auch anderswo in den skarnführenden Granulitzügen unseres Gebietes, z. B. zwischen dem Björnberg-Felde und Hörktjärn, verbreitet; ausserhalb des Gebietes sind derartige Plagioklasgranulite beobachtet worden, in welchen die poiki- 
litische Verwachsung in eine schriftgranitische Verwebungsart übergeht. ${ }^{1}$

Den Öraberg-Granuliten ähnlich, aber noch bunter ausgebildet ist die Granulitformation in dem weiter nördlich gelegenen Norsberg-Felde. Das Hauptgestein ist ein hellrötlicher, ziemlich mikroklinreicher Granulit von dem Aussehen der Oraberg-Granulite; weissliche Oligoklasite und Plagioklasgranulite kommen jedoch auch vor. Hornblende-, pyroxenund granatführende Skarngesteine treten sehr reichlich auf und sind in gewissen Zügen zu kompakteren Massen angehäuft. Auf beiden Seiten von dem See Norsen sind recht bedeutende Kalkstein-Amphibolit-Skarn-Komplexe aufgeschlos-

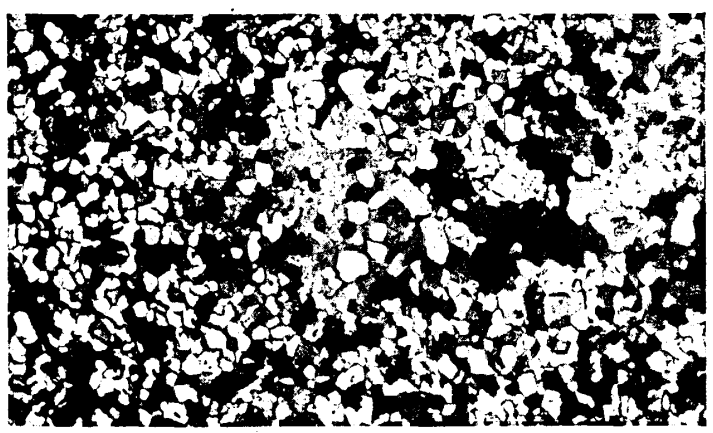

Fig. 7. Skarnführender Granulit, Öraberget. Vergr. etwa $20 \times$.

sen; Eisenerzschürfe finden sich über das ganze Gebiet zerstreut. Sämtliche Gesteine sind von rötlichen mikroklinreichen, aplitischen Adern netzartig durchwoben. Die stetige und ausserordentlich bunte Verwebung und Durchdringung der dunklen und hellen Gesteine, wie sie z. B. in den Gebirgen nördlich vom Norsen vorzüglich zum Vorschein kommt, bietet einen ganz grossartigen Anblick dar.

Im Hangenden werden die Öraberg-Granulite von weisslichen ausgeprägten Plagioklasgranuliten abgelöst, die mit dem vorher beschriebenen cordieritführenden Zweiglimmer-

1 Gate Beispiele bieten die 'granitischen, Granulite im Brattberget im Kirchspiel Nya Kopparberg. 
gneis verknüpft sind. Als femisches Mineral enthalten sie einen rotbraunen Biotit oder auch einen dünnnadeligen Klinoanthophyllit. Eine porphyrische Ausbildung ist öfters merkbar und kommt im Dünnschliff sehr schön zum Vorschein (Fig. 11, Taf. 2). Sowohl Quarz als Plagioklas kommen als Einsprenglinge oder Anhäufungen vor. Die grösseren Feldspate zeigen einen sehr komplizierten $\mathrm{Z}_{\text {willingsbau mit }}$ symmetrischen Auslöschungsschiefen bis zu $-17^{\circ}$. Bei gewissen Varietäten unter diesen offenbar sehr An-armen Plagioklasgranuliten deuten das scheckige Aussehen und die bisweilen zu beobachtenden perthitischen Mikroklinflecke auf eine nicht ganz unerhebliche Beimischung des Or-Molekels in den albitischen Einsprenglingen. Das Grundgewebe enthält ein polygonales Aggregat aus Quarz neben einem selten lamellierten Feldspat, der wohl als Albit oder Albitanorthoklas aufzufassen ist. Grössere Skarnansammlungen scheinen diesem Granulitzug zu fehlen; an der östlichen Grenze desselben finden sich einige Eisenerzschürfe mit klinoanthophyllitführenden Magnetiten von Melings-Typus» oder auch mit quarzreichen, z. T. mit Eisenglanz gemischten, etwas gebänderten Amphibolerzen; ganz ähnliche Erze sind durch zahlreiche Schürfe auch weiter südlich zwischen Storstenstorp und Björnudden aufgeschlossen.

Auf diese Plagioklasgranulite folgt dann der erzführende Granulitzug des Björnberg-Feldes, der durch die reichliche Beimengung von Grünsteinen ausgezeichnet ist (vergl. die Kartenskizze S. 124). Diese Granulite sind ebenfalls Plagioklasgranulite von recht wechselnder Ausbildung. Proben aus dem Hangenden der in der Långgrube gebauten Kalkeisenerzlinse zeigen ein rötliches, gleichmässig körniges Gestein mit dunkleren Bändern und Flammen. Unter dem Mikroskop tritt ein Gewebe aus einem Plagioklas mit symmetrischer Auslöschungsschiefe bis zu $-15^{\circ}$ und viel Quarz ohne gröbere Ausscheidungen hervor; neben einem reichlichen grünlichen Biotit ist etwas-blassgrünliche Hornblende und ein 
wenig Magnetit vorhanden. Von diesem Gestein hat Grabe die folgende Analyse ausgeführt:

\begin{tabular}{|c|c|c|c|}
\hline . . . 75.46 & 124.93 & Q.... 34.02 & $s . .2 .82-3.28$ \\
\hline . . . . 0.12 & 0.15 & Or .... 1.36 & \\
\hline $\mathrm{Al}_{2} \mathrm{O}_{3} \ldots . .11 .20$ & 10.96 & . . 46.64 & Or . . . 2.4 \\
\hline $\mathrm{FeO} . . .2 .70$ & \multirow{2}{*}{3.86} & An . . . . $\quad 5.18$ & $\mathrm{Ab} \cdot . .88 .3$ \\
\hline$\cdot \cdot \cdot$ & & $\quad \Sigma$ sal. 87.20 & An . . . . 9.3 \\
\hline . . . & 5.73 & $\mathrm{CaSiO}_{3} \ldots .1 .00$ & \\
\hline $\mathrm{CaO} . .$. & 2.79 & $\mathrm{MgSiO}_{3} \cdot \ldots .75$ & $\Sigma$ F. . . 20.06 \\
\hline $\mathrm{Na}_{2} \mathrm{O} \cdot$. & 8.86 & $\mathrm{FeSiO}_{3} . \quad . \quad 4.91$ & $\mathrm{Al}_{2} \mathrm{O}_{3} . .-0.86$ \\
\hline $\mathrm{K}_{2} \mathrm{O} \ldots \ldots$ & 0.24 & $\mathrm{FeTiO}_{3} \ldots . \quad 0.23$ & \multirow{4}{*}{$\begin{array}{c}\mathrm{I}^{+}: 3^{+}: \mathrm{II}: 5 \\
\text { Yukonos }\end{array}$} \\
\hline $\mathrm{P}_{2} \mathrm{O}_{5} \ldots \ldots$ & $(0.07)$ & Apatit. . . 0.07 & \\
\hline Gl. V. . . . . & & $\Sigma$ fem. 11.96 & \\
\hline 99.93 & & 99.16 & \\
\hline
\end{tabular}

Ein Vergleich mit der Plagioklasgneis-Analyse S. 33 lässt sehr grosse Übereinstimmungen ersehen. Der sehr geringe $\mathrm{K}_{2} \mathrm{O}$-Gehalt lässt vermuten, dass der grünliche Biotit dieses Granulits 'ein Natron-Biotit ist.

Kompaktere Skarngesteine haben in diesem Gesteinszug nur eine geringe Verbreitung. Zwischen den z. T. recht grob und massig ausgebildeten Grünsteinen und den hellen Plagioklasgranuliten entwickeln sich hier eine Reihe Gesteine von intermediärer Zusammensetzung, die entweder als inhomogene Hornblendeskarn-Granulit-Mischgesteine oder auch als Quarz-Hornblende-Syenite ausgebildet sind. Westlich von der Trollhättengrube im nördlichen Teil des Erzfeldes haben derartige Mischgesteine eine grosse Verbreitung, die als bunte Breccien mit hellrötlichen granulitischen Trümmern von der Zusammensetzung eines etwas quarzführenden Oligoklasits und einer dunklen Zwischenmasse aus Hornblendeskarn ausgebildet sind. Ähnliche bunte Mischgesteine, obgleich von mehr schlieriger Ausbildung, treten mehrfach in der Fortsetzung der Björnberg-Gesteine nach SSW hin auf. - Die hornblendesyenitischen $Z_{w}$ ischengesteine sind am besten im Lie- 
genden der Löfhällgrube zu sehen. Die dortigen Gesteine zeigen z. T. eine ganz massige, etwas trachytoidale Struktur mit $\mathrm{cm}$-langen rötlichen, karlsbaderverzwillingten Feldspatleisten, in einer dunklen hornblendereichen Masse eingebettet. Diese Feldspatleisten scheinen ursprünglich von anorthoklasartiger Zusammensetzung gewesen zu sein, sind indessen zu antiperthitischen Verwachsungen von Albitoligoklas, etwa $\mathrm{An}_{15} \mathrm{Ab}_{\mathrm{s} 5}$, und Mikroklin oder sogar zu kleinkörnigen Aggregaten derselben Gemengteile geworden. Sie sind aussen öfters mit Quarz grob poikilitisch oder sogar schriftgranitisch (Fig. 2 Taf. 1) verwachsen. Neben den grösseren Leisten kommt ein ähnlicher Plagioklas mit Quarz und ein wenig Mikroklin zusammen als eine granulitische $Z_{\text {wischenmasse vor; dabei }}$ zeigt das Mineral ebenfalls eine Tendenz, den Quarz poikilitisch einzuschliessen, ganz wie es bei den Öraberg-Granuliten besprochen wurde. Die Hornblende bildet meistens grössere poikilitische Individuen; Titanit und langnadelig ausgebildeter Apatit kommen in diesem eigentümlichen Gestein auch reichljch vor. - Der beschriebene Syenit hăngt gegen W. mit einem dioritischen Gestein ohne scharfe Grenze zusammen; gegen 0 wird er von einem Pyroxenamphibolit abgelöst, welcher das Muttergestein des in der Löfhällgrube geschürften Eisenerzes bildet; in der Fortsetzung des Gesteinszuges gegen SSW finden sich ähnliche syenitische Gesteine in den Halden der Snickar- und der Pell-Grube, die indessen meistens eine schlierige Parallelstruktur erkennen lassen und vielfach in granulitische Gesteine mit mehr oder weniger scharf abgetrennten Schlieren von Hornblendeskarn übergehen.

Auf der westlichen Seite von Grängesberg kommt ein kleiner Zug aus skarnschlierigen Granuliten etwas westlich von Täppan mitten in den Porphyrgranuliten vor. Proben dieser Gesteine zeigen eine Abwechselung von quarzarmen oligoklasitischen und quarzreicheren plagioklasgranulitischen Bändern. Amphibolite sind sehr zahlreich und auch zwei kleine Kalkstein-Linsenkomplexe kommen vor. Einige Schürfe 
mit etwas quarzigen Granat-Amphibol-Erzen scheinen innerhalb dieses Gesteinszuges gelegen zu sein.

In dem Bachtal zwischen Örtjärnsdammen und Gällsåsdammen finden sich Ausbisse von einem weissen, quarzitisch aussehenden und von Quarzadern durchwobenen Granulit mit spärlichen Hornblendeschlieren und wiederholten Amphibolitbänken. In einer Probe wurden die Alkalien von GraBe mit folgenden Resultaten bestimmt:

$$
\begin{aligned}
& \mathrm{Na}_{2} \mathrm{O} \text {. . . . . . . . . . } 4.74 \% \\
& \mathrm{~K}_{2} \mathrm{O} \text {. . . . . . . . . . } 0.70 \%
\end{aligned}
$$

Da das Gestein ausser Quarz und einem Plagioklas optisch $=\mathrm{An}_{11} \mathrm{Ab}_{89}$ nur höchstens $2 \%$ Biotit, Erz, Orthit und Apatit enthält, könnte die Zusammensetzung etwa folgendermassen berechnet werden: $\mathrm{SiO}_{2} 81 \% ; \mathrm{Al}_{2} \mathrm{O}_{3} 11 \% ; \mathrm{CaO} 1.10 \%$; $\mathrm{Na}_{2} \mathrm{O} 4.74 \% ; \mathrm{K}_{2} \mathrm{O} 0.70 \% ; \mathrm{MgO}, \mathrm{FeO}$ und Gl. V. $1.5 \% ; \mathrm{s}=4.3$; $\mathrm{Or}: \mathrm{Ab}: \mathrm{An}=8.0: 81.5: 10.5 ;$ Yukonos. Wie die meisten quarzreicheren Plagioklasgranulite ist auch dieses Gestein als ein sehr gleichmăssiges polygonales Gewebe mit nur vereinzelten etwas gröberen Plagioklasanhäufungen ausgebildet (Fig. 16, Taf. 3). - Ganz ähnliche weisse Granulite treten an manchen Lokalen auf der Südseite des Ortjärnsfjäll-Granitmassives zu Tage.

Die Långudden-Halbinsel ist von groben Plagioklasgranuliten aufgebaut, die vielleicht besser als Granulitgneise zu bezeichnen wären. Auf der westlichen Seite zeigen sie rötliche Farbe und enthalten spärliche Flasern einer tintenbläulichen Hornblende nebst grossen Orthiten und anderen kleinen Gemengteilen. Gegen 0 hin nehmen die Gesteine weissliche Farben an, statt der Hornblende tritt Biotit nebst ein wenig Muskovit auf, und neben dem vorzüglich frischen und scharflamellierten Albitoligoklas $\left(\mathrm{An}_{\mathbf{8}} \mathrm{Ab}_{\mathbf{9 2}}\right)$ wird ein wenig Mikroklin merkbar. - Die Ausbildung dieser groben Granulite ist übrigens eine sehr einförmige; Amphibolite und Skarne werden nur selten angetroffen, und nur auf der nordwestlichen Seite des 
Gesteinszuges tritt ein kleiner Erzzug auf, der z. T. Serpentineisenerze von „Gubbo-Typus» enthält. - Ähnliche grobe Gesteine haben eine grosse Verbreitung auch auf der Südseite des Sees N. Hörken.

Die Granulite an der sïdlichen Kartengrenze scheinen ebenfalls zum grössten Teil zu den Plagioklasgranuliten zu gehören, obwohl skarnschlierige Entwickelungsformen nur eine beschränkte Verbreitung haben. Amphibolite sind dafür um so reichlicher zu sehen. Die Granulite in den Gebirgen nördlich von Bergslags-Hörken und Silfverhyttan zeigen meistens eine undeutliche porphyrische Ausbildung durch etwas gröbere, stengelig ausgezogene Quarzkörner. Die Mikrostruktur einer derartigen Varietät ist in Fig. 15, Taf. 3 reproduziert. Es kommen langgezogene linsenförmige Quạzanhäufungen in dem plagioklasgranulitischen Grundgewebe eingelagert vor, wodurch eine an sächsische Granulite (Fig. 13, Taf. 3) etwas erinnernde, obwohl viel gröbere Struktur zustande kommt.

Die grosse Verbreitung der natronreichen und speziell der extremen, hier als Plagioklasgranulite bezeichneten Gesteine innerhalb der skarn- und skarnerzführenden Gebiete ist offenbar eine Tatsache von grossem petrographischem Interesse und grosser genetischer Bedeutung. Wie ich in meiner früheren Arbeit über die Genesis der mittelschwedischen Eisenerze hervorgehoben habe, findet sich auch in allen anderen mittelschwedischen Skarnerzbezirken, deren Gesteine bisher überhaupt in chemisch-petrographischer Hinsicht untersucht worden sind, ein ganz ähnlicher natronreicher Gesteinscharakter wieder, und möchte ich in dieser Hinsicht auf eine dem genannten Aufsatz beigefügte Analysentabelle und eine dazu gehörige graphische Analysendarstellung verweisen. ${ }^{1}$

1 G. F. F. 29 (1907) : 152-155. 


\section{Die Grünsteine.}

\section{Diorite und Gabbrodiorite.}

Die meisten Grünsteinvorkommen von solcher Grösse, dass sie auf der Übersichtskarte haben eingezeichnet werden können, haben das Aussehen von kleinkörnigen bis mittelkörnigen hornblendereichen Dioriten. Als Beispiel von solchen Dioriten könnte das Gestein auf der Südseite der Sees Ortjärn erwähnt werden, das als ein relativ bedeutendes Massiv innerhalb des dortigen Plagioklasgranulitzuges auftritt, und das übrigens auch dadurch bemerkenswert ist, dass es einige kleine Vorkommnisse von pyroxenführenden Skarneisenerzen enthält. Der Mineralbestand des dortigen Hauptgesteinstypus ist unter Nr. 1 in der Tabelle. Seite 72 angeführt; die Struktur ist in Fig. 19, Taf. 4 wiedergegeben. Der Plagioklas bildet grössere Tafeln, die hauptsächlich aus einem Labradorandesin, etwa $A n_{50} A b_{50}$, mit Kernen bis zu $A n_{55} A_{b_{45}}$ und unregelmässigen Hüllen von Andesinen bestehen. Die kräftig grüngefärbte Hornblende bildet ein Gewebe von kurzprismatischen Individuen, das vereinzelte Anhäufungen von Eisenerz einschliesst und fleckenweise von Quarz löcherig durchwachsen ist. In der Umgebung der Eisenerzschürfe enthält das Gestein feinkörnige Schlieren eines reichlich magnetitimprägnierten Biotit-Quarz-Amphibolits; weisse plagiaplitische Adern sind bisweilen häufig zu sehen.

Unter den Grünsteinen innerhalb der roten HörkenGneise ist das kleine Massiv auf der Südseite von Aborrtjärn seiner Neigung zu Differentiierung wegen bemerkenswert. $\mathrm{Am}$ häufigsten kommt ein dunkles Gestein von feinnadeliger Struktur vor, das im Dünnschliff aus einer bräunlich grünen, magnetitbestäubten Hornblende mit eingestreuten dünnen, gleichwie zerfressenen Plagioklasleisten $\left(\mathrm{An}_{60} \mathrm{Ab}_{40}\right)$ besteht. Mit diesem an Uralitdiabase erinnernden Gestein zusammen kommen einerseits plagioklasreichere diorit-ähnliche Varietäten vor 
andererseits auch plagioklasarme gabbrodioritische Gesteine mit grossen spiegelnden Hornblendeindividuen, die in fast reine Hornblendegesteine mit eingestreuten Tafeln eines sehr blassen Glimmers übergehen. An der westlichen Grenze des Massives ist ein weisser zuckerkörniger Plagioklasit $\left(\mathrm{An}_{31} \mathrm{Ab}_{69}\right)$ bisweilen mit dem Hornblendefels in derselben schlierenbreccienähnlichen Art verwoben zu sehen, wie im allgemeinen die salischen und femischen Gesteine in unserem Gebiete miteinander verknüpft zu sein pflegen. In derselben Kontaktzone kommen

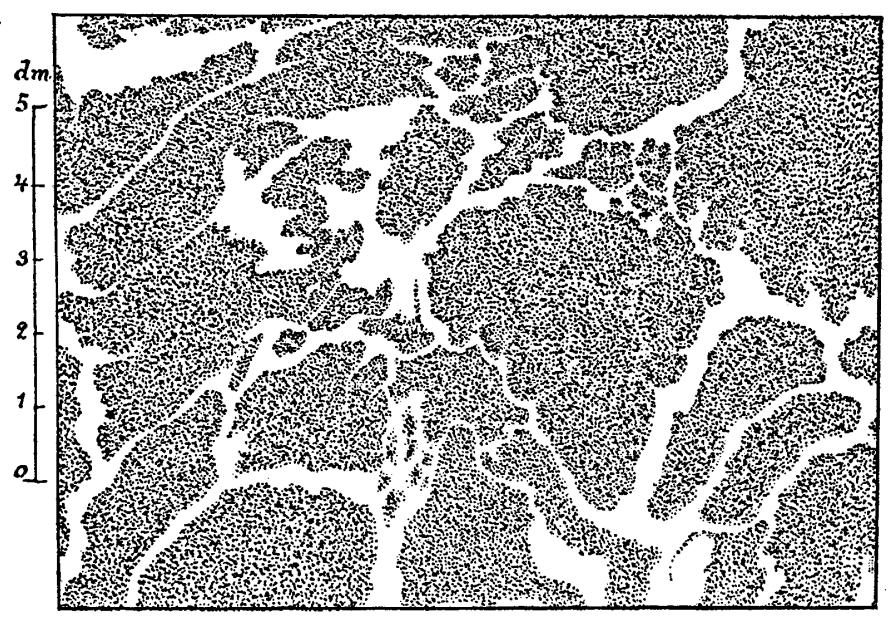

Fig. 8. 'Klumpen-Diorit, westlich von der Eisenbahnstation Björnhyttan.

schliesslich auch mit Magnetkies angereicherte Schlieren von glimmerreichem Hornblendefels vor, die zu einigen Schürfen Veranlassung gegeben haben. - Die Grünsteine in dem Massiv nördlich von Björnhyttan können als glimmerführende Gabbrodiorite bezeichnet werden und zeigen ebenfalls eine recht schwankende Ausbildung.

In gewissen Gneiszügen, vor allem innerhalb der Plagioklasgneise in der Umgegend des Sees Glaningen, kommen häufig Grünsteine von einer eigentümlichen Ausbildung vor, die durch Fig. 8 veranschaulicht werden könnte. Diese 
Gesteine bestehen aus dicht angehäuften dunklen Klumpen von rundlich gebuchteter Begrenzung, die in einer spärlichen hellen $Z_{w}$ ischenmasse, meistens von dem Charakter eines Plagioklasgranites, suspendiert sind. Das Aussehen dieser »Klumpen-Diorite ist demjenigen des vorher (S. 28) besprochenen gemischten Ganggesteins aus dem Karl-Johan-Schacht ganz ähnlich; die dunklen Klumpen weichen in der Tat nur durch ein etwas gröberes Korn von der malchitischen Komponente dieses Ganges ab. Bisweilen nehmen die Klumpen-Diorite ein mehr breccienartiges Aussehen an, wobei der Plagioklasgranit scharfeckige Dioritbrocken verkittet (Långblå-Grube, Fredmundberget); auch das umgekehrte Verhältnis - grössere Brocken von Plagioklasgestein mit untergeordneter Zwischenmasse von dunklem Gestein - ist bisweilen zu sehen (Gehöft Långblå).

\section{Amphibolite.}

Diejenigen unzähligen Grünsteine, die allzı klein und geologisch unselbständig sind, um auf den Karten vermerkt werden zu können, zeigen meistens ein feineres Korn $(0.1-0.3 \mathrm{~mm}$, auf den Plagioklas bezogen), zumal wenn sie in granulitischen Gesteinszügen auftreten; öfters auch eine merkbare, wenn auch selten ausgeprägtere Parallelstruktur. Sie können fast ausnahmslos als echte Plagiollasamphibolite klassifiziert werden; Epidot-Zoisit-Minerale haben in dieser Gesteinsreihe eine sehr geringe Bedeutung, und Albit fehlt ganz; auch die granatführenden eklogitischen Abarten sind dem hier behandelten Teil der mittelschwedischen Eisenerzformation ganz fremd.

Die.Verbreitung der Amphibolite innerhalb der verschiedenen Gesteinszüge wurde schon vorher besprochen. $\mathrm{Zu}$ sammenfassend könnte gesagt werden, dass sie nur gewissen gröberen roten Gneisen und Urgraniten ganz fehlen, während sie innerhalb anderer Gneiszüge dieses Typus gleichwie in dem Granitgneise nur spärlich vorhanden sind; am häufigsten kommen sie in den Porphyr- und Exportfeld-Gra- 
nuliten ebenso wie in dem roten Granulitgneis vor; innerhalb der skarnführenden Granulite sind sie z. T. reichlich vorhanden, scheinen jedoch in gewissen Gesteinszügen durch die Skarngesteine grossenteils ersetzt worden zu sein.

Der volumenometrisch ermittelte Mineralbestand einer Reihe Amphibolitvarietäten aus verschiedenen Gesteinszügen ist in der Tabelle auf S. 72 zusammengestellt. Obwohl die meisten Gesteine der Hauptsache nach eine einfache binäre dioritische Zusammensetzung ans grüner Hornblende und mittelsaurem Plagioklas zeigen, kommen doch in Bezug auf Zusammensetzung und gegenseitige Proportionen der Hauptgemengteile oder in der Beschaffenheit der akzessorischen Gemengteile mancherlei Variationen vor. Es scheint in der Tat fast jeder Gneis- oder Granulittypus von seinen speziellen Amphibolitvarietäten begleitet $\mathrm{zu}$ sein. Als eine allgemeine Regel scheint dabei zu gelten, dass der Gehalt an Hornblende relativ zu dem Plagioklase mit der Basizität des letzteren schnell abnimmt und auch durch das Auftreten eines akzessorischen Quarzgehaltes rasch herabgedrückt wird (vergl. Fig. 21, S. 145)

Der normale Amphibolittypus innerhalb der Exportfeldund Porphyrgranulite und auch in den roten Granulitgneisen ist durch die beiden basischen Andesin-Amphibolite Nr. 2-3 reprăsentiert. In diesen Gesteinen befindet sich die Hornblende in entschiedener Vormacht. Der Plagioklas ist ein basischerer Andesin, etwa $A_{40} A_{60}$ bis $A_{45} A_{45}$, öfters mit zonarem Bau. Nebengemengteile kommen nur in sehr geringer Menge vor. Gewisse Varietäten zeigen makroskopisch ein weissgesprenkeltes dioritisches Aussehen infolge grösserer rundlicher Plagioklaskörner, die immer in Gegensatz zu'den vorzüglich frischen Andesinen des Grundgewebes durch Zoisitisierung ganz getrübt sind und demnach wahrscheinlich basischeren Ausscheidungen einer früheren Kristallisationsphase entsprechen. - Die Struktur des Gesteins Nr. 3 ist in Fig. 21, Taf. 4 wiedergegeben; die chemische Zusammensetzung ist unten (S. 76) angeführt. 


\begin{tabular}{|c|c|c|c|c|c|c|c|c|c|c|}
\hline 罙 & 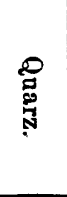 & 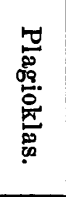 & 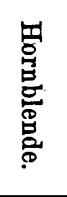 & 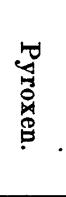 & 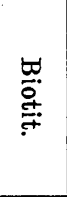 & 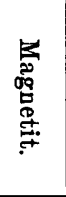 & 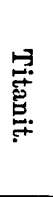 & 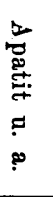 & 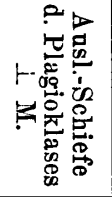 & 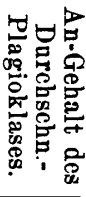 \\
\hline 1 & 3.2 & 31.9 & 63.9 & - & - & 1.0 & sp. & sp. & $21-32^{\circ}$ & 50 \\
\hline 2 & - & 43.3 & 56.2 & - & - & sp. & 0.3 & 0.2 & $22-25^{\circ}$ & 44 \\
\hline 3 & 1.3 & 40.0 & 56.6 & - & - & 0.2 & 1.2 & 0.5 & $20-22^{\circ}$ & 40 \\
\hline 4 & - & 52.5 & 43.1 & - & 0.1 & - & 3.8 & 0.5 & $-15^{\circ}$ & 32 \\
\hline 5 & - & 68.7 & 27.7 & - & - & - & 3.0 & 0.6 & $9-10^{\circ}$ & 27 \\
\hline 6 & 3.0 & 87.0 & 6.2 & - & 0.6 & - & 0.7 & 2.5 & $6-8^{\circ}$ & 25 \\
\hline 7 & - & 38.5 & 49.9 & 6.9 & - & 1.3 & 2.8 & 0.6 & $-18 \div 2^{\circ}$ & 37 \\
\hline 8 & - & 40.9 & 43.0 & 13.2 & - & - & 2.6 & 0.3 & $15-18^{\circ}$ & 34 \\
\hline 9 & 1.0 & 62.7 & 29.0 & - & 0.7 & 5.8 & 0.1 & 0.7 & $11^{\circ}$ & 28 \\
\hline 10 & - & 31.8 & 50.0 & - & 17.7 & - & 0.3 & 0.2 & $15^{\circ}$ & 32 \\
\hline 11 & 6.9 & 48.1 & 39.2 & - & 0.3 & 2.9 & 2.3 & 0.3 & $18-21^{\circ}$ & 39 \\
\hline 12 & 13.5 & 46.0 & 28.3 & - & - & 11.2 & - & 1.0 & $18-21^{\circ}$ & 39 \\
\hline 13 & 8.0 & 58.7 & 22.4 & - & sp. & 8.5 & 1.6 & 0.8 & $15-20^{\circ}$ & 37 \\
\hline 14 & 6.2 & 45.9 & 32.2 & - & 7.9 & 7.1 & - & 0.7 & $23^{\circ}$ & 43 \\
\hline
\end{tabular}

1. Örtjärn aus Plagioklasgranulit; 2. W. von Ormbergstjärn ans Exportfeld-Granulit; 3. Orrleksdammen aus rotem Granulitgneis; 4. Skakelbacken aus Plagioklasgneis; 5. SO von Örabergsdammen ans Plagioklasgranulit; 6. W von Täppan aus Plagioklasgranulit; 7. N. Hammargrabe; 8. Löfhällgrube im Björnbergfelde; 9. ebenda; 10. Karl-Johan-Schacht aus dem Granitgneise; 11. Eisenbahneinschnitt nahe bei der Ängesgrabe aus Lomberg-Granulit; 12.

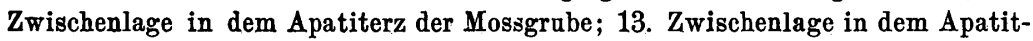
erz der Skärningen-Grube; 14. Storstenstorp aus den Björnberg-Grünsteinen.

Diesen Amphiboliten schliesst sich eine Reihe weniger femischer Gesteine an, die in gewissen skarnführenden Granulitzügen und in den Plagioklasgneisen (Nr. 4) ihre Hauptverbreitung zu haben scheinen. Die Plagioklase zeigen die Charaktere der sauren Andesine oder angrenzenden Glieder der Oligoklasreihe; die Hornblende tritt dem Plagioklas gegenüber an Menge zurück und zeigt eine blassere Farbe, vor allem nach $\mathfrak{a}$ und $\mathfrak{b}$; die Titansäure ist als reichlicher Titanit ausgeschieden.

1 Hauptsächlich Epidot, Orthit und Zirkon. 
Bei den eigentlichen Oligoklas-Amphiboliten mit noch saureren Plagioklasen (Nr. 5) ist eine sehr bedeutende Abnahme des Hornblendegehaltes za konstatieren, und es stellen sich bald als Endglieder der nicht quarzigen Amphibolitreihe fast reine granulitähnliche Oligoklasite $(\mathrm{Nr} .6)$ ein, die, wie vorher hervorgehoben wurde; nicht seltene Glieder innerhalb der skarnführenden Granulitzüge sind. Homogene OligoklasAmphibolite scheinen übrigens nicht häufig vorzukommen; es haben die entsprechenden Gesteine offenbar eine ausgeprägte Tendenz zu gebänderter oder eutaxitischer Ansbildung, wobei die Gemengteile sich zu abwechselnden Schlieren von Hornblendeskarn und oligoklasitischem Granulit trennen, wie es in fast allen Skarngranulitzügen unseres Gebietes öfters zu sehen ist.

Als eine interessante Spezialreihe sind die Pyroxen-Amphibolite (Nr. 7-8) den saureren Andesinamphiboliten an die Seite zu stellen. Derartige Amphibolite sind für die auch in so manchen anderen Hinsichten eigentümlich entwickelte $\mathrm{Ge}$ steinsformation in der Umgebung von der N. Hammargrube bezeichnend, bilden auch das Nebengestein des pyroxen-amphibolführenden Eisenerzes an der Löfhäll-Grube im Björnberg-Felde. Die Gesteine aus den beiden Verbreitungsbezirken sind einander sehr ähnlich, nur enthält das Björnberger Gestein spärlich eingestreute rötliche Einsprenglinge eines weit zersetzten, z. T. skapolitisierten Plagioklases, die dem N. Hammargruben-Gestein fehlen. Der Pyroxen ist ein hellgrüner, schwach pleochroitischer malakolithischer Augit, vielleicht mit nicht ganz unerheblichem Alkaligehalt; auch die Hornblende dieser Amphibolite dürfte, nach der kräftig blaugrünen Farbe zu schliessen, verhältnismässig alkalireich sein. Titanit kommt reichlich in diesen Amphiboliten vor.

Magnetit scheint in den quarzfreien Amphiboliten ein seltenerer Übergemengteil zu sein, kann sich jedoch innerhalb gewisser Eisenerzzüge auch in solchen Amphiboliten anreichern. Der Magnetit-Amphibolit Nr. 9 bildet z. B. das Ne- 
bengestein eines ein wenig nördlich von der oben erwähnten Löfhäll-Grube gelegenen Eisenerzschurfes. Auch in die PyroxenAmphibolite des N. Hammargrubengebietes ist Magnetit mehr oder weniger reichlich eingesprengt.

Die allerdings recht spärlichen Biotit-Amphibolite aus dem Granitgneis (Nr. 10) stellen einen eigentümlichen lamprophyrartigen Typus von vorzüglich geschieferter Struktur (Fig. 21, Tàf. 4) dar. Sie dürften chemisch und genetisch den hornblendereichen femischen Konkretionen dieses Gneises nahe entsprechen und stehen zu diesen in demselben Verhältnis wie der vorher (S. 27) besprochene Biotit-Plagioklas-Schiefer zu den Biotit-Plagioklas-Konkretionen des Gneises.

Obwohl mehrere der oben erwähnten Amphibolitvarietäten ein wenig Quarz enthalten, scheinen doch die eigentlicnen Quarz-Amphibolite eine recht gut abgegrenzte Parallelreihe zu bilden. Ausser durch den grösseren Quarzgehalt weichen sie durch geringere Beteiligung der Hornblende im Verhältnis zu dem Plagioklase $a b$; die Hornblende zeigt meistens einen kräftigeren Stich ins Bläuliche, und Magnetit ist ein selten fehlender Übergemengteil. Als Haupttypus der Quarz-Amphi- bolite können die Amphibolite der Lomberg-Granulite (Nr. 11) aufgestellt werden. Der Plagioklas ist ein zonar gebauter Andesin $\left(\mathrm{An}_{40} \mathrm{Ab}_{60}-\mathrm{An}_{36} \mathrm{Ab}_{64}\right)$, der auch in sonst ganz frischen Proben immer mehr oder weniger weit getrübt erscheint und sehr zu Epidotbildung neigt. Der Magnetit bildet vereinzelte, grosse, bis zu $5 \mathrm{~mm}$ messende Körner, und Titanit ist ziemlich reichlich vorhanden.

In gewissen Abänderungen, die als Quarz-Magnetit-Amphibolite bezeichnet werden können (Nr. 12-13), kann sich der Magnetit und der Quarz auf Kosten der Hornblende bedeutend anreichern, wodurch schliesslich Gesteine von ziemlich heller Farbe und hornblendegranulitischem Aussehen entstehen können. Derartige Varietäten kommen vielfach in den $\mathrm{Z}_{w i}$ schenbändern der Apatiterz-Linsenkomplexe bei Grängesberg vor. Ähnliche, z. T. biotit-reiche Gesteine mit kräftig bläu- 
lichen Hornblenden (Nr. 14) scheinen in gewissen skarnerzführenden Gesteinszügen, z. B. in dem grünsteinreichen Björnberger Erzzug, eine grosse Verbreitung zu haben.

Unter den Quarz-Amphiboliten sind homogene Gesteine mit saureren Plagioklasen (sauren Andesinen oder Oligoklasen) nicht angetroffen worden. Wahrscheinlich waren Gesteinszüge von solcher ursprünglicher Zusammensetzung zu einer weiteren Differentiierung sehr geneigt, wobei die salischen Bestandteile sich als Plagioklasgranulite und Oligoklasite ausschieden, während die femischen Gemengteile in der Form von basischeren Amphiboliten und Hornblendeskarnen konzentriert wurden.

In diesem Zusammenhang sind noch zu erwähnen einige seltene amphibolitische Gesteinsvarietäten, in welchen die gemeine Hornblende zum kleineren oder grösseren Teil durch einen hellen monoklinen ( $\mathrm{Mg}$, Fe)-Amphibol ersetzt worden ist. Ein derartiger Klinoanthophyllit-Amphibolit wurde in den granulitischen Plagioklasgneisen an dem Hochofen zu Björnhyttan beobachtet. Das etwas gebänderte graugrüne Gestein besteht aus einem gerade auslöschenden Oligoklas $\left(\mathrm{An}_{21} \mathrm{Ab}_{79}\right)$ und zwei Amphibolarten, einer hellfarbigen mit wenig merkbarem Pleochroismus und kräftiger Doppelbrechung $(\gamma-\alpha$ etwa $=0.030)$, einer anderen von kräftig bläulich-grüner Farbe; dazu lagenweise angehäufter Magnetit und Apatit nebst ein wenig Orthit und Biotit; Quarz reichlich in gewissen Bändern. Die beiden Amphibole sind meistens zu prismatischen Kristallen verwachsen, deren mittlere Teile aus der hellen Art bestehen, während der an Menge etwas untergeordnete grüne Amphibol an den Enden abgesetzt ist; beiden Amphibolen ist dabei gemeinsam eine Auslöschungsschiefe $c: c=17-18^{\circ}$ und eine feine $\mathrm{Ab}$ sonderung nach (001), welche Fläche meistens auch als Verwachsungsebene dient. ${ }^{1}$ In den Plagioklasgranuliten zwischen

1. Ganz ähnliche zweiamphibolige Amphibolite finden sich anf dem Eisenerzfeld za Flogberget (im NO von dem Grängesberg gebiet); durch eine bisher nicht publizierte Gesteinsanalyse ist die Klinoanthophyllit-Natur des hellen Amphibolgemengteils in diesem Fall unzweidentig dargetan worden. 
Björnberget und Öraberget sind Gesteine beobachtet worden, die ganz aus Oligoklas mit eingestrenten garbenartigen Anhäufungen eines. dünnnadeligen Klinoantbophyllites bestehen (Fig. 24, Taf. 4).

Von Amphiboliten des Grängesberggebietes sind die folgenden zwei Analysen von GraBE ausgeführt worden:

\begin{tabular}{|c|c|c|c|}
\hline . . . 49.68 & 82.25 & & \\
\hline . . . & 0.88 & . . . . & . . . . 10.8 \\
\hline $\mathrm{Al}_{2} \mathrm{O}_{3} \cdot \cdot \cdot 16.40$ & 16.05 & $\mathrm{Ab} . . . .25 .44$ & $\mathrm{Ab} \cdot \cdot \cdot .43 .8$ \\
\hline $\mathrm{Fe}_{2} \mathrm{O}_{3} \ldots .$. & 2.16 & An :. . . . 27.98 & An . . . . 45.4 \\
\hline $\mathrm{FeO} . .$. & 1086 & $\Sigma$ sal $\quad 60.06$ & \\
\hline $\mathrm{MnO}$ & 10.00 & $\mathrm{CaSiO}_{3} \cdot . \cdot 9.16$ & $\Sigma \mathrm{F} . . .22 .07$ \\
\hline $\mathrm{MgO}$ & 15.50 & $(\mathrm{MgFe}) \mathrm{SiO}_{3} \quad(14.55)$ & $\mathrm{CaSiO}_{3} \cdot .7 .87$ \\
\hline $\mathrm{CaO}$. & 18.11 & $(\mathrm{MgFe})_{2} \mathrm{SiO}_{4} \cdot(8.29)$ & $(\mathrm{MgFe}) \mathrm{SiO}_{3} \quad 13.09$ \\
\hline $\mathrm{Na}_{2} \mathrm{O}$ & 4.83 & $\mathrm{FeTiO}_{3} \cdot . . \quad 1.33$ & $(\mathrm{MIgFe})_{2} \mathrm{SiO}_{4} \quad 5.12$ \\
\hline . . . & 1.19 & $\mathrm{Fe}_{3} \mathrm{O}_{4} \ldots \ldots .02$ & \\
\hline $\mathrm{P}_{2} \mathrm{O}_{5} \cdot \cdots \cdot$ & $(0.21)$ & Apatit. . . 0.21 & III $: 5:$ III + $: 4^{+}$ \\
\hline Gl. V. . . . . & & $\Sigma$ fem. $\quad 38.56$ & Camptonos \\
\hline 100.13 & & 98.62 & \\
\hline
\end{tabular}

\begin{tabular}{|c|c|c|c|}
\hline . . . . 50.29 & 83.26 & & \\
\hline . . . . 1.35 & 1.69 & $\mathrm{Or} \cdot \cdot \cdot \cdot$. & Or $\cdot \cdot \cdot$ \\
\hline $\mathrm{Al}_{2} \mathrm{O}_{3} \ldots . .16 .00$ & 15.66 & $\mathrm{Ab} \cdot . \cdot . \cdot 27.48$ & $\mathrm{Ab} \cdot . \cdot 48.5$ \\
\hline $\mathrm{Fe}_{2} \mathrm{O}_{3} \ldots . \cdot 2.14$ & 1.34 & An . . . . 27.29 & An . . 45.4 \\
\hline$\cdot \cdot$ & 1200 & $\Sigma$ sal 58.45 & \\
\hline MnO & & $\mathrm{CaSiO}_{3} \cdot . \quad \cdot 9.37$ & $\Sigma \mathrm{F} . . .21 .63$ \\
\hline . $\quad 5.92$ & 14.80 & $(\mathrm{MgFe}) \mathrm{SiO}_{3}$ & $\mathrm{CaSiO}_{3} \cdot .8 .05$ \\
\hline $\mathrm{CaO}$. & 18.25 & $(\mathrm{MgFe})_{2} \mathrm{SiO}_{4} \cdot(5.53)$ & $(\mathrm{MgFe}) \mathrm{SiO}_{3} \cdot 17.05$ \\
\hline $\mathrm{Na}_{2} \mathrm{O}$ & 5.22 & $\mathrm{FeTiO}_{3} \cdot . \quad . \quad 2.57$ & $(\mathrm{MgFe})_{2} \mathrm{SiO}_{4} \quad 3.36$ \\
\hline $\mathrm{K}_{2} \mathrm{O}$ & 0.66 & $\mathrm{Fe}_{3} \mathrm{O}_{4} \ldots$ & \\
\hline $\mathbf{P}_{2} \mathbf{O}_{5}$. . . . & $(0.42)$ & Apatit. . . 0.42 & III : כ̌ : III + : 5 - \\
\hline Gl. V. . $\quad . \quad 1.52$ & & $\Sigma$ fem 40.16 & Ornos \\
\hline 100.11 & & 98.61 & \\
\hline
\end{tabular}

Leider wurden zu den Analysen zwei nur wenig ver. schiedene Gesteine ausgewählt, die beide zu den basischeren Andesinamphiboliten gehören. Die erste Analyse bezieht sich 
auf einen Amphibolit innerhalb der Exportfeld-Granulite auf der westlichen Seite von Ormbergstjärn, die zweite auf ein Gestein aus den roten Granulitgneisen bei Orrleksdammen. Der Mineralbestand der beiden Gesteine ist unter Nr. 2 und 3 in der Tabelle S. 72 angeführt. In dem Chemismus sind sie einander sehr ähnlich; das erstere Gestein enthält einen etwas basischeren Plagioklas und ist durch grössere zersetzte Plagioklaskörner weiss gesprenkelt. Ein Vergleich der Analysenberechnungen mit dem volumenometrisch ermittelten Mineralbestand bringt die ziemlich sabnormative» Ausbildung dieser Gesteine zum Vorschein. Während nach den Analysen die salischen und femischen Molekeln etwa im Verhältnis 60:40 gemengt sind, ist das quantitative Verhältnis zwischen den salischen und femischen Mineralgemengteilen nur etwa wie $40: 60$. Es haben sich demnach in der grünen Hornblende der Gesteine $20 \%$ salische als Feldspate zu berechnende Molekel mit den ortho- und metasilikatischen (MgFeCa)-Molekeln kombiniert; demzufolge ist auch der optisch ermittelte Plagioklas um etwa $8 \%$ An-ärmer als der aus den Analysen zu berechnende. Wenn man den Mineralbestand der Amphibolite ebensowohl wie denjenigen der mineralogisch ähnlich ausgebildeten Diorite oder gangförmigen Malchite als das Endprodukt eines magmatischen Kristallisationsprozesses aufzufassen berechtigt ist, dürfte derselbe jedenfalls erst nach durchgreifenden Umsetzungen zwischen festen und flüssigen Phasen während des Kristallisationsprozesses zustande gekommen sein, was gewiss nur bei ziemlich langsam vorgehender Kristallisation möglich ist.

Es ist leicht zu sehen, dass die analysierten Amphibolite im Vergleich mit echten gabroidischen Grünsteinen einen entschieden An-ärmeren Charakter zeigen. Während letztere Gesteine in dem amerikanischen Systeme grösstenteils unter den "Hessosen» und „Auvergnosen» zu suchen sind, gehören unsere Amphibolite zu den `Ornosen» oder zu angrenzenden Gliedern unter den etwas kalireicheren "Camptonosen.» Und doch re- 
präsentieren die analysierten Gesteine nur die An-reichsten und basischsten Glieder der ganzen Reihe. Wenn man auch die An-ärmeren Glieder bis zu den einfachen Oligoklasiten berücksichtigt, muss die ganze Amphibolitreihe als eine recht eigentümliche natronreiche Grünsteinreihe aufgefasst werden, die unter bisher bekannten Gesteinsformationen nur sehr spärliche Analoga haben.

Es bleibt noch übrig, die geologische Erscheinungsform der Amphibolite zu erörtern. Infolge der Seltenheit von grösseren zusammenhängenden Aufschlüssen ist es zwar im allgemeinen nicht möglich, den Verlauf der einzelnen Amphibolitbänke

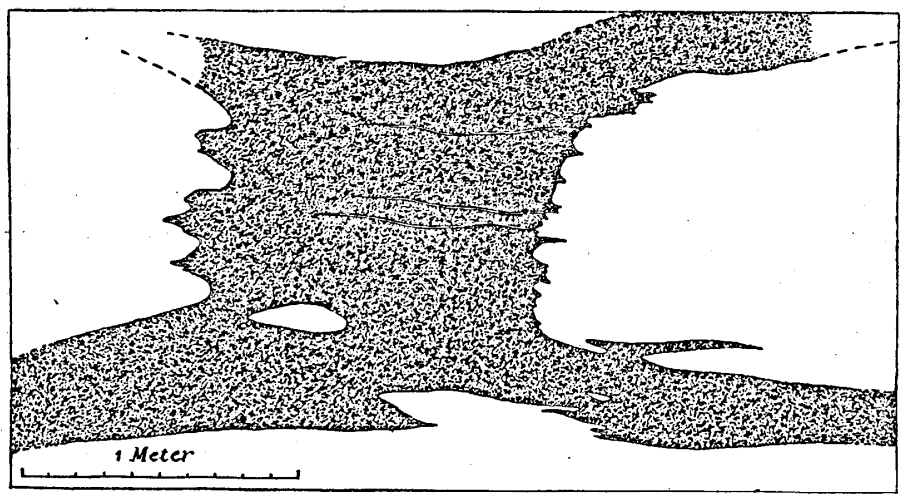

Fig. 9. Amphibolit im roten Granulitgneis am Südufer des Orrleksdammen.

auf weitere Strecken zu verfolgen; die unzähligen kleineren Aufschlüsse bieten indessen so überreinstimmende und charakteristische Verhältnisse dar, dass sich daraus ein Gesamtbild von der allgemeinen Erscheinungsart dieser Gesteine gut rekonstruieren lässt.

Fig. 9 veranschaulicht die Verwebungsart der Amphibolite innerhalb des sehr amphibolitenreichen Granulitgneiszuges am Orrleksdammen. Der abgezeichnete Amphibolit bildet eine etwas breitere Partie, die in den Granulitgneis in seinem Streichen eingeschoben ist und mit zackigem Kontakt scharf gegen das helle Gestein absetzt. Von diesem »Knotenpunkt» aus ver- 
zweigen sich schmälere langgezogene Äste, die, wenn es die Bedeckung gestattete, ohne Zweifel sich bis zu einem neuen ¿Knotenpunkt verfolgen lassen würden, wo sie sich mit anderen ähnlichen Ästen vereinigten. In dieser Weise scheint in der Tat der ganze Granulitgneiszug in kleinere oder grössere unregelmässige Gneispartien zerstückelt $\mathrm{zu}$ sein, um welche die dunklen Gesteine mit charakteristischen zackigen Kontakten netzartig herumlaufen. Wenn eine deutlichere Parallelstruktur in dem Granulitgneis zum Vorschein kommt, ist sehr hänfig zu sehen, wie die amphibolitischen Zwischenbänder die Flaserigkeit des Granulitgneises schief überqueren; wenn dann eine Orientierung auch in den Amphiboliten vorhanden ist, verläuft dieselbe, ganz unabhängig von der Flaserigkeit des Gneises, mit der Richtung der Amphibolitbänder konform. So lange man nur derartige schief überquerende amphibolitische Zwischenbänder zu sehen Gelegenheit hat, möchte man dieselben vielleicht als Gänge ertlären wollen, die den schon erstarrten Granulitgneis durchbrochen haben; wenn man indessen mit der ganzen Verwebungsart vertraut wird, erweist sich eine derartige Auffassung als durchaus ungenügend. Gerade in dem hier behandelten Granulitgneiszug zeigen die mehrfach zu beobachtenden, von den hellen Gesteinspartien in die dunklen hineinragenden aderartigen Apophysen, die sich bisweilen bis zu breccienartigen Verwebungen steigern können, dass es eben die helle Gesteinskomponente ist, die dem etwas später erstarrten Gestein entspricht.

Die Amphibolite innerhalb der anderen Granulit- und Gneiszüge bieten der Hauptsache nach übereinstimmende Verhältnisse dar. Der in Fig. 10 wiedergegebene Amphibolit aus den Exportfeldgranuliten im Liegenden des Tagebaus Skärningen lässt ebenfalls die charakteristichen zackigen oder gefranzten Kontakte und die schief verlaufenden $Z$ wischenbänder erkennen; nur ist der ganze Gesteinskomplex viel mehr gestreckt und ausgewalzt. Auch den anderen Gesteinen - 
Erzen, Skarnen, Kalksteinen, - gegenüber verhalten sich die Amphibolite auf ganz dieselbe Weise (vergl. Fig. 12, S. 102 und Fig. 18, S. 116). In den Apatiterz-Linsenkomplexen bei Grängesberg treten sie reichlich als $Z$ wischenbänder auf; die erzleeren Querbänder, durch welche der Exportfelder Erzkomplex einige Male unterbrochen ist, stellen der Hauptsache nach Amphibolit-»Knotenpunkte» der oben beschriebenen Art dar.

Die Erscheinungsform dieser A mphibolitverwebungen könnte etwa zu den folgenden Vorstellungen über ihre Entstehung Veranlassung geben. Es waren die Gesteinskomponenten der jetzigen Komplexe ursprünglich ineinander gelöst. In diesen magmatischen Lösungen trat dann eine zentrifugale Entmischung

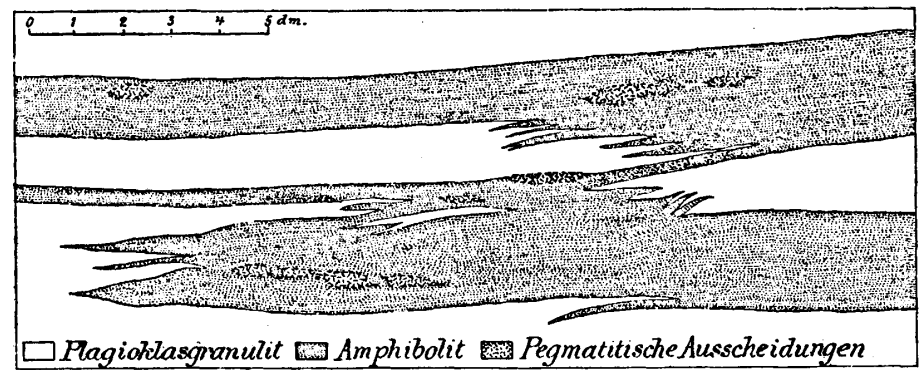

Fig. 10. Amphibolit und Exportfeld-Granulit im Liegenden der Grube Skärningen.

ein, wodurch der salische Anteil zu grösseren oder kleineren Zentren konzentriert wurde, die von einander durch Kränze aus dem femischen Magmateil mehr oder weniger vollständig abgeschlossen waren, etwa in der Weise, wie die femischen Mineralgemengteile in einem zentrisch struierten Augengranit angeordnet sind. Durch Bewegungen während des Entmischungsprozesses und nach demselben wurde die zentrische Anordnung indessen zu einer mehr oder weniger gestreckt linsenförmigen deformiert, die etwa mit der Anordnung der Gemengteile eines flaserigen Augengneises verglichen werden könnte. 
Die Granulit-Amphibolit-Verwebung wäre nach dieser Auffassung als eine besondere und interessante Abart unter den in der Natur so mannigfaltig entwickelten Assoziationsformen zwischen komplementären salischen und femischen Gesteinen z. B. der Erscheinung der »gemischten Gänge» oder der Granophyrgranit-Diabas-Verwebungen oder auch der gebänderten Abwechslung zwischen den hellen Granatgranuliten und den dunklen Noritgranuliten innerbalb der sächsischen Granulitformation an die Seite zu stellen. Es scheint mir in der angedeuteten $\mathrm{W}$ eise nicht schwierig, die oben beschriebenen Erscheinungen, wie die "Knotenpunkte», die schief überque-

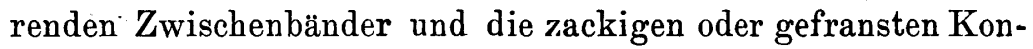
takte, zu verstehen. Diese Auffassung lässt auch die mehrfach manifestierte .Blutsverwandtschaft zwischen den Amphiboliten und den assoziierten Gesteinen zu ihrem Recht kommen und ermöglicht schliesslich die weite und regelmässige, fast regionale Verobreitung der Erscheinung zu erklären. Für die Deutung der Granulit-Amphibolit-Erscheinung scheint mir ein Studium der Gesteinsentwickelung innerhalb des N. Hammargrubengebietes sehr instruktiv zu sein. Es liegt auf der Hand, dass die Granulit-Ampbibolit-Verwebungen ganz ähnliche Erscheinungen wiedergeben, wie sie in etwa 100 : facher Verkleinerung in den inhomogenen Gesteinen des letztgenannten Gebietes zu sehen sind. Wenn wir die Ausbildung letzterer Gesteine als eine eutaxitische bezeichnen, können wir die Erscheinungsform der Granulit-Amphibolit-Komplexe als eine Eutaxit-Architektur bezeichnen.

Eine derartige Eutaxit-Architektur ist nach meinen Beobachtungen für fast die ganze eisenerzführende Formation des südlichen Dalekarliens und der angrenzenden Teile des Läns Örebro in hohem Mass bezeichnend. Es scheint in dieser Hinsicht eine ausgesprochene Verschiedenheit zwischen den genannten Gebieten und gewissen weiter südlich gelegenen Erzbezirken, z. B. dem Striberg- und vor allem dem Åmmeberg-Gebiet, zu bestehen, wo die Grünsteine ebensowobl wie alle anderen Glie- 
der der erzführenden Gesteinsreibe zu langgezogenen, konformen, gewundenen Bändern angehäuft sind.

\section{Die Skarngesteine.}

Skarngesteine von kompakterer Ausbildung und weiterer Ausdehnung kommen nur in den sskarnführenden Granulitzügen, vor allem in dem Norsberggebiet vor. Bei weitem am häufigsten sind mehr oder weniger dunkelfarbige Hornblendeskarne, die fast ganz aus einer kurzprismatischen gemeinen Hornblende nebst etwas Orthit und Titanit bestehen. Varietäten mit sehr dunkelfarbigen Hornblenden enthalten öfters etwas Plagioklas und Quarz als ein untergeordnetes Gewebe zwischen den Hornblendeanhäufungen. Durch Zutreten von gewissen Gemengteilen, wie Pyroxen, Granat, Epidot, Biotit, entsteht indessen gleichwie unter den Amphiboliten eine mannigfaltige Variationsreihe. Diese Gemengteile sind hier und da mit nur wenig Hornblende vermengt als besondere Skarnvarietäten ausgesondert, die im ganzen in unserem Gebiete jedoch nur eine beschränkte Verbreitung haben. In der Nähe von Eisenerzanhänfungen erweisen sich die Skarne immer mehr oder weniger reichlich magnetitimprägniert. -

Die geologische Erscheinungsform der Hornblendeskarne bietet manche Analogien mit derjenigen der Amphibolite dar; nur sind sie noch unregelmässiger begrenzt, wozu kommt, dass sie fast niemal's scharf gegen die Granulite absetzen, sondern durch inhomogene,' schlierige oder breccienartige Mischgesteine mit ihnen verknüpft erscheinen, wie es vorher (S. 58 -65) beschrieben wurde; an manchen Lokalen sind sie auch in engem Zusammenhang mit Amphiboliten oder sogar dioritischen Gesteinen zu sehen. Sowohl die geologischen als die chemischen Verhältnisse deuten darauf, dass die Bildungsart der Hornblendeskarne eine von derjenigen der Amphibolite nicht prinzipiell verschiedene ist. Die Ursachen dafür, dass gewisse Gesteinszüge als Granulit-Hornblendeskarn-Komplexe 
statt als Granulit-Amphibolit-Komplexe ausgebildet worden sind, dürften vielmehr nur in gewissen Eigentümlichkeiten des ursprünglichen chemischen Charakters dieser Gesteinszüge zu suchen sein, und es liegt dann sehr nahe, diese verschiedene Aüsbildung mit dem in den meisten skarnführenden Granulitzügen konstatierten extrem natronreichen Gesteinscharakter zusammenzustellen. Wie die Skarnbildung von diesem Gesichtspunkt aus erklärt werden kann, soll später in Zusammenhang mit der allgemeinen Diskussion der chemischen Gesteinscharaktere etwas näher erörtert werden.

Ausserhalb der sskarnführenden Granulite» kommen meistens nur unbedeutende und wenig gesammelte Skarnbildungen vor. Als Beispiele sind erstens zu erwähnen die aus Hornblende, Pyroxen, Biotit, Titanit, Granat u. ä. m. bunt zusammengesetzten Skarnanhäufungen des N. Hammargrubengebietes und die kleinen Amphibolskarnbildungen in den Exportfelder Eisenerzen, die ebenfalls in natronreichen Gesteinszügen auftreten; dann weiter die quarzigen Granat-EpidotAmphibol-Skarnanhäufungen der Granat-Epidot-Granulite und einige ähnliche granatreiche Skarnbildungen im Lombergfelde (z. B. an der Grube Vattenflaskan), im Gudmundbergfelde, im Fredmundberget (z. B. an der Köpmanngrube) und im Finnäsfelde (an der Byberggrube), die zu den an Kali und Kalk reicheren Granulitzügen gehören.

Eine interessante Abteilung unter den Skarngesteinen bilden die Biotitskarne, die fast reine Biotitgesteine darstellen; ein ausserhalb der mittelschwedischen Eisenerzformation wohl nur selten beobachteter Gesteinstypus. Derartige Gesteine kommen als kleinere Bänke vielfach mit den Hornblendeskarnen und Skarnerzen zusammen; ausserdem finden sie sich bei allen Apatiterzgruben mehr oder weniger reichlich mit diesen Erzen assoziiert. Sogar den quarzigen Eisenglanzerzen vom Lombergtypus fehlen sie nicht ganz. Wie ich in meiner früheren Darstellung betont habe, sind es hauptsächlich derartige Biotitgesteine, die als s. g. .Begrenzungsskölar die 7-100170. 
meisten mittelschwedischen Eisenerzvorkommen konform begleiten und darum in der Diskussion über die Genesis dieser Erze ein spezielles Interesse erlangt haben. Bezüglich der Bezeichnung dieser Gesteine als »Skölar» ist hervorznheben, dass unter dem Namen Sköl in der schwedischen Bergbauterminologie und auf den schwedischen Grubenkarten mehrere genetisch verschiedene Dinge zusammengefasst worden sind. Es umfasst dieser Begriff erstens reine Verruschelungsbildungen, die offenbar gar nichts mit der Genesis unserer Erze zu tun haben. Dann werden als Skölar bezeichnet mehrerlei mürbe und talkige Bildungen, die durch Hydrierung gewisser Gesteine, vor allem der Skarne, entstanden sind; eine gewöhnliche Entwickelungsform dieser Skölgesteine sind Talk-Chlorit-Gesteine mit eingetreuten Magnetitoktaëdern, deren Entstehung wohl meistens einer Umwandlung von Amphibolskarnen zuzuschreiben ist. Diesen beiden Arten von Skölbildungen sind gemeinsam die lockere Beschaffenheit und die den normalen Gesteinen der erzführenden Formation gegenüber unzweifelhaft sekundären Charaktere. Dies trifft indessen im allgemeinen nicht mehr zu bezüglich der dritten und wichtigsten Art von Skölgesteinen, der konform verlaufenden Begrenzungsskölar oder Seitenskölar. Wie ich mich bei einer grossen Zahl Erzvorkommen überzeugt habe, hat man in diesen Skölbildungen mit Biotitgesteinen zu tun, die nach ihrer ganzen Beschaffenheit und Erscheinungsart in geognostischer und genetischer Hinsicht durchaus integrierende Glieder der eisenerzführenden Gesteinsreihe darstellen und die dann nach ihrem chemisch-mineralogischen Charakter nur als eine besondere Abteilung unter den Skarngesteinen am besten einzureihen sind. Dass eben diese Biotitskarne im Gegensatz zu anderen Skarnvarietäten mit verschiedenen, genetisch recht ungleichartigen Bildungen unter dem Namen sSkölar» zusammengestellt worden sind, dürfte davon herrühren, dass sie öfters, speziell an ihren Kontakten mit den Eisenerzen, sehr gute Ablösungen darbieten, nach welchen wahrscheinlich auch 
Bd 32. H. 2.] FISENERZFÜHR. FORMATION VON ORÄNGESBERG.

in manchen Fällen kleinere spätere Gleitungen und Verschiebungen sich vollzogen haben; dadurch wurden sie mehr oder weniger aufgelockert und zu Zersetzungen geeignet. Gleichwie die anderen Skarnarten haben die Biotitskarne somit bisweilen durchgreifende Hydrierungsprozesse (Chloritisierung) durchgemacht; es scheint indessen, dass für diese Gesteine die Bezeichnung „Chloritskölar» eine weit grössere Anwendung gefunden hat, als es der tatsächlichen Beschaffenheit der Gesteine entspricht; innerhalb unseres Gebietes zeigen die Biotitskarne nur ausnahmsweise Andeutungen von solchen Umwandlungen.

\section{Die Kalksteine.}

Das Grängesberggebiet ist nicht sehr reich an Kalksteinen. Die grössten Vorkommen sind im Norsbergfelde gelegen; andere Vorkommen finden sich in den Öraberggranuliten, an der Långgrube im Björnberget, an den Pullerogruben und an einigen Lokalen in der südlichen Fortsetzung des Björnberger Gesteinszuges. Dazu kommen die kleinen Kalksteine westlich von Täppan und einige Vorkommnisse in der Umgegend von B:s Hörken.

Die Gesteine zeigen einen immer rasch variierenden $\mathrm{Mi}$ neralbestand mit abwechselnden reichlich serpentin-, glimmer- oder amphibolführenden Varietäten und reineren karbonatischen Bändern. Spinell wurde in einem noch olivinhaltigen Serpentinkalkstein aus Öraberget beobachtet; eine Varietät mit smaragdgrünem fuchsitischem Glimmer kommt bei Pullero Limgrube vor. Die mit Kalkeisenerzen assoziierten Kalksteine im Björnberget und bei Pullero sind öfters selbst mit Magnetit imprägniert. Pyroxenkalksteine scheinen dagegen zu fehlen; möglicherweise hängt dies damit zusammen, dass den vorhandenen Kalksteinen nach den allerdings nur wenig eingehenden Untersuchungen, die diesen Gesteinen bisher gewidmet werden konnten, etwas Dolomitspat beigemengt zu sein scheint; bei solchen Kalksteinen dürfte im allgemei- 
nen eine Tendenz, statt Pyroxene Amphibole auszuscheiden, bestehen:

$$
2 \mathrm{CaMg}\left(\mathrm{SiO}_{3}\right)_{2}+\mathrm{CaMg}\left(\mathrm{CO}_{3}\right)_{2} \rightarrow \mathrm{CaMg}_{3}\left(\mathrm{SiO}_{3}\right)_{4}+2 \mathrm{CaCO}_{3} \text {. }
$$

Innerhalb der Kalksteine oder an deren Kontakten mit Amphiboliten kommen indessen skarnartige Anhäufungen von Pyroxen mit rotbraunem Granat häufig vor.

Sämtliche Kalksteine des Gebietes sind an die skarnführenden Granulitzüge gebunden. Ihre geologische Erscheinungsart stimmt mit derjenigen mancher Eisenerze nahe überein. Niemals sind die einzelnen Kalksteinbänke auf weitere Erstreckungen zusammenhängend zu verfolgen, sondern sie bilden Komplexe aus nach und neben einander angehäuften kleineren Linsen mit Zwischenbändern aus Amphiboliten, seltener auch aus skarnschlierigen Granuliten oder Amphibol-GranatPyroxen-Skarnen. Diese Kalkstein-Amphibolit-Granulit-SkarnKomplexe bieten offenbar ganz ähnliche Verhältnisse dar wie die Apatiterz-Amphibolit-Granulit-Komplexe des Exportfelder Erzzuges. Eine derartige intime Asșoziation zwischen körnigen Kalksteinen und Amphiboliten ist übrigens nicht auf das Grängesperggebiet beschränkt; sie findet sich in allen Kalksteinvorkommen im südlichen Dalekarlien wieder, die ich zu besuchen Gelegenheit gehabt habe, und scheint überhaupt für diejenigen Karbonatgesteine, die an die skarnführenden Gesteinszüge des Mittleren Schwedens gebunden sind, eine sehr konstante und bemerkenswerte Erscheinung zu sein.

\section{Die Eisenerze.}

Unser Kartengebiet darf unzweifelhaft als das an Eisen: erzen reichste Gebiet innerhalb der mittelschwedischen Eisenerzprovinz bezeichnet werden. Dies trifft zu besonders mit Rücksicht auf die Grösse des in diesem Gebiet vorhandenen Erzvorrates, aber auch in Bezug auf die Anzahl und Häufig. keit der Erzvorkommen muss es als eine sehr grubenreichè 
Gegend angesehen werden. Auf der Übersichtskarte Taf. 8 ist ein. Versuch gemacht, die Lage der verschiedenen. Gruben oder Grubenkomplexe anzudeuten, soweit meine eigene Beobachtungen ausreichen; gewiss wären noch mehr Gruben zu verzeichnen gewesen, wenn die mehr peripherischen Teile des Gebietes in allen Details hätten durchstreift werden können. Was den chemisch-mineralogischen Charakter der Erzvorkommnisse betrifft, so sind Repräsentanten für die meisten aus Mittelschweden bekannten Eisenerztypen in diesem Gebiete beobachtet. Bei dem Studium der vorhandenen Erzvarietäten hat sich indessen eine detailliertere Einteilung und schärfere Fixierung der bisher aufgestellten Erztypen als wünschenswert herausgestellt. Aus diesen Gründen möchte ich an dieser Stelle der Beschreibung der Erzvorkommnisse eine allgemeine Übersicht über die Systematik der mittelschwedischen Eisenerze vorausschicken.

\section{Über die chemisch-mineralogische Systematik der mittel- schwedischen Eisenerze.}

Die erste Begründung der jetzigen Systematik für die mittelschwedischen Eisenerze rührt von A. SJögreN her (G. F. F. 2 [1874]:5), der für diese Erze die folgenden drei Hauptabteilungen aufstellte:

I. Quarz- und feldspathaltige Eisenerze.

II. Pyroxen- und hornblendehaltige Eisenerze.

III. Manganhaltige und kalkige Eisenerze.

In den Erläuterungen zu der TöRnEBonm'schen Übersichtskarte wurde die grosse Mannigfaltigkeit der vorhandenen Erzvarietäten dargetan, obwohl kein Versuch, die Systematik weiterzuführen, unternommen wurde. Der erste. Versuch einer detaillierteren Gliederung dieser interessanten Gesteinsreihe wurde von O. B. Santesson in seiner Beschreibung der wichtigeren Grubenfelder im Län Örebro (S. G. U. Ser. B b, N:r 4, 1889) gemacht; zur näheren chemischen Definierung der auf- 
gestellten Erztypen wurden auch die vorhandenen Erzanalysen benutzt. Unter Absehen von gewissen geognostischen Einteilungsgründen, die von Santesson eingemengt waren, die sich aber später als ziemlich unfruchtbar erwiesen baben, kann das von Santesson gegebene Klassifizierungsschema folgendermassen wiedergegeben werden:

1. Quarzige Eisenerze.

a. Quarzgebänderte Eisenglanzerze von StribergTypus.

b. Dünnschieferige Eisenglanzerze von PershytteTypus.

c. Körnige Eisenglanzerze von 'Stråssa-Typus.

d. Schuppige Eisenglanzerze von Lomberg-Typus.

2. Chlorit- und feldspathaltige Eisenerze.

a. Feinkörnige Eisenglanzerze von Blanka-Typus.

b. Schuppige Eisenglanzerze von Åboberg-Typus.

3. Hornblende- und pyroxenhaltige Eisenerze von Lerberg-Typus.

4. Magnesiareiche Eisenerze von Rösberg-Typus.

5. Kalzithaltige Eisenerze von Sikberg-Typus.

6. Dolomithaltige Eisenerze von Högborn-Typus.

7. Manganreiche Eisenerze von Viker-Typus.

In den älteren Klassifikationen wurden die Apatiteisenerze des südlichen Dalekarliens nicht besonders beriicksichtigt, sondern meistens mit den quarzigen Erzen vereinigt. Von HJ. SJöłRen (G. F. F. 15 [1893] : 483) wurden diese Erze als eine neue Hauptabteilung den drei von A. SJögren aufgestellten Abteilungen angereiht. Später hat HJ. SJöGREN (G. F. F. 28 [1906] : 314) auch die tonerdereichen quarzigen Erze als eine selbständige Hauptabteilung aufstellen wollen.

In meiner früheren Darstellung (G. F. F. 29 [1907]: 169-186 und 285-300) wurde in Übereinstimmnng mit der älteren von HJ. SJöGReN gegebenen Einteilung die Gliederung in die 4 Hauptgruppen: Apatiteisenerze, Quarzeisenerze, Skarneisenerze 
Bd 32. H. 2.] EISENERZFÜHR. FORMATION VON GRÄNGESBERG.

und Kalkeisenerze beibehalten. Bezüglich der Quarzeisenerze wurde durch eine graphische Darstellung gezeigt, wie die schon von Santesson unterschiedenen Strukturtypen auch chemisch-mineralogisch definiert werden können. Es wurden demnach diese Erze in zwei Reihen gegliedert: eine verhältnismässig $\mathrm{Al}_{2} \mathrm{O}_{3}$-reiche und $\mathrm{CaO}$-arme, gleichzeitig auch durch die Neigung zu gleichmässiger, schuppiger (Eisenglanzerze) oder körniger (Magnetiteisenerze) Struktur gekennzeichnet; die andere relativ $\mathrm{Al}_{2} \mathrm{O}_{3}$-arm und $\mathrm{CaO}$-reich, gleichzeitig durch die Neigung zur quarzgebänderten Ausbildung charakterisiert. Unter den Erzen der ersteren Reihe wurden die ( $\mathrm{Mg}, \mathrm{Ca}) \mathrm{O}$ armen, neben Quarz hauptsächlich Alkalifeldspat und Muskovit enthaltenden Erze des Lomberg-Pershytte-Typus von den etwas basischeren Erzen des Stråssa-Typus unterschieden. Die quarzgebänderten Erze wurden in 3 Abteilungen gegliedert, der sehr saure Striberg-Typus, der an Ca Fe-Granat ziemlich reiche Norberg-Typus und der etwas CaO-ärmere Stripa-Typus, der neben Quarz Amphibol, Epidot und Granat enthält. Unter den Skarneisenerzen wurden 5 Abteilungen aufgestellt: Quarz-Amphibolerze, Amphibolerze, Pyroxenerze, Magnesiaskarnerze und Manganskarnerze. Die Kalkeisenerze wurden zunächst in eine manganarme und eine manganreiche Reihe gegliedert; unter der ersteren Reihe wurden die Serpentin-Kalkeisenerze des Sköttgrube-Typus von den Amphibol-Kalkeisenerzen des Sikberg-Typus abgetrennt; unter den Mangan-Kalkeisenerzen wurden die silikatreicheren Erze des Ställberg-Viker-Typus von den reineren Karbonaterzen des Klackberg-Typus abgeschieden.

Wie ich in meinem Aufsatz schon hervorgehoben habe, war die von mir vorgeschlagene Einteilung in gewissen Teilen, speziell bezüglich der Skarneisenerze, nur als eine vorlänfige aufzufassen. Um eine sichrere Basis für die Klassifizierung zu erreichen, habe ich seitdem unter Benutzung der vom Järnkontoret herausgegebenen Analysensammlung ${ }^{1}$ wei-

1 Analyser à svenska järn- och manganmalmer. Stockholm 1906. 
tere Berechnungen der vorhandenen Analysen von den wichtigeren mittelschwedischen Eisenerzen ausgeführt. Die Resultate sind graphisch auf Taf. 5 dargestellt. Die Ordinate giebt die Basizität der Erze an, die hier durch das prozentische Verhältnis zwischen der Summe der Molekularzahlen für die bivalenten Oxyde ( $\mathrm{CaO}, \mathrm{MgO}, \mathrm{FeO}, \mathrm{MnO})$ und die Molekularzahlen der Kieselsäure ausgedrückt wird. Für ein ideales Quarzeisenerz entspricht dieses Verhältnis der Ordinate $\mathrm{y}=0$, für ein metasilikatisches Skarneisenerz derjenigen $\mathrm{y}=50$ und für ein reines Karbonateisenerz $\mathrm{y}=100$; die Apatiteisenerze sind von der Darstellung ausgeschlossen. Als Abszisse ist gleicherweise das Verhältnis der CaO-Zahlen zu der Summe der Zahlen der anderen Oxyde ( $\mathrm{MgO}, \mathrm{FeO}, \mathrm{MnO}$ ) gewählt. Dadurch wird unter den Karbonateisenerzen eine Trennung zwischen den hauptsächlich Kalzit oder dolomitische Doppelkarbonate oder endlich einfache ( $\mathrm{Mg}, \mathrm{Fe}, \mathrm{Mn}$ )-Karbonate enthaltenden Typen bewirkt; während gleicherweise die Skarneisenerze sich verschiedenartig gruppieren müssen, je nachdem sie hauptsächlich Kalksilikate (Ca Fe-Granat und Epidot), diopsidische Doppelsilikate, strahlsteinartige Doppelsilikate oder reine ( $\mathrm{Mg}, \mathrm{Fe}, \mathrm{Mn}$ )-Silikate (Olivine, Serpentin, Chlorit, ( $\mathrm{Mg}, \mathrm{Fe}, \mathrm{Mn}$ )-Amphibole und Granate, Biotit oder Talk) enthalten; die spezifisch manganreichen Erze innerhalb dieser beiden Hauptabteilungen sind durch offene Kreise bezeichnet. Unter den Quarzeisenerzen sind die quarzgebänderten Erze durch die Bezeichnung mit offenen Kreisen von den nicht gebänderten Erzen unterschieden. Obwohl das in meiner früher publizierten graphischen Darstellung als Abszisse benutzte Verhältnis $\mathrm{Al}_{2} \mathrm{O}_{3}$ : $\mathrm{CaO}$ offenbar auf die Strukturausbildung der Quarzeisenerze in erster Linie bestimmend einwirkt, geht doch aus dem Diagramm hervor, dass auch das hier als Abszisse benutzte Verhältnis ( $\mathrm{Mg}, \mathrm{Fe}, \mathrm{Mn}$ ) $\mathrm{O}: \mathrm{CaO}$ eine der Hauptsache nach übereinstimmende. Scheidung der beiden Strukturreihen und deren chemisch-mineralogischen Unterabteilungen zu bewirken vermag. Dies erklärt sich daraus, dass 
die Magnesia der Quarzeisenerze meistens in der Form von $\mathrm{Al}_{2} \mathrm{O}_{3}$-reichen Silikaten wie Biotit und Chlorit vorhanden ist, die sich gleichzeitig mit den spezifischen Tonerdeträgern dieser Erze, dem Muskovit und den Alkalifeldspaten, anzureichern pflegen. Ausnahmen bieten einerseits einige etwas quarzgebänderte Erzvarietäten bei Stråssa und bei der Nygrube im Norbergfelde dar, die relativ viel Magnesia als Strahlstein enthalten; andererseits einige $\mathrm{Al}_{2} \mathrm{O}_{3}$-reiche, nicht gebänderte Erze, z. B. in dem Lombergfelde bei Grängesberg, die neben Muskovit und Alkalifeldspat hauptsächlich Kalksilikate wie Epidot enthalten.

Um bei den Erzen, deren Analysenörter auf dem Diagramm angegeben sind, eine schnelle Orientierung über die Art und die Proportionen der eingehenden Lagerartminerale zu ermöglichen, habe ich gleichzeitig auch die Projektionsörter der wichtigeren lagerartbildenden Mineralsubstanzen durch schwarze Kreuze angegeben. Dabei ist allerdings zu bemerken, dass die Projektionsörter beliebiger Mischungen zwischen verschiedenen Mineralen im allgemeinen nicht auf die die Projektionsörter der Minerale verbindende Gerade, sondern auf eine diese Projektionsörter verbindende hyperbolische Kurve fallen. Derartige Kurven sind für einige Mineralkombinationen berechnet und in das Diagramm eingezeichnet worden.

Es liegt auf der Hand, dass die durch chemische Analyse ermittelte Totalzusammensetzung eines Erzes im allgemeinen auf mehrere verschiedenartige Mineralkombinationen zurückgeführt werden kann; welche Kombinationsart die tatsächlich vorhandene ist, muss dann durch spezielle Untersuchungen entschieden werden. Bei gewissen karbonatgemischten Skarnerzen, wie den Erzen von Gubbo, Nordmarken und Finnmossen, könnten die Analysen z. B. ebensowohl auf eine Mineralkombination Magnesit + Diopsid oder Kalzit + Anthophyllit als auf die Kombination Dolomit + Strahlstein zurückgeführt werden. Man kann nur, den Schluss ziehen, dass chemisch übereinstim- 
mende Erze auch dieselbe Mineralkombination enthalten müssen, wenn sie unter gleichartigen Bedingungen auskristallisiert sind. Eine genauere Untersuchung der mittelschwedischen Eisenerze von diesen Gesichtspunkten aus wäre offenbar von grossem theoretischem Interesse; zur Zeit ist leider die Kenntnis von der chemisch-mineralogischen Ausbildung bei mehreren der hier vorhandenen Erztypen eine ganz mangelhafte.

Für die Apatiterze ist eine besondere graphische Übersicht in Fig. 11 gegeben. Die Ordinate giebt ebenfalls die

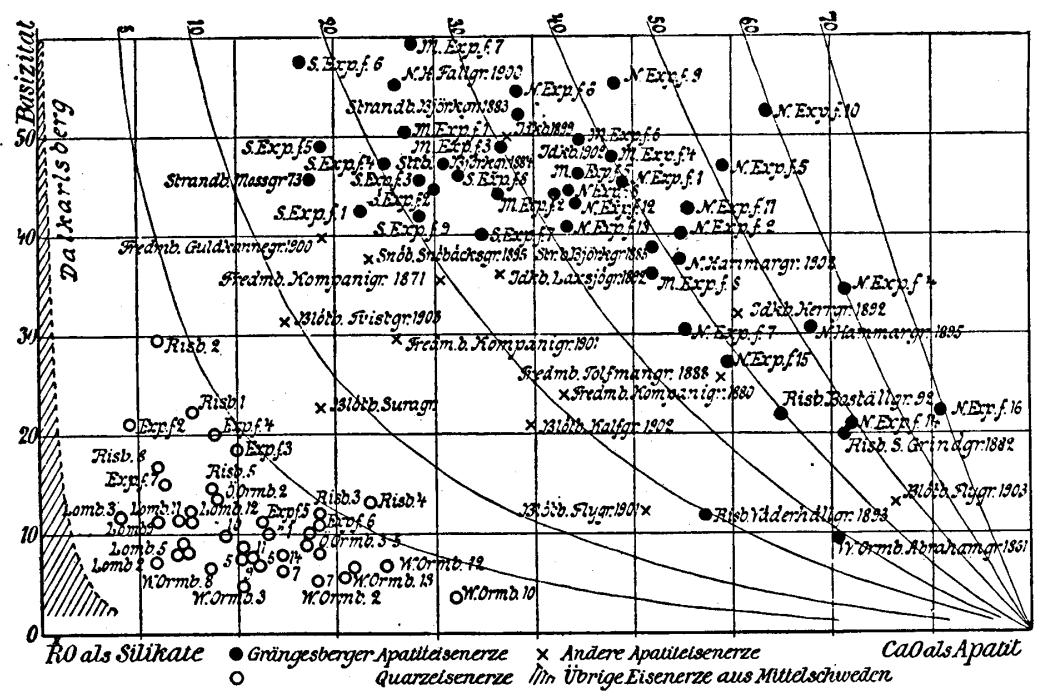

Fig. 11.

Basizität der Erze unter Abrechnung des Apatites an. Die Abszisse stellt als Mass für den Apatitgehalt das molekularprozentische Verhältnis zwischen den als Apatit gebundenen $\mathrm{CaO}$-Zahlen und den als Silikate vorhandenen bivalenten Oxyden dar; die eingezeichneten Kurven zeigen gleichzeitig das Verhältnis zwischen den erstgenannten CaO-Zahlen und der Summe der Molekularzahlen für $\mathrm{SiO}_{2}$ und bivalente Oxyde, das als ein Mass für die Apatitbeteiligung im Verhältnis zu 
Bd 32. H. 2.] EISENERZFÜHR. FORMATION VON GRÄNGESBERG. 93 dèm gesamten Gehalt an Skarnsilikaten, Feldspaten und Quarz gelten könnte.

Aus den beiden Diagrammen dürften die chemischen Gründe für die folgende, etwas erweiterte Systematik der mittelschwedischen Eisenerze leicht $z u$ verstehen sein.

\section{Apatiteisenerze.}

1. Amphibol-Apatiterze von Exportfeld-Typus. Diese Apatiterze zeigen die Basizität der metasilikatischen Skarnerze (Abt. III: b); mineralogisch entsprechen sie dabei zum grössten Teil einer apatitreichen Parallelreihe zu den Strahlsteinerzen des Kallmora-Dalkarlsberg-Typus (III: b: 3). Apatitärmere Übergangsformen zu den Skarnerzen fehlen jedoch ganz; sogar die Dalkarlsberg-Erze, die unter den Skarnerzen eine ungewöhnlich apatitreiche Reihe bilden, nehmen in dem obigen Diagramm einen von den apatitärmsten Exportfeld-Erzen noch weit entfernten Platz ein. Auch in geognostischer Hinsicht sind diese Apatiterze von den Skarnerzen scharf getrennt; dagegen sind sie gleichwie die meisten mittelschwedischen Apatiterze mit Quarzeisenerzen der Reihe II: A öfters geognostisch eng verknüpft. - $\mathrm{Zu}$ diesen Amphibol-Apatiterzen gehört die Hauptmasse der Erze des Grängesberger Exportfeldes einschl. des Strandbergfeldes. Diesen Erzen schliessen sich auch die Erze des N. Hammargruben-Gebietes am nächsten an, weichen aber durch ihren grossen absoluten Apatitgehalt und den Gehalt an dunkleren, kalkreicheren Amphibolen neben grünem Pyroxen, Titanit und sogar Granat ab. Ausserhalb des Kartengebietes ist der Typus bei Idkersberg, weiter nördlich in Dalekarlien, vertreten.

2. Quarz- und feldspatführende Apatiterze von RisbergTypus. Diese Erze stellen apatitreiche Äquivalente gewisser Quarzeisenerze der Reihe II: A dar. Sie sind für die zum Risbergfelde gerechneten, im Liegenden des Exportfelder Erzzuges auftretenden Apatiterzkomplexe bezeichnend, scheinen 
auch im nordwestlichen Teil des Exportfeldes ebensowie im Blötbergfelde in untergeordneter Menge vorzukommen.

3. Apatiterze von Blötberg-Typus. Die relative Apatitbeteiligung ist in diesen Erzen eine geringere, und sie entsprechen gewissermassen einem $Z$ wischentypus zwischen den Apatiterzen des Exportfeld-Typus und den schuppigen oder körnigen Quarzeisenerzen. Neben dem Apatit enthalten sie Biotit oder eine dunkle Hornblende nebst mehr oder weniger reichlichem Quarz und Feldspat. Zu diesem Typus scheinen die Apatiterze bei Blötberget, Fredmundberget und Långblå grösstenteils zu gehören, woran sich die Apatiterze bei Lekomberg und einigen anderen (Yrruben weiter nördlich in Dalekarlien schliessen dürften. ${ }^{1}$ Bei Grängesberg sind hierher sicher gehörige Erze bisher nicht angetroffen; die Apatiterze und die Quarzeisenerze bilden hier in chemischer Hinsicht offenbar zwei Gesteinsreihen, die mit einander nicht zusammenlaufen, sondern durch eine chemische Diskontinuität von einander geschieden sind, in derselben Weise wie hier bei mebreren anderen mit einander assoziierten Gesteinstypen zu konstatieren ist, dass sich die chemischen Veränderungen nicht allmählich, sondern sprungweise vollziehen.

\section{Quarzeisenerze. Basizität 0 bis 20-25.}

II: A. Reihe der schuppigen oder körnigen Quarzeisenerze, mit relativ viel $\mathrm{Al}_{2} \mathrm{O}_{3}$ und $\mathrm{NgO}$ im Verhältnis zu dem $\mathrm{CaO}$. Gehalt.

1. Quarzeisenerze von Lomberg-Pershytte-Typus. Basizität zwischen 0 und 10 bis 12 . Neben Quarz hauptsächlich Alkalifeldspate, Muskovit, Biotit, Chlorit und Epidot vorhanden. Hierher gehören die charakteristischen schuppigen Eisenglanzerze innerhalb der Lomberg-, Ormberg- und Risberg-Felder

1. Weit ausserhalb des Apatiterzbezirkes des südlichen Dalekarliens wurde ein wahrscheinlich hicrhergehöriges kleines Apatiterzvorkommen bei Öfvergran im Kirchspiel Tunaberg, Södermanland, im vorletzten Sommer von mir beobachtet. Dieses Vorkommen scheint in einem Zug von roten Granulitgneisen aufzatreten, der auch mehrere Vorkommnisse von schuppigen Eisenglanzerzen enthält. 
bei Grängesberg. Andere Repräsentanten finden sich innerhalb des Kartengebietes bei Blötberget und im Finnäsfelde.

2. Quarzeisenerze von Stråssa-Typus. Basizität zwischen 10 oder 12 und 20 bis 25. Meistens körnige Magnetiterze oder auch grobschuppige Eisenglanzerze, die neben dem Quarz Feldspate, Glimmer, Amphibol und Epidot enthalten. Zu diesem Typus rechne ich gewisse etwas basischere Magnetiterze innerhalb der Quarzeisenerzzüge bei Grängesberg; die quarzigen Erze in den Gudmundberg-, Blötberg- und FredmundbergFeldern dürften auch grösstenteils hierher gehören.

II: B. Reihe der quarzgebänderten Eisenerze, mit relativ viel $\mathrm{CaO}$ im Verhalltnis zu dem Gehalt an $\mathrm{Al}_{2} \mathrm{O}_{3}$ und $\mathrm{MgO}$.

1. Quarzgebänderte Eisenerze von Striberg-Typus. Basizität 0 bis 10 oder 12. Neben Quarz nur winzige Mengen von Silikaten, hauptsächlich Kalksilikate, wie Granat und Epidot, vorhanden. $\mathrm{Zu}$ diesem wohlbekannten Typus gehörige Erze dürften in dem Grängesberger Gebìet nur im Finnäsfelde (Våghalsgrube) vorkommen.

2. Quarzgebänderte Eisenerze von Stripa-Typus. Basizität zwischen 10-12 und 20-25. Neben Quarz bauptsächlich Epidot und Amphibol, wozu sich einerseits Glimmer und Feldspat, andererseits Granat gesellen kann. Die Bänderung im Vergleich mit den Erzen des Striberg-Typus mehr verschwommen und unregelmässig. $\mathrm{Zu}$ diesem weit verbreiteten Typus könnten in unserem Gebiete einige epidotreiche Erze im südlichsten Teil des Lombergfeldes (Storbotten, Ivarrännan) gerechnet werden, deren Ausbildung zwischen der gleichmässig schuppigen und einer unregelmässig quarzgebänderten schwankt; ebenso gewisse Erze im Gudmundberget und Finnäsfelde.

3. Quarzgebänderte Erze von Norberg-Typus. Basizität wie im vorigen Typus, von welchem der Norberg-Typus sich durch reichlichen Gehalt an $\mathrm{CaFe}$-Granat bei sehr geringem $\mathrm{MgO}$-Gehalt und durch eine schärfere Bänderung unterscheidet. Dieser Typus scheint ebenfalls in dem Finnäsfelde (Bybergsgrube) vertreten $z u$ sein, dessen verschiedene Gruben so- 
mit eine recht vollständige Probenreibe der verschiedenen Typen von Quarzeisenerzen liefern.

III. Skarneisenerze. Diese Abteilung umfasst alle die verschiedenartigen Erze, deren Basizität in das weite Intervall zwischen $\mathrm{y}=20-25$ und $\mathrm{y}$ etwa $=70$ fällt. Es ist hier daher eine Gliederung in 3 Unterabteilungen vorgenommen worden.

III: a. Quarzige Skarneisenerze. Basizität zwischen 20-25 und etwa 40.

1. Quarz-Amphibol-Erze von Lerberg-Typus. Unter den ( $\mathrm{MgFeMn}) 0$-reicheren quarzigen Skarnerzen könnten gewiss mehrere ziemlich verschiedene Abarten unterschieden werden; es scheinen indessen nur die Quarz-Amphibol-Erze des Lerberg-Typus von grösserer Bedeutung zu sein, welche Erze für den Striberger Bezirk sehr bezeichnend sind, und woran sich auch die bekannten Erze der Bispberger Storgrube eng anschliessen. Diese Gruppe hat in unserem Gebiete keine typischen Repräsentanten; die quarzigen Amphibolerze auf der westlichen Seite des Björnberger Grünsteinzuges dürften auf der Grenze zu den Stripa-Erzen stehen.

2. Quarz-Granat-Epidot-Amphibol-Erze, von Tuna-Hästberg-Typus. Unter dieser Bezeichnung möchte ich eine Reihe quarziger Skarnerze vereinigen, die durch den Reichtum an Granat oder Epidot neben mehr oder weniger Hornblende gekennzeichnet sind; bei den quarzreicheren Gliedern neigt der Quarz zu einer lentikularen oder unregelmässig bandförmigen Ausbildung. Diesen Typus habe ich nach dem TunaHästberg-Feld in Dalekarlien benannt, wo derartige Erze, mit Pyroxenerzen und Mangankalkerzen vergesellschaftet, eine grosse Verbreitung haben. Hierher gehören die meisten kleinen Erzvorkommnisse in den Granat-Epidot-Granuliten westlich von Grängesberg, weiter die Erze im südlichsten Teil des Lomberger Erzzuges (Vattenflaskan u. a.) und mehrere Erzvorkommen im Gudmundbergfelde, Fredmundberget (Köpmanngrube) und Finnăsfelde (Bybergsgrube Nr. 1, Godgrube). 
III: b. Metasilikatische Skarneisenerze. Basizität zwischen etwa 40 und $55^{1}$. Wenn wir von einigen bisher wenig bekannten manganreichen Abarten absehen, lassen sich in dieser Unterabteilung die folgenden fünf Typen gut unterscheiden:

1. Gedrit- oder Klinoanthophyllit-Erze von Meling-Typus. Derartige extrem ( $\mathrm{Mg}, \mathrm{Fe}) \mathrm{O}$-reiche Skarnerze sind für das Meling-Feld im Kirchspiel Westanfors sehr charakteristisch. Das radialstrahlig ausgebildete Amphibolmineral ist in den von mir untersuchten Proben ein Gedrit. An diese Gedriterze schliessen sich innerhalb des Grängesberg-Gebietes die vorher erwähnten ( $\mathrm{Mg}, \mathrm{Fe}$ )-Amphibolerze westlich von dem Björnberger Erzzug an, deren Amphibolmineral jedoch zu den Klinoanthophylliten gehört, und die überdies etwas quarzführend sind.

2. Talk-Erze von Rösberg-Typus. Diese Erze (Rösberg, Alabama bei Persberg) dürften wohl nur als Umwandlungsformen der Strahlsteinerze der nächstfolgenden Gruppe oder auch der Gruppe III : c: 2 aufzufassen sein.

3. Strahlstein-Erze von Dalkarlsberg-Kallmora-Typus. Diese Erze zeigen ein Verhältnis $\mathrm{CaSiO}_{3}: \Sigma \mathrm{RSiO}_{3}$ annähernd $=25 \%$, dem Gehalt an strahlsteinartigen, wahrscheinlich nur wenig $\mathrm{Al}_{2} \mathrm{O}_{3}$-haltigen Amphibolen entsprechend, wozu sich öfters etwas Biotit gesellt. Repräsentanten dieses Typus scheinen in dem Grängesberg-Gebiet nur in geringer Menge den Erzen der nächsten Gruppe beigemischt zu sein.

4. Hornblende-Pyroxen-Erze von Björnberg-Typus. Das Verhältnis $\mathrm{CaSiO}_{3}: \Sigma \mathrm{RSSiO}_{3}$ fällt zwischen 30 und $50 \%$; demgemäss enthalten diese Erze kalkreichere, zu den gemeinen

1 Bei der Berechnung der Erźanalysen kommt nur diejenige Feo-Menge in Betracht, die übrig bleibt, nachdem alles $\mathrm{Fe}_{2} \mathrm{O}_{3}$ mit $\mathrm{FeO}$ zu Magnetit vereinigt worden ist. Dieses Verfahren giebt, besonders für die saureren $(y<50)$ Skarnerze, eine zu kleine Basizität und einen zu geringen FeO-Gehalt in den Lagerarten. Daraus erklärt sich, dass die Analysenörter der tatsächlich metasilikatisch ausgebildeten Skarnerze etwas unterhalb der Linie $y=50$ angehäuft sind; am eine richtige Vorstellung von dem mineralogischen Charakter dieser Erze zu bekommen, muss man sich die Analysenörter in der Richtung der nach $\operatorname{der}(\mathrm{Mg}, \mathrm{Fe}) \mathrm{O}$-Ecke des Diagrammes verlaufenden Kurven verschoben denken. 
Hornblenden gehörige Amphibole, wozu sich malakolithische Pyroxene mehr oder weniger reichlich gesellen. In den sauersten Gliedern tritt etwas Quarz hinzu, wobei gleichzeitig die Mineralkombination Hornblende + Granat (bezw. Epidot) auf Kosten des Pyroxengehaltes an Bedeutung gewinnt. Dieser Skarnerztypus ist nach dem Vorkommen in dem Björnberger Erzzug benannt worden; hierher gehört übrigens die grosse Mehrzahl der Skarnerzvorkommnisse unseres Gebietes. Als Repräsentanten ausserhalb dieses Gebietes könnten erwähnt werden die Kärrgrube- und Flogberg-Felder im Skarnerzbezirk des Kirchspiels Norrbärke, das N. Ställberg-Feld im Kirchspiel Nya Kopparberg und das Getback-Feld im Norberger Erzbezirk.

5. Pyroxen-Granat-Erze von Persberg-Typus. Diese Erze enthalten $\mathrm{CaSiO}_{3}$ in Überschuss über die zur Bildung von diopsidischen Doppelsilikaten erforderliche Menge; dieser Überschuss hat sich bei Gegenwart von $\mathrm{Fe}_{3} \mathrm{O}_{4}$ (und $\mathrm{Al}_{2} \mathrm{O}_{3}$ ) als $\mathrm{Ca}(\mathrm{Fe}, \mathrm{Al})$-Granat (bezw. als Epidot) ausgeschieden. Dieser ausserhalb des Persberger Erzbezirkes ziemlich spärliche Typus scheint in dem Grängesberg-Gebiet zu fehlen.

III: c. Basische Skarnerze. Basizität 55 bis etwa 70. Die höhere Basizität ist durch das Vorhandensein von basischen Skarnsilikaten oder die Beimischung von Karbonaten bedingt.

A. Manganreiche basische Skarnerze ${ }^{1}$.

1. Knebelit-Erze von Ställberg-Viker-Typus. Diese Erze sind noch $\mathrm{zu}$. wenig studiert. Sie scheinen hauptsächlich Knebelit zu enthalten, wozu sich auch andere manganreiche Silikate (Amphibole und Granate) und mehr oder weniger reich-

1 Bei den manganreichen Erzen ist der ganze Mangangehalt in den AnaJysen meistens als $\mathrm{MnO}$ angegeben and wird in dieser Form bei den Berechnungen gänzlich zu den Lagerarten gerechnet, obwohl derselbe in der Wirklichkeit gewiss sich sowohl auf Erzminerale als anf Lagerartminerale verteilt, zum kleineren Teil wahrscheinlich auch in der Form von $\mathrm{Mn}_{2} \mathrm{O}_{3}$. Dies ist indessen für die Berechnungen ohne Belang, da die Analysen gleichzeitig meistens noch einen grösseren $\mathrm{FeO}$-Gehalt zeigen als den zur Magnetitbindung des vorhandenen $\mathrm{Fe}_{2} \mathrm{O}_{3}$-Gehaltes erforderlichen. Analysen, die diese Bedingang nicht erfüllen, sind nícht berücksichtigt worden. 
liche Karbonate gesellen, welch letztere wohl als $(\mathrm{Mn}, \mathrm{Fe}) \mathrm{O}$ reiche Dolomitspate (Manganbraunspate) aufzufassen sind. $\mathrm{Zu}$ diesem Typus gehören die zahlreichen Manganeisenerze, die mit den s. g. grauen Hälleflinten im Län Orebro mit auffallender Regelmässigkeit verknüpft sind. Hierhergehörige Erze kommen in dem am nordwestlichen Ende des Sees N. Hörken, ein wenig ausserhalb unseres Kartengebietes gelegenen Silkesberg-Feld vor, ebenso bei den Basttjärnsgruben gerade an der südlichen Kartengrenze. Hier sind auch einige Knebeliterze zu erwähnen, die mit den Eulysiten und anderen sehr eigentümlichen femischen Gesteinen zusammen in den südlichsten Verbreitungsgebieten der mittelschwedischen Erzformation auftreten. (Gillinge Grubenfeld bei Nyköping; Westerby, Garpa und Nyhyttan bei Åmmeberg.)

2. Manganskarnerze von Dannemora-Typus. Diese hauptsächlich bei Dannemora vertretenen Erze bilden eine von dem vorigen Typus deutlich verschiedene, $\mathrm{CaO}$-reichere Reihe. Als Lagerarten dürften wohl hauptsächlich Manganamphibole neben Manganbraunspaten vörkommen. - Auch einige noch $\mathrm{CaO}$ reichere karbonatgemischte Manganskarnerze kommen vor, sind jedoch ohne grössere Bedeutung.

B. Manganarme basische Skarnerze.

1. Serpentin-Erze von Bergsäng-Gubbo-Typus. Das hauptsächliche lagerartbildende Mineral ist Serpentin, wozu sich meistens ein wenig Strahlstein und dolomitische Karbonate gesellen. Inwieweit dieser Serpentin, auf dieselbe Weise wie der Serpentin der körnigen Kalksteine, auf ursprünglichen Olivin zurückzuführen ist, bleibt noch festzustellen; Überreste von unumgewandelter Olivinsubstanz sind in den von mir bisher untersuchten Proben nicht vorhanden. Dieser Erztypus wurde in der Bergsäng-Grube bei Nora und in der Gubbo-Grube im Norrbärker. Skarnerzbezirk beobachtet; in dem Grängesberger Gebiet. wurde auch ein hierhergehöriges Erzvorkommen auf der Halbinsel Långudden am N. Hörken angetroffen.

$8-100170$. 
2. An diese Serpentinerze schliesst sich eine Reihe etwas CaO-reicherer Skarnerze, die neben verschiedenen, meistens FeO-armen Mg-Ca-Silikaten, wie Serpentin, Glimmer, tremolitischen Amphibolen oder diopsidischen Pyroxenen, mehr oder weniger Karbonate enthalten, deren Mineralbestand jedoch bisher nicht ausreichend festgestellt worden ist. Sowohl in der chemisch-mineralogischen Ausbildung als in der geologischen Erscheinungsart zeigen diese Erze offenbar bemerkenswerte Übereinstimmungen mit den Skarnerzen bei Pitkäranta, die neuerdings von TRüsTEDT ausführlich beschrieben wurden ${ }^{1}$. Als Beispiele sind zu erwähnen mehrere Erze bei Persberg (Skärstöten und Gustav-Adolph-Grube), Nordmarken und Finnmossen im Filipstader Skarnerzbezirk; ein Teil der Erze bei Gubbo und im Nyberg-Felde im Norrbärker Skarnerzbezirk und die Erze der W. Malsjöberggrube im Kirchspiel Ludvika; in dem Grängesberger Gebiet scheinen derartige Erze indessen zu fehlen.

IV. Kalkeisener ze. Basizität etwa zwischen 70 und 100 . IV: A. Manganreiche Kalkeisenerze.

1. Mangankalkerze von Kolningsberg-Typus. Basizität etwa zwischen 70 und 85. Als Lagerarten dürften wohl, wie in den nahe verwandten Ställberg-Viker-Erzen, hauptsächlich Manganbraunspate neben Knebelit vorbanden sein, obwohl die Karbonate hier vorherrschend werden. Dieser für das Kolningsberg-Feld im Norberger Bezirk bezeichnende Typus fehlt in unserem Gebiet gleichwie die manganreichen Erze überhaupt.

2. Mangankalkerze von Klackberg.Typus. Basizität 85 bis 100. Dieser bisher nur aus dem Klackberg-Felde im Norberger Bezirk bekannte Erztypus stellt die reinsten mittelschwedischen Karbonaterze dar. Spezielle Untersuchungen über die chemisch-mineralogische Ausbildnng dieser Erze wären offenbar von grossem Interesse. Nach den Analysen sollte

1 Bull. Comm. Geol. Finl. Nr. 19, 1907. 
Bd 32. H. 2.] EISENERZFÜHR. FORMATION VON GRÄNGESBERG. 101 man als Lagerarten einfache $\mathrm{Mn}-\mathrm{Fe}-\mathrm{Mg}$-Karbonate neben Manganbraunspaten und manganreichen Silikaten erwarten ${ }^{1}$. IV: B. Manganarme Kalkeisenerze.

1. Amphibol-Kalzit-Erze von Siliberg-Typus. Ein reichlich silikatgemischter Typus $(\mathrm{y}=65-75)$, der in einigen Gebieten innerhalb des Läns Örebro vertreten ist.

2. Serpentin-Kalzit-Erze von Sköttgrube-Typus. Ein basischerer ( $y=75-90)$ Erztypus, der neben Kalzit hauptsächlich Serpentin und dazu etwas Strahlstein oder Dolomitspat enthält. Dieser nach dem etwas südlich von unserem Gebiete gelegenen Sköttgrube-Feld benannte Erztypus ist in dem Björnberger Erzzug durch die Kalkeisenerze der Långgrube, der Pullero Limgrube und einiger kleineren Gruben repräsentiert.

Nach dieser Übersicht über die verschiedenen mittelschwedischen Eisenerztypen und ihre Repräsentanten innerhalb des Grängesberg-Gebietes wollen wir einige wichtigere Erzvorkommnisse dieses Gebietes etwas näher beschreiben.

\section{Das Grängesberger Exportfeld.}

Die geologische Erscheinungsart der grossen Apatiterzmassen des Exportfeldes geht aus dem Grundriss und den Profilen auf Taf. 6 hervor, die nach der offiziellen Grubenkarte gezeichnet sind. Der Erzzug ist durch zwei grosse Tagebaue aufgeschlossen, die durch einen schmalen Band aus taubem Gestein getrennt sind. Die nördliche Grube wird als die Bergsbo Grube oder als Skärningen bezeichnet; die südliche Grube zerfällt in die Abteilungen Storbotten, Mossåker, Malingsbobrottet und Bredsjöbrottet. Die gesamte Länge des in diesen Gruben abgebauten Erzzuges beträgt über $900 m$; gegen

1 Da fast alle an $\mathrm{MnO}$ und $\mathrm{FeO}$ reicheren Mangankalkerze und karbonatgemischten Manganskarnerze gleichzeitig auch einen Gehalt an Graphit zeigen, während die (Mn, Fe)0-ärmeren Erze davon frei sind, dürfte man Anlass haben, diesen Graphitgehalt irgend einer Zersetzung von ( $\mathrm{Mn}, \mathrm{Fe}$ )-Karbonaten zuzuschreiben. 
$S$ wird derselbe noch weiter von einer Reihe jetzt nicht abgebauten Erzlinsen fortgesetzt, und gegen $\mathrm{N}$ folgen nach einer kurzen Unterbrechung die Erzlinsen des Strandbergfeldes. Die Breite erreieht ein Maximum von $90 \mathrm{~m}$ im nördlichen Teil von Skärningen, beträgt zwischen 20 und $40 \mathrm{~m}$ im mittleren Teil des Erzzuges und schwillt dann wieder im Bredsjöbrottet bis zu $75 \mathrm{~m}$ an.

Bei Betrachtung der Grubenkarte fällt der komplizierte innere Bau des Erzzuges sofort in die Augen. Der Erzzug erweist sich durchaus nicht als eine kompakte Erzmasse, sondern setzt sich aus einer grossen Zahl dicht gescharter, klei-

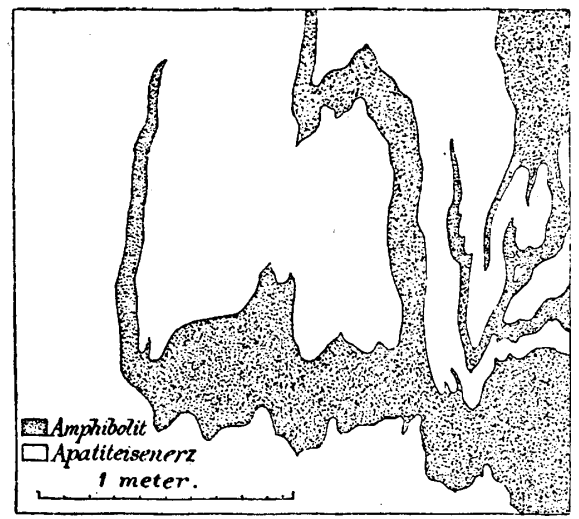

Fig. 12. Erz und Amphibolit zwischen Mossåker und Storbotten.

nerer und grösserer Erzkörper von linsenartiger oder ovaloidischer Form zusammen. Die verschiedenen Erzkörper sind voneinander durch schmale Zwischenbänder aus granulitischen und amphibolitischen Gesteinen getrennt, die gewissermassen als Abzweigungen von dem hangenden und liegenden Nebengestein des Erzzuges erscheinen. Besonders im Bredsjöbrottet ebensowie an der Grenze zwischen Mossåker und Storbotten ist diese Linsenarchitektur in einer sehr auffallenden Weise entwickelt. Am letzteren Lokal, wo bis vor wenigen Jahren ein Band zurückgelassen war, wurde die in Fig. 12 wiedergegebene Skizze gezeichnet, die die dortigen komplizierten Kontakt- 
Bd 32. H. 2.] EISENERZFÜHR. FORMATION VON GRÄNGESBERG. 103 verhältnisse zwischen Erz und Zwischengestein, hier Amphibolit, veranschaulicht.

Die südlichen und mittleren Teile des Erzzuges ebensowie die dem Hangenden am nächsten gelegene Hälfte der im Skärningen aufgeschlossenen Erzmasse enthalten apatitreiche Magneteisensteine mit 59-64\% Eisen und 0.8-1.5\% Phosphor (vergl. die Analysentabellen I-II und die Analysen 1-6 auf Tab. III). Neben dem Apatit kommt hauptsächlich eine lebhaft grüne aktinolithische Hornblende als Lagerart vor. Dabei nimmt die Beteiligung des Apatites im Verhältnis zu den silikatischen Gemengteilen ziemlich regelmässig von $\mathbf{S}$ nach $\mathbf{N}$ zu, wie aus dem Analysendiagramm auf S. 92 ersichtlich ist,

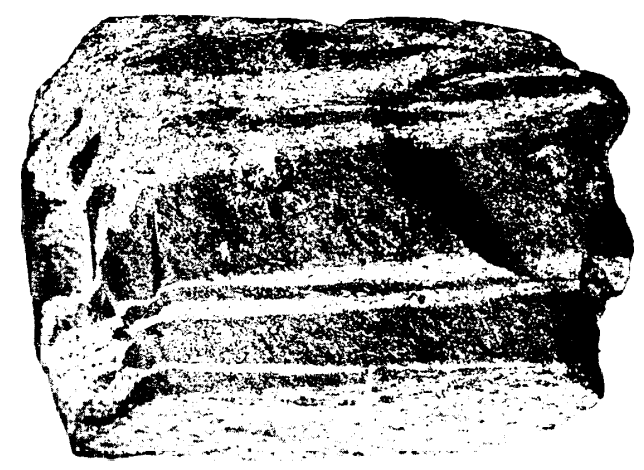

Fig. 13. Apatitgebändertes Erz. Skärningen. 1/2.

und auch der absolute Phosphorgehalt der Erze ist durchschnittlich etwas höher in den nördlichen als in den südlichen Teilen des Erzzuges. Der Apatit ist meistens gleichmässig in der kleinkörnigen Magnetitmasse verteilt und makroskopisch wenig sichtbar. Dicht bei dem Hangenden findet sich indessen ziemlich regelmässig ein Bard aus sehr apatitreichem Erz mit bis $8 \%$ Phosphor, das eine gebänderte Abwechselung zwischen dunklen magnetitreichen und grünlich grauen apatitreichen Lagen und Linsen ersehen lässt (Fig. 13). ${ }^{1}$

1 Eine Apatitprobe aus diesem gebänderten Erz hat nur Spuren von Chlor ergeben. Wahrscheinlich ist der Apatit des Grängesberggebietes durchgängig ein ansgeprägter Fluorapatit. 


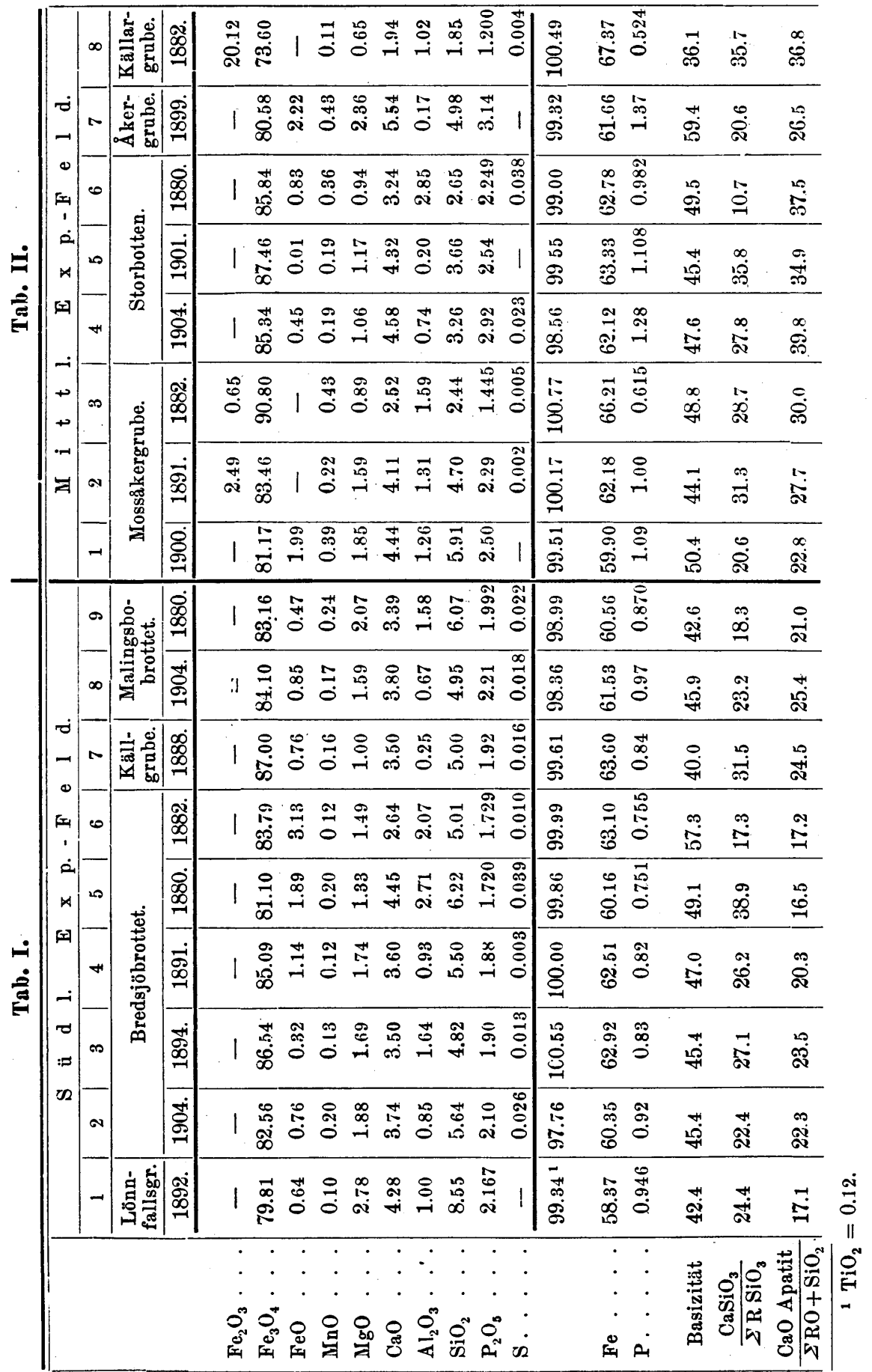


Bd 32. H. 2.] EISENERZFÜHR. FORMATION VON GRÄNGESBERG. 105

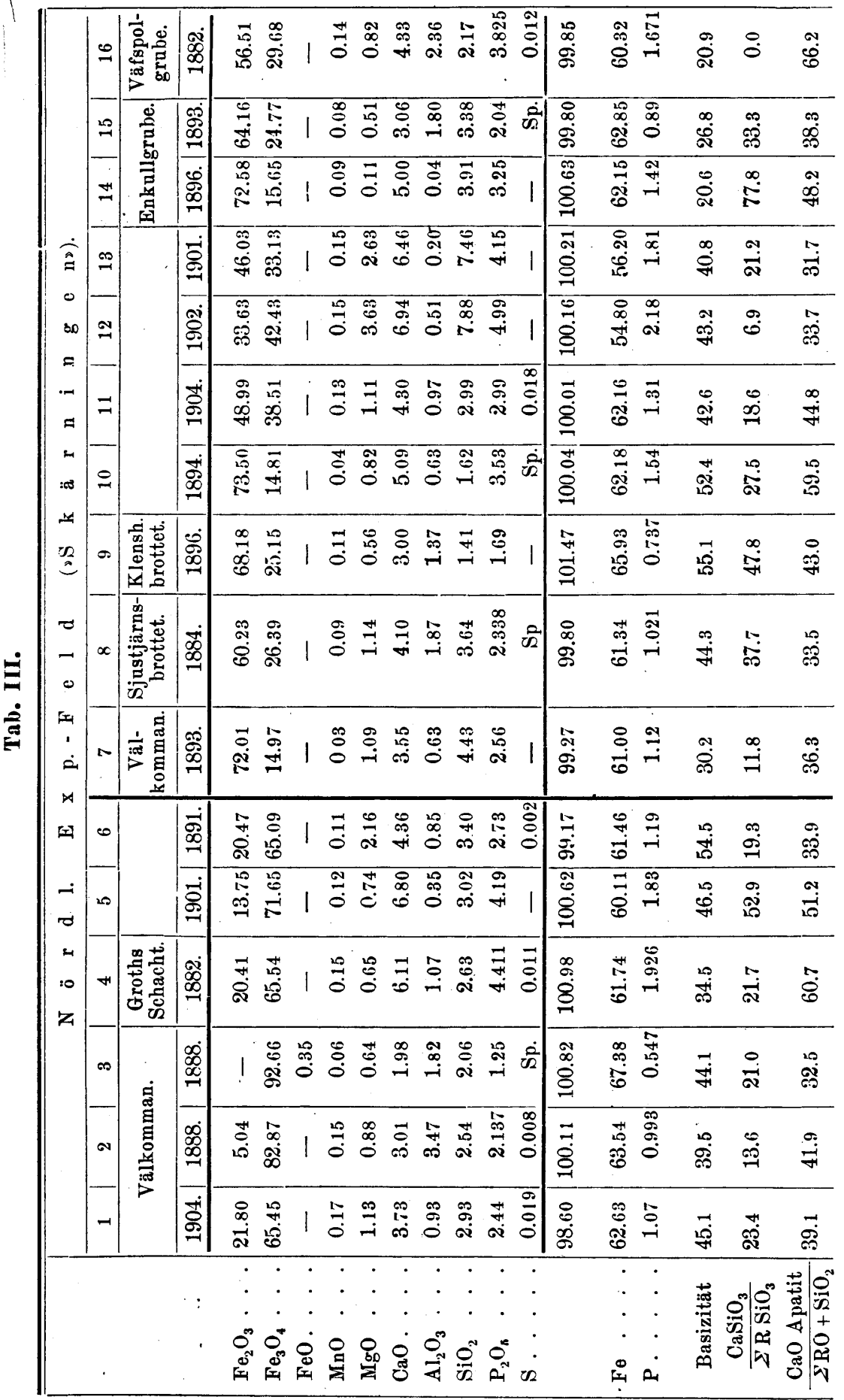


Die westliche Hälfte der im Skärningen abgebauten Erze besteht grösstenteils aus apatitreichen Roteisensteinen mit 60$63 \%$ Eisen und 1.25-2 \% Phosphor (Anal. 7-16, Tab. III). Der gewöhnliche Typus dieser Erze (s. g. »Mellanbrotts) zeigt eine gleichmässig kleinkörnige, mehr oder weniger magnetitgemischte Eisenglanzmasse; eine andere, hauptsächlich in dem südlichen Teil der Grube verbreitete Varietät (s. g. „Sjustjärnsten,, Anal. 8) enthält grössere Magnetitoktaëder einsprenglingsartig in eine lockere Eisenglanzmasse eingestreut (Fig. 14); eine dritte, spärlicher vorkommende Erzvarietät zeigt ein dunkles feinkörniges Magnetitgewebe, mit grösseren glänzenden Eisenglanzrhomboedern gespickt (Fig. 15). Als silikati-

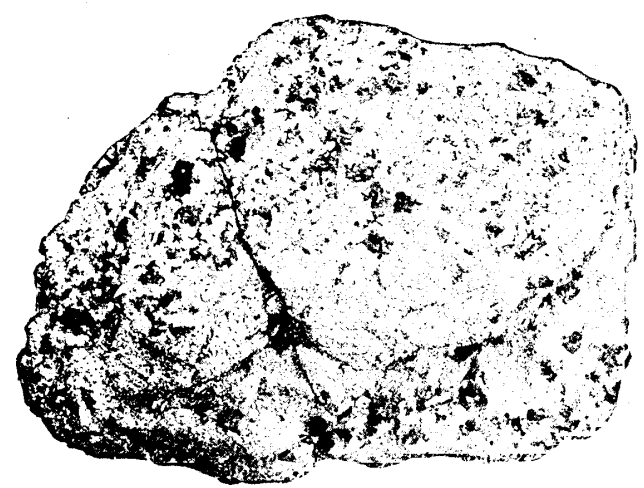

Fig. 14. Apatit-Glanzeisenerz mit Nagnetitkristallen. Skärningen. 1/2.

scher Gemengteil kommt auch in den Roteisensteinen meistens ein aktinolithischer Amphibol vor, der jedoch in gewissen Varietäten durch Biotit ersetzt wird. Im nördlichsten Teil der Grube finden sich auch Erze, die neben Apatit hauptsächlich Quarz und Feldspat enthalten; diese Erze (Anal. 14-16) zeigen demnach eine niedrige Basizität und schliessen sich den Apatiterzen des Risbergtypus an.

Unmittelbar am Liegenden der Grube Skärningen finden sich zwischen den apatitreichen Roteisensteinen und den Granuliten meistens Bänke aus schuppigen Quarzeisenerzen („Zäherzen») mit nur $0.12-0.20 \%$ Phosphor; sie setzen sich weiter 
Bd 32. H. 2.] EISENERZFÜHR. FORMATION VON GRÄNGESBERG. 107 südlich als ein kleinerer Parallelzug fort, der in einiger Entfernung von den Apatiterzen verläuft (vergl. die Analysen Tab. VIII). Das Auftreten dieser Erze ist von Interesse, weil dadurch die Annahme einer engen genetischen Verwandtschaft zwischen den Apatiterzen und den Quarzerzen des Grängesberggebietes eine kräftige Stütze erhält.

Die Eisenerze des Exportfeldes sind an gewissen Lokalen, z. B. im Storbotten, reich an Hohlräumen, deren Wände mit Quarzkristallen oder seltener mit Kalkspat und Flussspat bekleidet sind; die genannten Minerale sind dann öfters mit einem radialfaserigen Chloritmineral und Schwefelkies überzogen. Im Inneren der Höhlen findet sich meistens ein

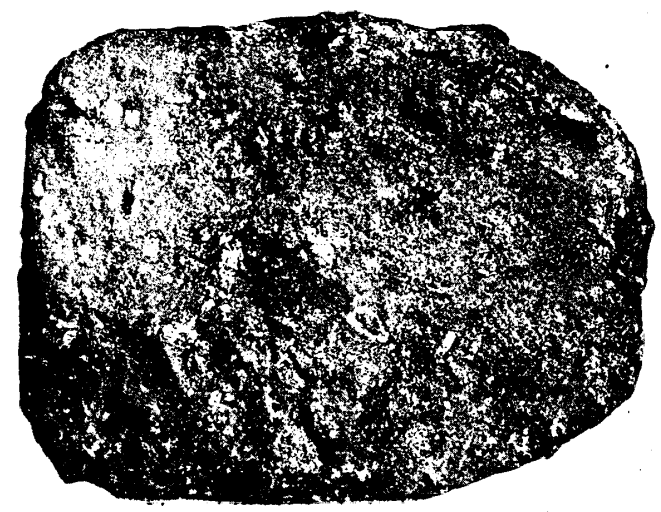

Fig. 15. Apatit-Magnetiterz mit Eisenglanzkristallen. Skärningen. 1/2.

flüssiges Bitumen, das bei Berührung mit der Luft schnell zu glänzenden schwarzen Kugeln erstarrt. ${ }^{1}$ Der Quarz bildet bisweilen deutliche Pseudomorphosen nach Kalkspat. In einer angeblich aus dem Skärningen stammenden Kalkspatdruse fand sich eine Schicht aus schwarzer Zinkblende als Unterlage für die Kalkspatkristalle. --

Die Granulite im Hangenden des Erzzuges zeigen eine sebr wechselnde Zusammensetzung. Neben biotitreichen „Export-

1 Nach Analysen von Hellawd (G. F. F. II [1875]: j17) enthält das Bergpech aus Grängesberg $8.32-8.50 \% \mathrm{H} ; 77.63-76.97 \% \mathrm{C} ; 10.63-10.79 \% 0$; $0.01 \%$ S; 3.41-3.73\% Aschbestandteile. 
feld-Granuliten» von der auf S. 52 beschriebenen Art kommen sehr inhomogene Gesteine mit Linsen und Schlieren aus Hornblendeskarn häufig vor, die bisweilen eine ovaloidische, an ausgewalzte Konglomerate oder Kugelgranite erinnernde Ausbildung annehmen können. Amphibolite sind vielfach, aber im ganzen nicht sehr häufig eingeschaltet. Hier und da finden sich zwischen den dunkleren Granulitbänken scharf begrenzte hellrötliche Gesteinsbänke, die sowohl in der Zusammensetzung als auch in der Struktur an Aplite erinnern. Die dicht an das Erz grenzenden Gesteinsschichten sind meistens sehr reich an Biotit und Hornblende und zeigen z. T. den Charakter eines Biotitskarngesteins. Apatit stellt sich öfters in diesen biotitreichen Grenzschichten reichlich ein, und Flusspat ist auch bisweilen zu sehen. An einigen Lokalen, z. B. im nördlichen Teil des Skärningen, sind auch kleine Erzschmitzen eingemischt, wodurch der Kontakt mit dem angrenzenden apatitgebänderten Erz weniger scharf erscheint. Diese schon infolge des Biotitreichtums leicht ablösenden Grenzschichten scheinen ausserdem durch spätere Gleitungen aufgelockert worden zu sein, was auch durch das Vorkommen von Gleitflächen in den überquerenden Pegmatitgängen bewiesen wird. Auf diese Weise dürfte die auf der Karte markierte lockere „Sköl»-Gesteinszone entstanden sein, die den ganzen Erzzug entlang zu verfolgen ist, obwohl sie streckenweise nur wenig ausgeprägt ist. Die Skölzone folgt z. T. dem unmittelbaren Erzkontakt, ist jedoch öfters in einiger Entfernung davon am besten ausgebildet.

Die Granulite des Liegenden gehören ebenfalls zum grössten Teil zu dem »Exportfeldtypus», obgleich meistens zú Varietäten, die weniger reich an Biotit sind. Porphyrische Struktur und Bänderung sind manchmal wohl entwickelt. Amphibolite sind sehr häufig; besonders an dem mittleren Teil des Skärningen giebt es gute Gelegenheiten, ihre interessante geologische Erscheinungsart zu studieren (vergl. Fig. 10, S. 80). Neben den Amphiboliten kommen auch, z. B. an der südwestlichen Seite 
Bd 32. H. 2.] EISENERZFÜHR. FORMATION VON GRÄNGESBERG. 109

des Skärningen, kleine Erzlinsen in diesen Granuliten vor, und die Gesteine scheinen selbst ziemlich allgemein etwas erzimprägniert zu sein. An denjenigen Teilen des Erzzuges, wo schuppige Roteisensteine im Liegenden des Erzlinsenkomplexes auftreten, z. B. in der Timmer- und der Enkullgrube, findet sich ziemlich regelmässig im unmittelbaren Liegenden Gesteinsbänke aus rötlichen, erzimprägnierten und erzgebänderten Granuliten, die zu dem kalifeldspatreichen »Lombergtypus» gehören (Fig. 16). In solchen Fällen wird die Grenze zwischen Erz und Nebengestein wenig deutlich, oder es kann sogar ein fast kontinuierlicher Übergang zwischen beiden stattfinden.

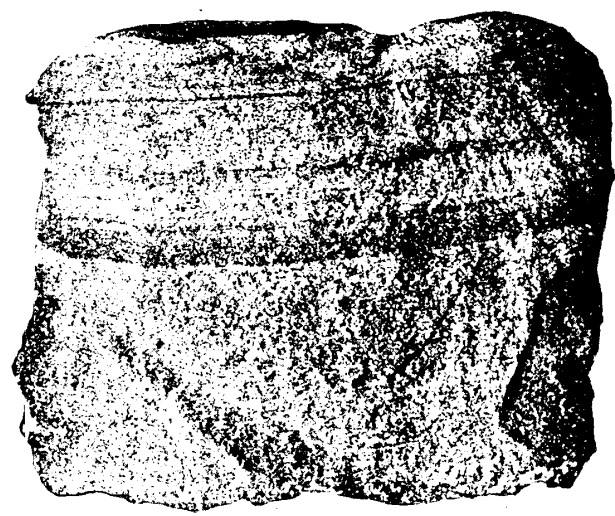

Fig. 16. Erzgebänderter ,Lomberggranulit , aus dem Liegenden des Skärningen. 1/2.

Die tauben Zwischenbänder des Erzlinsenkomplexes stimmen mit den Gesteinen des Liegenden und Hangenden im grossen und ganzen überein; doch scheinen Amphibolite darin eine noch grössere Verbreitung zu haben. So z. B. besteht die Scheidewand zwischen Skärningen und Storbotten ebensowie das komplizierte Gesteinsnetz zwischen Storbotten und Mossåker und viele der kleineren Zwischenbänder anderswo in den Gruben fast ganz aus Amphibolit. Diese Amphibolite scheinen zum grossen Teil zu der Abteilung der Quarz-Magnetit-Amphibolite zu gehören und sind bisweilen sehr reichlich magnetitimprägniert, ein Verhalten, das auf enge genetische $\mathrm{Be}-$ 
ziehungen zwischen diesen Gesteinen und dem Eisenerz deuten dürfte. Die breiteren $Z_{w}$ wischenbänder im Skärningen bestehen z. T. aus einer anderswo in den Exportfeldgranulitzügen nicht beobachteten Plagioklasgranulitvarietät, die statt des Biotites etwas Muskovit enthält und demzufolge eine auffallend helle Farbe zeigt. Andererseits sind gewisse $\mathrm{Z}_{w i}$ schenbänder aus sehr biotitreichen Granulitvarietäten aufgebaut; wo die Bänder auskeilen, reichert sich öfters der Biotit stark an, und es stellen sich dünne "Biotitskölar» als Fortsetzung der Granulitbänder ein.

Der Erzzug wird von zahlreichen Pegmatitgängen überquert. Auf den höheren Niveaus fanden sich solche Gänge hauptsächlich in der Skärningen-Grube; in der Tiefe brechen sie auch in die südlichen Teile des Erzzuges ein. An dem Liegenden des Erzfeldes bilden die Pegmatite ein System aus über einander gelagerten Gängen von flachem nordwestlichem Einfallen; an dem Hangenden nehmen sie indessen einen stei, len Verlauf an und laufen hier streckenweise mit den Granuliten konform. Weiter nördlich hängt dieses Gangsystem offenbar mit den in den dortigen Verbreitungsgebieten der Exportfeldgranulite und $\mathrm{N}$. Hammargrubengesteine vielfach beobachteten, ebenfalls flach gelägerten Pegmatitgängen zusammen. Die Gesteine sind meistens hellrötliche Mikroklinperthit II $^{-O l i g o k l a s-P e g m a t i t e ~ v o n ~ z i e m l i c h ~ w e c h s e l n d e r ~ G r o b-~}$ heit und Struktur; typisch schriftgranitische Ausbildung ist niemals beobachtet worden. Dunkle Minerale fehlen meistens fast ganz; Beryll- und Apatitkristalle sollen einige Male gefunden worden sein. Ein schwarzes Bitumen ist allgemein verbreitet als dünne Klüftenbelege oder in drusigen, quarzreichen Ausscheidungen. Mit diesem Bitumengehalt dürfte möglicherweise auch die ziemlich regelmässig zu beobachtende Erscheinung zusammenhängen, dass die Roteisensteine im Skärningen dicht an den überquerenden Pegmatitgängen in grobkörnige Magneteisensteine umgewandelt worden sind. - Einige kleine, die Granulite im Liegenden des Skärningen steil 
überquerende Pegmatitapophysen zeigen in ausgezeichneter Weise die Erscheinung der sgefalteten Gänges. Im Hangenden dieses Tagebaues wurden kleine mit den grösseren Pegmatitgängen möglicherweise nicht zusammengehörige Pegmatitadern beobachtet, die eigentümlicherweise gegen die umgebenden Granulite durch dünne Magnetitsalbänder abgegrenzt waren. Als lokale Entwickelungsformen der dortigen Pegmatitgänge fanden sich auch kleinkörnige, weisse oder gewöhnlicher grünlich gefärbte Gesteine, die fast ganz aus Albitoligoklas $\left(\mathrm{Ab}_{89} \mathrm{An}_{11}\right)$ mit eingestreuten Magnetitkörnern bestehen.

An dem nördlichen Ende des Skärningen keilen die Erzlinsen mit zackigem Kontakt in biotitreichen Granuliten aus. Die Grenze ist hier nicht sehr scharf, indem das Erz mit Biotit und anderen Granulitgemengteilen sehr verdünnt wird und andererseits den Granuliten Erz- und Apatitschmitzen beigemischt sind. - Der später erscheinende Erzlinsenkomplex des Strandbergfeldes bietet in kleinerem Massstab den Exportgruben ziemlich ähnliche Verhältnisse dar.

\section{Die Apatiterze des südlichen Risbergfeldes.}

In der westlichen und nördlichen Fortsetzung der im Liegenden des Exportfeldes auftretenden "Exportfeldgranulite» findet sich eine Reihe Apatiterzvorkommen, die zu der vorher als der Risbergtypus ausgeschiedenen Erzgruppe gehören. Diese Erze sind meistens nicht sehr reiche Magneteisensteine mit Lagerarten aus weisslichem Apatit, Quarz, Biotit und Feldspat. Von den Exportfelder Erzen weichen sie makroskopisch durch gröberes Korn und ein weissgesprenkeltes Aussehén sowie durch das gänzliche Fehlen des für die erstgenannten Erze meistens bezeichnenden Amphibolminerales ab. Bemerkenswert ist, dass die vorhandenen Analysen (Tab. IV) übereinstimmend einen grösseren Phosphorgehalt zeigen als den zur Apatitbindung des ganzen CaO-Gehaltes theoretisch erforderlichen. Demnach wäre auf Beimengungen anderer Phosphatmoleküle zu schliessen, was ich jedoch bis- 


\begin{tabular}{|c|c|c|c|c|c|c|c|c|c|c|c|c|c|c|c|c|}
\hline \multirow{6}{*}{ 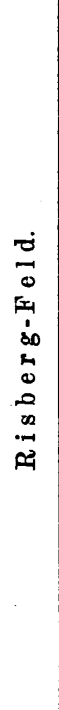 } & 咅离 & ஜ & | & 官 & $\stackrel{\circ}{\stackrel{ }{+1}}$ & $\begin{array}{l}\vec{H} \\
\stackrel{0}{\infty} \\
\stackrel{\infty}{\rightarrow}\end{array}$ & $\stackrel{+1}{0}$ & $\begin{array}{l}: \\
:\end{array}$ & "م: & & $\begin{array}{l}\infty \\
\infty \\
8 \\
8\end{array}$ & $\stackrel{\circ}{\infty}$ & & ชั่ & $\vec{D}$ & 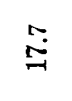 \\
\hline & \multirow{2}{*}{ 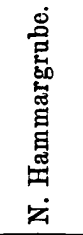 } & $\underset{\infty}{\stackrel{10}{\infty}}$ & 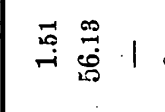 & $\stackrel{\theta}{0}$ & $\stackrel{5}{\circ}$ & $\underset{+\infty}{\infty}$ & $\dot{m}:$ & 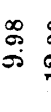 & & iे & $\stackrel{20}{\circ}$ & $\stackrel{8}{\stackrel{9}{\sharp}}$ & تั! & $\stackrel{\oplus}{\dot{m}}$ & $\frac{\infty}{6}$ & 趈 \\
\hline & & 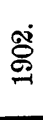 & 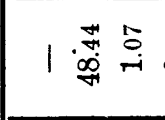 & 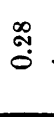 & $\stackrel{\mathscr{\infty}}{-}$ & $\stackrel{\sim}{\stackrel{9}{8}}$ & $\stackrel{\circ}{\circ}:$ & 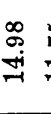 & I & & $\begin{array}{l}\stackrel{9}{1} \\
\stackrel{0}{\circ}\end{array}$ & के & $\frac{9}{10}$ & 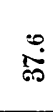 & 我 & $\stackrel{\mathscr{Q}}{\dot{q}}$ \\
\hline & 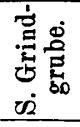 & $\underset{\infty}{\infty}$ & 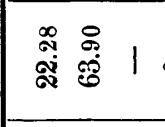 & $\stackrel{\circ}{\circ}$ & $\stackrel{0}{0}$ & $\underset{\infty}{0}$ & $\begin{array}{l}\infty \\
\stackrel{\infty}{\infty} \\
\text { oे }\end{array}$ & $\vec{\infty}$ & & $\stackrel{N}{0}$ & $\stackrel{\infty}{\stackrel{\infty}{\circ}}$ & $\stackrel{\infty}{\dot{\infty}}$ & $\underset{\sim}{\stackrel{\oplus}{-1}}$ & $\stackrel{0}{\circ}$ & $\stackrel{\circ}{\circ}$ & $\stackrel{\bullet}{\mathscr{f}}$ \\
\hline & 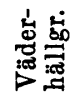 & $\stackrel{\infty}{\mathscr{\infty}}$ & 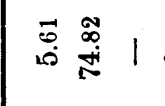 & 今̊ & $\stackrel{+}{\stackrel{H}{-1}}$ & 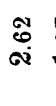 & $\stackrel{\infty}{\infty} \stackrel{2}{-}$ & $\stackrel{n}{\stackrel{\oplus}{二}}$ & ন্ণ & 1 & $\stackrel{\infty}{\infty}$ & $\underset{0}{70}$ & 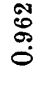 & $\stackrel{\circ}{\circ}$ & $\ddot{0}$ & $\stackrel{\infty}{\stackrel{\infty}{\rightarrow}}$ \\
\hline & 竘兽 & 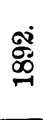 & 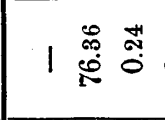 & $\stackrel{\circ}{0}$ & $\underset{\substack{0 \\
i}}{\stackrel{0}{+}}$ & - & $\stackrel{\infty}{\infty}$ & 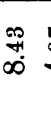 & $\stackrel{5}{\sigma}$ & & $\stackrel{\infty}{\circ}$ & 苫 & $\stackrel{7}{a}$ & $\stackrel{\infty}{\dot{\pi}}$ & $\stackrel{\circ}{0}$ & ஷ্ \\
\hline $\begin{array}{l}5 \\
\vdots \\
\text { है } \\
\text { ह }\end{array}$ & 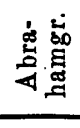 & \begin{tabular}{l}
$-\dot{0}$ \\
$\infty$ \\
\hdashline
\end{tabular} & 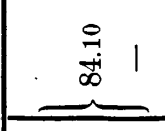 & 1 & ঙัণ & की & 울 & की & & $\stackrel{10}{0}$ & $\stackrel{\vec{\rho}}{\mathrm{s}}$ & $\ddot{8}$ & 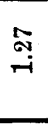 & $\stackrel{s}{\sigma}$ & $\dot{0}$ & $\overrightarrow{\text { Rे }}$ \\
\hline \multirow{4}{*}{ 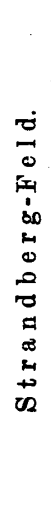 } & 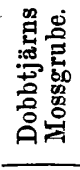 & $\underset{\stackrel{\leftrightarrow}{\infty}}{\stackrel{\infty}{\infty}}$ & 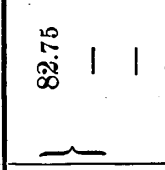 & $\stackrel{\circ}{\circ}$ & 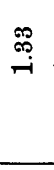 & $\begin{array}{l}\vec{\infty} \\
\stackrel{\infty}{i} .\end{array}$ & $\begin{array}{l}\text { Dै } \\
\text { ơ }\end{array}$ & $\begin{array}{l}\infty \\
\stackrel{1}{10} . \\
\text {. }\end{array}$ & & $\stackrel{5}{\circ}$ & $\stackrel{\infty}{\infty}$ & 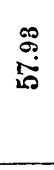 & 点 & 寈 & 范 & $\underset{+1}{\stackrel{\infty}{+}}$ \\
\hline & \multirow{3}{*}{ 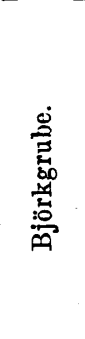 } & $\begin{array}{l}\mathscr{\infty} \\
\stackrel{\infty}{\infty} \\
\stackrel{\infty}{\sim}\end{array}$ & 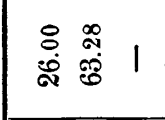 & $\stackrel{\sharp}{0}$ & $\stackrel{-j}{-1}$ & 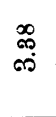 & 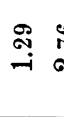 & $\begin{array}{l}0 \\
i \\
\text { a }\end{array}$ & & $\stackrel{\circ}{\circ}$ & ᄋ్ & $\stackrel{\text { ڤั }}{\oplus}$ & $\begin{array}{l}\vec{\infty} \\
\infty \\
0 \\
0\end{array}$ & ลี่ & ڤ్ & : \\
\hline & & $\underset{\text { ه্ं }}{\infty}$ & $1 \underset{\infty}{\stackrel{\infty}{\infty}} \stackrel{\infty}{0}$ & $\overrightarrow{0}$ & $\vec{m}$ & $\begin{array}{l}\infty \\
\infty \\
0\end{array}$ & 워 & ڤึ & تُ & $\dot{0}$ & $\stackrel{5}{\circ}$ & 足 & $\begin{array}{l}\infty \\
0 \\
0 \\
0\end{array}$ & 官 & 官 & $\stackrel{0}{\stackrel{+}{*}}$ \\
\hline & & $\begin{array}{l}10 \\
\infty \\
\infty \\
-\infty\end{array}$ & 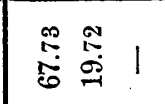 & $\stackrel{0}{0}$ & $\stackrel{\mathscr{N}}{\stackrel{-}{-}}$ & की & $\stackrel{\leftrightarrow}{\stackrel{\infty}{\infty}}$ & $\underset{8}{\infty}$ & 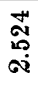 & $\stackrel{1}{0}$ & $\begin{array}{l}\stackrel{8}{0} \\
\dot{\circ}\end{array}$ & 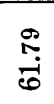 & & $\stackrel{\sim}{\infty}$ & $\stackrel{\infty}{\stackrel{\infty}{\rightarrow}}$ & $\begin{array}{l}\infty \\
\stackrel{\infty}{\infty}\end{array}$ \\
\hline & & $\cdot$ & 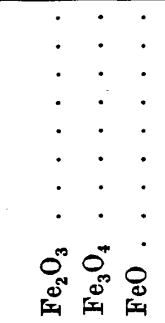 & $\begin{array}{l}\dot{ } \cdot \\
\dot{.} \\
\dot{.} \\
\dot{.} \\
\dot{0}\end{array}$ & $\begin{array}{l}\dot{ } \\
\dot{ } \\
\dot{ } \\
\dot{.} \\
\dot{.} \\
\dot{0}\end{array}$ & 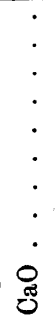 & $\begin{array}{l}\dot{\cdot} \\
\dot{\cdot} \\
\dot{\cdot} \\
\dot{\cdot} \\
\dot{0} \\
0^{m}\end{array}$ & 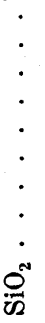 & $\dot{.}$ & $\begin{array}{l}\vdots \\
\vdots \\
\vdots \\
\vdots\end{array}$ & & $\begin{array}{l}\dot{ } \\
\dot{ } \\
\dot{ } \\
\dot{ } \\
\dot{0} \\
\dot{0}\end{array}$ & $\begin{array}{l}\ddot{.} \\
\dot{ } \\
\dot{ } \\
\dot{ } \\
\dot{ } \\
\dot{ } \\
\text { क }\end{array}$ & 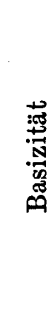 & 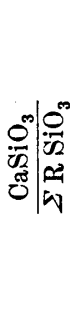 & 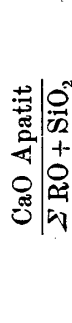 \\
\hline
\end{tabular}


Bd 32. H. 2.] EISENERZFÜHR. FORMATION VON GRÄNGESBERG. 113 her nicht zu prüfen Gelegenheit gehabt habe. - Von den zahlreichen alten Gruben ist die etwas westlich von dem Strandbergfeld gelegene Mossgrube neuerdings wieder aufgenommen worden. Das dortige Erz bildet einen Linsenkomplex mit $Z$ wischenbändern aus hellfarbigen hornblendearmen Quarz-Magnetit-Amphiboliten; im Hangenden der Apatiterze finden sich Bänder aus schuppigem Roteisenstein und eisenglanzimprägniertem „Lomberggranulit», während ebenschieferiger sExportfeldgranulit» das Liegende bildet. Ein wenig nördlich von dieser Grube sind einige andere hierhergehörige Erzkomplexe gelegen, die, der Form und Anordnung der dicht gedrängten Grubenhöhlen nach zu schliessen, von sehr kompliziertem Bau sein dürften.

\section{Die N. Hammargrube.}

Im nördlichsten Teil des Grängesberger Erzzuges findet sich innerhalb des Verbreitungsgebietes der eigentümlichen N. Hammargrubengesteine eine Reihe Apatiterzvorkommen, die ebenfalls zu dem Risbergfeld gerechnet werden, aber von den oben beschriebenen Risbergerzen recht verschieden sind. Diese Erze sind meistens wenig scharf von ihrem Nebengestein abgegrenzt, erscheinen vielmehr nur als schlierige Erzanhäufungen innerhalb desselben und zeigen dieselbe sehr inhomogene und wechselnde Ausbildung, die für die ganze Gesteinsarea bezeichnend ist. Ein anhaltender Erzbau hat nur in der $N$. Hammargrube stattgefunden. Diese Grube baute auf zwei benachbarten Erzstöcken von fast kreisförmigen Umrissen, die sich indessen nach der Tiefe zu schnell verengten und schon in $100 \mathrm{~m}$ Tiefe nicht weiter bauwürdig zeigten. Das Erz ist ein eisenarmer Magneteisenstein mit meistens 5-8\% Phosphor, einem A patitgehalt von $27-43 \%$ entsprechend, und dazu noch mit reichlichen silikatischen Gemengteilen, hauptsächlich malakolithischem Pyroxen, schwarzer Hornblende und leberbraunem Titanit, in gewissen Varietäten auch dunkelbraunem Granat. Die einzelnen Gemengteile, be- 
sonders der Apatit, sind gewöhnlich in wohlbegrenzten, kleinkörnigen Partien ausgeschieden, wodurch das Erz ein geflecktes Aussehen bekommt (Fig. 17): In dem Erz kommen ab und zu unscharf begrenzte pegmatitische Ausscheidungen vor, die hauptsächlich aus Oligoklas, Pyroxen und Titanit bestehen, wozu sich Apatit, Hornblende, Orthit, Quarz, grobspatiger gelbrötlicher Kalzit und Flusspat öfters gesellen. Diese Ausscheidungen sind reich an Hohlräumen, die mit Kalzit, Flussspat, Apophyllit ${ }^{1}$ und Bergpech ausgefüllt sind. Biotit ist nicht in dem Erz selbst vorhanden, kommt aber in besonderen

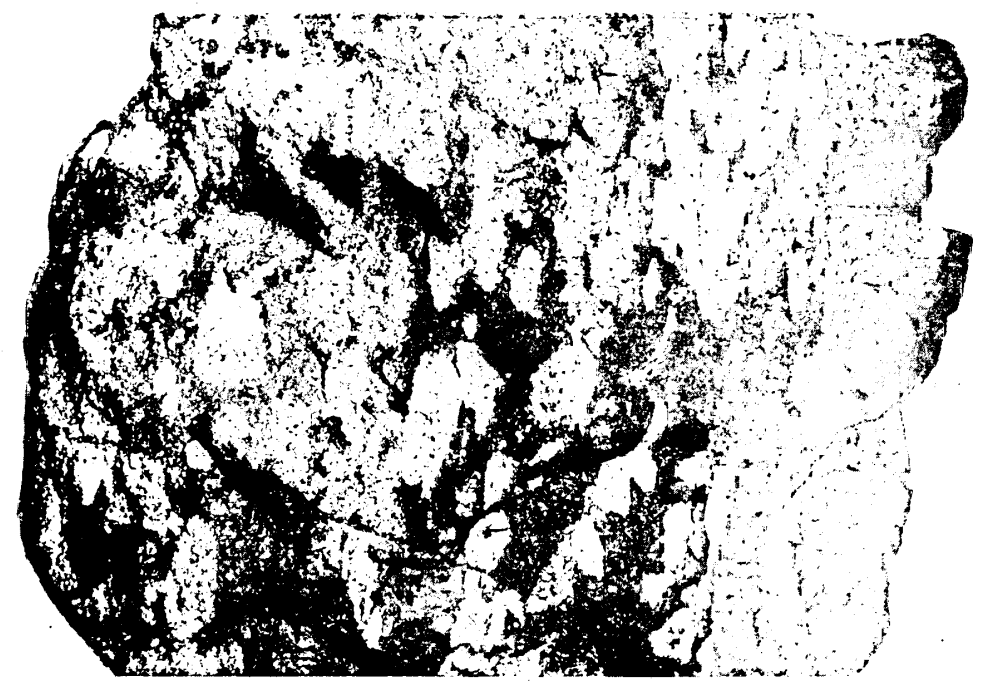

Fig. 17. Apatiterz aus der N: Hammargrabe. Hell = Apatit: hellgrau = Magnetit; dunkel $=$ Pyroxen und andere Silikate. $2 / 3$.

skarnartigen Massen angehäuft vor. - Die N. Hammargrube gehört gewiss $\mathrm{zu}$ den eigentümlicheren Lagerstätten Mittelschwedens; sie dürfte in mehreren Hinsichten mit den Apatitlagerstätten 'innerhalb der „Grenville, series» in Canada Berührungspunkte haben.

1 Das Mineral ist von G. HALLberg analysiert und beschrieben worden (G. F. F. 15 [1893]: 327-331). 


\section{Die Blötberg- und Fredmundbergfelder.}

Diese Erzfelder sollen hier nur kurz erwähnt werden. Die geologische Erscheinungsart der Blötberger Erze stimmt mit derjenigen der Exportfelder Erze nahe überein. Es findet sich ein etwa $20 \mathrm{~m}$ breiter Linsenkomplex aus mehr oder weniger reichlich apatitgemengten Magneteisensteinen mit mehreren tauben $Z$ wischenbändern, im Liegenden von gedritführenden granulitischen Plagioklasgneisen (vergl. S. 37) mit kleineren Erzbändern und reichlichen Amphiboliten umgeben und im Hangenden an sehr biotitreiche, z. T. ssköl»-artige Gesteinsvarietäten grenzend. Ganz wie bei Grängesberg sind auch bei Blötberget die apatitführenden Magneteisensteine sowohl mit apatitreichen Roteisensteinen wie mit apatitarmen schuppigen Roteisensteinen nahe assoziiert, welch letztere jedoch hier einen Parallelzug im Hangenden der Magneteisensteine bilden. Grosse Massen von Pegmatiten brechen in die Gruben ein und scheinen gewisse Störungen und Verschiebungen innerhalb des Erzzuges bewirkt zu haben.

Die Apatiterze des Fredmundbergfeldes treten in der Feldrichtung des Blötberger Erzzuges auf. Durch die geringere Grösse und Beständigkeit der Erzdepositionen, den basischeren und hornblendereichen Charakter der Erze und die gröbere und massigere Ausbildung der hauptsächlich aus Plagioklasgneisen mit kleineren Stöcken von Diorit- und Dioritbrecciengesteinen bestehenden Nebengesteine schliessen sich diese Apatiterzvorkommnisse den im folgenden zu beschreibenden Långblåer Erzvorkommen eng an.

\section{Die Långblågruben.}

Diese Apatiterzlagerstätte ist etwa $21 / 2 \mathrm{~km}$ westlich von Klenshyttan im nördlichsten Teil der von dem Grängesberger Granitgneis eingenommenen linsenförmigen Gesteinsarea gelegen. Es sind hier zwei kleine Erzkomplexe auf dem Bergabhang südlich vom Gehöft Långblå einige hundert Meter von- 
einander aufgeschlossen. Die geologischen Verhältnisse des oberen Komplexes sind in Fig. 18 dargestellt. Das Erz bildet einen Zug aus recht unregelmässig geformten Klumpen, die zumal in der Streichrichtung von einem dioritischen, z. T. breccienartigen Grünstein (vergl. S. 69) oder auch direkt von dem Granitgneis umgeben sind. Letzterer zeigt in der unmittelbaren Nähe des Erzzuges eine recht schwankende Ausbildung und ist selbst erzimprägniert sowie mit Klümpchen und Schlieren aus Erz, Hornblendeskarn und Grünstein gespickt; er schlägt auch in eine grauliche Gneisart vielfach

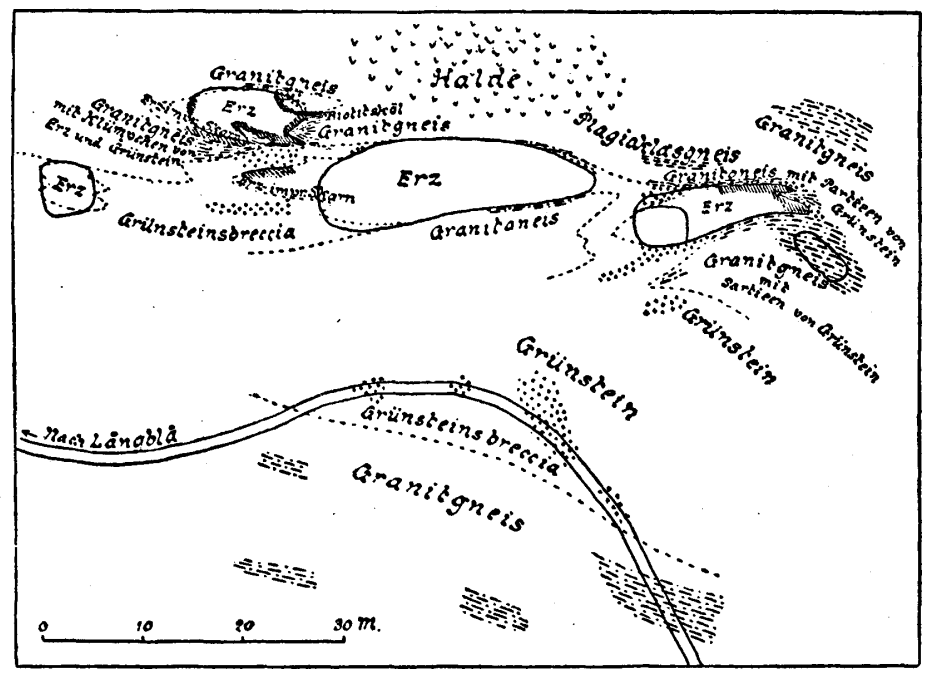

Fig. 18. Kartenskizze der Långblå-Graben.

über, die zu den Plagioklasgneisen gehören dürfte. Das Erz ist ein recht eisenreicher Magneteisenstein mit Apatit, Biotit und dunkler Hornblende als Lagerarten; letztere Bestandteile kommen auch als "Biotitskölar» und kleine Skarnanhäufungen in und neben den Erzstöcken vor. Eine von Sundholm mitgeteilte Erzanalyse zeigt $64.71 \% \mathrm{Fe}$ und $1.37 \% \mathrm{P}$.

Diese Erzvorkommen sind anscheinend von keiner grösseren praktischen Bedeutung, dagegen von nicht geringem theoretischem Interesse, indem sie eines der ziemlich seltenen Bei- 
Bd 32. H. 2.] EISENERZFÜHR. FORMATION VON GRÄNGESBERG. 117

spiele in Mittelschwedẹn von mit gröberen Gneisgesteinen eng verknüpften Eisenerzvorkommen darbieten. Dass die genetischen Beziehungen zwischen den Långblåer Apatiterzen und den umgebenden Granitgneis-Diorit-Gesteinen von ähnlicher Art sind wie z. B. diejenigen zwischen den Exportfelder Apatiterzen und ihren umgebenden Granulit-Amphibolit-Gesteinen, liegt m. E. zu bezweifeln kein Grund vor; nur trägt der letztere Gesteinskomplex Merkmale dafür, dass er einen viel durchgreifenderen Orientierungsprozess durchgemacht hat.

\section{Die schuppigen Quarzeisenerze des Grängesbergfeldes.}

Der südliche und westliche Teil des Grängesberger Erzzuges enthält hauptsächlich quarzige Roteisensteine ("Zäherze»), die zu der vorher als Lomberg-Pershytte-Typus bezeichneten, durch gleichmässige (nicht gebänderte) Struktur und schuppige Textur charakterisierten Abteilung gehören. Von diesem im ganzen etwa $4 \mathrm{~km}$ langen Zäherzzug wird der südliche, zum Län Örebró gehörige Teil als das Lombergfeld bezeichnet; die Grubenkomplexe im SW von dem Exportfeld werden als das westliche bezw. östliche Ormbergfeld abgetrennt, während die nördlichsten Gruben zu dem Risbergfeld gerechnet werden.

Der Eisenglanz dieser Erze ist immer mit Magnetit mehr oder weniger reichlich gemengt; in untergeordneter Menge kommen auch entschiedene Magneteisensteine vor, die eine mehr isometrisch körnige Textur zeigen. Die Lagerarten sind Quarz, Alkalifeldspat, Muskovit (hauptsächlich in gewissen Lombergerzen) und Biotit, meistens auch etwas Epidot, seltener Amphibol; ihre sowohl qualitative als quantitative $\mathrm{Zu}$ sammensetzung dürfte der Hauptsache nach mit derjenigen der Lomberggranulite übereinstimmen (verg]. die Analysentabellen V-IX). Im südlichen Teil des Lombergfeldes nehmen die Erze reichlich Epidot auf, wobei gleichzeitig eine Neigung zu quarzgebänderter Ausbildung merkbar wird; in den südlichsten dortigen Gruben treten schliesslich epidot- und granatführende, z. T. unregelmässig quarzgebänderte Erze von Stripa- 
[Febr. 1910.

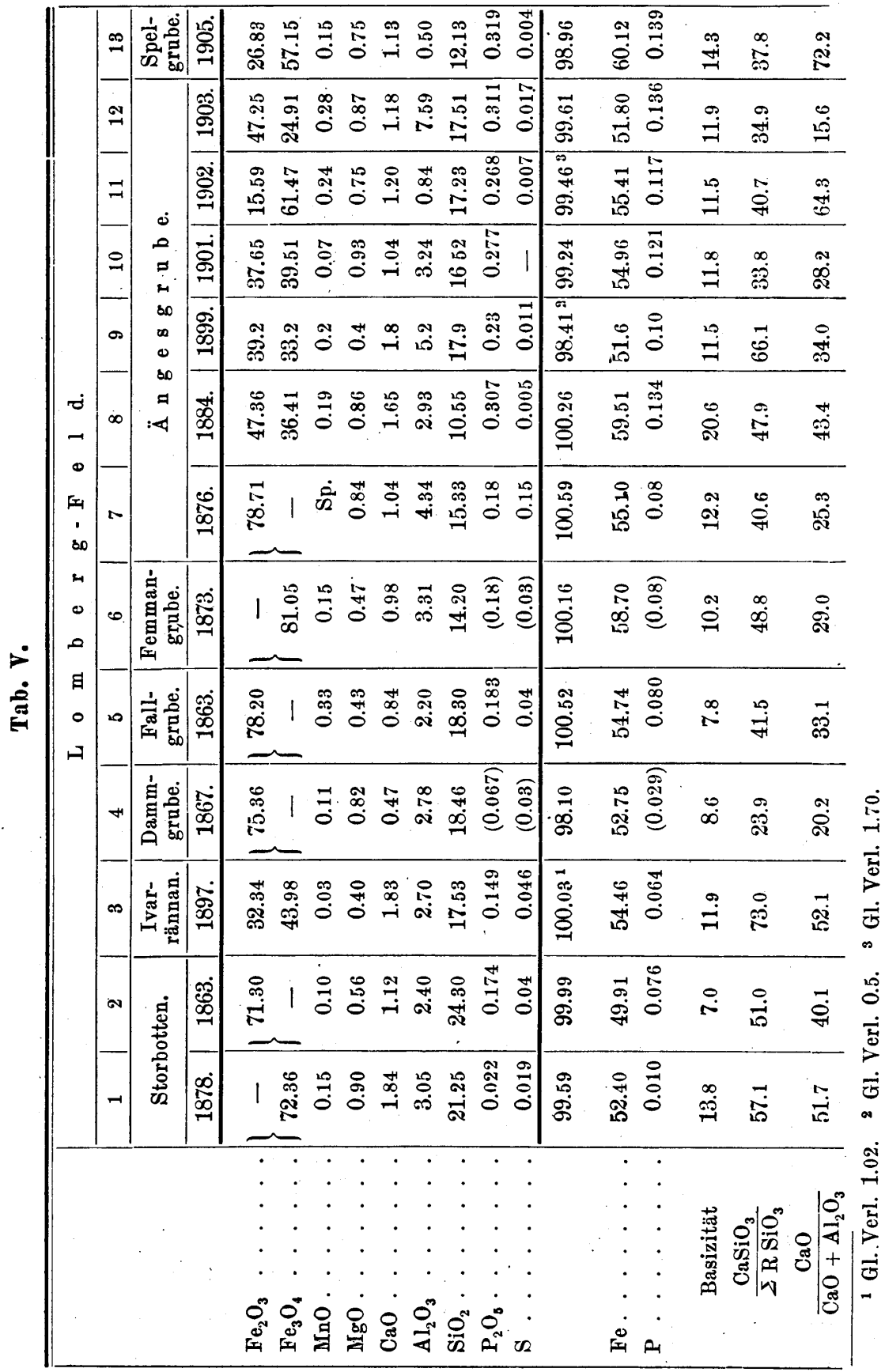


Bd 32. H. 2.] EISENERZFÜHR. FORMATION VON GRÄNGESBERG. 119

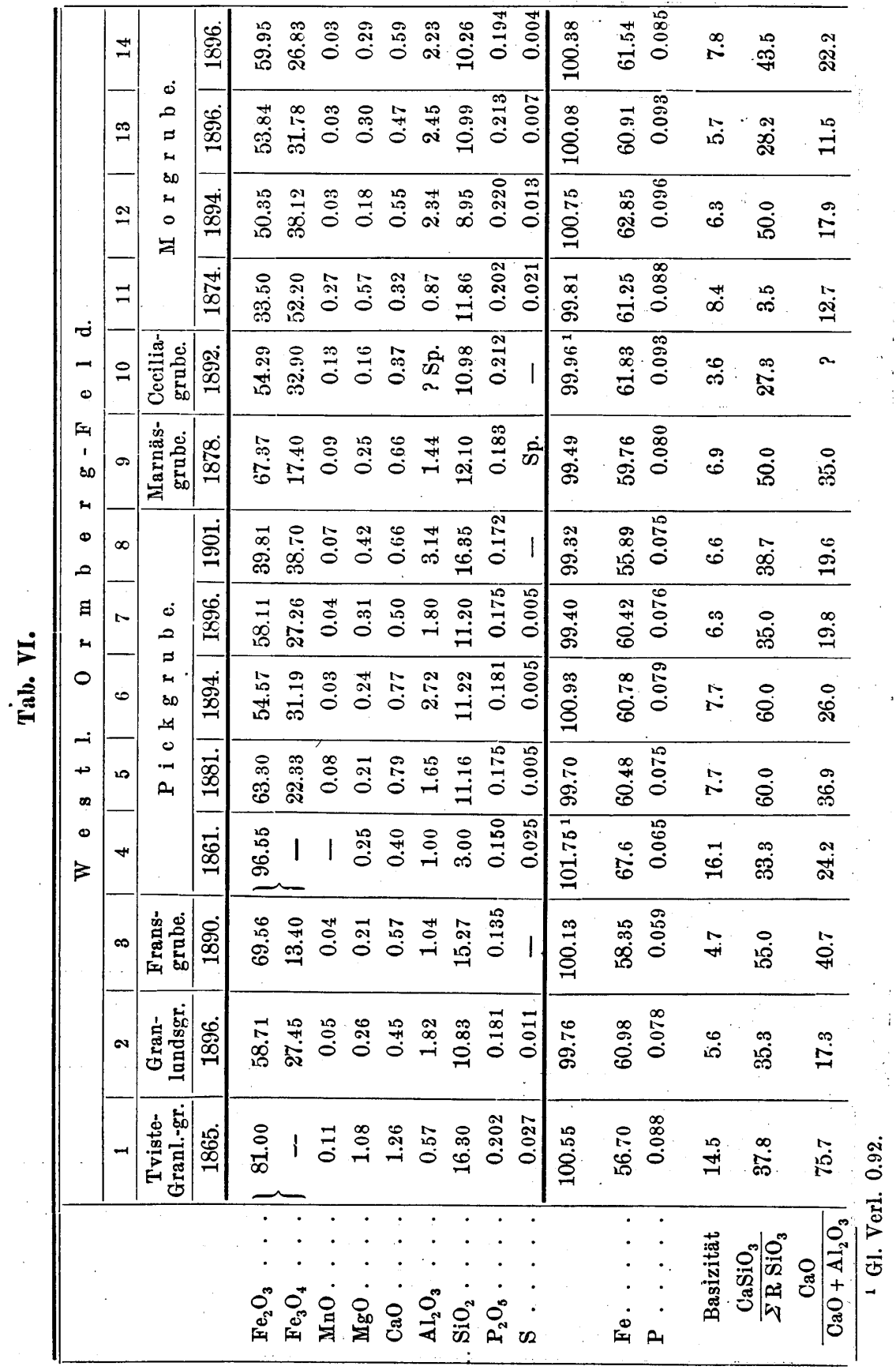

[357] 
[Febr. 1910.

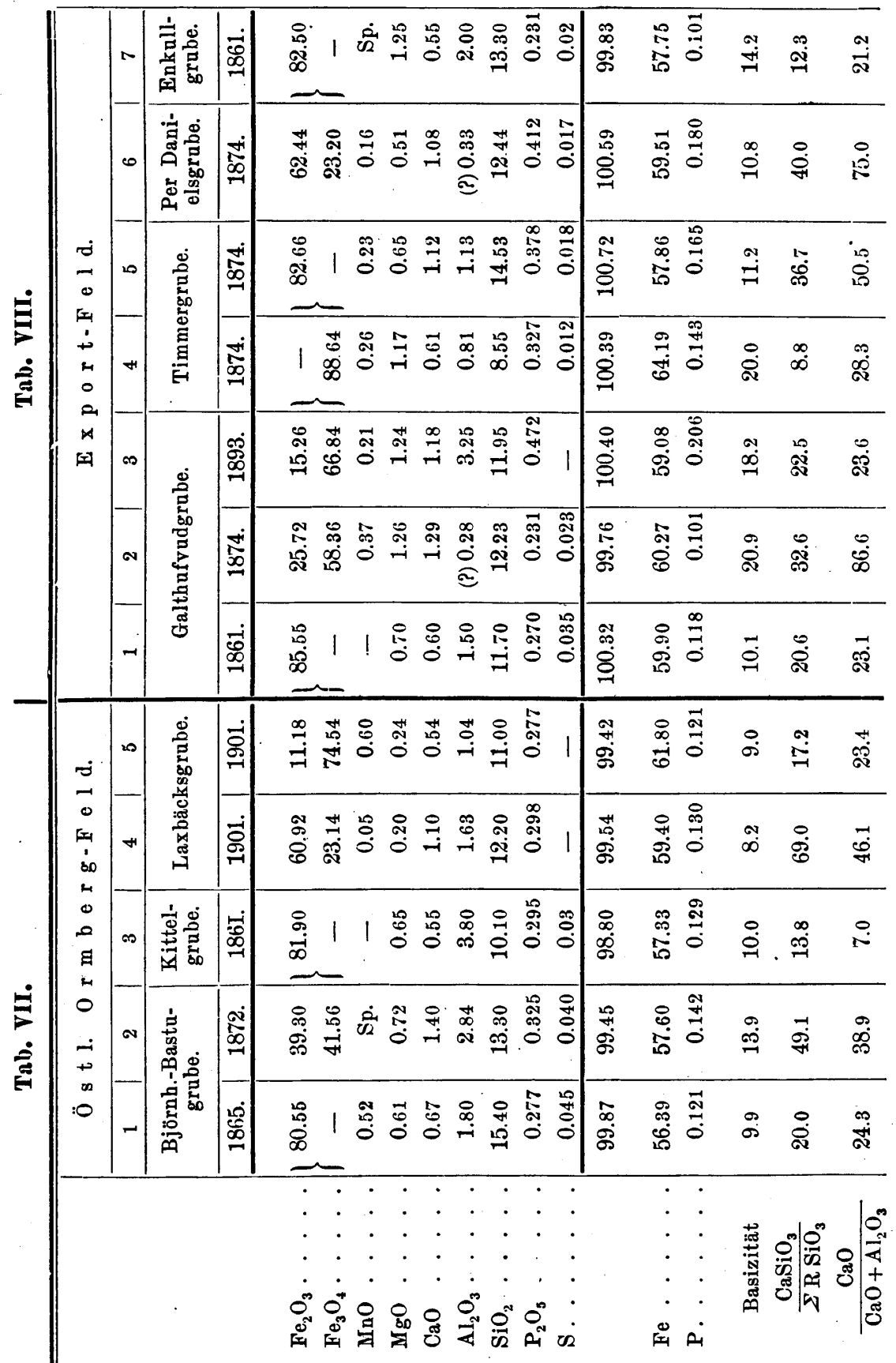


Bd 32. H. 2.] EISENERZFÜHR. FORMATION VON GRÄNGESBERG. 121

Tab. IX.

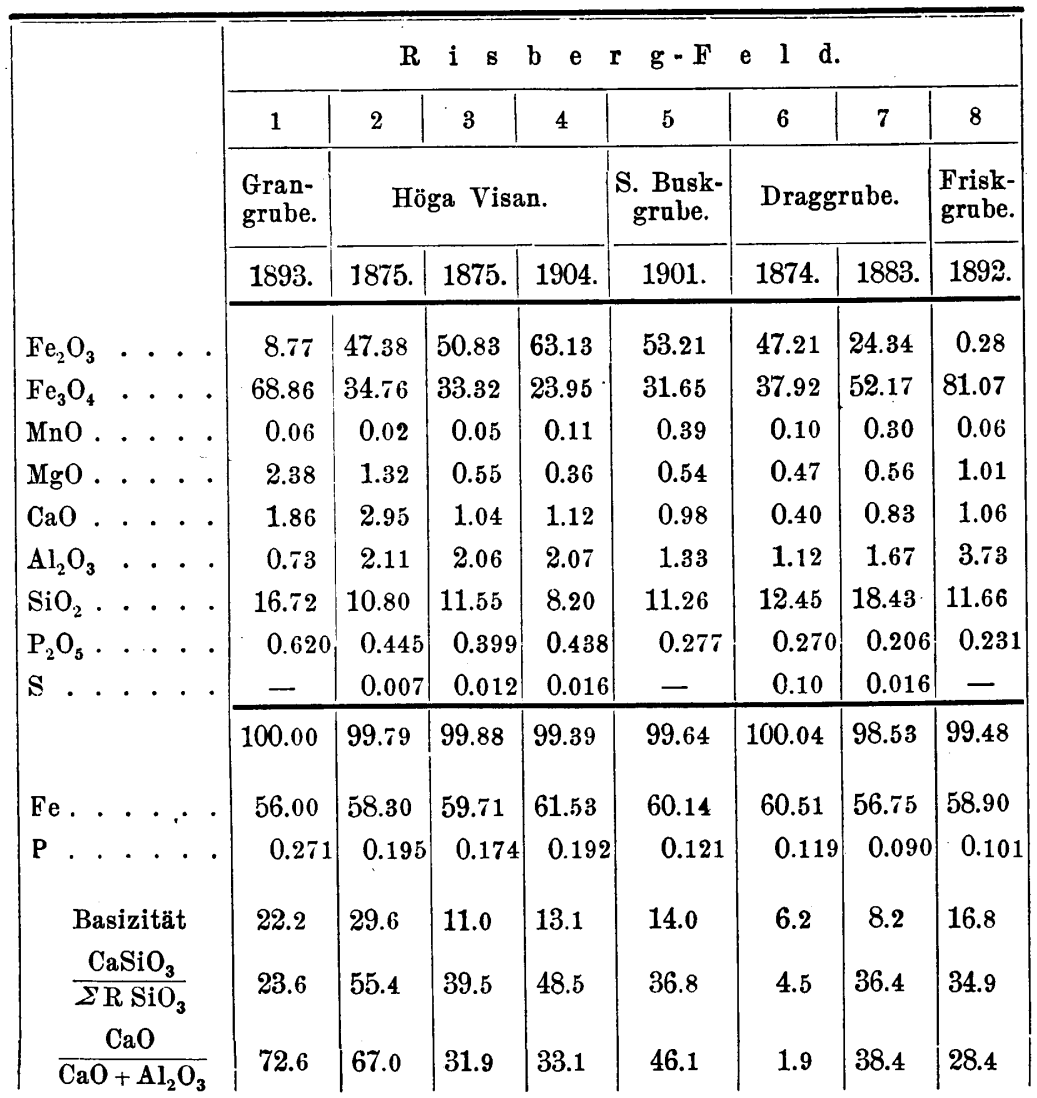

und Tuna-Hästberg-Typus anstatt der gewöhnlichen Zäherze auf. Diese Änderung in dem Erzcharakter steht in deutlicher Beziehung zu der auf S. 50 erwähnten Änderung in dem Gesteinscharakter.

Der Phosphorgehalt der Grängesberger Zäherze schwankt meistens zwischen 0.06 und $0.2 \%$ und ist somit entschieden höher als derjenige anderer mittelschwedischer Quarzeisenerze; es sieht demnach aus, als hätte der reichliche Zugang an Apatitsubstanz, der die Bildung der Grängesberger Apatiterze ermöglicht hat, auch auf die Beschaffenheit der benachbarten Quarzeisenerze einen gewissen Einfluss ausgeübt. Sowohl im 
Lombergfeld als im W. Ormbergfeld scheint der Phosphorgehalt allmählich von $\mathrm{S}$ gegen $\mathrm{N}$ zuzunehmen und erreicht sein Maximum in gewissen Gruben des Risbergfeldes. Diese Variationen können ebenfalls in Zusammenhang mit gleichzeitigen Änderungen in dem chemischen Charakter des Nebengesteins gebracht werden, indem die im südlichen Teil des Erzzuges vorwaltenden ,Lomberggranulite» gegen $\mathrm{N}$ hin immer mehr durch Gesteine des spezifisch apatitbringenden „Exportfeldtypus ersetzt zu werden scheinen.

Der Eisengehalt dieser Erze schwankt innerhalb weiter Grenzen; die reichsten Erze mit meistens 58 bis $63 \% \mathrm{Fe}$ hat das W. Ormbergfeld geliefert, während die Lombergerze im Durchschnitt etwa $58 \% \mathrm{Fe}$ enthalten. Die reicheren Erze sind regelmässig von Nebenzonen aus armen Erzen oder erzimprägnierten Granuliten umgeben, die Eisenglimmerschiefern ähnlich aussehen (Fig. 6, Taf. I). Die Erze dieses Typus treten somit in engeren Verband mit den umgebenden Granulitgesteinen ein, als es bei anderen mittelschwedischen Erztypen der Fall ist. Die vorhandenen $Z_{w}$ wischengesteine sind indessen niemals homogen ausgebildet, sondern zeigen immer eine ausgeprägte Tendenz, das Erz für sich als reichere Partien auszuscheiden, während die Lagerarten als damit abwechselnde rötliche granulitische Bänder und Linsen oder sogar als scharf begrenzte hellrote Lageraplite und Lagerpegmatite ausgesondert sind. Von den letztgenannten, überall in den Zäherzen zu beobachtenden pegmatitischen Ausscheidungen sind zu unterscheiden die besonders im Risbergfelde zahlreich einbrechenden, flach gelagerten Pegmatitgänge, die zu demselben Gangsystem wie die Exportfelder Pegmatite gehören dürften und ebenso wie diese eine Umwandlung der Glanzeisenerze in Magneteisenerze an ihren Seiten immer bewirkt haben.

Die einzelnen Zäherzkörper zeigen im Grundriss meistens langgestreckte Linsenform. Dabei sind öfters mehrere solche Erzlinsen nach und neben einander zu langen und schmalen Erzzügen geordnet. Eine stratigraphische Niveaubeständigkeit 
besteht jedoch niemals, sondern die Erzlinsen zeigen gewöhnlich eine staffelartige Anordnung oder anderlei Unregelmässigkeiten. Ein gutes Beispiel dieser Erscheinungsweise liefert der zu dem Risbergfeld gehörige, beinahe $900 m$ lange Erzzug, auf dessen südlichem Teil die Grube »Höga Visan» baut. - Die Ormberger Erzzüge weichen durch eine mehr komplexe, schwarmartige Gruppierung der Erzkörper ab. Zumal in den nördlichen dortigen Gruben haben die Erze weniger langgestreckte und ziemlich unregelmässige Formen gezeigt. Diese Besonderheiten in der gröberen Architektur spiegeln sich treu in den unregelmässigen eutaxitartigen Strukturen der die Reicherze umgebenden Imprägnationszonen ab. - Nach der Tiefe zu haben sich die Zäherze meistens gut beständig erwiesen und scheinen der Hauptsache nach auch in dieser Richtung eine langgestreckte Linsenform mit in der Schichtebene steil südlich gerichteten oder aufrechten Linsenachsen zu besitzen. Eine ungewöhnlich regelmässige, fast idealische Linealform hat der in der Alten Granlundsgrube im W. Ormbergfeld gebaute Erzkörper gezeigt, welcher mit einer höchstens $28 m$ betragenden horizontalen Länge von der Oberfläche aus bis zu $380 m$ vertikaler Tiefe zu verfolgen war, einer Länge von etwa $470 m$, nach der Linealachse gerechnet, entsprechend. Nach HEDBERG's Angaben haben sowohl die Zäherzlinsen als auch der Exportfelder Erzkomplex ihre grösste horizontale Sektionsarea in einer Tiefe zwischen 100 und $200 m$ unter der jetzigen Oberfläche gezeigt.

\section{Die Skarn- und Kalkeisenerze des Björnbergfeldes.}

Fig. 19 stellt die geologischen Verhältnisse im nördlichen Teil des Björnbergfeldes dar. Die Gruben sind in zwei Zügen gereiht, die durch ein Band aus dioritischem Amphibolit getrennt sind. Der westliche Erzzug enthält in seinem nördlichen Teil eine Reihe stockförmiger Skarnerzlagerstätten, die jedoch insgesamt schon oberhalb $100 \mathrm{~m}$ Teufe ausgekeilt haben. Die Erze (Anal. 1-4, Tab. X) waren körnige, ziemlich eisen- 
reiche Magneteisensteine mit Lagerarten von grünem Pyroxen und dunklem Amphibol. Sie waren zunächst von kleineren Pyroxen-Amphibolskarnmassen umgeben, die dann auf den Seiten in inhomogene Skarn-Plagioklasgranulit-Mischgesteine übergehen. Zumal in der Djupgrube sind die Skarngesteine

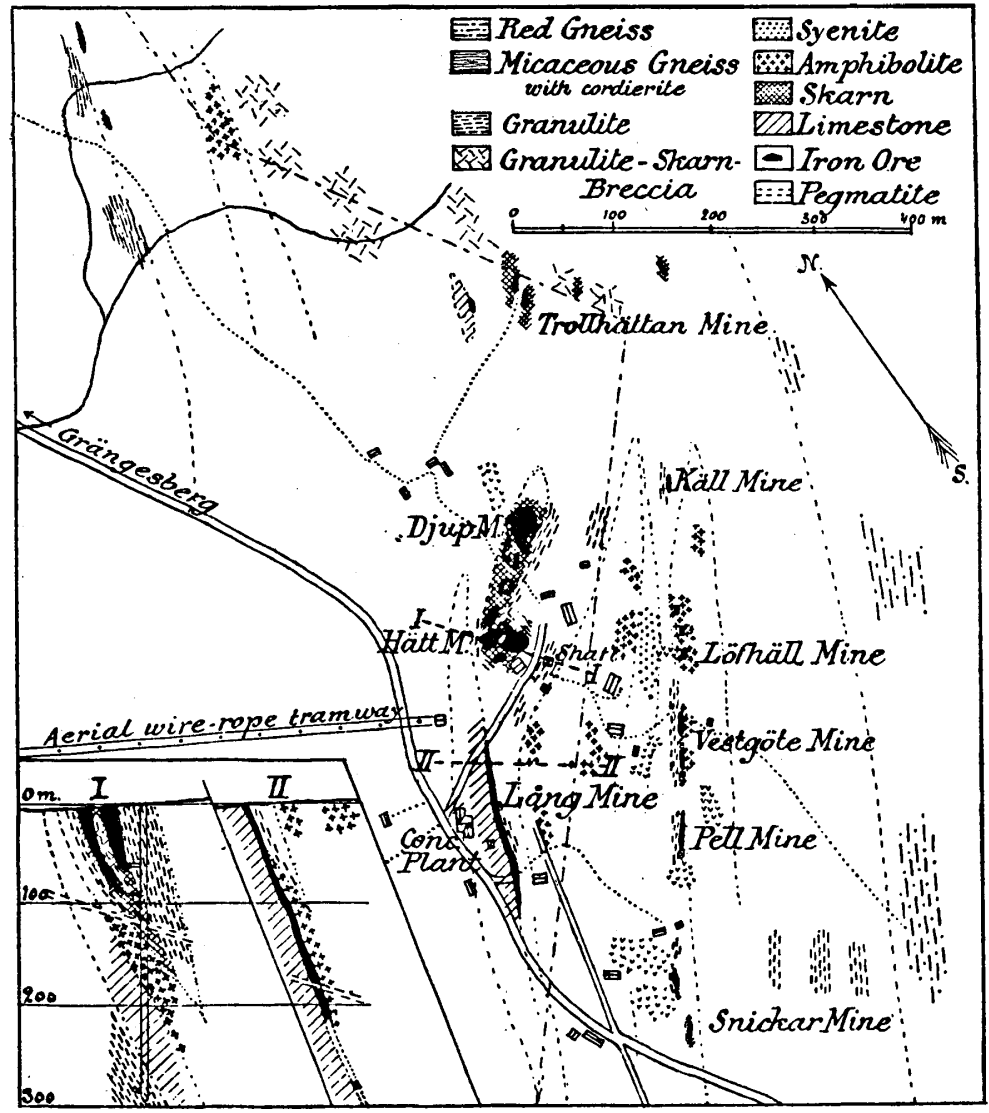

Fig. 19. Geologische Kartenskizze des Björnberger Erzfeldes.

und auch das Erz öfters von Glimmeradern netzartig durchwachsen. Einzelne Adern erreichen eine Breite von mehreren $d m$ und sind im Inneren mit einem grobkörnigen Gemenge aus Glimmer, Hornblende, Pyroxen und Kalzit ausgefüllt, während an beiden Seiten sich eine Schicht aus grossen, senkrecht zu 
Bd 32. H. 2.] EISENERZFÜHR. FORMATION VON GRÄNGESBERG. 125 dem Salband gestellten Tafeln eines phlogopitischen Glimmers angesiedelt hat. Diese Glimmergänge dürften den canadensischen Phlogopitlagerstätten sehr ähnlich sein, sind jedoch offenbar zu klein, um eine praktische Bedeutung beanspruchen zu können.

Tab. $\mathbf{X}$.

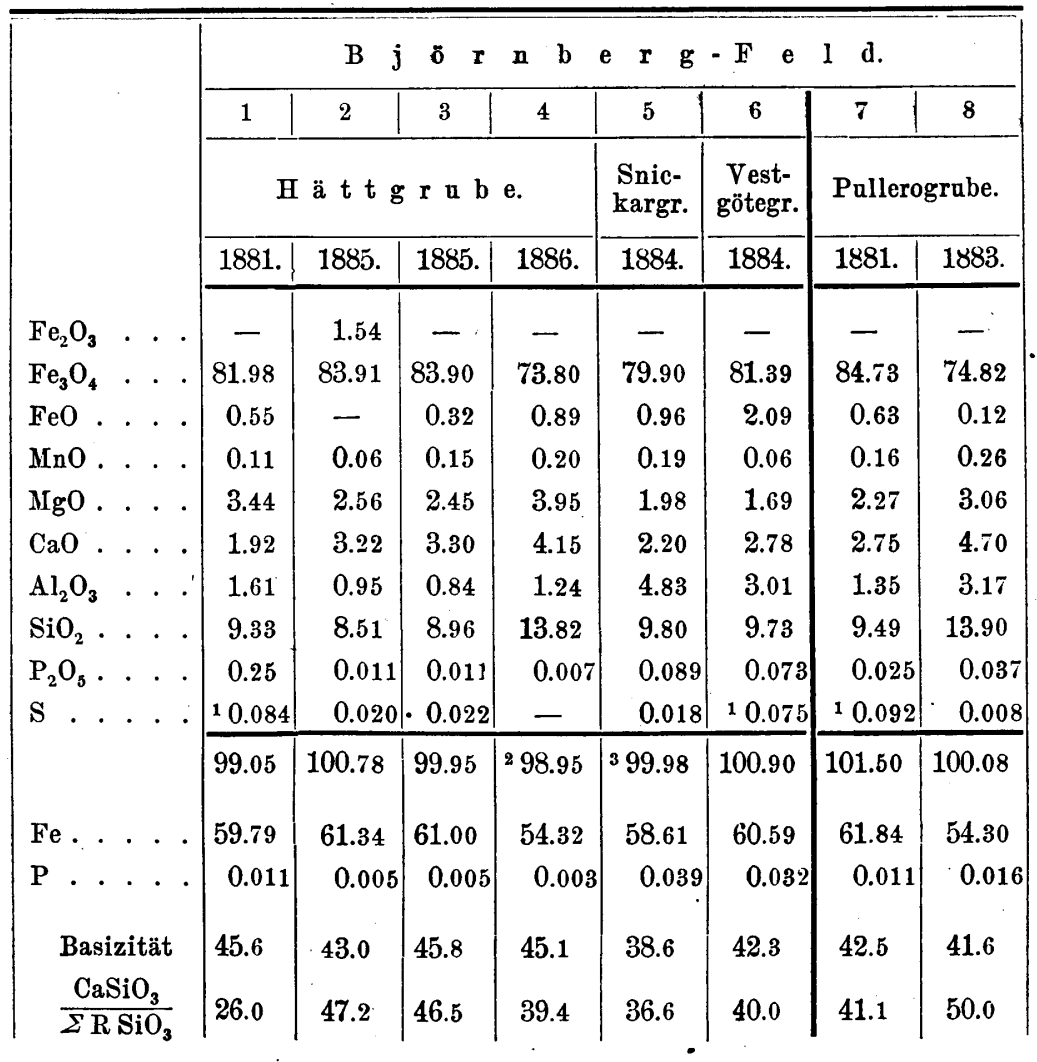

In der südlichen Fortsetzung dieses Skarnerzzuges ist die noch gebaute Lainggrube gelegen. In dieser Grube ist eine etwa $140 m$ lange und im Maximum 8-9 $m$ breite, steil aufgerichtete Kalkeisenerzlinse bis zu $280 \mathrm{~m}$ Tiefe verfolgt worden. Sie lagert grösstenteils zwischen Serpentinkalkstein

\footnotetext{
$1 \mathrm{FeS}_{2}$.

2 Gl. Verl. 0.89.

$3 \mathrm{As} 0.008$.
} 
im Liegenden und Grünstein im Hangenden. Das Erz ist ein grobkörniger, nicht sehr eisenreicher Magneteisenstein mit Lagerarten aus Kalzit, Serpentin und ein wenig Amphibol (Anal. 1-6, Tab. XI). Die Grenze gegen den Kalkstein ist in transversaler Richtung meistens eine recht scharfe, in longitudinaler dagegen eine mehr unbestimmte infolge allmählicher Verdünnung des Erzes mit Kalzit an den Enden der Linse. - Weiter südlich kommen ähnliche Kalkeisenerze in der Pullero Limgrube vor, die durch ihren verhältnismässig hohen Phosphorgehalt bemerkenswert sind (Anal. 7-9, Tab. XI).

Tab. XI.

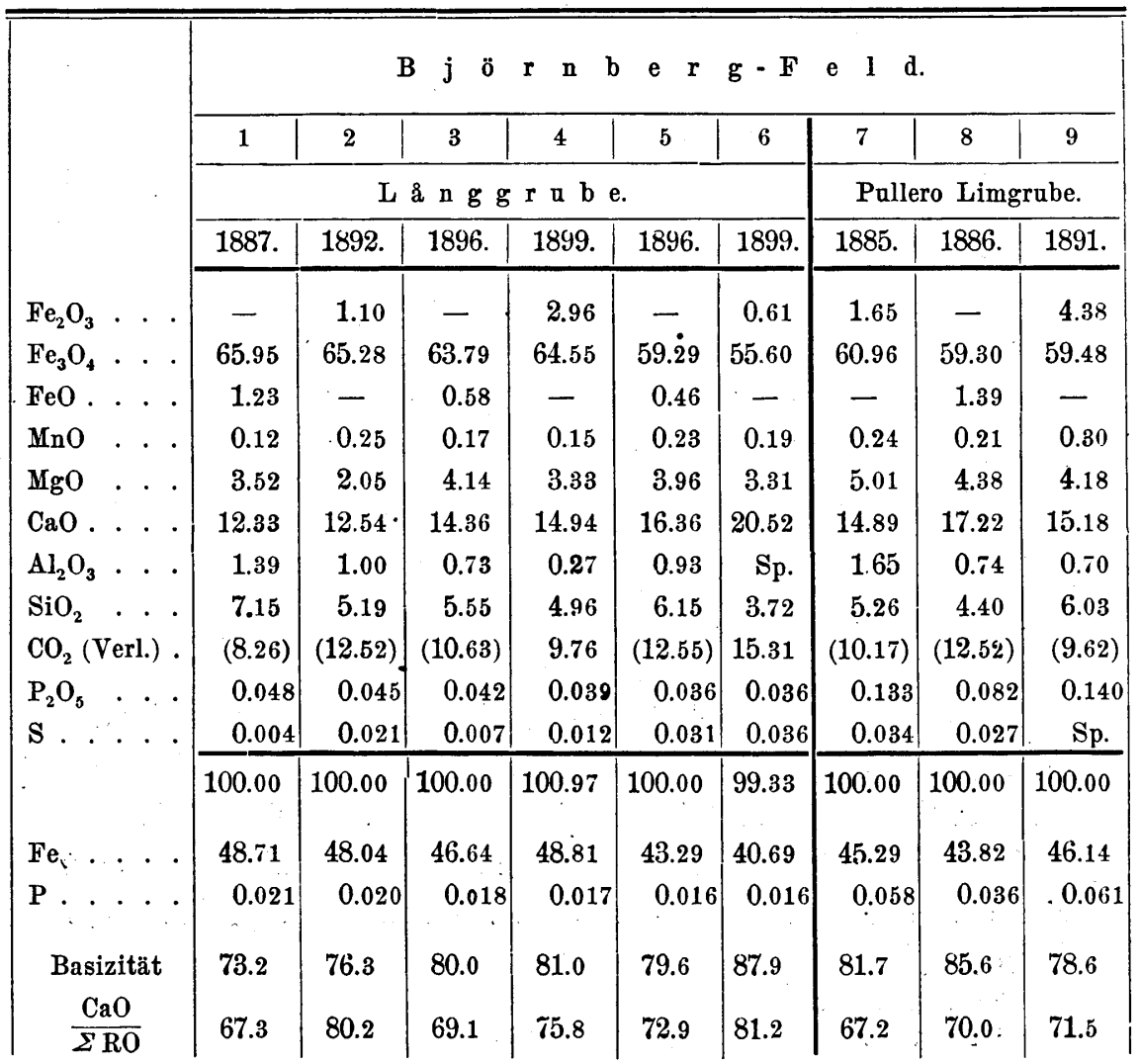


Der östliche Erzzug enthält nur Skarneisenerze, die neben Pyroxen und dunklem Amphibol bisweilen etwas Quarz führen und meistens auch mit viel Schwefelkies gemengt sind (Anal. 5-8, Tab. X). Eigentliche Skarngesteine kommen hier kaum vor, sondern die Erze scheinen ziemlich unvermittelt in inhomogenen, dunkelschlierigen, zu quarzsyenitischer Ausbildung neigenden Granulitgesteinen (vergl. S. 65) oder auch in Pyroxenund Magnetitamphiboliten zu lagern.

\section{Die Sulfiderze.}

Unter den spärlichen Sulfiderzvorkommen des Grängesberggebietes gehören die auf S. 68 erwähnten Magnetkiesvorkommen am Aborrtjärn offenbar zu dem Typus: Magnetkiesausscheidungen in gabbroiden Gesteinen. Innerhalb des auf S. 63 erwähnten, kleinen Eisenerzzuges westlich vom Björnberget ist auch ein Schurf auf quarzigen Magnetkies aufgenommen, der, mit Magnetit gemengt, eine Ausscheidung in einem inhomogenen Quarzamphibolit zu bilden scheint. Ein anderer Lagerstättentypus, nämlich Magnetkies und Kupferkies als innige Imprägnation eines Granatskarns, wurde in einem kleinen Schurf in dem Gudmundbergfeld beobachtet. Bei Silfverhyttan, ein wenig westlich von der Eisenbahnstation Bergslags-Hörken, finden sich mehrere alte Gruben mit Kupfer- und Bleierzen, die in einer ultrasauren, quarzitischen Facies der dortigen Granulitgesteine auftreten. Schliesslich ist zu erwähnen eine am Hötjärn, zwischen Lomberg und Silfverhöjden, gelegene Molybdenglanzlagerstätte; das Erz kommt in einem ultrasauren, nur sehr wenig Feldspat enthaltenden Pegmatit vor, der eine stockförmige Ausscheidung in rötlichen, etwas porphyrischen Hornblendegranuliten bildet.

\section{Die Granite.}

Das Gestein, welches das ziemlich hohe und steile Gebirge Örtjärnsfjället aufbaut, ist ein mittelkörniger Biotitgranit von 
rötlicher oder rötlich grauer Farbe. Die Struktur erscheint durchaus massig; auf den Bruchflächen treten zahlreiche, etwa cm-lange, karlsbaderverzwillingte Kalifeldspate hervor. Eine Probe einer relativ biotitreichen, im NW des Örtjärnsdammen anstehenden Varietät zeigte im Dünnschlift einen Mineralbestand aus $24.9 \%$ Quarz, $30.4 \%$ Mikrolilinperthit ${ }_{\text {II }}, 31.0 \%$ Oligoklas, $11.4 \%$ Biotit und 2.3\% Titanit nebst Apatit und Zirkon. Die Mikrostruktur lässt nicht viel von jener hypidiomorphen Ausbildung der Gemengteile erkennen, die Granite charakterisieren soll; vielmehr stimmt sie in mehreren Hinsichten mit der Struktur der vorher beschriebenen granitgneisigen Gesteine überein, obwohl die stengelige Orientierung dieser Gesteine hier ganz vermisst wird. Der Quarz ist grösstenteils in mosaikstruierten undulösen Feldern gesammelt. Der Mikroklinperthit ist fast.völlig in den grösseren Karlsbaderzwillingen vorhanden; er zeigt gute Mikroklingitterung mit reichlichen perthitischen Spindeln, deren Menge auf ein Ab-reicheres Glied der Abteilung II deutet. Der Plagioklas entspricht nach der fast geraden Auslöschung einem Glied $\mathrm{An}_{21} \mathrm{Ab}_{79}$ mit etwas basischeren Kernen in den grösseren Körnern; er kommt z. T. als Aggregate von bis zu $2 \mathrm{~mm}$ Korngrösse, grossenteils aber als ein verworrenes myrmekitisches Grundgewebe zwischen den grösseren Mikroperthiten vor (Fig. 4, Taf. 1). Der Biotit zeigt ebenso lappige und formlose Ausbildung wie in den Granitgneisen; der Titanit bildet bis sogar $4 \mathrm{~mm}$ lange Kristalle. Flussspat scheint einen sehr verbreiteten Übergemengteil dieses Granites zu bilden. - Wenn wir in diesem Granit einen Mikroklinperthit $\mathrm{Or}_{70} \mathrm{Ab}_{28} \mathrm{An}_{2}$ neben einem Oligoklas $\mathrm{Or}_{7} \mathrm{Ab}_{73} \mathrm{An}_{20}$ annehmen, berechnet sich nach den volumenometrischen Bestimmungen das Feldspatverhältnis $O r_{38 \cdot 2} A b_{50 \cdot 7} A n_{11 \cdot 1}$. Der Granit steht demnach in Bezug auf den An-Gehalt etwa in der Mitte zwischen den Gneisen des Granitgneistypus und denjenigen des roten Gneistypus unserer Gegend, gehört jedoch zu einer etwas kalireicheren Gesteinsreihe, obwohl er dennoch natron- 
Bd 32. H. 2.] EISENERZFÜHR. FORMATION VON GRÄNGESBERG. 129

reicher ist als die meisten schwedischen Granit- und Gneisgesteine von entsprechendem An-Gehalt.

In der Fortsetzung des Ortjärnsfjäll-Granits nach NO hin wird das Gestein allmählich basischer, Hornblende tritt hinzu und der Plagioklas wird An-reicher, etwa $\mathrm{An}_{25} \mathrm{Ab}_{75}$; durch Zurücktreten der grösseren Karlsbaderfeldspate erscheint das Korn etwas feiner, und eine schwache Parallelstruktur kommt öfters zum Vorschein.

Wie aus der obigen Darstellung hervorgeht, schliesst sich der Örtjärnsfjäll-Granit sowohl in struktureller als in chemisch-mineralogischer Hinsicht dem Grängesberger Granitgneis etwas an. Auch die Form des Massives nähert sich der stumpfen Linsenform gewisser zu der eisenerzführenden Formation gerechneten Gneise unseres Gebietes. Obwohl unmittelbare Kontakte zwischen dem Granit und den umgeben- . den Granuliten niemals gesehen wurden, geht indessen aus einigen Observationen in der Umgebung des Dorfes Ortjärn hervor, dass der Granit hier mit einer Ausbuchtung die in der Nähe anstehenden Plagioklasgranulite schief überquert; in einem Granitfelsen bei dem dortigen Schulhaus wurde auch ein scharf begrenztes Bruchstück von Plagioklasgranulit beobachtet. Wenn man nach Blöcken zu kartieren wagte, würde eine ähnliche überquerende Ausbuchtung auch südlich von Örtjärnsdammen gezeichnet worden sein. Die Bedeckung steht übrigens einer genaueren Auffassung von der Erscheinungsart dieses jüngeren Granits im Wege. Wenn man die vorzügliche Zerklüftung und Bankung des Gesteins als eine durch die anfänglichen Abkühlungsverhältnissen. bedingte Erscheinung auffasst, könnte das Massiv als eine lakkolithische Aufwölbung gedeutet werden; nach einer anderen und anscheinend gut begründeten Anschauung ${ }^{1}$ braucht eine derartige Zerklüftung jedoch nicht durch die ursprünglichen Abkühlungsverhältnisse bedingt zu sein, sondern hängt vielmehr mit der jetzigen Oberflächengestaltung zusammen. - Die grosse petrographische

\footnotetext{
1 Vgl. T. Nelson DaLe: Bull. U. S.. G. S. Nr. 313, S. 30-38.
} 
Übereinstimmung mit dem sogleich zu beschreibenden Enkullen-Granit dürfte jedenfalls dafür sprechen, dass irgend ein $\mathrm{Zu}$ sammenhang zwischen den beiden Granitmassiven in tieferen Niveaus besteht. Bei dieser Gelegenheit könnte auch erwähnt werden, dass ein flacher Gang aus einem dem Örtjärnsfjäll-Granit ziemlich ähnlichen Gestein in der Kalbengrube im Blötberget das Apatiteisenerz und dessen Nebengestein scharf durchsetzt.

Der Granit im südöstlichen Teil des Kartengebietes bildet den nördlichsten Ausläufer eines grossen Granitterrains, dessen Ausdehnung auf den Blättern IV und V der TöRnевонMschen Übersichtskarte zu sehen ist. Das Gestein, welches in zahlreichen Hügeln in der Umgegend von Enkullen ansteht, stimmt mit den salischeren Varietäten des Örtjärnsfjäll-Granits makroskopisch ziemlich nahe überein, ist jedoch etwas gröber mit bis $15 \mathrm{~mm}$ langen und $8 \mathrm{~mm}$ breiten Kalifeldspatkristallen. Die Struktur ist durchaus massig. Basische Konkretionen und saure pegmatitische Adern sind nicht selten zu sehen. Ein Gestein an der Chaussee etwa $1300 \mathrm{~m}$ nördlich von Råbron zeigte im Dünnschliff einen Mineralbestand aus $28.5 \%$ Quarz; $39.5 \%$ Mikroklinperthit mit reichlichen Albitspindeln, etwa $\mathrm{Or}_{70} \mathrm{Ab}_{28} \mathrm{An}_{2} ; 27.3 \%$ Oligoklas, im Durchschnitt etwa $\mathrm{Or}_{8} \mathrm{Ab}_{76} \mathrm{An}_{16}$ mit basischeren Kernen und etwas saureren Hüllen; $4.0 \%$ Biotit; $0.7 \%$ Epidot nebst etwas Apatit.und spärlichem Titanit. Daraus berechnet sich ein Feldspatrerhältnis $O r_{44 \cdot 7} A b_{47 \cdot 6} A n_{7 \cdot 7}$, was einem etwas salischeren Glied aus der Granitreihe des Örtjärnsfjäll-Granits entspricht. Die Struktur ist ziemlich typisch hypidiomorph-körnig. - In der Fortsetzung gegen 0 , ausserhalb der Kartengrenze, nimmt das Gestein einen etwas femischeren Charakter an und zeigt eine mit dem oben beschriebenen Örtjărnsfjäll-Granit fast ganz übereinstimmende Struktur und Zusammensetzung. Mit dem Enkullen-Granite gehört auch derjenige von WeIBULL ${ }^{1}$ beschriebene Granit zusammen, der bei Tennberget, ein wenig östlich von der Kartengrenze, ein Vorkommen von Diopsid-

${ }^{1}$ G. F. F. 18 (1886): 73-93. 
Bd 32. H. 2.] EISENERZFÜHR. FORMATION VON GRÄNGESBERG. 131

Kalkstein mit Vesuvian, Wollastonit und Granat einschliesst. Dieser Granit ist nach WEIBULL ein mittelkörniger, rötlichgrauer Biotitgranit mit grösseren Tafeln von einem Mikroklinperthit ohne regelmässige Mikroklingitterung und mit ziemlich reichlichen Albitspindeln, nach einer angeführten Alkalibestimmung der Durchschnittszusammensetzung $\mathrm{Or}_{73 \cdot 6} \mathrm{Ab}_{\mathbf{2 6} \cdot 4}$ entsprechend.

Die Kontakte des Enkullen-Granites gegen die Gesteine der eisenerzführenden Formation sind in unserem Gebiet niemals entblösst. Der Granit scheint indessen jene rundlichgebuchtete Umgrenzung $\mathrm{zu}$ haben, die nach TörneBoнM ${ }^{1}$ für die sjüngeren Granite» des mittleren Schwedens im allgemeinen bezeichnend ist, gleichwie wenn durch ein allmähliches Ablösen und Niedersinken von Schollen der Granulit- und Gneisgesteine Platz für diese Granite entstanden wäre.

\section{Die Diabase.}

Das ganze Kartengebiet ist von einem wahrscheinlich kontinuierlich fortlaufenden Diabasgang durchzogen. Der südlichste Ausbiss ist bei Pullero beobachtet; von dort aus ist der Gang durch zahlreiche Ausbisse in der Richtung nach $\mathrm{N} 30^{\circ} \mathrm{W}$ bis nach Laritstorp gut zu verfolgen; der weitere Verlauf ist nach einem Ausbiss an der. Chaussee nach Björnhyttan und einem anderen auf dem südöstlichen Abhang der Saxbergerhöhung gezeichnet.

Die Breite des Ganges scheint etwa 20 bis $30 \mathrm{~m}$ zu betragen. Die Hauptmasse ist von mittelgrobem Korn mit Plagioklastafeln von etwa 4-5 $\mathrm{mm}$ Länge; nach den Salbändern hin tritt eine rasche Verdichtung eín. Eine Probe des zentralen Diabases bei Pullero ergab folgenden Mineralbestand: $L a$ brador-Oligoklasandesin 54.3\%; anorthoklasartiger PlagioklasOrthoklas $_{\mathrm{IV}}$ 15.3\%; Quarz, z. T. als Mikropegmatit, etwa 3.0\%;

1 Erläuterungen zu der geol. Übersichtskarte von Mellersta Sveriges Bergslag, S. 21.

$10-100170$. 
Augit 11.7 \%; Olivin und Olivinpseudomorphosen 4.7\%; Eisenerz $6.5 \%$; braune und grüne Hornblende nebst Biotit etwa $4.5 \%$ Dieser Diabas gehört demnach zu einem sehr salischen Typus und wäre wahrscheinlich in dem amerikanischen Systeme unter die «Andose» einzureihen. Der Plagioklas ist zonar gebaut; die basischsten Kerne der tafeligen Individuen scheinen aus einem Labrador mit 55 bis $60 \%$ An zu bestehen; davon sinkt die Basizität zuerst langsam bis zu einem basischen Andesin, etwa $\mathrm{An}_{45} \mathrm{Ab}_{55}$, dann rasch bis zu etwa $\mathrm{An}_{30} \mathrm{Ab}_{\mathbf{7 0}}$ hinab. Dem letztgenannten Plagioklase ist ohne jede optische Diskontinuität ein etwas bräunlich bestäubter Feldspat angewachsen, der in symmetrischen Schnitten annähernd gerade auslöscht, in Schnitten annähernd nach $\mathrm{M}$ eine von $0^{\circ}$ bis $\mathrm{zu}$ etwa $+10^{\circ}$ allmählich steigende Auslöschungsschiefe zeigt und bisweilen eine perthitische Fleckigkeit erkennen lässt. In dieser Feldspatzone, welche die "Mesostasis" dieses Diabases bildet, dürfte sich demnach die Zusammensetzung von Oligoklasandesin aus durch kalireiche Oligoklasglieder, vielleicht von Rhombenfeldspat-Charakter, bis zu einem natronreichen Orthoklas IV kontinuierlich ändern; sie ist mit Nadeln eines anscheinend farblosen Minerals gespickt und umgiebt sich gegen die Olivin- und Augitkörner hin mit einer Reaktionszone aus grünen Hornblendefetzen, die dann in etwas kompaktere braune Hornblende übergehen. In den Zentren der Zwickel finden sich meistens einige Körner aus Quarz, die z. T. mit dem äussersten, den Plagioklastafeln angewachsenen Orthoklassaum mikropegmatitisch verwachsen sind. Die Olivinkörner sind meistens unter reichlicher Erzausscheidung in Iddingsit umgewandelt. Der Pyroxen ist ein blasser, obwohl deutlich pleochroitischer Diabasaugit, bisweilen mit eingeschlossenen. Resten einer stengeligen, schwächer doppeltbrechenden, grösstenteils zersetzten Pyroxenart, die wohl als Hypersthenaugit aufzufassen ist. Titaneisenerz kommt in langen Stäben und dendritischen Partien vor.

Der Kristallisationsprozess dieses Gesteins ist offenbar zu 
schnell vorgegangen, als dass tiefer eingreifende Umsetzungen zwischen den festen Ausscheidungen und der flüssigen Phase sich während desselben abspielen konnten; andererseits war er nicht schnell genug, um derartige Reaktionen vollständiger auszuschliessen. Die Ausbildung des Gesteins könnte etwa zu den folgenden Vorstellungen bezüglich seiner Entwickelungsgeschichte Anlass geben. Die Kristallisation ist in drei, allerdings nicht scharf getrennten Phasen vor sich gegangen. ${ }^{1}$ Die erste Phase wurde durch eine Ausscheidung von Kristallkeimen aus basischem Labrador oder vielleicht Bytownit eingeleitet, wozu sich Keime aus Olivin und Erz gesellten. In dem weiteren Verlauf vollzog sich unter geringer chemischer Ausgleichung die Ausscheidung des Plagioklases bis zu dem basischen Andesin; die Olivin- und Erzkeime wuchsen fort, und es schied sich ein Teil des Augites aus, der wahrscheinlich anfangs eine den Hypersthenaugiten näher kommende, an den ( $\mathrm{Mg}, \mathrm{Fe}) \mathrm{SiO}_{3}-\mathrm{Komponenten}$ reichere Zusammensetzung hatte. Am Ende dieser ersten sgabbroiden Kristallisationsphase war nur ein geringer Magmarest in den Zwischenräumen der früheren Ausscheidungen übrig, der eine mit gewissen Syeniten, und zwar den Laurvikiten, wahrscheinlich übereinstimmende Zusammensetzung hatte. Während der jetzt folgenden "syenitischen» Kristallisationsphase setzte sich die Augit- und Erzausscheidung anfangs fort, hörte aber auf in dem Masse, wie der flüssige Rest infolge der gleichzeitigen Ausscheidung der saureren Plagioklaszonen alkalireicher, speziell kalireicher, und ziemlich sauer geworden war, wonach sich sogar eine Umwandlung dieser Minerale zu Hornblende und Biotit überall dort einstellte, wo der flüssige Rest mit den früheren femischen Ausscheidungen in Berührung kam. Nach der Beendigung der zweiten Phase fanden sich nur einige kleine flüssige Reste in den $Z_{w}$ wickeln zwischen den Feldspattafeln, in welchen sich die Alkalifeldspatsilikate und die freie Kieselsäure angereichert hatten. Während der dann fol-

1 Vergl. G. F. F. 28 (1906): 523. 
genden "granitischen» Kristallisationsphase setzte sich aus dieser Flüssigkeit ein natronreicher Orthoklas auf die umgebenden Feldspattafeln ab; dadurch wurde der flüssige Rest schliesslich sauer genug, um eine Kristallisation von Quarz zu erlauben. Der allerletzte flüssige Rest wurde zu einer gleichzeitig kristallisierten mikropegmatitischen Verwachsung von Quarz und Orthoklas ${ }_{\text {IV }}$, ganz nach der Art der, eutektischen Mischungen.

Der Salbandsdiabas ist ähnlich zusammengesetzt, entbehrt jedoch den Olivin und enthält nadelkopfgrosse, mit Chlorit und Quarz ausgefüllte Poren. Westlich vom Örabergsdammen wurde an dem östlichen Salband des Ganges eine bemerkenswerte Entwickelungsform dieses Diabases beobachtet. Das feinkörnige Gestein ist hier mit bis $\mathrm{zu} 2 \mathrm{~cm}$ langen, gerundet elliptischen Feldspatkristallen gespickt, die im frischen $\mathrm{Zn-}$ stand eine dunkelgraue Farbe zeigen, öfters aber durch eine Art von Umwandlung gerötet worden sind. Die Feldspate sind unscharf von der Diabasmasse abgegrenzt und schliessen an der Peripherie die normalen Diabasgemengteile poikilitisch ein. Im Dünnschliff zeigen sie in ausgezeichneter Weise eine „gekörnelte» Struktur mit vielen von Mikropegmatit nebst etwas Quarz ausgefüllten „Lösungsräumen», ganz wie.es von BäCKsTRöM ${ }^{1}$ in durchaus ähnlichen "Feldspateinschlüssen aus einem Diabas bei Alsarp in Småland und von HoLmquist ${ }^{2}$ in den Feldspaten der inhomogenen Ganggesteine auf der Insel Rödö beschrieben wurde. Die „Einschlüsse» enthalten an der Peripherie oder als unregelmässige Streifen im Inneren helle feinlamellierte Partien, die in einem leider nicht genügend senkrecht zu der Kante $\mathrm{P}: \mathrm{M}$ angefertigten Schliff eine Auslöschungsschiefe zwischen $11^{\circ}$ und $16^{\circ}$, einem Oligoklasandesin mit $30-35 \%$ An etwa entsprechend, zeigten. Dieser Feldspat ist nicht scharf von anderen hellen Partien zu scheiden, die eine äusserst zarte Albitlamellierung erkennen lassen

1 Bih. Sv. Vet.-Ak. Handl. 16 (1890), II, N:o 1.

2 S. G. U., Ser. C, Nr. 181 (1899), S. 52-81. 
Bd 32. H. 2.] EISENERZFÖHR. FORMATION VON GRÄNGESBERG. 135

und bisweilen durch Zutreten verwaschener Querstreifen die Natronmikrokiinstruktur bekommen. Letzterer Feldspat ist seinerseits durchaus unscharf von der meistens getrübten "gekörnelten» Hauptmasse der „Einschlüsse» abgegrenzt. Diese Masse zeigt eine feine netzartige Durchdringung von zwei mehr oder weniger deutlich abgesonderten Komponenten, wovon der schwächer lichtbrechende, wahrscheinlich ein Orthoklas, dem stärker brechenden quantitativ untergeordnet ist, welch letzterer übrigens in seinen Eigenschaften nicht sehr von dem fleckenweise noch erhaltenen Natronmikroklin verschieden zu sein scheint. Dem gekörnelten Feldspat ist zuletzt ein Feldspat mit den Eigenschaften der natronreichen Orthoklase zonar angewachsen, der die Wandungen der "Lösungsräume» bekleidet und an der mikropegmatitischen Füllmasse derselben teilnimmt.

Aus einigen möglichst frischen und reinen Feldspatovoiden wurde das Material zu der folgenden Analyse herausgelesen. Die Alkalien sind von Dr. R. Mavzelius bestimmt; die übrigen Bestimmungen von dem Verfasser:

\begin{tabular}{|c|c|c|}
\hline . . . . . 61.17 & 101.27 & Or..... 21.2 \\
\hline $\mathrm{Al}_{2} \mathrm{O}_{3} \ldots . . .21 .36$ & 20.90 & $\mathrm{Ab} \cdot \cdot \cdot \cdot \cdot \cdot .55 .9$ \\
\hline $\mathrm{Fe}_{2} \mathrm{O}_{3} \ldots . . . .2 .51$ & 1.57 & An. . . . . . . 22.9 \\
\hline $\mathrm{MgO}$. . . . . . 0.67 & 1.68 & \\
\hline . . . . . 4.15 & 7.41 & . . . . . 32.37 \\
\hline $\mathrm{Na}_{2} \mathrm{O} \cdot \ldots . .5 .62$ & 9.05 & $\mathrm{Al}_{2} \mathrm{O}_{3} \ldots \ldots+1.01$ \\
\hline $\mathrm{K}_{2} \mathrm{O}$. . . . . . . 3.23 & 3.43 & $\mathrm{SiO}_{2} \cdot \cdot \cdot+11.58$ \\
\hline Gl. V. . . • . 1.05 & & \\
\hline 99.76 & & \\
\hline
\end{tabular}

Wie aus dem mikroskopischen Aussehen der »Einschlüsse» zu verstehen ist, war nicht ein reines Material zu gewinnen. Die Magnesia steckt in Augit und Chlorit, das Eisenoxyd überdies in Titaneisenerz und ferritischen Pigmenten; der $\mathrm{Al}_{2} \mathrm{O}_{3}$-Überschuss rührt von Chlorit und anderen Zersetzungsprodukten her, enthält auch die Titansäure; der beträchtliche 
$\mathrm{SiO}_{2}$-Überschuss dürfte grossenteils von dem Quarz der „Lösungsräume herkommen. Die Kalk- und Alkalibestimmungen ergeben eine Feldspatmischung $\mathrm{Or}_{21 \cdot 2} \mathrm{Ab}_{55 \cdot 9} \mathrm{An}_{22 \cdot 9}$, wobei der An-Gehalt infolge Einschlüsse von Augit wahrscheinlich ein wenig zu hoch ausgefallen ist. Zum Vergleich ist die Molekularzusammensetzung einiger verwandten Feldspate hier zusammengestellt: ${ }^{1}$

\begin{tabular}{|c|c|c|c|c|c|c|c|c|}
\hline & & 1. & 2. & 3. & 4. & 5. & 6. & 7. \\
\hline Or....... & 21.2 & 19.2 & 16.4 & 15.2 & 19.8 & 22.8 & 28.6 & 36.8 \\
\hline$A b \ldots$ & 55.9 & 58.1 & 61.8 & 58.9 & 62.0 & 66.6 & 61.3 & 60.2 \\
\hline An... & 22.9 & 22.7 & 21.8 & 25.9 & 18.2 & 10.6 & 10.1 & 3.0 \\
\hline
\end{tabular}

Nr. 1-3 sind Rhombenfeldspate aus den Rhombenporphyren des Kristianiagebietes, welche Feldspate, von der Form abgesehen, unseren Einschlussfeldspaten sehr ähnlich aussehen. Nr. 4-5 sind Feldspate aus einem sDiabas» bei Chalanches d'Allemont in der Dauphiné, bezw. aus einem "Augitporphyrit» bei Ajatskaja im Ural, die angeblich als grosse "Einsprenglinge» in basischen Gesteinen eingeschlossen vorkommen. Die Feldspate Nr. 6 und 7 kommen als ähnliche "Einschlüsse» im Basalt des Hohenhagen bei Göttingen, bezw. in einem Basalt bei Royat in der Auvergne vor; ersterer Feldspat bildet nach KLEIN grosse ellipsoidische Kristalle und zeigt die Natronmikroklinstruktur, ganz wie sie in dem Feldspat des Grängesberger Diabases noch fleckenweise zu sehen ist; der Basaltfeldspat hat indessen seinen ursprünglichen, sanidinartigen Habitus beibehalten, und die Körnelung ist unterblieben.

Wie die mikroskopische Untersuchung lehrt, giebt die durch die Analyse ermittelte Zusammensetzung der „Einschlussfeldspate gewiss nur den Durchschnitt einer unregelmässig zonar gebauten Mischungsreihe an, die sich von einem wahrscheinlich kalireichen Oligoklasandesin bis zu dem natron-

1 Die Analysen finden sich unter folgenden Nummern in HiNTzE's Handbuch wieder: 1. Note Pag. 1486; 2. Orthoklas Nr. 246; 3. Ebenda Nr. 239; 4. Oligoklas Nr. 54; 5. Ebenda Nr. 111; 6. Kalinatronfeldspat Nr. 3; 7. Orthoklas Nr. 176. 
reichen Orthoklas der Mikropegmatitfetzen erstreckt. Dabei walten indessen die intermediären, zu der Körnelung neigenden Glieder entschieden vor, und es ist darum nicht $\mathrm{zu}$ bezweifeln, dass die Zusammonsetzung der gekörnelten Hauptmasse mit derjenigen der eigentümlichen, meistens natronmikroklinstruierten »Kalkanorthoklase» oder 》Kalioligoklase»vom Typus der norwegischen Rhombenfeldspate übereinstimmt. Unter solchen Umständen dürfte die Entstehung der gekörnelten Struktur einfach einer antiperthitischen Entmischung solcher unbeständigen, extrem ternär zusammengesetzten Natronmikroklinfeldspate zugeschrieben werden können, wobei ein Teil des den Mischkristallen ursprünglich homogen beigemengten Kalifeldspates als Orthoklas ausgeschieden worden ist, während der Rückstand gleichzeitig eine weniger ternäre Plagioklaszusammensetzung bekommen hat. Für eine derartige Auffassung spricht weiter das Vorhandensein von homogenen Feldspatpartien mit noch erhaltener Mikroklinstruktur mitten in der gëkörnelten Masse, wie es auch Bäckström in den von ihm untersuchten „Einschlüssen» erwähnt; ebenso das oben erwähnte Vorkommen ähnlicher "Einschlüsse in Basalt, die ihren Natronmikroklincharakter unverändert beibehalten haben.

Obwohl es nicht bestritten werden soll, dass die Entstehung derartiger in Diabasen und Basalten anscheinend recht häufig vorkommender Pseudoeinsprenglinge in gewissen Fällen auf eine stattgefundene Resorption von fremdem feldspathaltigem Material zurückgeführt werden kann, dürften sie jedenfalls in ihrer jetzigen Form nicht als Fremdlinge, sondern als tatsächliche Ausscheidungen aus dem Diabas- bezw. Basaltmagma aufzufassen sein, und die Bezeichnung derselben als »Einschlüsse» erscheint daher wenig zutreffend. Dass sie andererseits von echten Einsprenglingen genetisch verschieden sind, geht aus ihrer chemischen Zusammensetzung und ihrem inneren Bau unzweideutig hervor. Es liegt auf der Hand, dass ihre Hauptmasse nicht mit den Feldspatausscheidungen der frühesten Kristallisationsphase des umgebenden normalen Diabases, da- 
gegen völlig mit denjenigen der späteren ssyenitischen, Phase chemisch übereinstimmt, während die Füllmasse ihrer „Lösungsräume» durchaus den Ausscheidungen der letzten, "granitischen» Kristallisationsphase des Diabases entspricht.

Neben dem beschriebenen grösseren Gang sind auch einige kleine Diabasgänge spärlich beobachtet worden, z. B. in der Grube Höga Visan, in einem Eisenbahneinschnitt bei Lomberget und in einem anderen westlich von der Station Björnhyttan.

\section{Die genetischen Verhältnisse der Gesteine der erzfüh- renden Formation.}

Die petrogenetischen Fragen, die sich mit der Deutung der mittelschwedischen eisenerzführenden Formation eng verknüpfen, sind von so tiefeingreifender Art, dass es gar zu weit führen würde, sie hier ausführlicher zu diskutieren. Es ist somit notwendig, die genetische Diskussion schon von Anfang an zu begrenzen und spezialisieren. Während ich bezüglich meines prinzipiellen Standpunktes auf meine früheren Aufsätze über die Genesis der mittelschwedischen Eisenerze verweisen möchte, ${ }^{1}$ soll sich die Aufgabe des folgenden $\mathrm{Ab}$ schnittes hauptsächlich auf eine Prüfung beschränken, inwieweit und auf welche Weise die von mir dort entwickelte magmatische Anschaungsweise sich auf das vorliegende spezielle Untersuchungsgebiet anwenden lässt.

\section{Die chemischen Charaktere der Gesteine.}

Es liegt auf der Hand, dass sich die erzführende Formation des Grängesberggebietes in ihrem chemischen Grundcharakter an die granitischen Magmagesteinsformationen anschliesst. Die grosse Hauptmasse dieser Formation besteht aus ausgeprägten Quarz-Feldspatgesteinen, während die damit ver-

1 G. F. F. 28 (1906): 516-538; 29 (1907): 143-186 and 285-300; 30 (1908): 232-255. 
Bd 32. H. 2.] EISENERZFÜHR. FORMATION VON GRÄNGESBERG. 139

knüpften amphibolitischen Gesteine den allgemeinen chemischen Charakter der in Granitformationen öfters vorhandenen dioritischen Grünsteine tragen. Dazu kommt noch eine Reihe eigenartig zusammengesetzter Gesteine, z. B. die Skarne und Erze, die indessen in allzu kleiner Menge vorhanden sind, um den chemischen Grundcharakter der Formation nennenswert zu beeinflussen. Nur einige wenige und spärlich verbreitete Typen unter diesen eigenartigen Gesteinen, wie der Zweiglimmergneis und die Kalksteine, zeigen in ihrer Zusammensetzung eine Differenzierung nach denselben Richtungen, die für die Gesteinsglieder der normalen Sedimentformationen bezeichnend sind.

Eine eingehendere Betrachtung der vorhandenen Gesteinstypen zeigt indessen, dass nur wenige derselben, z. B. die Porphyrgranulite, mit den innerhalb granitischer Formationen am meisten verbreiteten Gesteinstypen chemisch zusammenfallen. Mehrere derselben, wie die sauren Plagioklasgesteine (Plagioklasgranulite und Plagioklasgneise), entsprechen im Gegenteil chemischen Typen, die nur spärlich in den sauren Eruptivgesteinsformationen beobachtet worden sind. Die grosse Beteiligung.dieser natronreichen Gesteine in der erzführenden Formation unseres Kartengebietes ist überhaupt eine sehr bemerkenswerte Tatsache. Sie dürften hier fast die Hülfte der Gesamtarea einnehmen, während 35 bis $40 \%$ dieser Area auf die ebenfalls ziemlich natronreichen Gesteine des roten Gneistypus und nur 10 bis $15 \%$ auf die an Kali und Kalk reicheren Granitgneis- und Granulittypen kommen. Auch wenn wir die in diesen Zahlen einbegriffenen femischen Gesteinseinlagerungen berücksichtigen, so ist aus der oberflächlichen Verbreitung der verschiedenen Gesteinstypen zu schliessen, dass die Durchschnittszusammensetzung der ganzen Formation einem ziemlich sauren und alkalireichen granitischen Magmatypus mit entschiedener Natronvormacht entsprechen muss; bei Klassifizieren nach dem amerikanischen System würde derselbe wahrscheinlich unter die Lassenose fallen. 
Soweit aus vorhandenen chemisch-petrographischen Daten geschlossen werden kann, dürfte ein ähnlicher, saurer und zugleich natronreicher Gesteinscharakter in bedeutenden Teilen der mittelschwedischen Erzformation bestehen. Dagegen scheint ein solcher Charakter anderen Teilen des schwedischen Grundgebirges ziemlich fremd zu sein und dürfte überhaupt sowohl in kristallin-schieferigen als in massigen Gesteinsformationen eine seltene Erscheinung sein. Unter massigen Tiefengesteinen giebt es meines Wissens keine in der Litteratur näher beschriebene Gesteinsformation, die mit der erzführenden Formation des Grängesberggebietes in chemischer Hin-

\begin{tabular}{|c|c|c|c|c|c|c|c|c|c|c|c|}
\hline & 1. & 2. & 3. & 4. & 5. & 6. & 7. & 8. & 9. & 10. & 11. \\
\hline $\mathrm{SiO}_{2} \cdot$. & 77.28 & 68.96 & 74.00 & 70.08 & 64.11 & 68.45 & 68.96 & 76.65 & 75.46 & 49.68 & 50.29 \\
\hline $\mathrm{TiO}_{2} \cdot$ & 0.04 & 0.72 & 0.28 & 0.76 & 0.76 & 0.41 & 0.80 & 一 & 0.12 & 0.70 & 1.35 \\
\hline $\mathrm{Al}_{2} \mathrm{O}_{3}$ & 12.36 & 13.28 & 13.48 & 13.14 & 15.04 & 12.94 & 13.30 & 12.55 & 11.20 & 16.40 & 16.00 \\
\hline $\mathrm{Fe}_{2} \mathrm{O}_{3}$ & - & - - & - & - & - & - & - & - & - & 3.46 & 2.14 \\
\hline $\mathrm{FeO}$. . & 1.35 & 5.40 & 1.80 & 4.24 & 4.14 & 6.01 & 5.50 & 1.21 & 2.70 & 7.50 & 8.36 \\
\hline $\mathrm{MnO}$. & 0.10 & 0.12 & 0.10 & 0.12 & 0.15 & 0.15 & 0.16 & 0.08 & 0.08 & 0.32 & 0.27 \\
\hline $\mathrm{MgO}$. . & 0.15 & 0.97 & 1.99 & 0.94 & 0.68 & 0.95 & 1.71 & 0.66 & 2.29 & 6.20 & 5.92 \\
\hline $\mathrm{CaO}$. & 0.56 & 2.56 & 1.14 & 2.92 & 6.10 & 1.40 & 1.44 & 2.06 & 1.56 & 10.14 & 10.22 \\
\hline $\mathrm{Na}_{2} \mathrm{O}$. . & 3.87 & 3.63 & 6.08 & 2.93 & 1.86 & 2.21 & 4.78 & 3.10 & 5.50 & 3.00 & 3.24 \\
\hline $\mathrm{K}_{2} \mathrm{O}$. & 4.19 & 3.43 & 0.62 & 3.94 & 5.93 & 6.27 & 1.85 & 2.30 & 0.23 & 1.12 & 0.62 \\
\hline $\mathrm{P}_{2} \mathrm{O}_{5} \ldots$ & 0.03 & 0.16 & 0.07 & 0.11 & 0.18 & 0.12 & 0.17 & - & 0.03 & 0.09 & 0.18 \\
\hline \multirow[t]{2}{*}{ Gl. V. . . } & 0.60 & 0.96 & 0.80 & 1.00 & 0.64 & 0.96 & 1.12 & 1.10 & 0.76 & 1.52 & 1.52 \\
\hline & 100.53 & 100.19 & 100.36 & 100.18 & 99.59 & 99.87 & 99.79 & 99.71 & 99.93 & 100.13 & 100.11 \\
\hline Or. . & 39.9 & 32.4 & 5.8 & 38.4 & 52.5 & 58.5 & 18.3 & 26.2 & 2.4 & 10.8 & 6.1 \\
\hline $\mathrm{Ab}$. . & 55.9 & 52.0 & 86.0 & 43.4 & 24.9 & 31.4 & 71.6 & 53.9 & 88.3 & 43.8 & 48.5 \\
\hline An... & 4.2 & 15.6 & 8.2 & 18.2 & 22.6 & 9.8 & 10.1 & 19.9 & 9.3 & 45.4 & 45.4 \\
\hline
\end{tabular}

1. Roter Gneis (Alaskos), Lomberget; 2. Granitgneis (Adamellos), KarlJohan-Schacht; 3. Plagioklasgneis (Maripos), Skakelbacken; 4. Porphyrgranulit (Toscanos), Täppan; 5. Granat-Epidotgranulit (S. R. 2 von Dacas), Sköttorp; 6. Lomberggranulit (Dellenos), Lomberget; 7. Exportfeldgranulit (Dacos). Skärningen; 8. Skarnführender Granulit (Alsbachos), Öraberget; 9. Skarnführender Plagioklasgranulit (Yukonos), Björnberget; 10. Andesinamphibolit (Camptonos), Ormbergstjärn; 11. Andesinamphibolit (Ornos), Orrleksdammen. 
Bd 32. H. 2.] EISENERZFÜHR. FORMATION VON GRÄNGESBERG. 141 sicht völlig vergleichbar ist. Inwieweit Analogien mit gewissen alpinen Zentralgneisgebieten vorhanden sein können, die ebenfalls durch die Assoziation einer natronreichen granitischen Gesteinsreihe mit einer kalireicheren, dem roten Gneis-Typus ziemlich nahe stehenden charakterisiert zu sein scheinen, ist mir aus den zugänglichen Daten nicht möglich $\mathrm{zu}$ entscheiden.

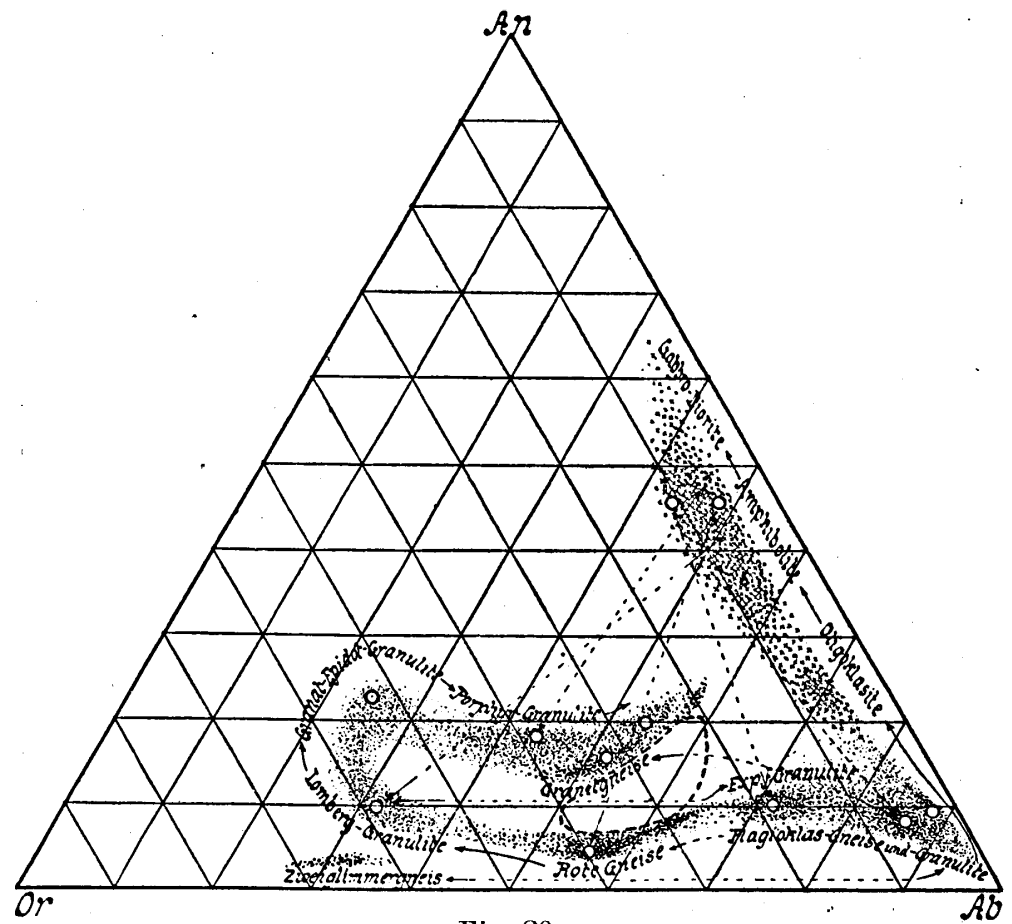

Fig. 20.

Es sollen nun die gegenseitigen chemischen Beziehungen der verschiedenen Gesteinstypen etwas näher diskutiert werden. $\mathrm{Zu}$ diesem $\mathrm{Zweck}_{\text {wabe }}$ ich die im Vorigen angeführten chemischen Analysen in der beigefügten Tabelle zusammengestellt. Neben den Analysenzahlen sind auch die daraus berechneten Verhältnisse der feldspatbildenden Komponenten angeführt. Letztere Zahlen sind in der beigefügten Dreieck- 
projektion (Fig. 20) graphisch dargestellt. Dabei ist gleichzeitig unter Mitberücksichtigung der mikroskopischen Beobachtungsresultate ein Versuch gemacht, die Gruppierung aller innerhalb des Gebietes beobachteten feldspatigen Gesteinstypen der erzführenden Formation approximativ anzudeuten.

Betrachten wir zunächst die Quarz-Feldspatgesteine (Gneise und Granulite) für sich, so bietet ihre Gruppierung innerhalb des Feldspatdreieckes mehreres von Interesse dar. Die verschiedenen Haupttypen nebst den vorhandenen $Z_{w i-}$ schengesteinen verteilen sich auf zwei Reihen: eine An: arme, wozu die Plagioklasgesteine, die roten Gneise und die Lomberggranulite gehören; und eine verhältnismässig An: reiche, welche die skarnführenden OOraberggranulite (nebst einigen verwandten, aber weniger sauren Porphyrgranuliten und porphyrischen Granulitgneisen), die Granitgneise, die Porphyrgranulite und die Granat-Epidotgranulite umfasst. Nur an dem Kali-Ende sind die beiden Reihen durch $Z$ wischeng]ieder kontinuierlich verbunden; im übrigen sind sie durch eine chemische Diskiontinuitätsarea scharf voneinander getrennt.

In meiner früheren Arbeit ${ }^{1}$ habe ich durch eine entsprechende graphische Zusammenstellung der vorhandenen Granitanalysen gezeigt, dass zwischen dem Projektionsgebiet der allgemeinen Granitreihe und demjenigen der s. g. Natrongranite eine auffällige Diskontinuitätsarea auftritt, in welche keine der mir bekannten Analysen von typischen granitischen Tiefengesteinen fällt. Diese Diskontinnitätsarea wird dagegen bei den entsprechenden Ergussgesteinen vermisst; sie ist hier im Gegenteil von einem durch mehrere Analysen repräsentierten Dacitgesteinstypus eingenommen. Aus diesen Beobachtungen habe ich den Schluss gezogen, dass die entsprechenden granitischen Magmen unter den Bedingungen langsamer Abkühlung einer weiteren Spaltung regelmässig unterliegen. Die gestrichelte Kurve in Fig. 20 zeigt nun die

1 G. F. F. 29 (1907) : 147-150. 
Bd 32. H. 2.] EISENERZFÜHR. FORMATION VON GRÄNGESBERG. 143

Lage und Ausdehnung dieser für granitische Tiefengesteine geltenden Diskontinuitätsarea. Es liegt auf der Hand, dass sie im grossen und ganzen der für die Grängesberger Quarz-Feldspatgesteine geltenlen entspricht; nur hat sich bei den letzteren die Diskontinuitätsarea weiter nach den Seiten ausgedehnt. Das tatsächliche Vorhandensein einer derartigen gesetzmässigen chemischen Diskontinuität fasse ich somit als ein Zeugnis dafür auf, dass das Gesteinsmaterial der erzführenden Formation eine magmatische Entwickelungsphase durchgemacht hat; dabei wurde die chemische Zusammensetzung der Gesteine von bestimmten Differentiationsgesetzen beherrscht, denjenigen ähnlich, die für massige, unter Tiefengesteinsbedingungen gebildete Gesteine gelten.

Für die Erklärung der stetigen und scharfen chemiscihen Variationen innerhalb der erzführenden Formation ist es nun von Bedeutung hervorzuheben, dass der vorher berechnete chemische Durchschnittscharakter dieser Formation offenbar einem in diese Diskontinuitätsarea fallenden Magmatypus entspricht, von dem wir somit sogleich voraussagen können, dass er unter geeigneten äusseren Bedingungen einem Zerfall in chemisch scharf getrennte Teilmagmen unterliegen muss. Damit soll zwar nicht behauptet werden, dass alle die jetzigen Granulit- und Gneisgesteine durch Spaltung einer ursprünglich gleichförmig zusammengesetzten Magmamasse entstanden sind. Dagegen scheint es recht plausibel, dass die in unserem Gebiet vielfach zu beobachtende enge Assoziation $\mathrm{zwischen}$ einerseits mehr oder weniger kalireichen und andererseits extrem natronreichen Gesteinen durch den Zerfall instabiler Magmen von mittlerer Zusammensetzung zustande gekommen ist. Als Beispiele solcher im Verhältnis konjugierter Spaltungsgesteine zueinander stehender Gesteinstypen könnte das Gesteinspaar Lomberggranulit-Exportfeldgranulit wie auch das Paar Granitgneis-Plagioklasgneis herangezogen werden. In hauptsächlich derselben Weise könnten auch

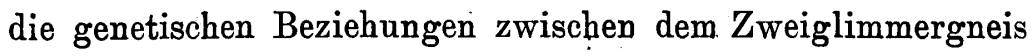


und den umgebenden Plagioklasgranuliten aufgefasst werden, obwohl in diesem Fall ein überreichlicher Gehalt an Tonerdesilikaten in dem Stammmagma zu seiner Spaltungstendenz beigetragen haben dürfte.

Während die chemischen Diskontinuitäten innerhalb der Quarz-Feldspatgesteine erst bei eingehenderen chemischen und mikroskopischen Untersuchungen deutlich hervortreten, fallen jene Diskontinuitäten, die die amphibolitischen PlagioklasHornblendegesteine von den Quarz-Feldspatgesteinen trennen, schon bei einer flüchtigen Durchwanderung des Gebietes sofort in die Augen. Wenn wir von einigen speziellen Fällen absehen, entspricht diese Diskontinuität im allgemeinen einer sprungweisen Änderung des Kieselsäuregehaltes von etwa $50 \%$ in den Amphiboliten bis zu $68 \%$ oder mehr in den assoziierten Granuliten oder Gneisen. Es liegt auf der Hand, dass diese Differenzierungsart in ihren Hauptzügen der für Magmagesteinsformationen im allgemeinen bezeichnenden Spaltung in femische und salische Gesteine entspricht. Die Schärfe, womit sie sich innerbalb der erzführenden Formation vollzogen hat, deutet auf speziell günstige Differenzierungsbedingungen, mit denen vergleichbar, die den Zerfall gewisser granitischer Magmen in konjugierte lamprophyrische und aplitische Spaltungsgesteine bewirkt haben.

Wie ich bei der Beschreibung der Amphibolite hervorgehoben habe, zeigen die mit verschiedenen Granulit- und Gneistypen assoziierten Amphibolitgesteine auch unter einander gewisse chemisch-mineralogische Verschiedenheiten, und ihre Zusammensetzung scheint somit von dem Charakter der umgebenden Quarz-Feldspatgesteine einigermassen abhängig za sein. In dieser Hinsicht ist zu erwähnen, dass die weniger hornblendereichen und saurere Plagioklase enthaltenden Amphibolitvarietäten fast ausschliesslich in den Plagioklasgranulitzügen anzutreffen sind, während die Amphibolite der kalireicheren Gesteinszüge grösstenteils $z \mathfrak{u}$ den basischeren Varietäten gehören. Strengere Beziehungen zwischen den 
Bd 32. H. 2.] EISENERZFÜHR. FORMATION VON GRÄNGESBERG. 145

Spezialcharakteren der Amphibolitvarietäten und dem Feldspatcharakter der Quarz-Feldspatgesteine sind indessen selbstverständlich nicht zu erwarten; erstere sind vielmehr mit gewissen Spezialcharakteren der letzteren Gesteine in erster Linie verknüpft, die nicht mit ihrem Feldspatcharakter direkt zusammenzuhängen brauchen. Als Beispiele solcher speziellen Zeugnisse von Blutsverwandtschaft ist der Pyroxengehalt derjenigen Amphibolite, die in den pyroxenführenden Gesteinen des $N$. Hammargrubengebietes auftreten, sowie der Magnetitgehalt der mit Eisenerzvorkommen verknüpften $\mathrm{Ge}_{\boldsymbol{\theta}}$ steinsvarietäten anzuführen.

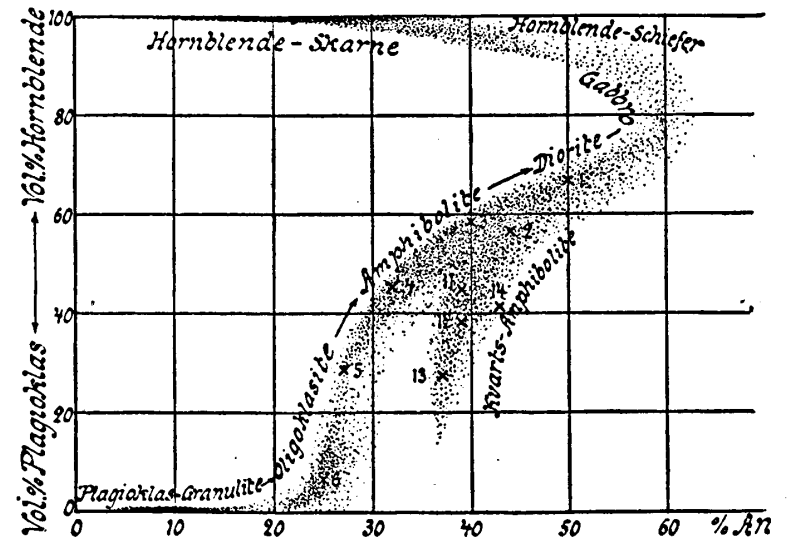

Fig. 21.

Die Skarnbildung ist nach der hier entwickelten Anschauungsweise der Amphibolitdifferenzierung an die Seite zu stellen. Es wurde im Vorigen mehrfach hervorgehoben, wie eng die hauptsächlichen Skarngesteine unseres Gebietes, nämlich die Hornblendeskarne, einerseits mit den Plagioklasgranuliten und andererseits mit den Amphiboliten verknüpft sind. Mit Rücksicht darauf ist in dem beigefügten Diagramm (Fig. 21) ein Versuch gemacht, die chemisch-mineralogischen Beziehungen dieser drei Gesteinsgruppen untereinander zu veranschaulichen, wobei die vorher (S. 72) angeführten volumenometri- 
schen Messungen an verschiedenen Amphibolitgesteinen zu Grunde gelegt worden sind ${ }^{1}$. Die Ordinate stellt das Verhältnis zwischen den volumprozentischen Gehalten an Hornblende und Plagioklas der Gesteine dar, während die Abszisse die Basizität des Plagioklases angiebt. Es zeigt die Gruppierung der Gesteine, wie die Hornblendeskarne durch eine ausgeprägte chemische Diskontinuität sowohl von den Plagioklasgranuliten wie. von den Amphiboliten geschieden sind. Die Diskontinuitätsarea verengert sich indessen nach rechts hin, indem die amphibolitischen Gesteine mit zunehmender Basizität des Plagioklases immer reicher an Hornblende werden; bei einem etwa $60 \%$ betragenden An-Gehalt des Plagioklases dürften wahrscheinlich Hornblendegesteine und HornblendePlagioklasgesteine kontinuierlich ineinander übergehen können, ein Fall, der indessen in unserem Gebiete nur in den gabbrodioritischen Gesteinen der roten Gneiszüge realisiert zu sein scheint.

Es könnten nun die Bedingungen der Skarndifferenzierung und der Entstehung jener eigentümlichen Entwickelungsfazies der erzführenden Formation, die vorher unter dem Namen sskarnführende Granulite beschrieben worden ist, etwa folgenderweise skizziert werden. Das Gestein॰material der Erzformation war zwar im ganzen ein recht saures und alkalireiches, aber zugleich ein an femischen Silikatsubstanzen verhältnismăssig reiches. Diese Substanzen hatten sich hier, wie gewöhnlich, vorzugsweise in den An-reicheren und zugleich weniger sauren Magmazügen, dann aber auch in gewissen natronreichen, mehr oder weniger An-armen und sauren Magmen angereichert. Bei weiterer Abkühlung auf die entsprechenden Differentiationstemperaturen trat eine Entmischung ein, wobei sich die femischen, hornblendebildenden Substanzen zugleich mit einem Teil der An- und Ab-Menge von der an Kieselsäure und Alkalifeldspatsilikaten reichen Hauptmasse

1 Die Spezialtypen Nr. 7-10 sind ausgelassen. 
Bd 32. H. 2.] EISENERZFÜHR. FORMATION VON GRÄNGESBERG. 147 abzuspalten bestrebten. Zufolge des grösseren An-Gehaltes und der geringeren Azidität war in den Magmazügen der erstgenannten Zusammensetzung verhältnismässig viel AnSilikat für diese Amphibolit-Differenzierung zugänglich, und es konnten sich hier somit auch Amphibolittypen mit basischeren Plagioklasen ausscheiden, die eine verhältnismässig grosse Menge von femischen Silikaten in sich aufzunehmen vermochten. In solchen Magmazügen waren also die Bedingungen für eine Hornblendeskarn-Differenzierung nur selten vorhanden, sondern die femischen Silikate wurden fast gänzlich in der Form von Amphiboliten ausgeschieden, wie es z. B. in den roten Granulitgneisen bei Orrleksdammen zu sehen ist, oder der salische Hauptteil war sogar auch nach vollendeter Amphibolit-Differenzierung noch An-reich genug, um recht beträchtliche Mengen von femischen Silikaten in homogener Lösung behalten zu können, wie es z. B. mit. den Porphyrgranuliten der Fall gewesen sein dürfte.

Ganz anders stellten sich die Differentiationsbedingungen innerhalb der natronreichen Magmazüge. Diese waren manchmal zu An-arm, als dass es überbaupt zu einer AmphibolitDifferenzierung kommen konnte, vielmehr mussten sich die femischen Silikate gänzlich in der Form von Skarnen ausscheiden. In anderen Fällen trat zwar eine reichliche Amphibolit-Differenzierung ein, aber zufolge des geringen AnGehaltes im Verhältnis zu dem Ab-Gehalt gehörten die Amphibolite meistens zu den saureren, natronreicheren Typen, die nur eine vérhältnismässig geringe Menge von hornblendebildenden femischen Silikaten in sich aufzunehmen vermochten, während der überschüssige -Rest als Hornblendeskarn ausgeschieden wurde. In gewissen Zügen, z. B. in dem N. .Hammargrubengebiet und im Björnberget, scheinen zunächst eigentümliche Magmen von quarz-oligoklasamphibolitischer oder oligoklasamphibolitischer, an die Ornöite erinnernder Zusammensetzung ausgeschieden worden zu sein; diese instabilen Magmen zerfielen "dann weiter während einer späteren 11-100170. 
Phase und wurden zu jenen bunten eutaxitischen oder breccienartigen Skarn-Oligoklasit-Plagioklasgranulit-Verwebungen, die für die genannten Gebiete so bezeichnend sind.

Wahrend die oben entwickelte Differentiationshypothese eine allgemeine chemische Erklärung der engen gegenseitigen Beziehungen zwischen Hornblendeskarnen, Amphiboliten und natronreichen Granuliten erlaubt, ist es zur Zeit nicht möglich, von diesem Standpunkte aus gleichzeitig eine bestimmte Erklärung zu geben, warum in unserem Gebiet, gleichwie in mehreren anderen Verbreitungsgebieten der erzführenden Formation, auch Kalksteine innerhalb derselben Gesteinsassoziation vielfach auftreten und auf dieselbe beschränkt sind. In Anbetracht des seltenen Vorkommens unzweifelhaft magmatischer Karbonatgesteine in der Natur könnte man geneigt sein, auch die hier auftretenden Karbonatgesteine auf irgend welche Kalksteine sedimentärer Herkunft zurückzuführen, die in eine grosse Magmamasse aufgenommen und derselben so vollständig einverleibt wären, dass sie jetzt als integrierende Glieder einer magmatischen Gesteinsreihe erscheinen. Andererseits warnt der eigenartige chemische Charakter der ganzen kalksteinführenden Gesteinsreihe davor, den bisher an massigen Magmagesteinsformationen gewonnenen Erfahrungen bezüglich der Seltenheit oder Abwesenheit unzweifelhaft magmatischer Karbonatgesteine in diesem Fall eine entscheidende Bedeutung beizumessen, und es scheint unter vorliegenden Umständen nicht ratsam, für die in Rede stehenden Kalksteine allein zufolge ihres Charakters von Karbonatgesteinen eine sedimentäre Vorgeschichte a priori anzunehmen. Die physikalische Möglichkeit einer rein magmatischen Bildungsweise dürfte kaum zu bezweifeln sein.

Die Eisenerzbildung wäre nach der hier entwickelten Auffassung einem der Amphibolit- und Skarn-Differenzierung analogen magmatischen Differentiationsprozesse zuzuschreiben. Man hat sich nach dieser Auffassung das Erzmaterial in den Quarz-Feldspatmagmen ursprünglich gelöst zu denken. Ganz 
wie die amphibolit- und skarnbildenden femischen Substanzen wurde es dann zunächst in gewissen Schlierenzügen angehäuft; die weitere Differenzierung dieses erzhaltigen Materiales hat schliesslich zu ähnlichen scharfen chemischen Diskontinuitäten geführt, wie es bei den vorher beschriebenen Differentiationsprozessen der Fall war. Zwischengesteine zwischen Erzen und Silikatgesteinen kommen somit in unserem Gebiet nur spärlich und hauptsächlich bei den schuppigen Eisenglanzerzen vor, und sie zeigen immer eine sehr inhomogene, eutaxitische oder gebänderte Ausbildung.

Ebensowenig wie die Amphibolit-Differenzierung ist diese Eisenerz-Differenzierung an Gesteinszüge eines bestimmten chemischen Charakters gebunden, sondern es scheinen die dafür geeigneten Bedingungen fast in allen chemischen Gesteinstypen der erzführenden Formation vorhanden gewesen zu sein. Es fehlen zwar Eisenerzausscheidungen in den Porphyrgranuliten und den roten Gneisen, aber wenigstens in den letzteren Gestein'en sind schwächere Erzimprägnationszonen mehrfach beobachtet worden, und Eisenerze stellen die hauptsächlichen femischen Gemengteile dieser Gesteine dar. Andererseits hat der chemisch-mineralogische Charakter der erzführenden Gesteinszüge allem Anschein nach einen bestimmenden Einfluss auf die chemisch-mineralogische Ausbildung der Erze ausgeiibt. Überblicken wir von diesen Gesichtspunkten aus die Verbreitung der verschiedenen Erztypen unseres Gebietes, so ergiebt sich zunächst, dass die kalireicheren Gesteinszüge die hauptsächliche Heimat der quarzigen Eisenerze sind. In dieser Hinsicht ist auf die enge Blutsverwandtschaft zwischen den Lomberg-Granuliten und den schuppigen Eisenglanzerzen des Lomberg-Typus hinzuweisen. Geht man von den Lomberg-Granuliten zu den benachbarten, ebenfalls kalireichen, aber weit kalkreicheren Granat-Epidotgranuliten über, so ist es von Interesse, die gleichzeitigen Änderungen in dem Charakter der eingelagerten Erze zu beobachten; die hier auftretenden Erze sịnd zwar noch quarzig, aber 
sie enthalten zugleích eine beträchtliche Menge von Kalksilikaten derselben Arten, die als akzessorische Gemengteile eben für die umgebenden Granulite bezeichnend sind.

Die meistens natronreichen Verbreitungsgebiete der »skarnführenden Granulite» sind dagegen die Heimat der Skarneisenerze. Diese Tatsache hängt offenbar mit denselben Verhältnissen zusammen, die auch die Erscheinung der Skarnbildung vorzugsweise auf Gesteinszüge eines natronreichen Charakters beschränkt haben. Es könnten mehrere spezielle Beispiele einer unverkennbaren Blutsverwandtschaft zwischen Skarnerzen und ihren Nebengesteinen angeführt werden; als ein sehr bezeichnendes möchte ich hier an das Auftreten der Klinoanthophylliterze des Melings-Typus innerhalb der klinoanthophyllitführenden Plagioklasgranulite westlich vom Björnberget erinnern. - Das Auftreten der manganarmen Kalkeisenerze des Sköttgrube-Typus innerhalb der skarnerzführenden Gesteinszüge ist auf dieselben Ursachen zurückzuführen, zufolge welcher auch die Kalksteine unseres Gebietes mit den skarnführenden Granuliten verknüpft sind.

Die Vertreter der Apatiteisenerze sind auf eine hauptsächlich von Gneisen eingenommene Gesteinsarea im mittleren Teil des Untersuchungsgebietes beschränkt. Mit Ausnahme der Långblåer Erze, die am nächsten mit dem Granitgneis verknüpft sind, treten diese Erze ebenfalls in Plagioklasgesteinen auf; ihre Muttergesteine gehören jedoch zu den basischeren, biotitreichen, nicht skarnführenden, aber an Amphiboliten reichen Plagioklasgranuliten des Exportfeld-Typus oder zu chemisch ähnlichen Plagioklasgneisen; nur die N. Hammargrubenerze, die ja als apatitreiche Äquivalente der Pyroxenamphibolskarnerze zu charakterisieren sind, lagern in Gesteinen, die mit gewissen femischen Gesteinsfacies der »skarnführenden Granulites vieles gemeinsam haben. Zufolge des stark spezialisierten chemischen Charakters der Apatiterze sind die Zeugnisse ihrer Blutsverwandtschaft mit den Nebengesteinen meistens weniger hervortretend. Es ist indessen $z u$ bemerken, 
dass die für die Apatiterzarea bezeichnenden Gesteinstypen, den mikroskopischen gleichwie auch den chemischen Untersuchungen nach zu schliessen, verhältnismässig reich an Apatit sind; wenigstens wenn man sie mit den ausserhalb dieser Area vorherrschenden roten Gneisen und skarnführenden Granuliten vergleicht. Für die Frage nach dem Ursprung dieser Erze ist es auch von Interesse zu erwähnen, dass in den Gneisgesteinen der Apatiterzarea auch weit ausserhalb der dortigen Grubenfelder schwache Erzimprägnationszonen mehrfach beobachtet, worden sind, die gleichzeitig eine schlierige Anreicherung mit Apatit regelmässig erkennen lassen (vergl. S. 35-36). Es liegt da nahe anzunehmen, dass die Apatiterze unseres Gebietes zunächst aus chemisch ähnlich zusammengesetzten, mit Erz und Apatit schlierig angereicherten Magmazügen differenziert worden sind.

In der vorhandenen Litteratur scheint eine magmatische Auffassung für die Grängesberger Apatiterze zuerst von HJ. SJöGREN (G.'F. F. 28 [1906]: 351-356) deutlich ausgesprochen worden zu sein. ${ }^{1}$ Mit Rücksicht auf die meistens scharf ausgebildeten chemischen Diskontinuitäten zwischen den Erzen und ihren Nebengesteinen hat dieser Forscher dann in seinen späteren Arbeiten über die mittelschwedischen Eisenerze ${ }^{2}$ diese Erze im allgemeinen nicht als Differentiationsprodukte aus ihrem unmittelbaren Nebengestein auffassen wollen, sondern behauptet, sie wären aus tiefer gelegenen Magmen abgespaltet und dann in der Form von magmatischen Lösungen in ihr jetziges Nebengestein epigenetisch eingedrungen. $\mathrm{Zur}$ Unterscheidung von syngenetischen Differentiationsprodukten hat er für Erze solcher epigenetisch-magmatischer Entstehung das Attribut sdiamagmatisch sorgeschlagen. - Nach der hier vertretenen Auffassung gehört es jedoch zu dem Wesen mag-

1 Zu einer magmatischen Erklärung dieser Erze dürfte schon früher G. LöFSTRAND (G. F. F. 16 [1894]: 147-148) geneigt gewesen sein, obwohl er sich nicht deutlich ausspricht.

${ }^{2}$ G. F. F. 30 (1908): $153-154$ und $384-385$. 
matischer Differentiationsprozesse, zu chemischen Diskontinuitäten zu führen. Diese Diskontinuitäten werden um so schärfer ausgeprägt, je weiter die Komponenten in ihrer chemischen Konstitution und ihren davon abhängenden physikalischen Eigenschaften voneinander verschieden sind, und je günstiger sich die auf die Separierungsfähigkeit der nicht mischbaren Magmateile bestimmend einwirkenden Bedingungen (z. B. Viskosität, Abkühlungsgeschwindigkeit, mechanische Umrührung) stellen. Die Eisenerzsubstanzen sind gewiss von den Gemengteilen der Silikatmagmen und zwar der saureren Magmen so weit verschieden, dass wir in diesem Fall bei magmatischer Differenzierung eine sehr weite chemische Diskontinuität normal zu erwarten haben. Wenn dies bisweilen nicht zutrifft, dürfte es Verzögerungen in der Separierung zufolge Hindernissen der oben angedeuteten Art zuzuschreiben sein.

Die im Vorigen besprochenen wichtigeren Arten von chemischer Differenzierung innerhalb der erzführenden Gesteinsreihe haben zu Gesteinswechseln von verschiedener geologischer Grössenordnung geführt. Wir können von diesem Gesichtspunkt aus zunächst eine Differenzierung von höherer Ordnung bemerken, die zu der Aufteilung der Formation in eine Anzahl mebr oder weniger wohl markierter, grösserer Gesteinseinheiten geführt hat. Als Beispiele solcher chemischgeologischen Gesteinseinheiten könnten erwähnt werden die Gebiete der Exportfeldgranulite, der Lomberggranulite, der Granitgneise und Plagioklasgneise westlich von Grängesberg u. s.'w. Die Gesteinswechsel dieser Grössenordnung sind zur Darstellung in einem der Übersichtskarte Taf. VIII etwa entsprechenden Massstab $(1: 60000)$ geeignet. Obwohl es wenig wahrscheinlich ist, dass alle die Gesteinswechsel dieser Grössenordnung durch den Żerfall einer einmal gleichförmig zusammengesetzten Magmamasse zustande gekommen sind, dürften doch nach dem Vorigen (S. 142-144) zwischen mehreren dieser Gesteinseinheiten chemische Beziehungen einer solchen Art bestehen, dass sie durch die Annahme einer 
Bd 32. H. 2.] EISENERZFÜHR. FORMATION VON GRÄNGESBERG. 153

Spaltung ehemaliger Magmen von einer mittleren Zusammensetzung erklärt werden können. Es soll indessen zur Zeit keine Meinung darüber ausgesprochen werden, inwieweit diese Gesteinswechsel einer Differentiation in situ zuzuschreiben sind, oder unter welchen geologischen Bedingungen sie überhaupt zustande gekommen sein können.

Innerhalb der Gesteinseinheiten der vorigen Grössenordnung ist fast immer eine Differenzierung von niedrigerer Ordnung zu beobachten; die dadurch bedingten Gesteinswechsel würden für eine detailliertere Darstellung eine Kartierung wenigstens in dem Massstab $1: 500$ erfordern. Hierher gehören grösstenteils die durch die amphibolit-, skarn- und eisenerzbildenden Differentiationsprozesse bedingten Gesteinswechsel, ebenso die in vielen Granulitzügen $z u$ beobachtenden bankförmigen Abwechselungen zwischen mehr oder weniger verschiedenen. Gesteinsvarietäten. Es sind die Gesteinswechsel dieser Grössenordnung, welche die vorher als Eutaxitarchitektur besprochene Erscheinungsart mancher Gesteinszüge der erzführenden Formation bedingen.

Von den Gesteinswechsel der vorigen Grössenordnungen sind noch $\mathrm{zu}$ unterscheiden jene Gesteinswechsel im Kleinen, die etwa in natürlicher Grösse abzubilden sind und schon zu den Strukturerscheinungen gerechnet werden können. Diese Gesteinswechsel schliessen sich in chemischer Hinsicht denjenigen der vorigen Stufe eng an, dürften aber hauptsächlich erst während der letzten Phasen der magmatischen Differentiationsperiode ausgebildet worden sein, nachdem das Magma schon zu viskos geworden war, als dass es zu einer schärferen Trennung der Magmateile kommen konnte. Anscheinend waren Bewegungen in dem viskosen Magma von entscheidender Bedeutung für die Ausbildung der Gesteinswechsel dieser Grössenordnung. Als Beispiele sind zu erwähnen die eutaxitische Ausbildung der N. Hammargrubengesteine und mancher anderen skarnschlierigen Granulitgesteine; die gebänderte. Ausbildung gewisser Exportfeldgranu- 
lite und anderer biotitreicher Granulite; endlich die gebänderte oder eutaxitische Ausbildung der die schuppigen Eisenglanzerze umgebenden Erzimprägnationszonen. Es scheinen die Erze des genannten Typus überhaupt aus einem viskoseren Medium differenziert worden zu sein, als es bei den Erzen der anderen Typen der Fall war. Eine derartige Kleindifferenzierung ist übrigens in allen Granuliten unseres Gebietes eine mehr oder weniger hervortretende Erscheinung, die offenbar als ein wesentliches petrographisches Merkmal der Granulitgesteine aufzufassen ist. Dagegen fehlt sie fast völlig den gröberen Gneisgesteinen, wie dem Granitgneis und den gröberen Varietäten der roten Gneise und der Plagioklasgneise.

\section{Die strukturelle Ausbildung der Gesteine.}

In meinem früheren Aufsatz ${ }^{1}$ habe ich auf die Möglichkeit einer Erklärung der Strukturen der erzführenden Gesteine hingewiesen, nach welcher ihre Entstehung der Hauptsache nach schon in die magmatische Entwickelungsphase dieser Gesteine zu verlegen und dem Einfluss von Deformationen und Störungen während des Kristallisationsprozesses zuzuschreiben wäre, während den sekundären Umwandlungen nach der Erstarrung meistens nur eine geringe Bedeutung beigemessen wird. Es liegt auf der Hand, dass eine sichere Beurteilung des derartigen Bewegungen in dem erstarrenden Magma beizumessenden Einflusses auf die resultierende Gesteinsstruktur eine viel eingehendere Kenntnis von dem Verlauf des Kristallisationsprozesses verschiedener chemischer Magmatypen bei normaler, ruhiger Erstarrung voraussetzt, als wir sie zur Zeit sicher besitzen. Um die der obenerwähnten Auffassung zu Grunde liegende allgemeine Betrachtungsweise zu veranschaulichen, mag hier indessen einer der in dem Grängesbergergebiet vertretenen chemischen Gesteinstypen,

1 G. F. F. 29 (1907): 165-169. 
z. B. der Porphyrgranulittypus, in strukturgenetischer Hinsicht etwas eingehender diskutiert werden.

I: A. Wir wollen dann zunächst den Kristallisationsprozess eines diesem Gesteinstypus entsprechenden Magmas bei schneller, aber ruhiger Erstarrung zu verfolgen versuchen; es würde dieser Fall etwa dem Kristallisationsprozess gewisser Varietãten unter jenen dacitischen Laven entsprechen, die in der amerikanischen Litteratur als Quarz-Latite bezeichnet worden sind. ${ }^{1}$ Es dürfte bei der Kristallisation einer derartigen Lava zunächst zwischen zwei Perioden zu unterscheiden sein. Der Kristallisationsverlauf während der ersten $\mathrm{Pe}$ -

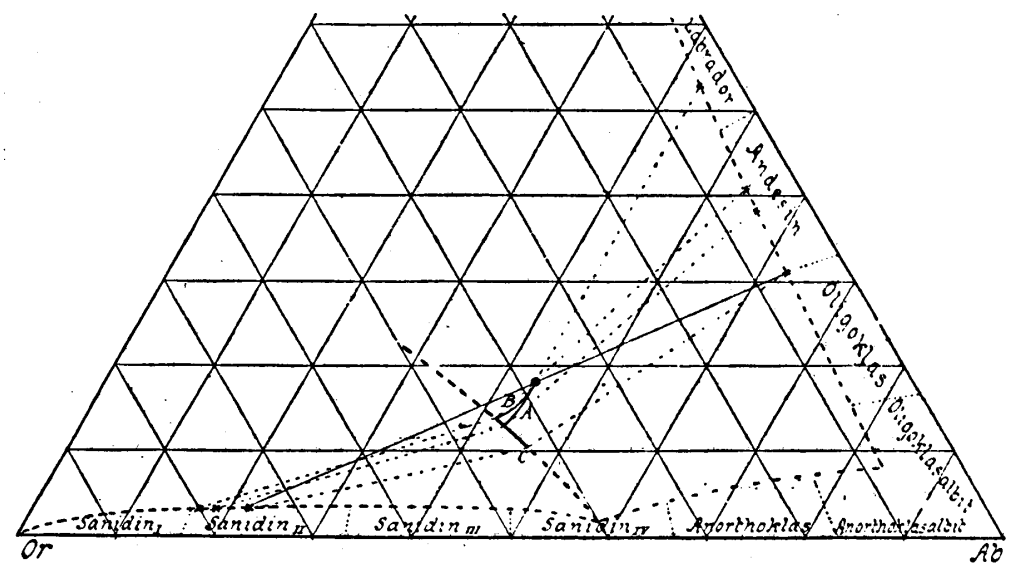

Fig. 22.

riode ist in Bezug auf die Feldspatbildung etwas schematisch durch die Kurve $A$ in Fig. 22 graphisch veranschaulicht worden; die femischen Gemengteile werden hier nicht berücksichtigt. Der in das Diagramm eingetragene Analysenort giebt das aus der Porphyrgranulitanalyse auf S. 42 berechnete Feld-

1 Unter den in der Litteratur erwähnten Lavagesteinen sind dem Porphyrgranulit chemisch am nächsten verwandt der von SpURR (U. S. G. S. P. P. 42 [1905]: 48) beschriebene Dacit oder Latit-des Mt. Brougher, Tonopah Nevada; weiter der von RaNsome (U. S. G. S. P. P.12 [1903]: 92) beschriebene Dacit von Old Dominion Mine, Globe District, Arizona, und der von LaGorio (T. M. P. M. 8 [1887]: 458) beschriebene ,Trachyt, des Monte Amiata, Toscana. 
spatverhältnis des ursprünglichen Magmas an. Nachdem die Sättigungstemperatur erreicht worden ist, scheidet sich eine Anzahl Kristallkeime aus Labrador, wahrscheinlich etwa $\mathrm{An}_{5} \mathrm{Ab}_{4}(\mathrm{Or})$, aus; auf diese Keime und auf etwas jüngere und saurere Keime setzen sich dann Schalen von sukzessiv saurer werdenden Mischungen (sauren Labradoren und basischeren Andesinen) ab; dadurch wird die Lösung immer reicher an der Or-Komponente, und der Kristallisationsweg erreicht schliesslich die Kurve für gleichzeitige Sättigung an Plagioklas und Sanidin, dessen Verlauf in Fig. 22 approximativ angedeutet ist. ${ }^{1}$ Damit beginnt die zweite Kristallisationsperiode dieses Magmas, während welcher eine gleichzeitige Ausscheidung von Sanidineinsprenglingen (Ab-ärmeren Gliedern der Abteilung II) und Schalen oder Mikroliten von saureren Andesinen längs der genannten Kurve vor sich geht. Nachdem die Temperatur tief genug gesunken ist und der flüssige Rest zufolge der früheren Feldspatausscheidung an Quarz gesăttigt worden ist, beginnt auch eine Ausscheidung von Quarzeinsprenglingen. Infolge der niedrigen Temperatur und des hohen $\mathrm{SiO}_{2}$-Gehaltes ist die Lösung indessen sehr viskos geworden, das Wachsen der Einsprenglinge wird immer mehr erschwert und es tritt früher oder später eine Unterkühlung des flüssigen Restes zu Glas ein, oder derselbe kann höchstens zu einem sehr feinen Kristallaggregat erstarren. Das Endprodukt ist ein porphyrisches Gestein mit zahlreichen kleineren Einsprenglingen von zonalstruiertem Plagioklas (saurerem Labrador bis saurerem Andesin), spärlicheren, aber häufig grösseren Einsprenglingen von Sanidin ${ }_{I I}$ und dazu ei-

1 Für die Begründung dieser Anschaungsweise ist auf die von ScHREINEMAKER gegebene allgemeine Herleitung zu verweisen (Z. ph. Ch. 50 [1905]: 169; 51 [1905]: 547; 52 [1905]: 511). Die approximative Lage der Plagioklas-Sanidin-Kurve bei quarzfreien Magmen ist von mir früher (G. F. F. 27 [1905]: 342) durch eine Zusammenstellung der vorhandenen Angaben über die Beschaffenheit der Feldspateinsprenglinge der trachytischen und basaltischen Lavagesteine abgeleitet worden; entsprechende Untersuchungen an sauren Ergussgesteinen zeigen, dass die Lage der Karve durch die Gegenwart freier Kieselsänre nicht nennenswert geändert wird. 
Bd 32. H. 2.] EISENERZFÜHR. FORMATION VON GRÄNGESBERG. 157

nigen wenig hervortretenden Quarzeinsprenglingen; die meistens gut idiomorph begrenzten Einsprenglinge sind in eine reichliche, saure, glasige oder feinkristallinische Grundmasse eingebettet.

I: B. Wir wollen nun den Fall diskutieren, wenn dasselbe Magma sehr langsam und ruhig kristallisiert; dieser Kristallisationsprozess würde demjenigen gewisser kalkreicherer Granite entsprechen. ${ }^{1}$ Auch in diesem Fall haben wir. zwischen den zwei obenerwähnten Kristallisationsperioden zu unterscheiden; der Kristallisationsweg während der ersten Periode (die Kurve B in Fig. 23) wird jedoch jetzt ein etwas abweichender, indem die sehr langsame Abkühlung einen stetigen chemischen Stoffaustausch zwischen den ausgeschiedenen Plagioklaskristallen und dem flüssigen Magma erlaubt und demzufolge die feste Phase sich durch ihre ganze Nasse mit der Lösung in Gleichgewicht einzustellen vermag; in dem Moment, wo der Kristallisationsweg die Plagioklas-Sanidin-Kurve erreicht, ist das Magma mit homogenen (nicht zonalstruierten) Einsprenglingen etwa von der Zusammensetzung eines basischeren Andesins gespickt. Während der dann folgenden zweiten Periode setzt sich die Kristallisation, wie im vorigen Fall, längs der Plagioklas-SanidinKurve fort, unter stetigem Weiterwachsen der Andesineinsprenglinge und gleichzeitiger Ausscheidung von Einsprenglingen eines natronarmen Sanidins ${ }_{\text {II }}$, aber unter fortgesetzter Erhaltung der Homogenität der Einsprenglinge; es fängt in dieser Periode auch die Quarzausscheidung an. Trotz der grossen Viskosität erlauben die langsame Abkühlung und die ruhigen Bedingungen ein kontinuierliches Weiterwachsen der vorhandenen Kristallkerne, und der flüssige Rest zwischen den Einsprenglingen wird immer geringer; in einem gewissen

- 1 Als granitstnierter Repräsentant des diskutierten chemischen Magmatypus ist anzuführen der von Ransome (U. S. G. S. P. P. 12 [1903]: 76) beschriebene ,Quarz-Monzonit, von Lost Gulch, Globe District, Arizona; ebenso der von Lindaren (U. S. G. S. 20 Ann. Rep. III [1900 ]: 82) beschriebene >Quarz-Mfonzonit, von Democrat Mine, Hailey, Idaho. 
Punkt auf der Kurve (C in Fig. 22), wo der Analysenort des sich in Gleichgewicht mit der Lösung befindenden Plagioklases (etwa $A n_{1} A b_{2}$ ) und derjenige des entsprechenden Sanidingliedes (mit zwischen 20 und $25 \mathrm{Mol} \%$ Ab)auf einer Geraden liegen, die auch durch den Analysenort des ursprünglichen Magmas geht, ist das Magma gänzlich zu einem grobkörnigen, hypidiomorphen Gemenge aus Oligoklasandesinkörnern, grossen Sanidin $_{\mathrm{I}}$-Individuen und Quarz erstarrt. Dieser Verlauf entspricht jedoch nur dem theoretischen Grenzfall; es zeigt die anch in den typischsten granitischen Tiefengesteinen immer nachweisbare Zonalstruktur der Feldspate, dass die chemische Ausgleichung zwischen Fest und Flüssig während der Erstarrung nur eine unvollständigé gewesen 'ist, besonders während der spăteren Phasen derselben; es kann somit die Kristallisation im Punkt C nicht völlig abgeschlossen sein, sondern sie muss sich unter Ausscheidung eines saureren Plagioklassaums und einer Ab-reicheren Sanidinschale noch etwas weiter fortsetzen. Mit zunehmender $\mathbf{A b}$ kühlungsgeschwindigkeit wird dieser zonale Bau ein immer ansgeprägterer, gleichzeitig nimmt die Neigung zu granitporphyrischer Ausbildung zu, indem der letzte Kristallisationsrest nicht Zeit genug hat, um sich gänzlich auf die früheren Kristallkerne abzusetzen, sondern sich zum kleineren oder grösseren Teil als ein kleinkörniges Kristallaggregat ausscheidet.

II: A. Es sollen weiter die entsprechenden Falle diskutiert werden, wenn dasselbe Magma sich während der Kristallisation, zufolge spontanen Fliessens oder zufolge anderer Ursachen, in einer orientierenden Bewegung befindet. Bei den Lavaströmen scheint die Bewegung von verhältnismässig geringfügigem Einfluss auf die Strukturausbildung zu sein; die dadureh in erster Linie bedingten fluidalen Erscheinungen. in der Grundmasse treten nämlich zufolge der glasigen oder ausserst feinkristallinischen Ausbildung derselben beim Vergleich mit den Strukturen der entsprechenden, nicht fluidal- 
Bd 32. H. 2.] EISENERZFÜHR. FORMATION VON GRÄNGESBERG. 159

struierten Gesteinsvarietäten nicht sehr scharf hervor. Dazu kommt zwar noch eine mehr oder weniger merkbare Zertrümmerung der früheren grösseren Einsprenglinge; in denjenigen Phasen der Erstarrung, wo das tlüssige Magma sehr viskos geworden ist, und wo somit die Bedingungen für eine mehr energische zertrümmernde Einwirkung in höherem Grade vorbanden sind, dürften die Bewegungen der Lava indessen von selbst aufhören.

II: B. Gehen wir dann schliesslich zu dem Fall der langsamen Erstarrung unter orientierender Bewegung über, so liegt zunächst kein Grund vor, anzunehmen, dass der unter I: B skizzierte chemische Verlauf bei einer gestörten Kristallisation nennenswert geändert wird. Wir müssen somit annehmen, dass auch in diesem Fall sich in den früheren Phasen der Kristallisation, während welcher das Magma noch ziemlich leichtbeweglich ist, eine Ausscheidung von reichlichen Andesineinsprenglingen vollzieht, wozu sich dann später Einsprenglinge von 'Sanidin ${ }_{\text {II }}$ und Quarz gesellen. In dem Masse wie das Magma zäher wird, fallen diese grösseren Einsprenglinge indessen einer immer energischer werdenden Zertrümmerung, Granulierung und Auswalzung anheim, und der flüssige Magmarest erstarrt grösstenteils als ein kleinkörniger Kristallbrei aus einem den Einsprenglingen gegenüber etwas saureren Plagioklas nebst viel Sanidin lich, dass die ursprüngliche Erstarrungsstruktur dieses kleinkörnigen Kristallbreies während der nach der Erstarrung zu - passierenden Ausglühungsperiode gewisse Modifizierungen zu erfahren hat, wie auch die Trübung der Feldspate zufolge Perthitisierung und anderer Umwandlungsprozesse offenbar in diese Periode zu verlegen ist.

Durch den oben unter II:B skizzierten Erstarrangsverlauf könnten meiner Auffassung nach die im Vorigen (S. 40-42) beschriebenen Struktureigenheiten der Grängesberger Porphyrgranulite, wie das reichliche Vorhandensein zerbrochener Andesineinsprenglinge, die teilweise Ersetzung der Einsprenglinge durch 
»Anhäufungens, das Auftreten und die Ausbildung des granulitischen Grundgewebes u.a.m., gedeutet werden. In prinzipiell ăhnlicher Weise wären dann auch die Strukturen der übrigen Granulittypen unseres Gebietes zu erklären, obwohl der den Verschiedenheiten in der chemischen Zusammensetzung entsprechende verschiedenartige chemische Verlauf des Kristallisationsprozesses mannigfaltige Modifizierungen in den Details bedingt. Es wäre somit anzunehmen, dass diese Gesteine, wenn sie unter ruhigen, aber übrigens ähnlichen Bedingungen kristallisiert hätten, als Granite oder möglicherweise als Granitporphyre ausgebildet worden wären. - In diesem Zusammenhang ist es auch von Interesse, hervorzuheben, wie eng meistens die Ausbildung der Granulitstruktur mit einer inhomogenen schlierigen oder gebänderten Ausbildung der Gesteine verknüpft ist, die nach der vorher (S. 153) angegebenen Auffassung ebenfalls in Zusammenhang mit Bewegungen in dem Magma zu bringen wäre. Obwohl diese chemischen Inhomogenitäten wohl grösstenteils schon vor dem Anfang der Erstarrung ausgebildet wurden, dürfte ihre Entstehung doch demselben durchgreifenden Orientierungsprozess zuzuschreiben sein, der auch die Ausbildung der Granulitstruktur hervorgerufen hat.

Es ist selbstverständlich, dass nach der oben entwickelten Auffassung mancherlei Modifikationen in der Strukturausbildung zu erwarten sein müssen je nach der verschiedenen Intensität des Deformationsprozesses und der verschiedenen zeitlichen Lage des Deformationsmaximums innerhalb des Kristallisationsintervalles des Magmas. Es könnte nach diesen Gesichtspunkten die ganze Strukturreihe gedeutet werden, die von den Granuliten durch die granulitgneisigen $\mathrm{Zwischenge-}$ steine bis zu den groben Gneisen und Urgraniten führt, welch letztere nur ziemlich geringfügige Zeugnisse der Deformation aufweisen und speziell darin mit massigen Graniten übereinstimmen, dass sich der spätere Kristallisationsrest des Magmas nicht als ein kleinkörniger Kristallbrei ausgeschieden hat; 
Bd 32. H. 2.] EISENERZFÜHR. FORMATION VON GRÄNGESBERG. 161

sondern ziemlich vollständig auf frühere Einsprenglinge oder Anhäufungen abgesetzt worden ist. Immerhin bleibt es eine auffällige Erscheinung, dass derartige grobe Gesteine in mehreren Fallen ziemlich unvermittelt mitten in den Granuliten auftreten. Man könnte dann annehmen, dass das Gneismagma zu dem Zeitpunkt der Erstarrung des umgebenden Granulitmagmas entweder schon verfestigt oder auch noch nicht emporgedrungen war; als eine dritte Möglichkeit wäre noch zu prüfen, ob nicht das erstere Magma zufolge eines abweichenden chemischen Charakters ein weit tiefer gelegenes Kristallisationsintervall besitzt und seine Erstarrung demzufolge sich der Hauptsache nach erst nach der vollständigen Erstarrung des umgebenden Granulitmagmas vollzieht. Eine derartige rein chemische Erklärung würde offenbar fürr die roten Gneise unseres Gebietes gut ausreichen, deren Chemismus, von der etwas grösseren Azidität abgesehen, ja mit demjenigen der Granophyre sehr eng zusammenfällt, und die somit der bei der niedrigsten Temperatur kristallisierenden Quarz-FeldspatMischung nahe entsprechen dürften. Die ausgeprägte Neigung der Gesteine des roten Gneis-Typus zu grober und massiger surgranitischer Ausbildung und das Fehlen dieses chemischen Typus unter den granulitisch struierten Gesteinen unseres Gebietes bleiben immerhin bemerkenswerte Tatsachen; auch ist hier zu erinnern an die auf S. 22 erwähnte Tendenz der roten Gneise, an den Kontakten mit den basischeren und kalkreicheren und demnach warscheinlich bei höherer Temperatur kristallisierten Granulittypen sich diesen gegenüber gewissermassen intrusiv zu verhalten. Die in den Grängesberger Granuliten zu beobachtenden Pegmatite und Aplite dürften auch dem roten Gneis-Typus chemisch ziemlich nahe kommen. 
Über die Verwendung des Namens "Granulit» als petrographische Bezeichnung für die mittelschwedischen erzführenden Gesteine.

In dem Aufsatz $\gg \mathrm{Om}$ en ändring af nomenklaturen för våra granuliter eller hälleflintgneisers hat Prof. HöGвом neuerdings (G. F. F. 30 [1908]: 58-59) die Meinung ausgesprochen, dass eine fortgesetzte Anwendung des Namens „Granulit» in dem von TörnEвоHм gegebenen. Sinne ungeeignet und irreführend wäre. $\mathrm{Da}$ ich nichtsdestoweniger in diesem Aufsatz den Namen Granulit konsequent angewandt habe, mögen hier auch die Gründe angegeben werden, warum ich im Gegensatz zu НӧGвом diesen Namen als völlig berechtigt und gut geeignet zur petrographischen Bezeichnung der in Rede stehenden Gesteine auch weiterhin ansehen möchte.

Die mittelschwedischen Granulite zeigen meiner Auffassung nach den Gneisgesteinen von normaler Grobheit gegenüber so auffallende petrographische Eigenheiten, dass es mir bei einer objektiven Klassifizierung sehr wünschenswert erscheint, sie aus der Gesteinsfamilie der „Gneise» auszusondern. Eine Bezeichnung derselben schlechthin als „Gneise» dürfte ebenso unrichtige Vorstellungen über ihre tatsächliche Beschaffenheit hervorrufen, als wenn man z. B. Aplite oder Granitporphyre schlechthin als Granite bezeichnen würde. Dasselbe trifft offenbar auch für die sächsischen Granulite und andere dichte, kristallin-schieferige Quarz-Feldspatgesteine zu. Es ist dann für die vorliegende Nomenklaturfrage zunächst von Bedeutung zu diskutieren, ob die tatsächlich $\mathrm{zu}$ beobachtenden petrographischen Unterschiede zwischen den mittelschwedischen und den sächsischen Granuliten untereinander zu einer Verteilung derselben auf mehrere petrographische Gesteinsfamilien nötigen, oder ob diese Verschiedenheiten sich nicht vielmehr nur zu einer weiteren Gliederung dieser Gesteine innerhalb einer und derselben Familie 
Bd 32. H. 2.] EISENERZFÜHR. FORMATION VON GRÄNGESBERG. 163

von dichten kristallin-schieferigen Quarz-Feldspatgesteinen besser eignen. Aus diesen Gründen ist im Folgenden ein Versuch gemacht, die wichtigeren chemisch-mineralogischen und strukturellen Verschiedenheiten zwischen den mittelschwedischen und den sächsischen Granuliten zu definieren; in Bezug auf die letzteren gründet sich die Darstellung auf die vorhandene Litteratur im Verein mit Studien an Material, das sich in den Sammlungen des hiesigen mineralogischen Instituts befindet.

Für eine eingehendere Vergleichung der chemischen Charaktere der beiden Gesteinsreihen ist der vorhandene Analysenvorrat noch zu geringfügig. Dies gilt nicht zum mindesten für die sächsischen Granulite; unsere chemische Kenntnis von diesen Gesteinen ist scheinbar noch fast ausschliesslich auf die von Scheerer ${ }^{1}$ publizierte Analysenreihe zu basieren, die in der beigefügten Tabelle nebst einigen Analysen der mit den Granuliten assoziierten "Trappgranulite wiedergegeben ist.

Da beide Gesteinsreihen Quarz-Feldspatgesteinen entsprechen, stimmen sie selbstverständlich in ihren chemischen Hauptzügen überein. Als spezifische Kennzeichen für die sächsische Granulitreihe oder wenigstens für die s. g. sächsischen Normalgranulite den mittelschwedischen Gesteinen gegenüber dürften hauptsächlich die folgenden chemisch-mineralogischen Spezialcharaktere hervorzuheben sein.

1. Das vorherrschende Feldspatmineral der »Normalgranulite ist ein Orthoklasperthit, der, dem Reichtum an feinen Albitspindeln nach zu schliessen, meistens zwischen 25 und $40 \mathrm{Mol}$ \% $\mathrm{Ab}$ enthalten dürfte und somit im allgemeinen der Abteilung III oder dem natronreicheren Teil der Abteilung II zuzurechnen wäre. Es ist dies offenbar ein wichtiger Unterschied von den mittelschwedischen Granuliten, unter welchen ausgeprägtere Perthitgesteine bisher nicht mit Sicherheit konstatiert worden sind. Die "Normalgranulite» verhalten sich in

1 N. J. f. Min. 1873 ; S. 677.

$12-100170$. 


\begin{tabular}{|c|c|c|c|c|c|c|c|c|c|c|c|}
\hline & 1. & 2. & 3. & 4. & 5. & 6. & 7. & 8. & 9. & 10. & 11. \\
\hline $\mathrm{SiO}_{2}$ & 76.33 & 74.60 & 7347 & 75.46 & 75.80 & 73.37 & 73.47 & 72.97 & 71.25 & 54.06 & 45.52 \\
\hline $\mathrm{Al}_{2} \mathrm{O}_{3}$ & 12.89 & 12.84 & 11.07 & 12.09 & 12.09 & 14.09 & 14.86 & 12.69 & 14.28 & 16.52 & 17.74 \\
\hline $\mathrm{Fe}_{2} \mathrm{O}_{3}$ & 2.35 & 2.66 & 5.33 & 3.75 & 2.42 & 3.31 & 3.64 & 4.55 & 4.32 & 110.89 & 213.24 \\
\hline $\mathrm{MgO}$. & 0.35 & 0.23 & 0.73 & 0.66 & 0.38 & 0.76 & 0.67 & 0.63 & 0.92 & 4.27 & 9.49 \\
\hline $\mathrm{CaO}$ & 0.45 & 0.73 & 1.83 & 1.22 & 1.45 & 1.54 & 1.62 & 2.33 & 2.84 & 11.35 & 10.40 \\
\hline $\mathrm{Na}_{2} \mathrm{O}$ & $(?)-$ & 2.39 & 2.89 & 2.46 & 2.72 & 2.49 & 1.80 & 3.16 & 2.76 & 2.85 & 2.52 \\
\hline $\mathrm{K}_{2} \mathrm{O}$. & (?) 7.59 & 5.82 & 3.76 & 3.96 & 4.27 & 4.25 & 3.95 & 3.46 & 3.02 & 0.38 & 0.07 \\
\hline $\mathrm{H}_{2} \mathrm{O}$ & 0.22 & 0.75 & 0.77 & 0.25 & 0.39 & 0.27 & 0.21 & 0.13 & 0.16 & - & - \\
\hline & 100.18 & 100.02 & 99.83 & 99.85 & 99.52 & 100.08 & 100.22 & 99.92 & 99.55 & 100.32 & 98.98 \\
\hline$s^{3} \ldots$ & - & 2.66 & 2.86 & 3.53 & 3.08 & 2.97 & 3.92 & 2.51 & 2.66 & 0.17 & $(0.00)$ \\
\hline Or. & - & 57.9 & 41.0 & 45.4 & 44.4 & 45.6 & 49.3 & 34.6 & 31.5 & 3.8 & 0.7 \\
\hline $\mathrm{Ab}$ & - & 36.0 & 47.8 & 42.8 & 42.9 & 40.5 & 33.8 & 48.1 & 43.6 & 43.4 & 37.8 \\
\hline An . . & - & 6.1 & 11.2 & 11.8 & 12.7 & 13.9 & 16.9 & 17.3 & 24.9 & 52.8 & 61.5 \\
\hline$\Sigma \mathrm{F}$ & - & 21.36 & 19.48 & 18.50 & 20.42 & 19.79 & 17.08 & 21.18 & 20.37 & 21.16 & 21.49 \\
\hline $\mathrm{Al}_{2} \mathrm{O}_{3}$ & - & $|+1.33|$ & -1 & $\mid+1.49$ & $|+0.33|$ & +2.51 & +4.55 & $\mid-0.01$ & $|+1.25|$ & $1-9.10$ & --5.35 \\
\hline
\end{tabular}

1. Rötlicher Granulit, Höllmühle bei Penig; 2. Schieferiger ,Gneisgranulit,, Steina ; 3. Granulit, Hartmannsdorf; 4. Grauweisser Granulit, Limbach; 5. Rötlicher Granulit, Nendörfchen; 6. Granweisser, schieferiger Granulit, Steina; 7. Hellgrauer Granulit, Neudörfchen: 8. Grauer HypersthenGranulit, Penig; 9. Dunkelgrauer Hypersthen-Granulit, Burgstädt; 10. iTrappgranulit,, Ringstal bei Mittweida; 11. 'Trappgranulit», Böhrigen.

dieser Hinsicht zu den letzteren Gesteinen etwa wie die schwedischen Perthitgneise und Perthitgranite zu unseren gewöhnlicheren Gneis- und Granittypen. Bei diesen Perthitgneisen und Perthitgraniten hängt nun das Auftreten der natronreicheren Perthite offenbar immer mit einem ziemlich alkalinen (An-armen) Chemismus eng zusammen. Ein solcher Charakter tritt indessen in der vorliegenden Analysenreihe der sächsischen Granulite nicht sehr deutlich hervor, was möglicher-

1 Einschl. $1.26 \% \mathrm{MnO}$.

2 Einschl. $0.59 \% \mathrm{MnO}$.

3 Bei der Berechnung ist alles Eisen als $\mathrm{FeSiO}_{3}$ gerechnet. 
weise auf einen nicht ganz unbeträchtlichen Kalkgehalt in dem vorhandenen Almandin zurückzuführen wäre. Jedenfalls wäre eine eingehendere chemisch-petrographische Untersuchung der sächsischen Granulite sehr zu wünschen.

2. Die sächsischen Granulite dürften im allgemeinen verhältnismässig reich an $\mathrm{FeO}$, dagegen sehr arm an $\mathrm{MgO}$ und $\mathrm{Fe}_{2} \mathrm{O}_{3}$ sein; gleichzeitig ist meistens ein $\mathrm{Al}_{2} \mathrm{O}_{3}$-Überschuss vorhanden. Diese chemischen Eigenschaften bedingen bei ihnen einen unverkennbaren, wenn auch quantitativ nicht besonders hervortretenden »Paracharakter», der in der eigentümlichen Beschaffenheit ihrer femischen Gemengteile und ihrer akzessorischen Mineralgesellschaft zum Vorschein kommt (FeOGranat, rotbrauner FeO-Biotit, FeO-reicher Hypersthen, FeOSpinell, Disthen, Sillimanit, Andalusit, Prismatin und sogar Korund). Ein recht ähnlicher Paracharakter findet sich zwar in einigen mittelschwedischen Granulitgebieten wieder, zumal in gewissen manganeisenerzführenden Gesteinszügen, ist jedoch dieser Granulitformation meistens fremd.

Eine interessante Analogie bietet die für die beiden Granulitformationen bezeichnende grosse Variationstendenz der Gesteine dar. Ganz wie wir es für die Grängesberger Granulitgesteine beschrieben haben, werden in den Beschreibungen der sächsischen Granulitformation die stetigen Gesteinswechsel sowohl im Kleinen (Bänderung etc.) wie in etwas grösserem Massstab übereinstimmend betont. Über grosse Teile der beiden Formationen hin bleibt dabei die innige Assoziation der hellen salischen Granulite mit dunklen femischen Gesteinsbänken eine sehr hervortretende Erscheinung. Gleichwie in der mittelschwedischen Granulitformation scheint schliesslich auch in der sächsischen die grosse Variationstendenz der Gesteine zu der Fintstehung einer Reihe von Gesteinsabarten sehr eigentümlicher Zusammensetzung lokal Veranlassung gegeben zu. haben (z. B. die von SAUER und KaLkowskY beschriebenen prismatin- und korundführenden Gesteinseinlagerungen). 
Bei diesen Übereinstimmungen in der allgemeinen Variationsweise der Gesteine bestehen stets Unterschiede in den chemischen Details. Während die grünsteinartigen Einlagerungen der mittelschwedischen Granulitzüge meistens den Charakter von amphibolitischen Hornblende-Andesingesteinen tragen, sind die entsprechenden Gesteinsglieder der sächsischen Formation hauptsächlich Pyroxen-Labradorgesteine von noritischem Charakter. Anstatt unserer meistens aus Hornblende oderPyroxenen derDiopsid-Malakolith-Reihe bestehenden Skarngesteine werden aus der sächsischen Granulitformation websteritische Pyroxengesteine oder eklogitische Pyroxen-Granatgesteine nebst Serpentingesteinen erwähnt u. s.w. Auch in dieser Hinsicht zeigen indessen gewisse mittelschwedische Granulitgebiete, z. B. das extrem kalireiche und zugleich recht tonerdereiche Åmmeberggebiet, gewisse Anklänge an die sächsische Granulitfazies.

In struktureller Hinsicht haben die mittelschwedischen und die sächsischen Granulite gemeinsam das dichte bis feine Korn und die kristallin-schieferige Anordnung und bis in die feinsten Details eingreifende Orientierung der Gemengteile. Es ist auch hervorzuheben, dass die in den mittelschwedischen Granuliten sehr häufig zu beobachtende, verschwommen porphyrische Ausbildung auch in den sächsischen Gesteinen allgemein zu verspüren ist, obgleich dieselbe hier nur in den s. g. augengranulitischen Varietäten deutlicher hervortritt. Bei diesen Übereinstimmungen bleibt indessen die entschieden mehr dünnlamellare Struktur meistens ein gutes Kennzeichen der sächsischen Normalgranulite, vor allem die für diese Granulite bezeichnende dünnplattige Ausbildung des Quarzes oder die sQuarz feuilletés-Struktur (Fig. 13, Taf. 3). Obwohl eine Auswalzung der grösseren Quarzkörner auch in schwedischen Granuliten eine häufige Erscheinung ist, habe ich bisher niemals in diesen Gesteinen die typische Quarz feuilleté-Struktur gesehen. Nach den vorliegenden Angaben scheint sie indessen auch innerhalb des sächsischen Granulitgebietes allein auf die 
sehr dichten und dünnplattigen, quarzreichen und biotitarmen Normalgranulite beschränkt zu sein, die nur in den peripheren Teilen des Gebietes auftreten und auch dort anderen Granulitvarietäten im ganzen quantitativ untergeordnet sein sollen. Schon in den damit abwechselnden glimmerreicheren Varietäten tritt die Struktur weniger hervor; ein Teil dieser Biotitgranulite scheint eine typisch isometrisch-körnige Struktur zu besitzen, die nicht von derjenigen mancher mittelschwedischen Biotitgranulite zu unterscheiden ist (Fig. 14, Taf. 3).

Zusammenfassend wären somit die folgenden petrographischen Charaktere als die Hauptmerkmale der sächsischen Normalgranulite den mittelschwedischen Granuliten gegenüber anzugeben:

1. Der Perthitcharakter.

2. Der $\mathrm{FeO}-\mathrm{Al}_{2} \mathrm{O}_{3}$-Paracharakter und damit zusammenhängende Gehalt an Almandin.

3. Der noritische Charakter der assoziierten Grünsteineinlagerungen.

4. Die Quarz feuilleté-Struktur.

Was die drei erstgenannten Charaktere betrifft, so hängen sie offenbar alle mit einem interessanten chemischen Spezialcharakter dieser Gesteinsformation zusammen. Dass ein derartiger chemisch-mineralogischer Spezialcharakter jedoch nicht ausreicht, um die Absonderung der Granulitgesteine von sächsischem Typus als eine selbständige Gesteinsfamilie zu motivieren, dürfte kaum zweifelhaft sein. In dieser Hinsicht ist daran zu erinnern, dass es bisher niemals vorgeschlagen worden ist, die Alkaligranite, die Alkalisyenite u. s. w. aus den Gesteinsfamilien der Granite bezw. der Syenite u. s. w: auszusondern, um sie als selbständige Gesteinsfamilien aufzustellen. Und doch ist wohl nicht zu behaupten, dass der alkaline Spezialcharakter von geringerer klassifikatorischer Bedeutung ist als der chemisch-mineralogische Spezialcharakter der Gra- 
nulite von sächsischem Typus. Ein mehr oder weniger ähnlicher Spezialcharakter ist ja auch in gewissen Granit- und Gneisformationen beobachtet worden. Hier in Schweden findet er sich in den südwestlichsten Teilen der „Järngneis»Formation mehrfach, besonders deutlich in der von HeNNIG beschriebenen Gesteinsreihe auf dem Kullen in Schonen (Rote Perthitgneise - dunklere gebänderte Gneise mit Granat und Pyroxen - Granat-Pyroxenamphibolite mit Hypersthen - feldspatfreie Granat-Pyroxen-Hornblendegesteine). Wenn unter den dichten kristallin-schieferigen Quarz-Feldspatgesteinen dem Vorkommen von FeO-Granat u. s. w. eine besonders hohe klassifikatorische Bedeutung beigemessen wird, erfordert die Konsequenz, dass dies auch bei den gröberen gneisigen oder granitischen Parallelreihen eingehalten wird.

Noch weniger eignet sich die für einen geringeren Teil der sächsischen Granulite bezeichnende Quarz feuilleté-Struktur als petrographische Basis für eine scharfe systematische Scheidung der sächsischen und der mittelschwedischen Granulite. In diesem Zusammenhang ist es von .Interesse hervorzuheben, dass auch unter den Graniten die kalkarmen, durch natronreichere Perthitfeldspate gekennzeichneten Varietäten (z. B. die Rapakiwigranite) gleichzeitig durch eine besondere Ausbildungsweise des Quarzes öfters ausgezeichnet sind.

Da es, soweit ich finden kann, nicht möglich ist, chemisch-mineralogische und strukturelle Merkmale zu definieren, die zu einer. scharfen systematischen Scheidung zwischen den mittelschwedischen und den sächsischen Granuliten berechtigen können, möchte ich es nicht nur als berechtigt, sondern sogar als selbstverständlich ansehen, dass diese Gesteine bei einer objektiven petrographischen Klassifizierung in einer und derselben Gesteinsfamilie unter einem gemeinsamen Familiennamen vereinigt werden. Es dürften dabei sehr geringe Aussichten bestehen, den in der schwedischen gleichwie in der deutschen Litteratur wohleingeführten Namen Granulit durch irgend einen neuen Namen zu ersetzen. Die Ver- 
Bd 32. H. 2.] EISENERZFÜHR. FORMATION VON GRÄNGESBERG. 169 suche, den Namen Granulit nur für eine spezielle Varietät unter den Granulitgesteinen und zwar für die biotitärmsten, FeO-granathaltigen Varietäten unter den sächsischen Granuliten $\mathrm{zu}$ reservieren, dürften ebenso fruchtlos sein; es zeigt ja die Erfahrung, wie solche allgemeinen Gesteinsnamen immer von selbst den weiteren Umfang nehmen, der ihnen etymologisch zukommt. Wie wenig Vorstellungen von weissen, glimmerfreien, $\mathrm{FeO}$-granatführenden Gesteinen sich nunmehr mit dem Namen Granulit zu verknüpfen brauchen, zeigen solche in der deutschen petrographischen Litteratur öfters vorkommenden Gesteinsnamen wie „Biotitgranulit», "Hornfelsgranulit», „Turmalingranulit» u. s. w. Es ist schwer zu verstehen, warum dann die petrographische Bezeichnung der mittelschwedischen Granulitgesteine als „Granulites notwendig zu irrigen Vorstellungen von ihrer petrographischen Beschaffen. heit führen sollte. Es sollte übrigens bei den sächsischen ebensowohl wie bei den mittelschwedischen Granuliten die Verpflichtung bestehen, bei der petrographischen Charakterisierung sich nicht mit dem allgemeinen Namen Granulit zu begnügen, sondern durch geeignete Präfixe auch die wichtigsten Spezialcharaktere der za charakterisierenden Varietäten zum Ausdruck zu bringen. 


\section{Erklärungen der Tafeln.}

\section{Tafel 1,}

Fig. 1. Roter Gneis, Lomberget. Vergr. $130 \times$, Nicols +. Zeigt die Struktur des recht natronreichen Mikroklinperthits. (Vergl. p. 8.)

Fig. 2. Quarzhornblendesyenit, Löfhällsgrube, Björnberget. Vergr. $20 \times$, Nicols +. Durchkreuzungszwilling von Mikroklin-Oligoklas-Antiperthit mit Saum von Quarz-Plagioklas-Mikropegmatit. (Vergl. p. 65.)

Fig. 3. Granitgneis, Karl-Johan-Schacht. Vergr. $41 \times$, Nicols +. Zeigt mit Quarz poikilitisch gespickten Oligoklas. (Vergl. p. 24.)

Fig. 4. Granit, Örtjärnsfjället. Vergr. $41 \times$, Nicols + . Zeigt das myrmekitische Grundgewebe zwischen den grösseren Mikroklinperthitleisten. (Vergl. p. 128.)

Fig. 5. Plagioklasgneis, Skakelbacken. Vergr. $19 \times$, Nicols + . Polygonales Aggregat aus Albitoligoklas zwischen gröberen Quarzfeldern. (Vergl. p. 33.)

Fig. 6. Eisenarmer schuppiger Roteisenstein, Morgrube, W. Ormbergfeld. Vergr. $15 \times$.

\section{Tafel 2.}

Fig. 7. Porphyrischer Granulitgneis, SW von dem See Glaningen. Vergr. $18 \times$, Nicols + . Unregelmässig geförmter Einsprengling von Andesin (dunkel) mit Saum aus Oligoklas (hell), von einem grobgranulitischem Quarz-Feldspat-Grundgewebe umgeben. (Vergl. p. 35.)

Fig. 8. Porphyrgranulit, Täppan. Vergr. $14 \times$. Links unten opaker Andesineinsprengling (dunkel); links oben Mikroklinanhäufung (hell); rechts granulitisches Grundgewebe mit streifenweise angehäufter Hornblende (dunkel). (Vergl. p. 40.)

Fig. 9. Exportfeldgranulit, Hangendes des Skärningen. Vergr. $17 \times$, Nicols + . Plagioklasanhäufung in plagioklasgranulitischem Grundgewebe. (Vergl. p. 52.)

Fig. 10. Skarnführender Granulit, Öraberget. Vergr. $14 \times$. Granulitisches Gewebe mit streifenweise angehäufter Hornblende, die sich unten (in der Fortsetzung der abgebildeten Partie) zu einer Skarnschliere konzentriert. (Vergl. p. 61.)

Fig. 11. Porphyrischer Plagioklasgranulit westlich vom Björnberget. Vergr. $20 \times$, Nicols + . Unregelmässig begrenzter und geknickter Einsprengling von albitischem Plagioklas nebst einer kleinen 
Quarzanhäufung (links), in einem plagioklasgranulitischen Grundgewebe eingebettet. (Vergl. p. 63.)

Fig. 12. Lomberggranulit, Lomberget. Vergr. $15 \times$. Zeigt die Imprägnation des granulitischen Gewebes mit Eisenerz (schwarz), das sich streifenweise anhäuft.

\section{Tafel 3.}

Fig. 13. Hypersthenführender Granatgranulit, Sect. Hohenstein, Sachsen. Vergr. $14 \times$. Zeigt die dünn-lamellare Ausbildung des Quarzes (hell). (Vergl. p. 166.)

Fig. 14. Biotitgranulit mit einzelnen Granaten, Etzdorfer Mühle, Sect. Waldheim, Sachsen. Vergr. $18 \times$, Nicols + . Zeigt die ziemlich isometrisch-körnige Struktur. Mitten links ein grösseres Korn aus feinstreifigem Perthit. (Vergl. p. 167.)

Fig. 15. Plagioklasgranulit nördlich von Bergslags-Hörken. Vergr. $14 \times$. Gestreckt linsenförmige Quarzanhäufung in einem granulitischen Grundgewebe mit $\|$ : geordneten Biotittafeln. (Vergl. p. 67.)

Fig. 16. Plagioklasgranulit, NW von Örtjärnsdammen. Vergr. $18 \times$, Nicols +. Zeigt die isometrisch-polygonale Struktur des QuarzPlagioklas-Gewebes. (Vergl. p. 66.)

Fig. 17. Skarnführender Granulit, Öraberget. Vergr. $14 \times$. Ausgezeichnet gleichmässig-körniges Quarz-Feldspat-Gewebe mit \| : geordneten feinen Biotittafeln. (Vergl. p. 61.)

Fig. 18. Dasselbe Gestein. Vergr. $18 \times$, Nicols +.

\section{Tafel 4.}

Fig. 19. Diorit, Örtjärn. Vergr. $13 \times$. (Vergl. p. 68.)

Fig. 20. Malchitartiges Gestein. Gemischter Gang in Granitgneis, Karl-Johan-Schacht. Vergr. $13 \times . \mathrm{Zu}$ der Mitte ein Aggregat von verfiltzter Hornblende, von einem hellen, biotitdurchspickten Plagioklasgewebe umgeben. (Vergl. p. 29.)

p. 71.)

Fig. 21. Andesinamphibolit, Orrleksdammen. Vergr. $14 \times$. (Vergl.

Fig. 22. Quarz-Magnetit-Amphibolit. Zwischenband in dem Apatiterz des Skärningen. Vergr. $14 \times$. Schwarz $=$ Magnetit; grau $=$ Hornblende; weiss $=$ Andesin und Quarz:

Fig. 23. Biotit-Amphibolit aus dem Granitgneis im Hangenden des Skärningen (zusammen mit der auf S. 29 erwähnten Eisenerzausscheidung). Vergr. $14 \times$.

Fig. 24. Klinoanthophyllit-Oligoklas-Gestein. Westlich von Björnberget. Vergr. $13 \times$. (Vergl. p. 76.)

\section{Tafel 5.}

Graphische Zusammenstellung der Analysen der wichtigeren mittelschwedischen Eisenerze. Klb. = Klackberg; Kolnb. = Kolningsberg; $13-100170$. 
Dm. $=$ Dannemora $;$ Dkb. $=$ Dalkarlsberg $; \mathrm{Pb} .=$ Persberg; T. $-\mathrm{Hb} .=$ Tuna-Hästberg; K.-Lb. = Klacka-Lerberg; Sb. $=$ Striberg; Ph. = Pershyttan; Gb. = Grängesberg.

\section{Tafel $6^{1}$.}

Grundriss und Profile des Grängesberger Exportfeldes. Massstab $1: 2000$. (Nach der offiziellen Grubenkarte.)

\section{Tafel $7^{1} \cdot$}

Geologische Karte des Grängesberger Erzzuges. Massstab 1:10000.

\section{Tafel $8^{1}$.} $1: 60000$.

Geologische Ubersichtskarte der Grängesberger Gegend. Massstab

${ }^{1}$ Da diese Karten dem in Englisch gedruckten Führer für die Exkursion nach Grängesberg während des bevorstehenden internationalen Geologen-Kongresses beigefügt werden sollen, sind die Legenden in dieser Sprache angegeben. Dasselbe trifft auch für die Kartenskizze in der Textfigar $19 \mathrm{zu}$.

\section{Berichtigung.}

Auf Taf. 5 ist die Basizität des Epidotes $=33.3$ anstatt $=40$ angegeben worden. Die Basizität der lagerartbildenden Biotite sollte eher etwas kleiner als etwas grösser als 50 angegeben werden. 

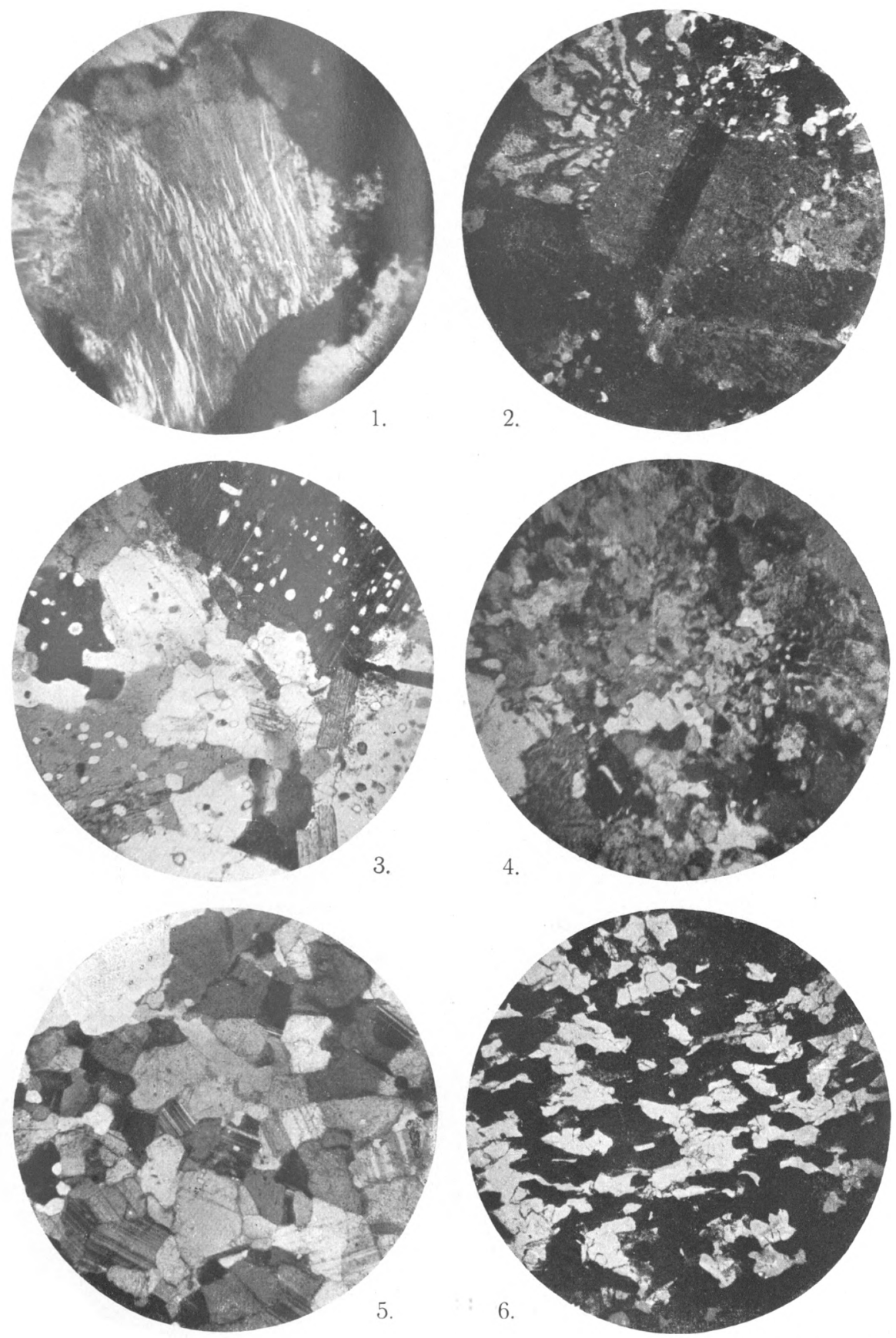

Cederquists Graf. A.-B., Sthlm. 

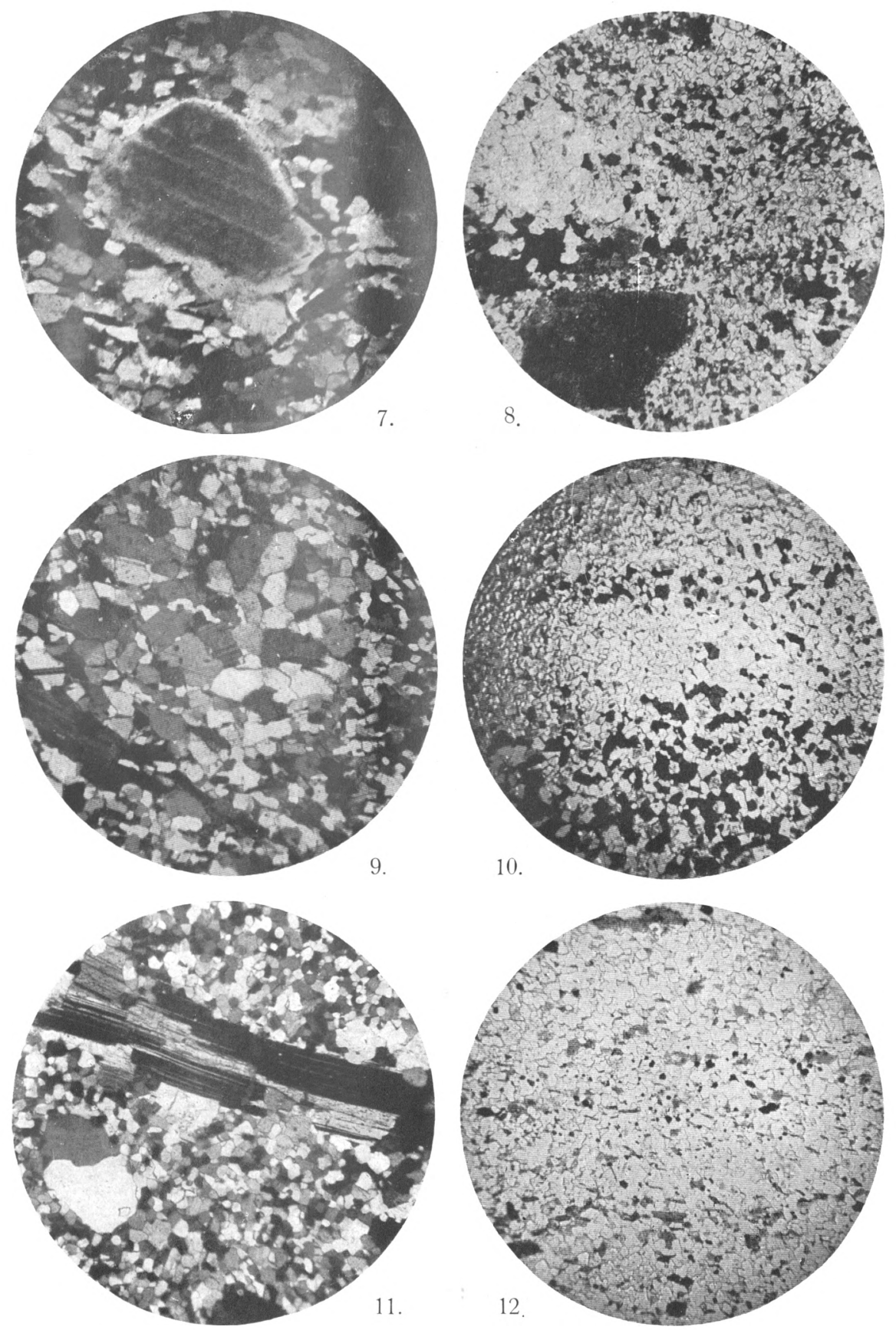


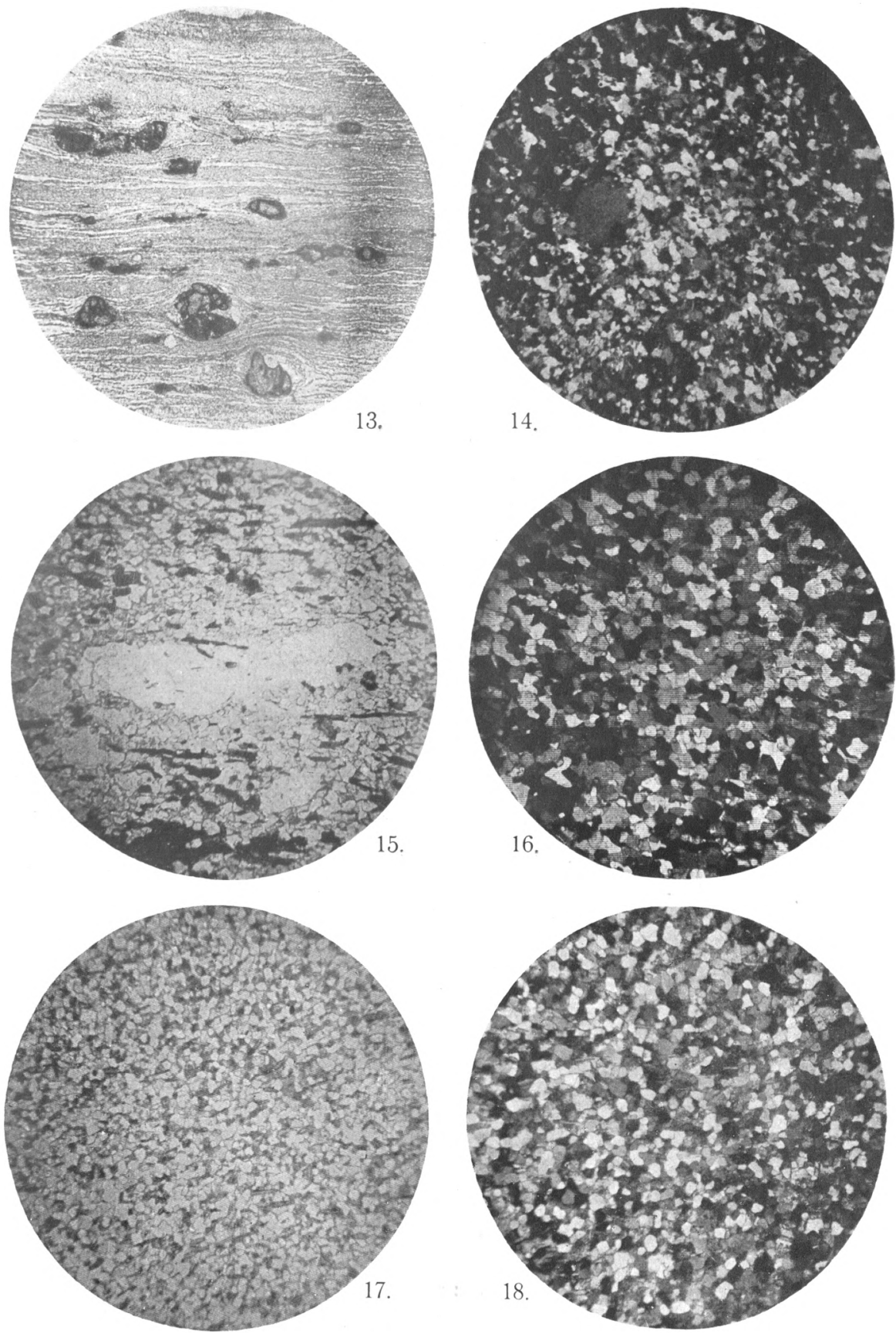

Cederquists Graf. A.-B., Sthlm. 


\section{.}



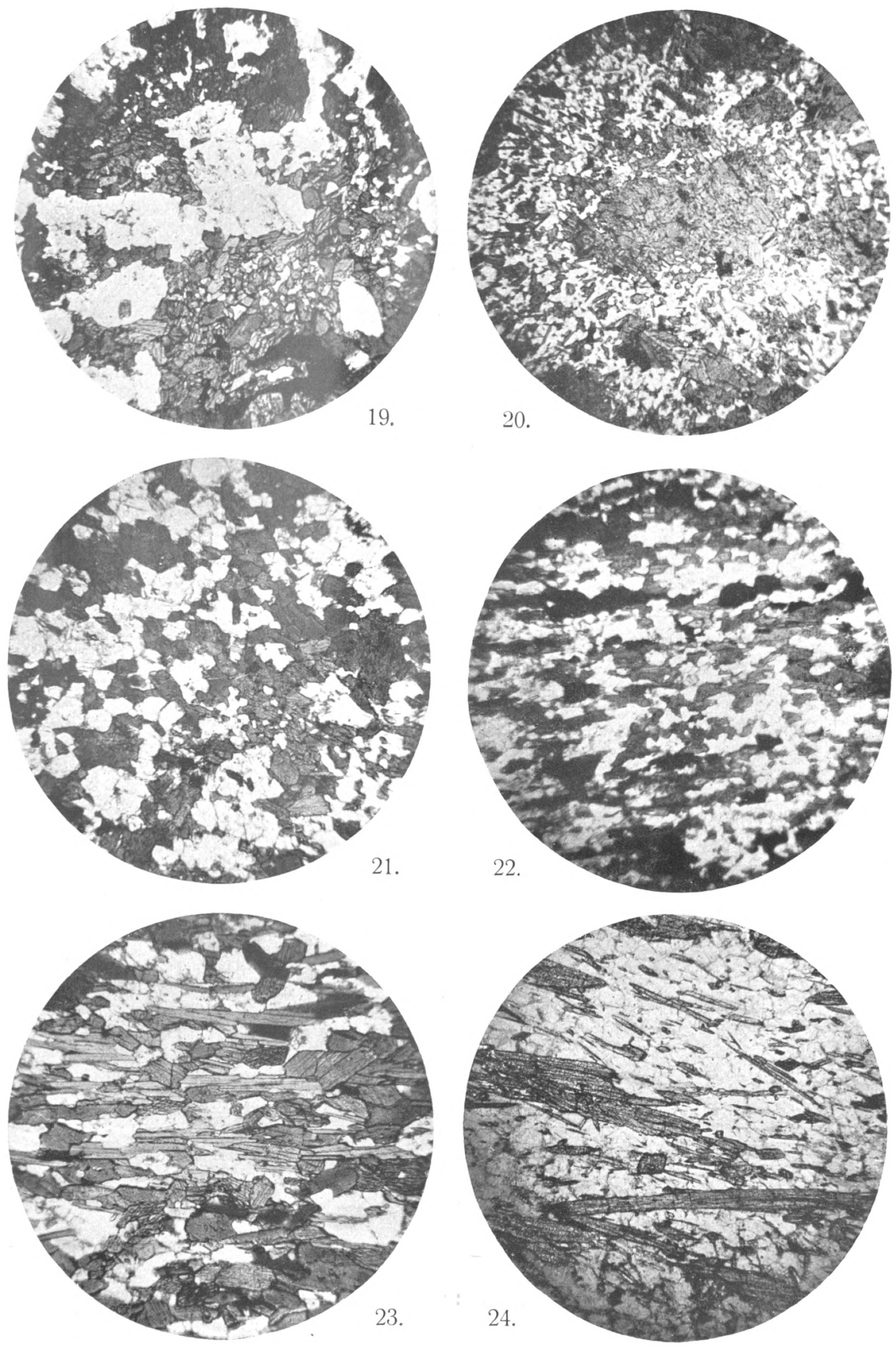


$$
\text { ' }
$$




$$
\text { 30 }
$$




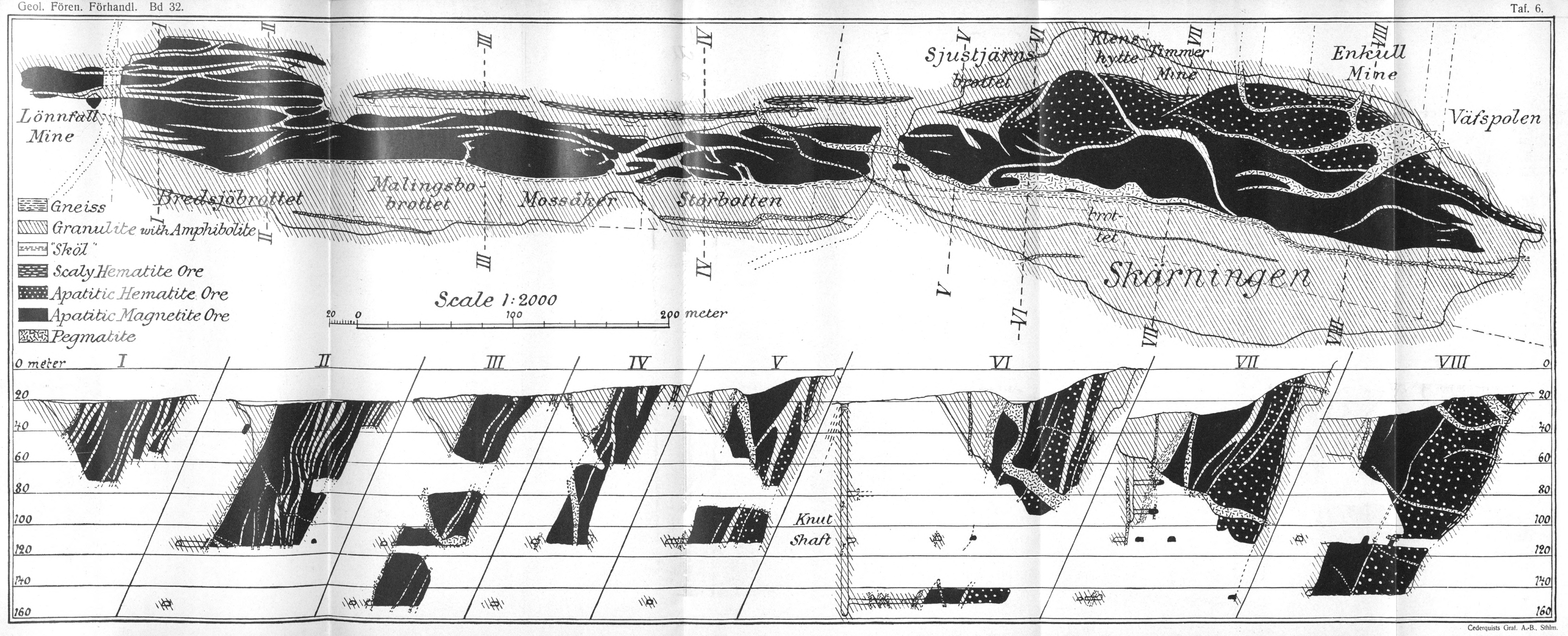










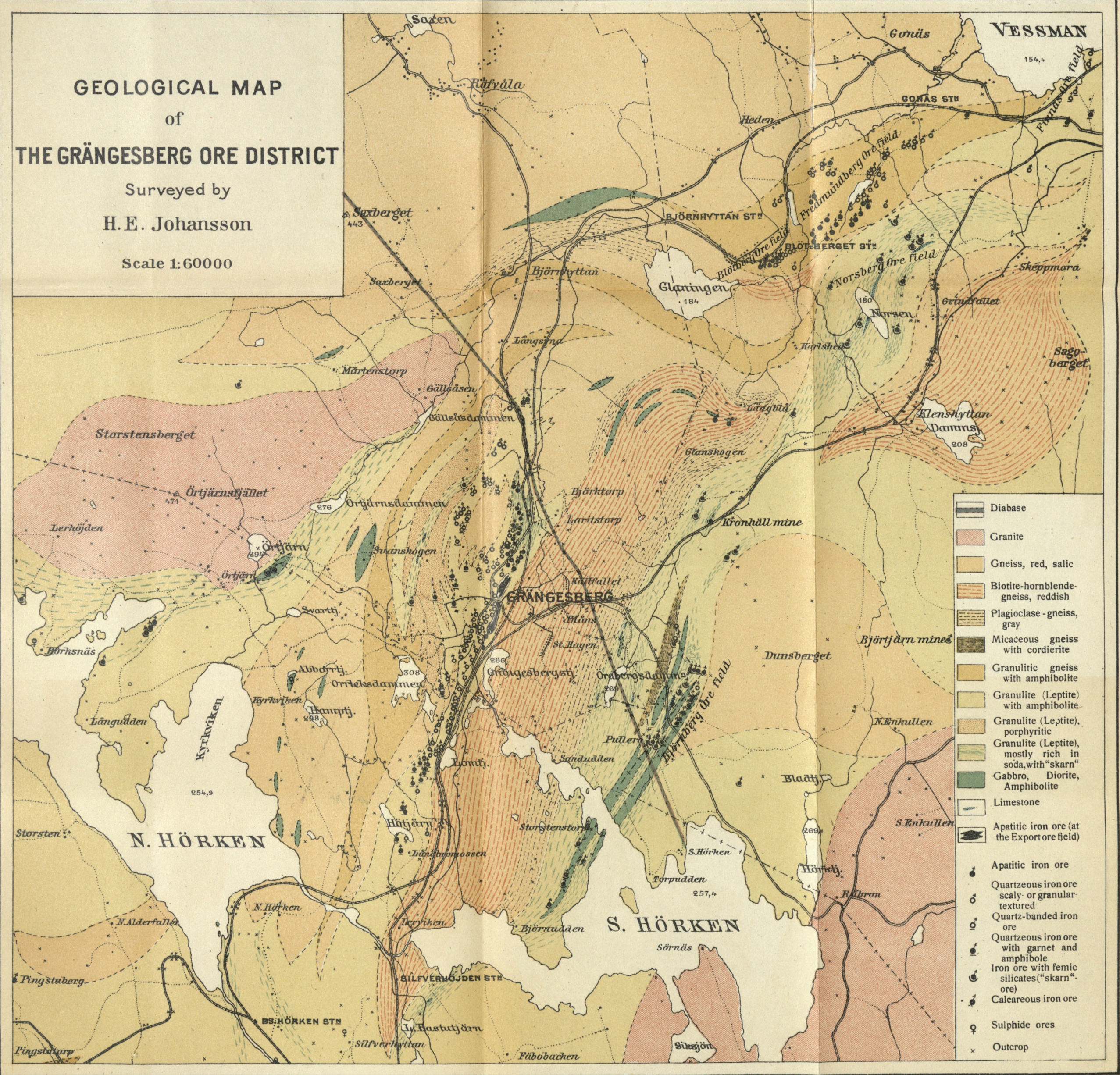

Gen. Stab. Lit Anst.Stockh. 

$\cdot$ 
